\title{
Ring expansion of cyclobutylmethylcarbenium ions to cyclopentane or cyclopentene derivatives and metal-promoted analogous rearrangements
}

\author{
Erika Leemans, Matthias D'hooghe, Norbert De Kimpe* \\ Department of Sustainable Organic Chemistry and Technology, Faculty of Bioscience \\ Engineering, Ghent University, Coupure Links 653, B-9000 Ghent, Belgium \\ *norbert.dekimpe@UGent.be
}

\section{Table of Contents}

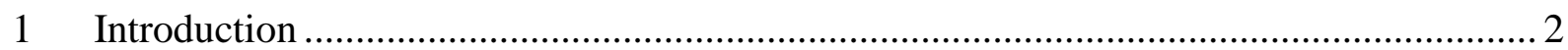

2 Ring expansion of cyclobutylmethylcarbenium ions through activation of a carbon-

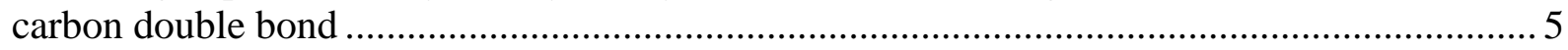

2.1 Acid-promoted activation of alkenylcyclobutanes .......................................... 7

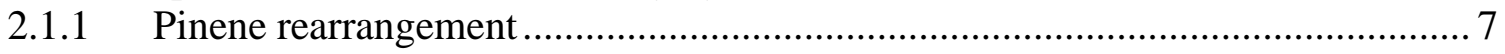

2.1.2 Ring expansion of vinylcyclobutanes (different from pinene) .......................... 9

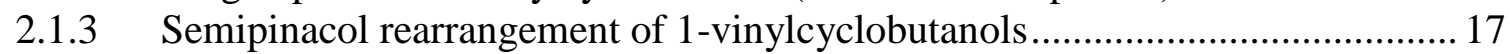

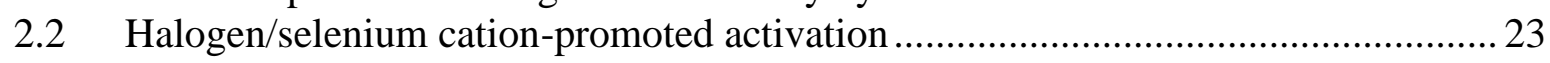

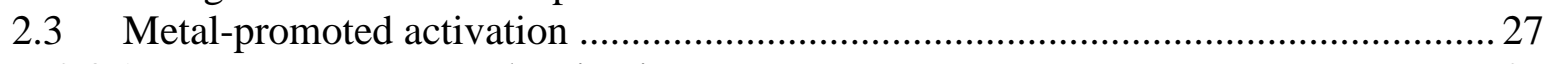

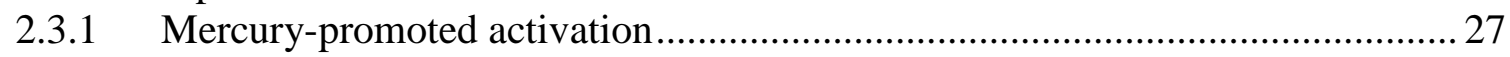

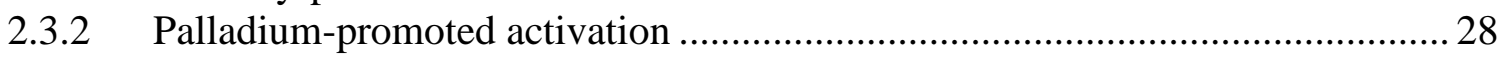

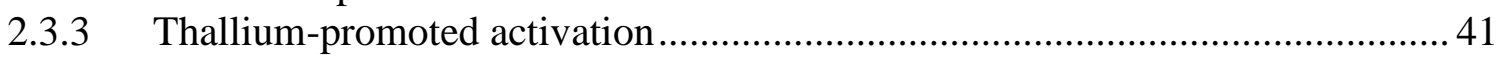

2.4 Conjugated double bond (1,3-dienyl group) activation ...................................... 43

3 Ring expansion of cyclobutylmethylcarbenium ions through activation of an allene ..... 44

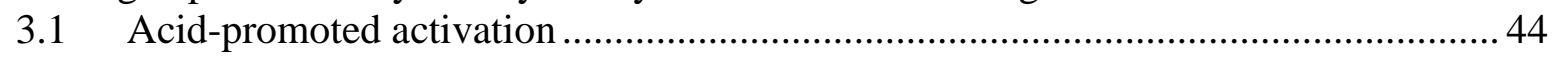

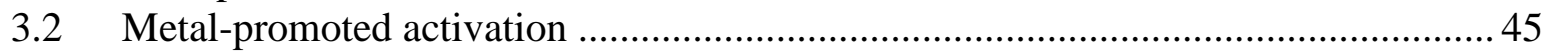

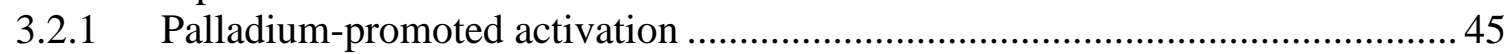

3.2.2 Ruthenium- or gold-promoted activation .................................................... 49

4 Ring expansion of cyclobutylmethylcarbenium ions through activation of an alkynyl

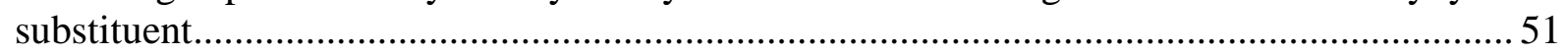

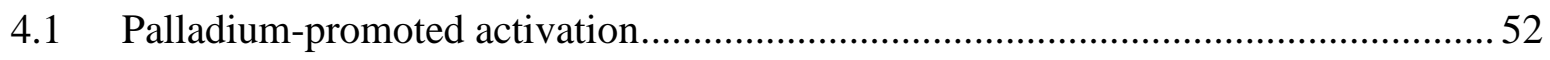

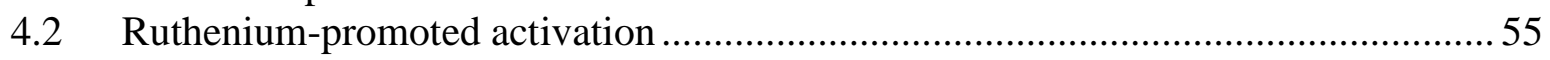

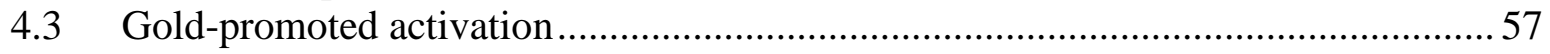

5 Ring expansion of cyclobutylmethylcarbenium ions through activation of a carbonyl

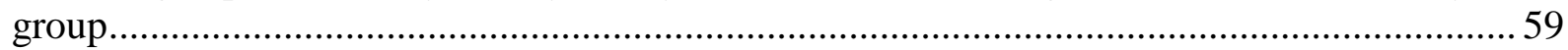

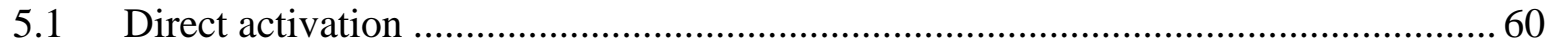

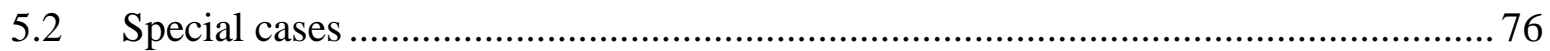

6 Formation of cyclobutylmethylcarbenium ions through expulsion of a leaving group ... 79

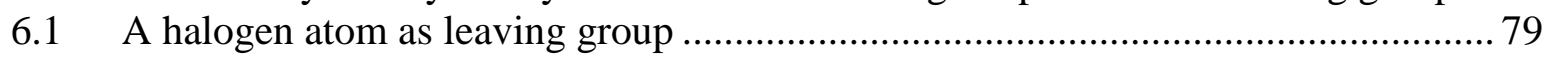

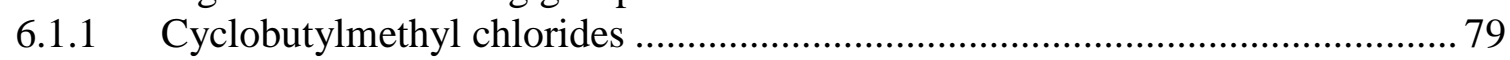

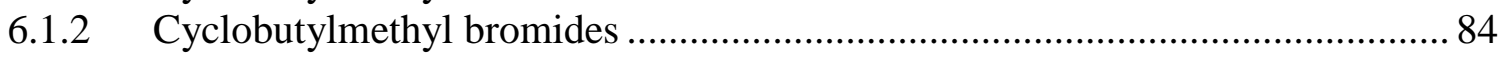

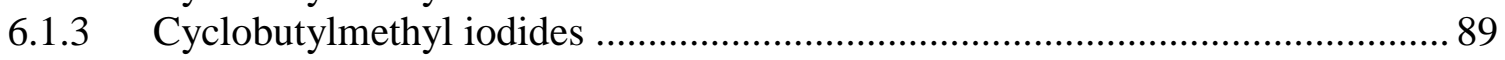

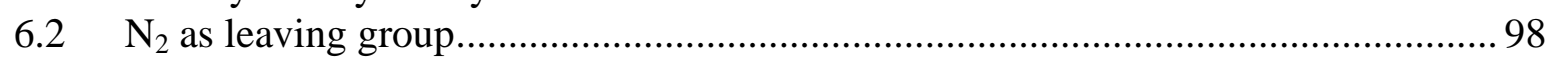

6.2.1 Via azide addition across methylenecyclobutanes ...................................... 98

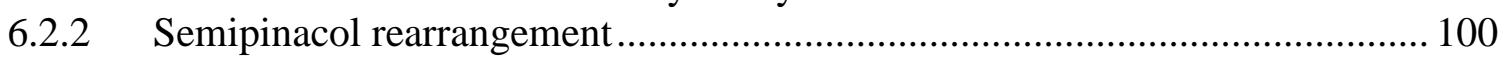

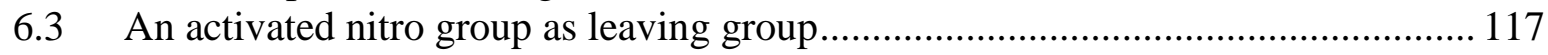

6.4 An activated hydroxy group as leaving group .................................................. 118 


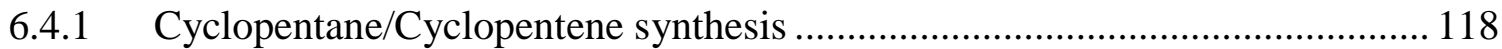

6.4.2 Pinacol rearrangement (cyclopentanone synthesis) ..................................... 127

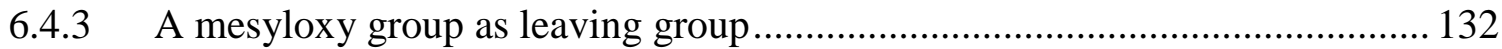

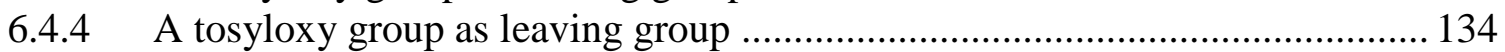

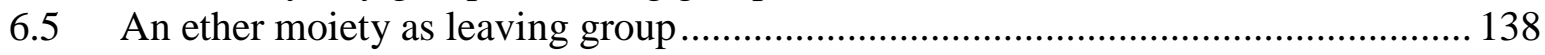

6.5.1 An alkoxy or aryloxy group as leaving group .............................................. 138

6.5.2 Ring opening of an epoxide as driving force for the ring expansion reaction 147

6.5.3 Ring opening of an activated tetrahydrofuran ring as driving force for the ring

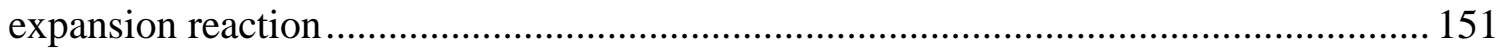

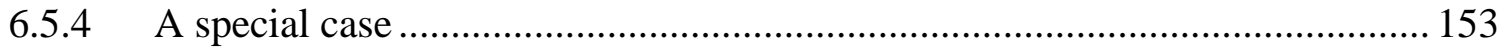

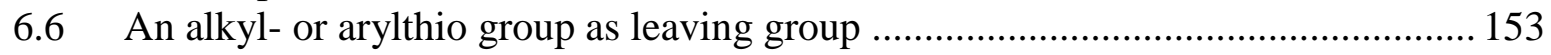

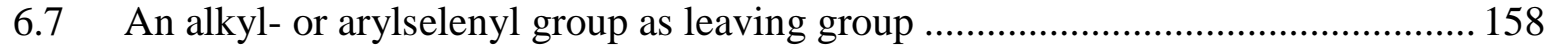

6.8 Sulfone, sulfoxide and selenoxide groups as leaving group ................................. 160

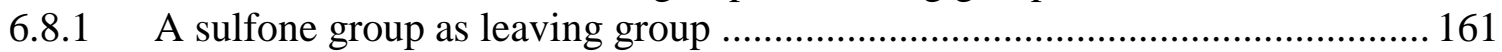

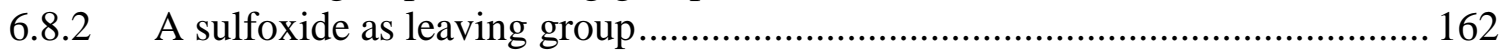

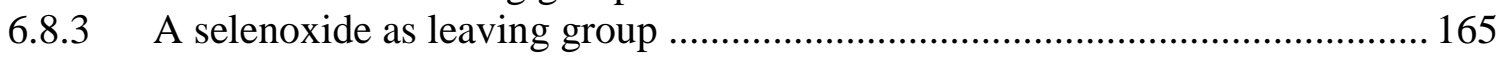

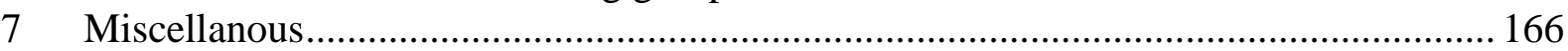

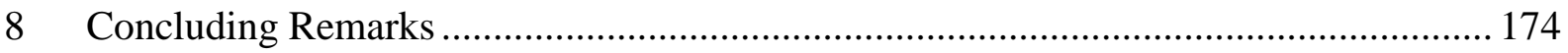

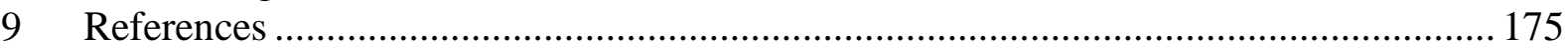

\section{Introduction}

The synthesis of five-membered carbocycles remains an important task within the design of functionalized target compounds bearing a cyclopentane unit. ${ }^{1}$ Ring enlargement reactions are commonly used to access five-membered ring systems. Many of these methodologies utilize ring strain in consort with the generation of a positive charge on a carbon atom adjacent to a four-membered ring as a driving force for the ring expansion reaction. ${ }^{2}$ In this way, the cyclobutylmethylcarbenium ion $\mathbf{1}$ can rearrange smoothly under mild conditions to provide the cyclopentylcarbenium ion 2 (Scheme 1). ${ }^{3}$

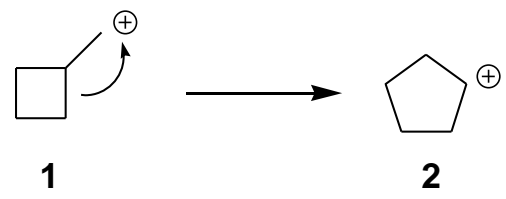

Scheme 1 
The ring enlargement of cyclobutanes to five-membered rings is associated with a release of $20 \mathrm{kcal} / \mathrm{mol}$ (ring strain energy). In contrast, the relief of strain associated with $\mathrm{C}_{3}$ to $\mathrm{C}_{4}$ and $\mathrm{C}_{5}$ to $\mathrm{C}_{6}$ enlargements is less pronounced, ${ }^{4}$ but the activation barrier for 1,2-shifts is higher in cyclobutanes than in cyclopentanes or cyclohexanes. ${ }^{5}$ In addition to experimental work, theoretical studies on cyclobutylmethyl and cyclopentylcarbenium ions have been performed in the past. ${ }^{6}$

Some of the classical methods applied to ring homologation by a one carbon atom are the Demjanov, $^{7}$ the Tiffeneau-Demjanov, ${ }^{7}$ the Wagner-Meerwein $^{8}$ and the pinacol rearrangement. ${ }^{9}$ Well-known ring homologation methods which incorporate a heteroatom into the ring are the Baeyer-Villiger reaction (oxygen) ${ }^{10}$ and the Beckmann rearrangement (nitrogen). ${ }^{11}$

Cyclobutanones are readily available derivatives of cyclobutanes. ${ }^{12}$ The chemical reactivity of cyclobutanones is considerably different from that of cyclic ketones with larger rings due to the ring strain of ca. $25 \mathrm{kcal} / \mathrm{mol}$. Information regarding the influence of the ring strain on regio-, chemo- and stereoselective transformations of four-membered ring ketones is of particular importance. ${ }^{13}$ Cyclobutanones can be constructed through a variety of methods ${ }^{14}$ and may be further functionalized by means of Grignard reactions, ${ }^{12}$ aldol reactions of cyclobutanone enolates with aldehydes, ${ }^{15}$ and many other reactions to offer a convenient fourcarbon ring substrate for further ring enlargement reactions. Enantioselective reactions involving deprotonations, alkylations, reductions, and other functionalization reactions of the carbonyl group of cyclobutanones represent practical approaches to optically enriched cyclobutanes starting from racemates. ${ }^{16}$ The interest in cyclopentanes and cyclopentanones stems from their presence in a wide variety of natural products. Their structures characterize the core of different classes of substances like steroids and sesquiterpenes, but also 
jasmones, ${ }^{17}$ pyrethroids and prostaglandins. ${ }^{18}$ Substituted cyclopentenones are found in various naturally occurring, biologically active compounds, like pentenomycins. ${ }^{19}$

In 1988, Bellus and Ernst reviewed the ring enlargement of cyclobutanones and cyclobutenones to cyclopentanones very briefly. ${ }^{13}$ Almost a decade later, in 1997, Wong published a review on the formation of five-membered rings through cyclobutylmethylcarbenium rearrangements. ${ }^{20}$ Although Wong's review provided a useful introduction to the field of cyclobutylmethylcarbenium to cyclopentylcarbenium ion rearrangements, only a minor part of the existing literature was covered. The application of cyclobutane derivatives in organic synthesis in general was reviewed in 2003 by Namyslo and Kaufmann. ${ }^{21}$ Transformations of cyclobutane rings through ring expansion reactions were described in a small paragraph in the latter review, where only a selected number of examples were given with a few in natural product synthesis. Furthermore, also other types of four- to five-membered ring expansion reactions, e.g. transformations of azetidines to pyrrolidines, ${ }^{22}$ azetidinones to pyrrolidines ${ }^{23}$ and oxetanes to tetrahydrofurans, ${ }^{24}$ have been reported in the literature.

The purpose of the present review is to provide a comprehensive coverage on the ring rearrangement of four- to five-membered carbocyclic rings via cyclobutylmethylcarbenium ions and metal-promoted analogous rearrangements. The review is built up according to the creation of a positive centre for migration of a cyclobutane bond. Both the formation of localized carbenium ions and electrophilic $\pi$-complexes resulting from metal-activation of unsaturated $\mathrm{C}-\mathrm{C}$ bonds will be dealt with. In addition to rearrangements through intermediate cyclobutylmethylcarbenium ions $\mathbf{1}$, especially through semi-pinacol type rearrangements, ring expansion reactions of cyclobutylmethyl halides $\mathbf{3}$ (and analogous substrates) are of particular 
importance and will also be discussed in this overview. Although emphasis will be put on these two types of rearrangements, the relevance of anion-mediated ring enlargements through e.g. intermediates 4 will be highlighted as well.

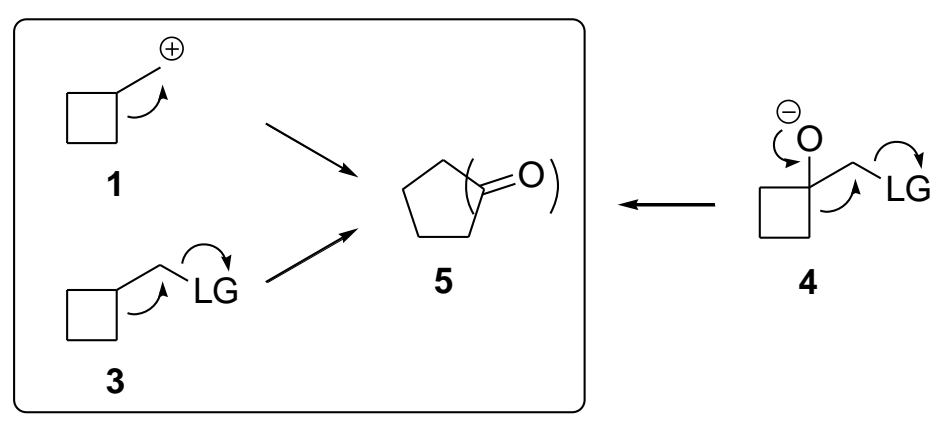

The activation of a double bond as a driving force for ring rearrangement is first described, followed by the activation of an allene substituent and a triple bond. In that part, the metalpromoted ring expansion of alkynylcyclobutanols towards cyclopentanones is covered for the first time. Subsequently, the activation of a carbonyl compound via several methods is described. In another part, different kinds of leaving groups, e.g. halogens, nitrogen gas, a nitro group, activated hydroxy and alkoxy groups, and activated sulfur and selenium species, are evaluated as precursors for the formation and ring expansion of cyclobutylmethyl carbenium ions. In a last paragraph, miscellaneous examples, which could not be subdivided into the previous classes, are described. The rearrangement of heterocycles fall out the scope of this review, as well as cyclobutene ring rearrangements and radical-mediated ring expansions. $^{25}$

\section{Ring expansion of cyclobutylmethylcarbenium ions through activation of a carbon-carbon double bond}


Alkenylcyclobutanes $\mathbf{6}$ are interesting substrates for the synthesis of cyclopentanes and cylopentanones via rearrangement reactions. The $\pi$-system of the double bond is prone to a Markovnikov-controlled electrophilic attack, thereby creating electron-deficiency at the desired position to trigger a ring expansion (Scheme 2). ${ }^{26}$ In particular, alkenylcyclobutanols 6 comprise suitable substrates for a cyclobutylmethyl to cyclopentyl rearrangement and are readily accessible through addition of an alkenyllithium reagent to cyclobutanones.

The cyclobutane ring possesses the capability of interacting with an adjacent alkenyl group or $\mathrm{sp}^{2}$-hybridized centre. The direct conjugation of the Walsh orbitals in a cyclobutane ring with the $\pi$-orbitals of adjacent double bonds has been investigated by semiempirical ${ }^{27}$ and $a b$ initio calculations and photoelectron spectroscopy. ${ }^{28}$ While the bonding of the cyclobutane ring attenuates its ability to delocalize charge, the approximately $20 \mathrm{kcal} / \mathrm{mol}$ of strain energy released by expansion of the four- to a five-membered ring may compensate for the electronic deficits.

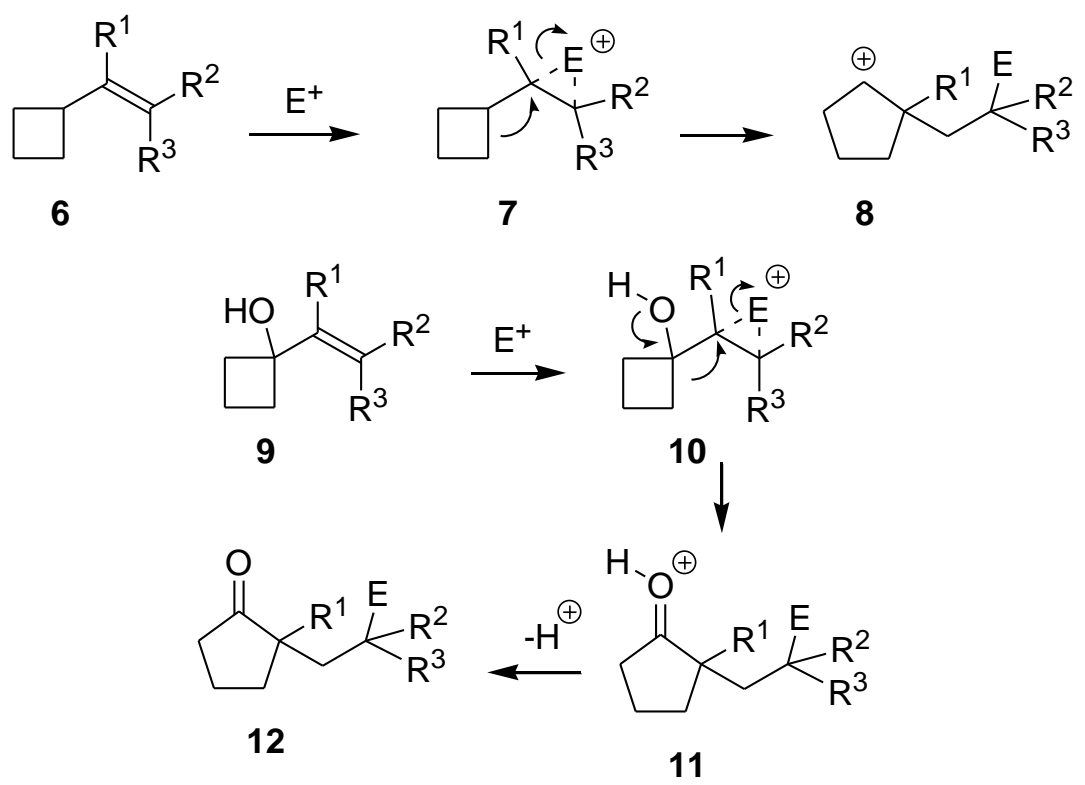

Scheme 2 
Different activation types are described in this section, from acid-promoted and halogen/selenium cation-promoted activation to the use of metals for efficient ring rearrangement.

\subsection{Acid-promoted activation of alkenylcyclobutanes}

\subsubsection{Pinene rearrangement}

An important illustration of the acid-promoted ring expansion of vinylcyclobutanes to cyclopentanes or cyclopentenes comprised the conversion of $\alpha$-pinene into camphane. ${ }^{29}$ Addition of hydrogen chloride to $\alpha$-pinene initially led to hydrogen chloride adduct, which isomerized to 2-chlorocamphane (= bornyl chloride) containing some fenchyl chloride. ${ }^{29}$ In an analogous approach, chlorination of $\alpha$-pinene $\mathbf{1 3}$ with undistilled $t$-butyl hypochlorite led to the formation of carvyl chloride $\mathbf{1 4}$ (see Schema 3 for a possible mechanism) and 2,6dichlorocamphane $\mathbf{1 5}$ as a minor side product (Scheme 3$).{ }^{30}$ The same reaction was also executed with bromine to synthesize 2,6-dibromocamphane as the sole product. ${ }^{31}$ The corresponding yields were not mentioned in the original article.

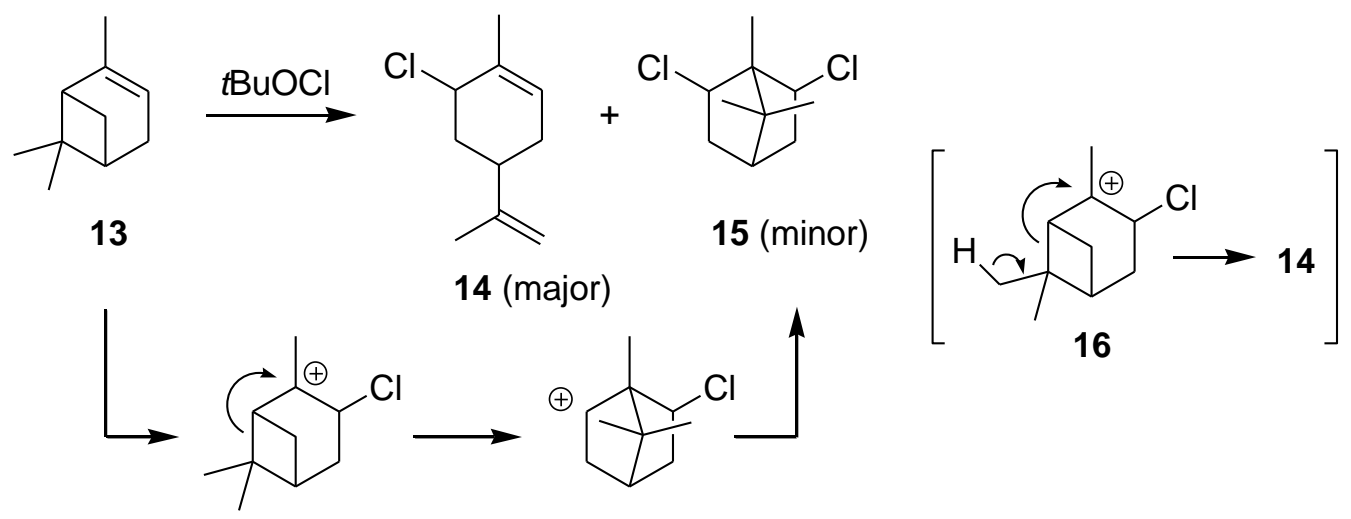

16

Scheme 3 
Other authors have also reported the addition of hydrogen chloride to $\alpha$-pinene $\mathbf{1 3}^{32}$ with formation of 2-chlorocamphane $\mathbf{1 7 a}$ in $34 \%$ yield in pentane ${ }^{32 a}$ or in $40 \%$ yield in acetic acid. ${ }^{32 b}$ In addition, hydrobromination was performed on $\alpha$-pinene $\mathbf{1 3}$ in chloroform to yield 2-bromocamphane $\mathbf{1 7 b}$ in $70 \%$ (Scheme 4$){ }^{33}$<smiles>CC1=CCC2CC1C2(C)C</smiles>

13

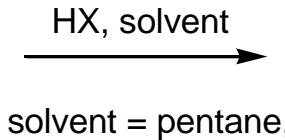

solvent $=$ pentane,
$\mathrm{CH}_{3} \mathrm{CO}_{2} \mathrm{H}, \mathrm{CHCl}_{3}$

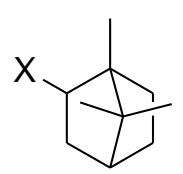

$17 \mathrm{a}(\mathrm{X}=\mathrm{Cl}: 34-40 \%)$

$17 \mathrm{~b}(\mathrm{X}=\mathrm{Br}: 70 \%)$

\section{Scheme 4}

2-Chlorocamphane 17a was also obtained as a side product in $24 \%$ yield via hydrochlorination of $\alpha$-pinene $\mathbf{1 3}$ through addition of eight equiv of acetyl chloride in ethanol at $30{ }^{\circ} \mathrm{C}$ for 15 minutes, affording 1-chloro-4-(1-chloro-1-methylethyl)-1-methylcyclohexane 18 in 57\% yield and 2-chloro-1,3,3-trimethylbicyclo[2.2.1]heptane 19 in 19\% yield (Scheme $5) .^{34}$
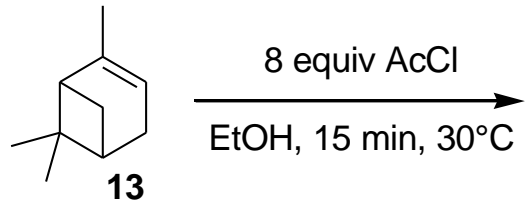

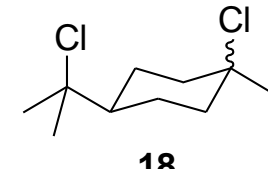

18

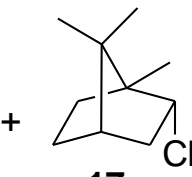

$17 a$

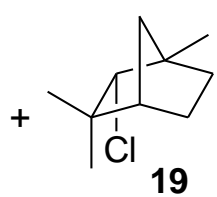

19

18:17a:19 (57:24:19) (95\%)

Scheme 5

Other reagents were applied as well, such as sulfuric acid in chloroform ${ }^{35}$ and thionylchloride in dichloromethane, ${ }^{36}$ to synthesize 2 -chlorocamphane in 54-63\% yield. When oxalic acid was 
used, 2-hydroxycamphane was obtained in $41 \%$ yield. ${ }^{37 a}$ The same 2-hydroxycamphane was synthesized in $89 \%$ yield when benzoyl peroxide was added in combination with chloroacetic acid and sodium hydroxide in water (probably implying a sodium acetate-promoted reaction). ${ }^{37 \mathrm{~b}}$ When perchloric acid and 3,5-di(trifluoromethyl)benzonitrile 20 were added to ()- $\alpha$-pinene 13, the corresponding racemic isobornylamide derivative 21 was isolated as the main product (Scheme 6). No yield was mentioned for this reaction. ${ }^{38}$

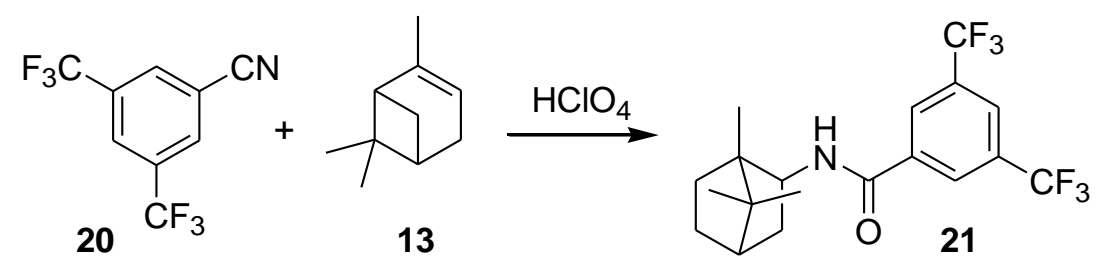

Scheme 6

\subsubsection{Ring expansion of vinylcyclobutanes (different from pinene)}

The same methodology as described above was applied to other types of vinylcyclobutanes. Acid- and Lewis acid-catalyzed rearrangements of $\alpha$-vinylcyclobutanones via methanesulfonic acid or boron(III) fluoride etherate have been reported, leading to for example ring annelated cyclopentenones, bicyclo[3.1.0]hexanones, bicyclo[5.3.0]decenones, bicyclo[4.3.0]nonenones or spiro[4.5]decenones.

In a first example, Beereboom reported an acid-catalyzed rearrangement of 2,6,6trimethylbicyclo[3.2.0]hept-2-en-7-one 22 with 0.1 equiv of $p$-toluenesulfonic acid monohydrate in toluene at reflux temperature for 24 hours to afford a mixture of three compounds in $89 \%$ crude yield. ${ }^{39}$ The starting material was isolated, as well as the ring expanded 3,3-dimethyl-6-methylidenebicyclo[2.2.1]heptan-2-one $\mathbf{2 3}$ (no mechanism 
provided; Scheme 7). The author did neither mention the ratio of the compounds nor the identification of the third compound.

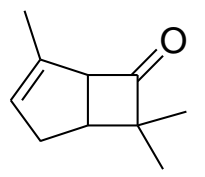

22

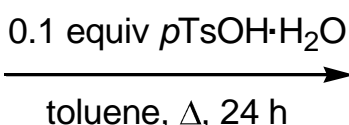

toluene, $\Delta, 24 \mathrm{~h}$

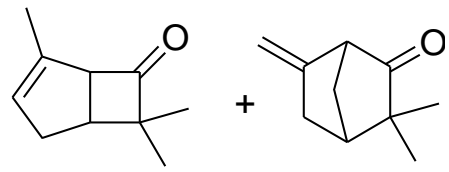

22:23 (89\% crude)

Scheme 7

In a second example, the formate of hibaene $\mathbf{2 5}$, a tetracyclic diterpene, was synthesized using formic acid as promoter for the ring expansion of compound $24{ }^{40}$ When tetracyclic olefin 24 was dissolved in an excess of formic acid and stirred at room temperature for 12 hours, the formate 25 was obtained in a quantitative yield (Scheme 8).

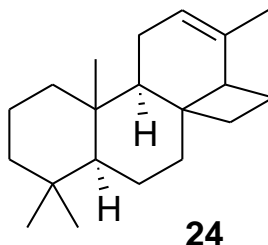

24

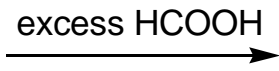

$\mathrm{rt}, 12 \mathrm{~h}$

Scheme 8

In research on illudoid sesquiterpenes, a protoilludyl carbenium ion 27 was generated. ${ }^{41}$ Stirring of alkene $\mathbf{2 6}$ in formic acid afforded a mixture of rearranged products $\mathbf{2 8}$ and $\mathbf{3 1}$ in a $7: 3$ ratio when the reaction took place at reflux for 30 minutes, and in a 9:1 ratio when the reaction was executed at room temperature for three hours (Scheme 9). The authors did not report the exact yields of the two products. No hirsutene skeleton $\mathbf{3 2}$ was found under these reaction conditions, which could be formed via a triple 1,2-shift from carbenium ion 27. 


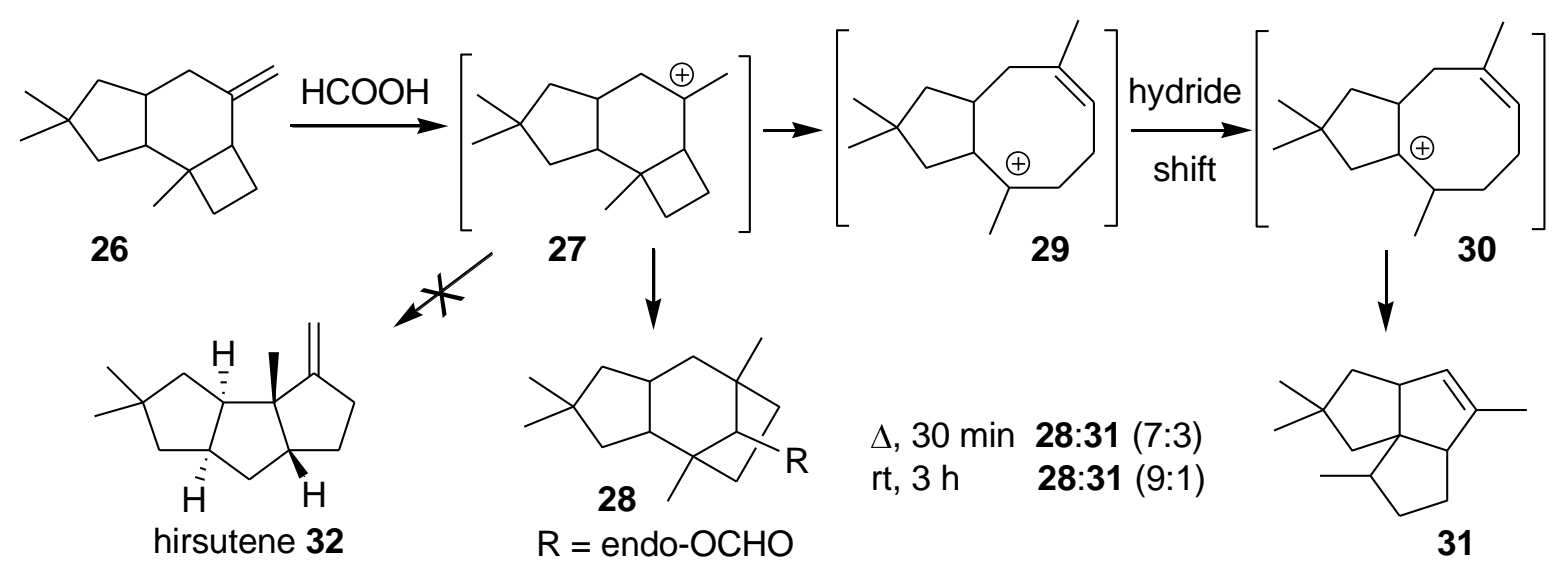

Scheme 9

A racemic synthesis of the tricyclic sesquiterpene isocomene $\mathbf{3 6}$ was developed by Pirrung (Scheme 10). ${ }^{42}$ The last step of this total synthesis involved an acid-catalyzed cyclobutylmethyl to cyclopentylcarbenium ion rearrangement. Upon treatment with 0.3 equiv of $p$-toluenesulfonic acid in benzene for one hour at reflux temperature, 2,6,8-trimethyl-5methylenetricyclo[6.3.0.0 ${ }^{1,6}$ ] undecane $\mathbf{3 3}$ was transformed into racemic isocomene $\mathbf{3 6}$ in $98 \%$ yield.

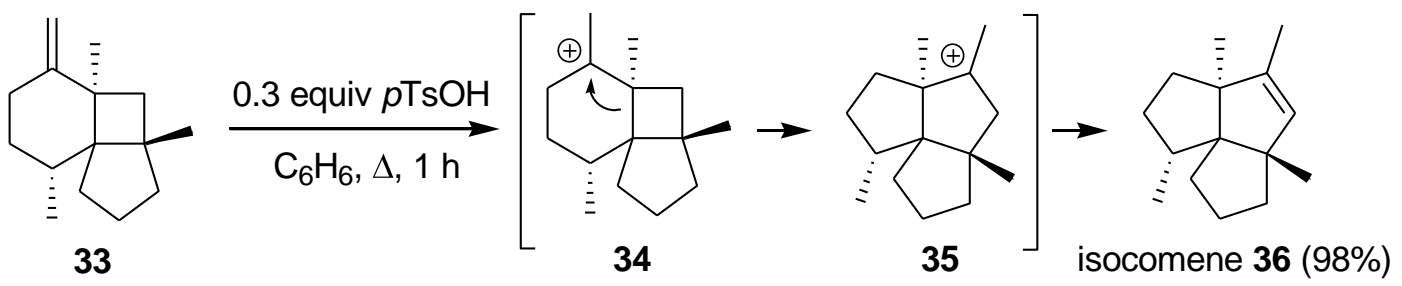

Scheme 10

In the presence of a 10:1 mixture of methanesulfonic acid/ $\mathrm{P}_{2} \mathrm{O}_{5}$ (Eaton's reagent), a 1,2rearrangement of vinylic cyclobutanone $37(\mathrm{R}=\mathrm{Me})$ to $51 \%$ of spiro[4.5]dec-2-en-1-one 38 was observed, and accompanied by a minor but significant degree of 1,3-rearrangement (13\%) toward bicycle 39 (Scheme 11). This reaction was improved to 53\% of the 1,2rearrangement product $\mathbf{3 8}$ and $8 \%$ of the 1,3-rearrangement product $\mathbf{3 9}$, respectively, when no 
$\mathrm{P}_{2} \mathrm{O}_{5}$ was added. ${ }^{43}$ The nor-methyl analogue $37(\mathrm{R}=\mathrm{H})$ yielded only bicyclic compound 39 in $65 \%$ yield under the same reaction conditions.

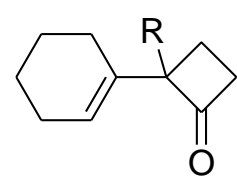

37

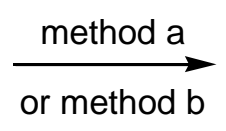

$\mathrm{R}=\mathrm{H} \quad$ method a

$\mathrm{R}=\mathrm{Me}$ method a method $b$<smiles>[R]C1C=CC(=O)C12CCCCC2</smiles>

38

$-$

$51 \%$

$53 \%$<smiles>[R]C1CCC(=O)C2=C1CCC[C@@H]2[O-]</smiles>

$65 \%$

$13 \%$

$8 \%$

method a: $\mathrm{MeSO}_{3} \mathrm{H} / \mathrm{P}_{2} \mathrm{O}_{5}(10: 1), 15 \mathrm{~min}$

method b: 0.2 equiv $\mathrm{MeSO}_{3} \mathrm{H} / \mathrm{CH}_{2} \mathrm{CH}_{2}, 10 \mathrm{~h}$

\section{Scheme 11}

The above described 1,3-rearrangement was completely suppressed in the ring enlargement of spirovinylcyclobutanones 40, 42 and 44 (Scheme 12). ${ }^{43 a}$ Vinylcyclobutanones 40, 42 and 44, in the presence of 10:1 methanesulfonic acid/ $\mathrm{P}_{2} \mathrm{O}_{5}$ or solely methanesulfonic acid, afforded only the corresponding 1,2-rearranged products $\mathbf{4 1}, \mathbf{4 3}$ and $\mathbf{4 5}$, in 33 to $52 \%$ yield, respectively. In this case, a 1,3-rearrangement would imply a violation of Bredt's rule. No reaction temperatures were mentioned in this article.

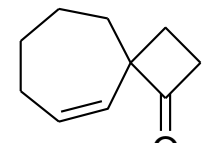

$40 \mathrm{O}$<smiles>CC1=CCCCC12CCC2=O</smiles>

42<smiles>O=C1CCC12CCCC1=C2CCCC1</smiles>

44
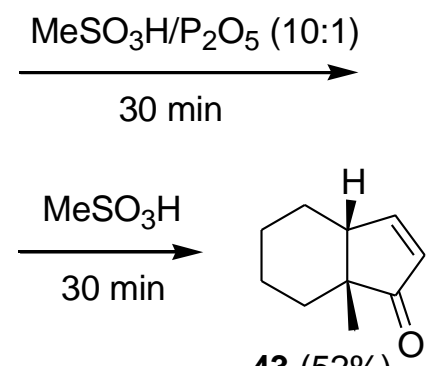

$43(52 \%)$

$$
\underset{45 \mathrm{~min}}{\stackrel{\mathrm{MeSO}_{3} \mathrm{H}}{\longrightarrow}}
$$<smiles>O=C1C=C[C@H]2CCC[C@H]3CCCC[C@]123</smiles>

$45(33 \%)$

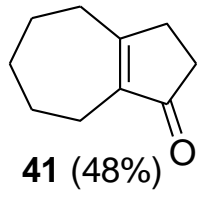

$41(48 \%)$ 


\section{Scheme 12}

Treatment of bicyclic dienones 46 with three to eight equiv of $\mathrm{BF}_{3} \cdot \mathrm{Et}_{2} \mathrm{O}$ in 1,2dimethoxyethane gave rise to 4-alkylidenebicyclo[3.3.0]octenones 47 in moderate yield (35$36 \%$ ), accompanied by a small amount of bicyclo[4.2.1]nonadienones 48 (7-10\%) (Scheme $13)^{44}$

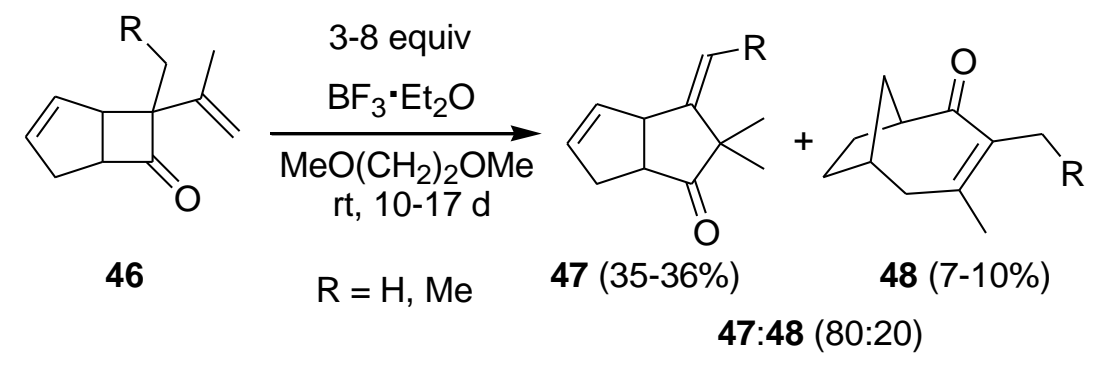

Scheme 13

Under Lewis acid or acid catalysis (0.2 equiv of $\mathrm{BF}_{3} \cdot \mathrm{Et}_{2} \mathrm{O}$ or 0.2 equiv of $\left.\mathrm{MeSO}_{3} \mathrm{H}\right), 3,3-$ dialkyl-2-methyl-2-vinylcyclobutanones $\mathbf{4 9}$ underwent ring opening to substituted allylvinyl ketones and divinylketones 50. When higher acid concentrations were used, i.e. up to one equiv of methanesulfonic acid, cyclobutanones were transformed into cyclopentenones 49 in $51-71 \%$ yield (Scheme 14). ${ }^{45}$ However, the authors stated that this transformation occurred by a Nazarov cyclisation of the intermediate dienones instead of through a cyclobutylmethylcarbenium to cyclopentylcarbenium ion rearrangement. The 3,3dialkylcyclobutanones first underwent $\mathrm{C}(\alpha), \mathrm{C}(\beta)$-bond cleavage under mild acid conditions, because in this way the original $\mathrm{C}(\beta)$ became a stable tertiary carbenium ion. Deprotonation produced the dienones 50. The subsequent cyclization to cyclopentenones 49 required intermediate acid conditions via a Nazarov-type mechanism. 


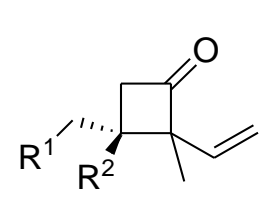

49

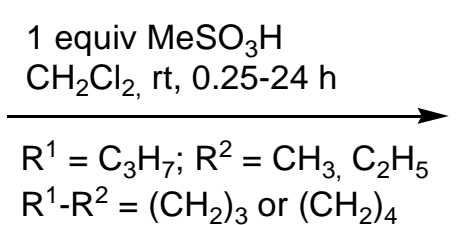

$\mathrm{R}^{1}-\mathrm{R}^{2}=\left(\mathrm{CH}_{2}\right)_{3}$ or $\left(\mathrm{CH}_{2}\right)_{4}$

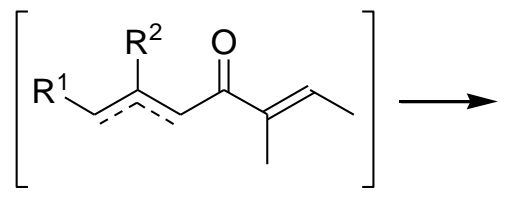

50

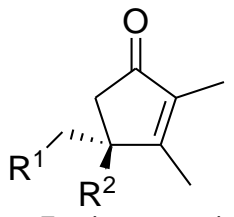

$51(51-71 \%)$

Scheme 14

On the other hand, 3-alkyl- and 3,4-dialkylcyclobutanones $\mathbf{5 2}$ did not yield the corresponding dienones $\mathbf{5 0}$ or cyclopentenones $\mathbf{5 1}$ using the above-described methods, but were converted into cyclopentenones $\mathbf{5 4}$ under more vigorous reaction conditions or under stronger acid catalysis, i.e. treatment with neat $\mathrm{MeSO}_{3} \mathrm{H}$. This transformation proceeded by a different mechanism. At first, a cyclobutylmethylcarbenium ion $\mathbf{5 3}$ is formed and ring expansion via a $[1,2]$-acyl shift to a cyclopentylcarbenium ion is followed by formation of a double bond to produce cyclopentenones 54 in 46 to $76 \%$ yield (Scheme 15). ${ }^{45}$

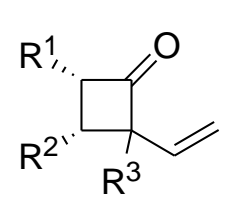

52

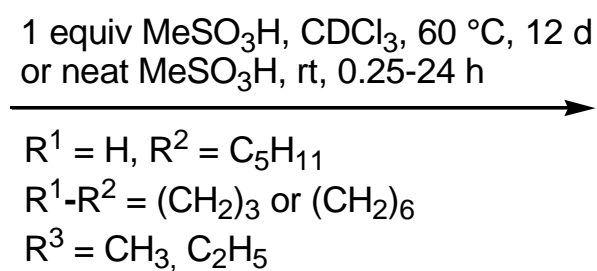

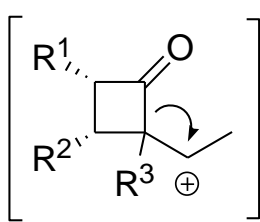

53

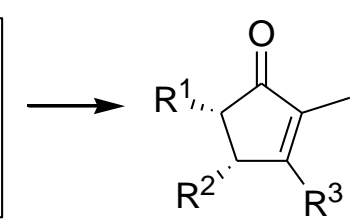

$54(46-76 \%)$

Scheme 15

When cyclobutanone 55, which carried a 1-isobutenyl group at the $\alpha$-position, was exposed to 0.9 equiv of boron(III) fluoride etherate in dichloromethane at room temperature for 24 hours, no cyclopentenone but the bicyclo[3.1.0]hexanone spiro derivative $\mathbf{5 8}$ was obtained in $82 \%$ (Scheme 16). ${ }^{46}$ The proposed mechanism again involved a $\mathrm{C}(\alpha), \mathrm{C}(\beta)$-bond cleavage to produce a tertiary carbenium ion $\mathbf{5 6}$ which cyclised to produce another tertiary carbenium ion 57, which was finally trapped by the enolate to afford the highly substituted 
bicyclo[3.1.0]hexanone spiro derivative 58. No cyclobutylmethylcarbenium ion was involved in this transformation.

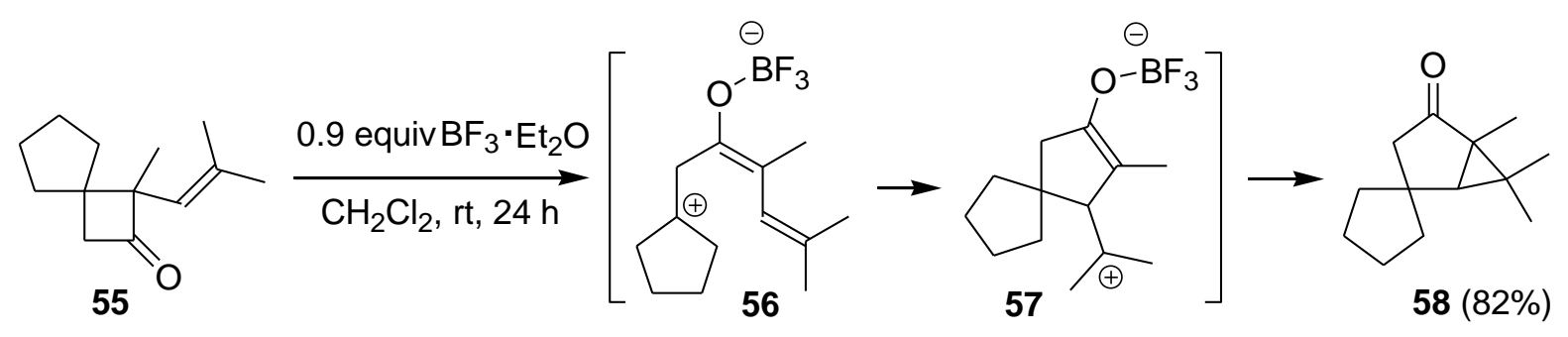

Scheme 16

The synthesis of bicyclo[2.2.1] heptan-7-ols $\mathbf{6 0}$ was achieved in 81 to $98 \%$ yield by reaction of 4-methylenebicyclo[3.2.0]heptanes $\mathbf{5 9}$ with a 0.5 molar solution of sulfuric acid in acetic acid for 16 hours at room temperature, followed by reduction of the resulting acetate with lithium aluminium hydride in diethyl ether for 0.5 hours at room temperature (Scheme 17). ${ }^{47}$ The exclusive formation of the norbornane derivative $\mathbf{6 0}$ under thermodynamic control was in accordance with the lower energy of the bicyclo[2.2.1] heptane skeleton $\left(62.8 \mathrm{~kJ} \mathrm{~mol}^{-1}\right)$, as compared to that of bicyclo[3.2.0]heptane $\left(138.2 \mathrm{~kJ} \mathrm{~mol}^{-1}\right)$. The obtained ring expanded products were used in the synthesis of 7-norbornanones 61 .<smiles>[R]C1CC12CCC(=C)C21CC1</smiles>

59 a) $\mathrm{H}_{2} \mathrm{SO}_{4} / \mathrm{AcOH}, \mathrm{H}_{2} \mathrm{O}$, rt, $16 \mathrm{~h}$

b) 2.1 equiv $\mathrm{LiAlH}_{4}, \mathrm{Et}_{2} \mathrm{O}, \mathrm{rt}, 0.5 \mathrm{~h}$

$\mathrm{R}=\mathrm{H}, \mathrm{Me}$

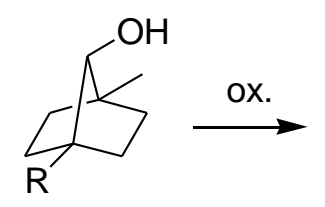

$60(81-98 \%)$

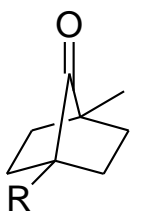

61

Scheme 17

The synthesis of dihydrojasmone $\left(\mathrm{R}^{2}=\mathrm{C}_{4} \mathrm{H}_{9}\right)$ and analogs 64 from cyclopropanol derivatives 62 was reported in 55-90\% yield via the intermediacy of cyclobutanones $\mathbf{6 3}$ (Scheme 18). ${ }^{48}$ 
Precursors 63 were prepared from cyclopropanes 62 through a three-step synthesis involving (i) addition of the lithium salt of a terminal alkyne across the carbonyl group, (ii) $\mathrm{LiAlH}_{4}$ promoted reduction of the triple bond to the corresponding alkene, and (iii) $\mathrm{BF}_{3} \cdot \mathrm{Et}_{2} \mathrm{O}-$ or $\mathrm{MeSO}_{3} \mathrm{H} / \mathrm{P}_{2} \mathrm{O}_{5}$-mediated cyclopropane to cyclobutane ring enlargement. The ring expansion of cyclobutanones 63 to cyclopentenones 64 was completed in five minutes using 17 equiv of methanesulfonic acid/phosphorus pentoxide (10:1) in diethyl ether at room temperature. The cyclopentenone $64\left(\mathrm{R}^{2}=\mathrm{H}\right)$ is a known synthetic precursor of methylenomycin $\mathrm{B}$, a cyclopentanoid antibiotic produced by Streptomyces coelicolor. ${ }^{49}$

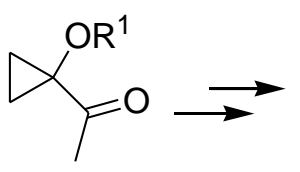

62

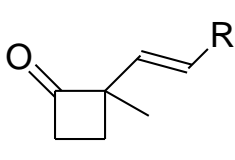

63

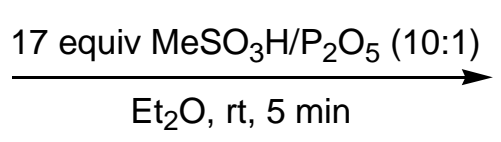

$\mathrm{R}^{1}=$ tetrahydropyran-2-yl, $\mathrm{SiMe}_{2} t \mathrm{Bu} ; \mathrm{R}^{2}=\mathrm{H}, \mathrm{C}_{4} \mathrm{H}_{9}$

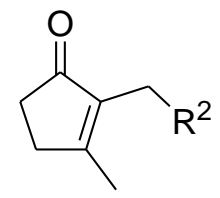

$64(55-90 \%)$

\section{Scheme 18}

Upon treatment with 15 equiv of methanesulfonic acid (neat) at room temperature for three hours, or 30 equiv of methanesulfonic acid in dichloromethane, enantiopure 2,3-dimethyl-2vinylcyclobutanones $(2 S, 3 S)$-65 and $(2 R, 3 S)-\mathbf{6 5}$ underwent acid-catalysed ring expansion into a 9:1 mixture of 2,3,4- and 2,3,5-trimethylcyclopentenones $\mathbf{6 6}$ and $\mathbf{6 7}$ in 56\% yield (Scheme 19). ${ }^{2 b}$ This rearrangement led to a complete racemisation of the obtained cyclopentenones.

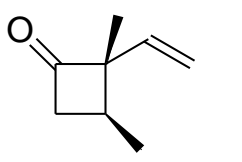

$(2 S, 3 S)-65$

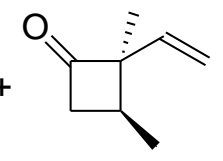

$(2 R, 3 S)-65$
15 equiv $\mathrm{MeSO}_{3} \mathrm{H}, \mathrm{rt}, 3 \mathrm{~h}$

or 30 equiv $\mathrm{MeSO}_{3} \mathrm{H}, \mathrm{CH}_{2} \mathrm{Cl}_{2}$$$
\text { (1) }
$$

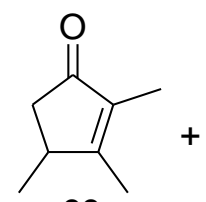

66

Scheme 19 


\subsubsection{Semipinacol rearrangement of 1-vinylcyclobutanols}

As mentioned in the introduction, 1-(1-alkenyl)cyclobutanols 9 comprise suitable substrates for a semipinacol-type cyclobutylmethylcarbenium to cyclopentylcarbenium ion rearrangement.

The acid-catalyzed ring expansion of 1-isopropenylcyclobutanol 68 was investigated using a variety of acids and solvents without success as no ketonic product could be detected, mostly delivering dark, tarry residues. ${ }^{50}$ However, a solution of 1-isopropenylcyclobutanol $\mathbf{6 8}$ in sulfuric acid and ethanol in the presence of 2,4-dinitrophenylhydrazine (2,4-DNP) resulted in the hydrazone of 2,2-dimethylcyclopentanone 69 in 51\% yield (Scheme 20).

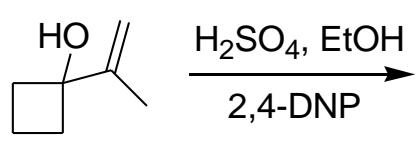

68

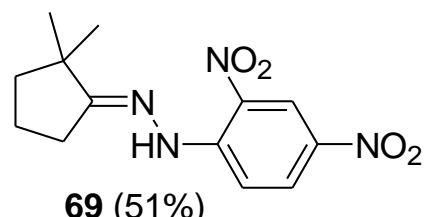

$69(51 \%)$

Scheme 20

When a phenylsulfanyl group as carbanion-stabilizing sulfur substituent was introduced at the 2-position of 1-vinylcyclobutanol, different ring expansion products were obtained in the presence of acid. ${ }^{51} \mathrm{O}$-Silylated 1-isopropenyl-2-phenylthiocyclobutanol $\mathbf{7 0}$ was treated with para-toluenesulfonic acid in toluene at reflux temperature, leading to 2,2-dimethyl-3phenylthiocyclopentanone $\mathbf{7 1}$ in $62 \%$ yield (Scheme 21). The silyl ether protection of the hydroxy group was necessary because the unprotected cyclobutanol, upon treatment with potassium hydride to synthesize the corresponding potassium salts, gave 2-methyl-4- 
phenylthiocyclohexanone as a mixture of cis- and trans-isomers (ratio 5:1) in 69\% yield. The effect of sulfur was demonstrated by comparing 2-phenylthio-1-vinylcyclobutanol with 2benzyl-1-vinylcyclobutanol. If both were subjected to reaction conditions which caused complete rearrangement of the first cyclobutanol, the reaction with the latter only resulted in unchanged starting material.

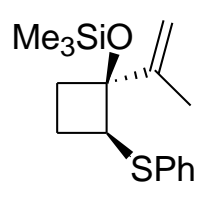

70

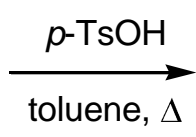

In another approach, tert-butyldimethylsilyl ethers of 1-alkenylcyclobutanols $\mathbf{7 2}$ were rearranged to the corresponding ring expanded $\alpha$-(1-phenylthioalkyl)cyclopentanones $\mathbf{7 3}$ or 74 in 83 to $98 \%$ or 84 to $96 \%$ yield, respectively, upon successive treatment with benzenesulfanyl chloride at $-78{ }^{\circ} \mathrm{C}$ and silver tetrafluoroborate at $-40{ }^{\circ} \mathrm{C}$ (Scheme 22). ${ }^{52}$ The conversion was stated to occur via episulfonium ions. Depending on the different substituents $\left(\mathrm{R}^{1}, \mathrm{R}^{2}, \mathrm{R}^{3}\right.$ and $\left.\mathrm{R}^{4}\right), 2,3,5$ - or 2,3,4-trisubstituted cyclopentanones were isolated as the sole reaction product. For unsymmetrical 1-alkenylcyclobutanols $\left(R^{3} \neq H\right)$, the most substituted alkyl group migrated preferentially, following the expected migratory aptitudes.

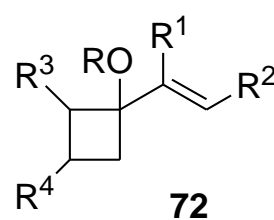

$\mathrm{R}=\mathrm{SiMe}_{2} \mathrm{tBu}$
1) 1 equiv $\mathrm{PhSCl}$, $\mathrm{CH}_{2} \mathrm{Cl}_{2},-78^{\circ} \mathrm{C}$

2) 1.5 equiv $\mathrm{AgBF}_{4}$, $\mathrm{CH}_{2} \mathrm{Cl}_{2},-40^{\circ} \mathrm{C}$ 3) $-10^{\circ} \mathrm{C}-0{ }^{\circ} \mathrm{C}, 1-1.5 \mathrm{~h}$

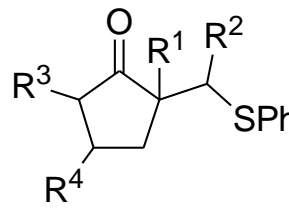

$73(83-98 \%)$<smiles></smiles>

$74(84-96 \%)$

$$
\begin{array}{ll}
R^{1}=H, M e & R^{1}=H, R^{2}=H \\
R^{2}=H, M e & R^{3}=s^{5} \text { tBu } \\
R^{3}=H, R^{4}=P h & \text { and } R^{4}=H \text { or } R^{3}-R^{4}=\left(C_{2}\right)_{4}
\end{array}
$$




\section{Scheme 22}

In the total synthesis of $( \pm)$-cis-sativenediol 78 and ( \pm -helminthosporal $\mathbf{7 9}$, one of the last steps comprised an acid-catalyzed semipinacol rearrangement of diols 75 (Scheme 23). ${ }^{53}$ Treatment of each isomer (or the mixture) with methanolic hydrogen chloride for two minutes at room temperature afforded a 3:1 mixture of olefinic ketones $\mathbf{7 6}$ and $\mathbf{7 7}$ in $\mathbf{7 6 \%}$ yield.
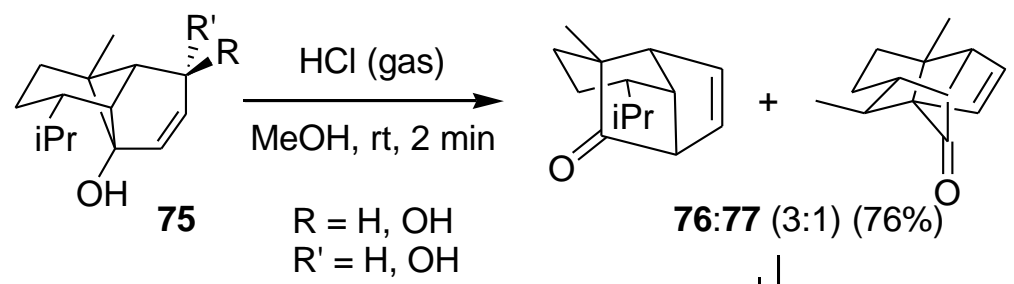<smiles>C=C1C2CCC(C)(C2)C1C(F)(F)F</smiles>

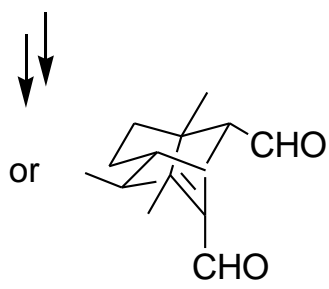

cis-sativenediol 78 helminthosporal 79

\section{Scheme 23}

A special case in the acid-catalyzed rearrangement of vinylcyclobutanols started with the reaction of cyclobutanone $\mathbf{8 0}$ with the 2-lithio derivative of 2,3-dihydrothiophene, reported by Paquette and co-workers. ${ }^{54}$ The obtained product $\mathbf{8 1}$ was not isolated but immediately slurried with Dowex-50x resin in dichloromethane at $20{ }^{\circ} \mathrm{C}$. After 48 hours the resin was filtered off and spiro compound $\mathbf{8 2}$ was obtained in $89 \%$ yield after purification by column chromatography (Scheme 24).

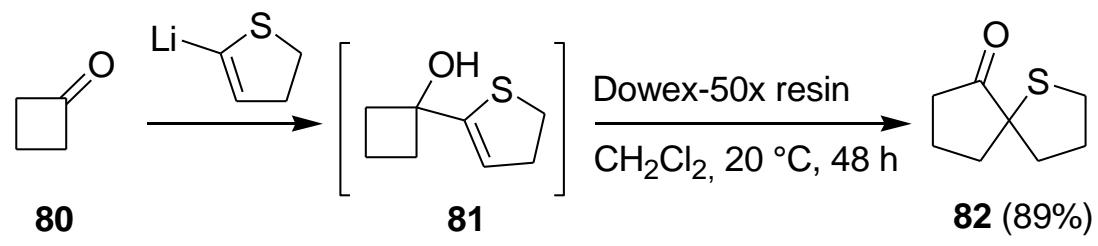




\section{Scheme 24}

The scope of the Bronsted and Lewis acid-promoted spirocyclization of 1-vinylcyclobutanols $\mathbf{8 3}$ with an acetal moiety acting as initiator in the cyclization reaction was demonstrated by Trost and Chen. ${ }^{55}$ The spiroannelated products are cyclopentanones derived from ring expansion of the cyclobutanol unit from which the second ring was formed by attack of the terminator on the initiator moiety. Spirocyclization to [4.5]- and [4.6]-systems proceeded smoothly, whereas spirocyclization to a [4.7]-system failed. Examples of acids used were trimethylsilyl trifluoromethanesulfonate (TMSOTf), $\mathrm{CF}_{3} \mathrm{SO}_{3} \mathrm{H}, \mathrm{SnCl}_{4}$ and $\mathrm{Ph}_{3} \mathrm{CSbCl}_{6}$. When 0.7 equiv of pyridine and one equiv of trimethylsilyl triflate was added to a solution of 7,7dimethoxy-2-(1-hydroxycyclobutyl)-1-heptene $\mathbf{8 3}$ in dichloromethane at $0 \quad{ }^{\circ} \mathrm{C}$, 7methoxyspiro[4.6] undecan-1-one $\mathbf{8 5}$ was isolated after 15 minutes in 86\% yield (Scheme 25). Extension of this cyclization methodology to form eight-, nine- or 13-membered rings failed under the same reaction conditions. Subjecting aldehyde $\mathbf{8 6}$ to $10 \%$ triflic acid afforded a 1.3:1 cis/trans mixture of 7-hydroxyspiro[4.5]decan-1-one $\mathbf{8 7}$ in $90 \%$ yield.<smiles>C=C(CO)CCCCC(OC)OC1(O)CCC1</smiles>

83<smiles>C=C(CCCC=O)C1(O)CCC1</smiles>

86
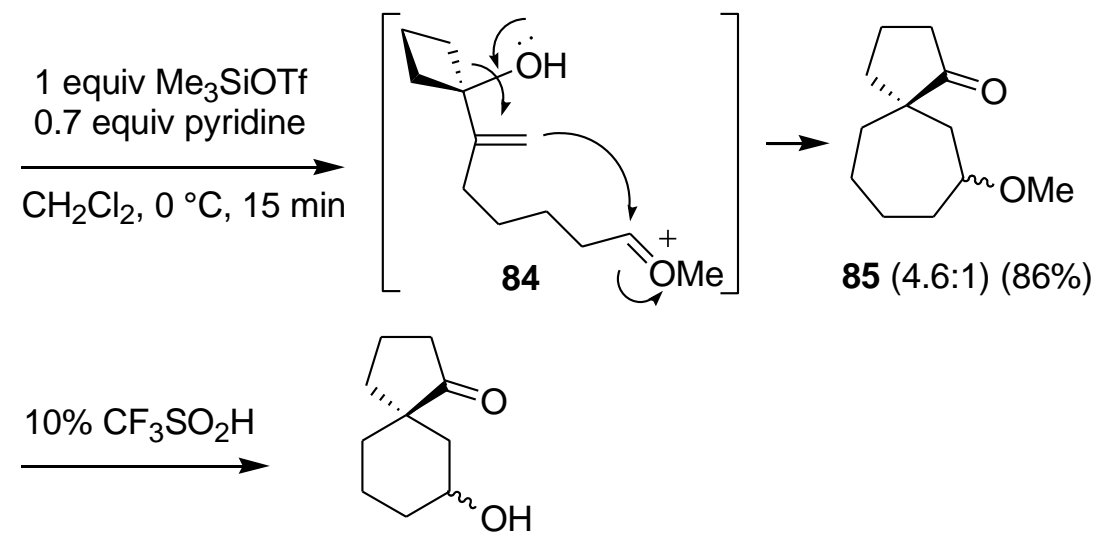

87 (90\%) (1.3:1) (cis/trans)

\section{Scheme 25}


Another example of the acid-promoted ring expansion of propenylcyclobutanols comprised the synthesis of $( \pm)$ - $\alpha$-cuparenone ${ }^{56}\left(\mathrm{R}^{1}=\mathrm{Me}, \mathrm{R}^{2}=4-\mathrm{MeC}_{6} \mathrm{H}_{4}\right)$ and cyclopentanone $89\left(\mathrm{R}^{1}=\right.$ Me, $\left.\mathrm{R}^{2}=3-\mathrm{MeC}_{6} \mathrm{H}_{4}\right)$ as the direct precursor of $( \pm)$-herbertene. ${ }^{57}$ Herbertanes belong to an expanding family of sesquiterpenes possessing a 3-methyl-(1,2,2trimethylcyclopentyl)cyclohexane skeleton. In recent years, herbertanes have become popular synthetic targets as some members of this family exhibit a wide range of biological activities such as antifungal, neurotrophic and anti-lipid peroxidation. ${ }^{58}$ Isopropenylcyclobutanols 88 were treated with one equiv of $p$-toluenesulfonic acid in benzene under reflux to synthesize the corresponding 2,2-dimethylcyclopentanones 89 in good to excellent yields (70-98\%) (Scheme 26). ${ }^{59}( \pm)-\alpha$-Cuparenone 89 was synthesized in $76 \%$ yield, and the precursor of $( \pm)$ herbertene in 70\% yield. 3-(4-Methoxyphenoxymethyl)-2,2,3-trimethylcyclopentanone was synthesized in $70 \%$ yield and is a known precursor of capsorubin 90 (Figure 1), a ketocarotenoïd which, together with capsanthin, constitutes the red pigment of paprika. ${ }^{60}$<smiles>[R]C(=C)C1(O)CCC1([R7])O</smiles>

88

$\mathrm{R}^{1}=\mathrm{Me},\left(\mathrm{CH}_{2}\right)_{4} \mathrm{C}_{6} \mathrm{H}_{5} ; \mathrm{R}^{2}=\mathrm{H}, \mathrm{Me}$ $\mathrm{R}^{3}=\left(\mathrm{CH}_{2}\right)_{2} \mathrm{C}_{6} \mathrm{H}_{5}, 4-\mathrm{MeC}_{6} \mathrm{H}_{4}, 3-\mathrm{MeC}_{6} \mathrm{H}_{4}$ $4-\mathrm{MeOC}_{6} \mathrm{H}_{4} \mathrm{OCH}_{2}, 3-\mathrm{MeC}_{6} \mathrm{H}_{4} \mathrm{OCH}_{2}, \mathrm{C}_{10} \mathrm{H}_{21}$

Scheme 26

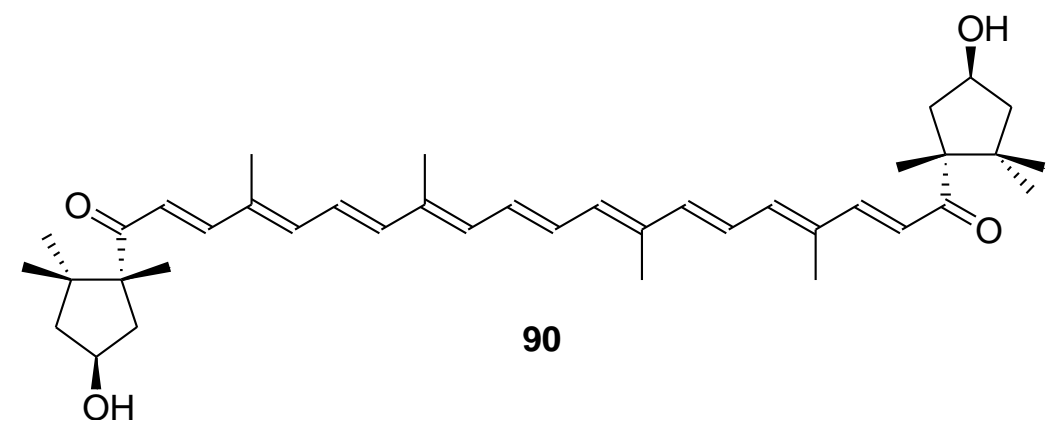




\section{Figure 1}

Recently, a semipinacol-based acid-promoted ring expansion of cyclobutanols toward functionalized 1-azaspirocyclic cyclopentanones has been reported. ${ }^{61}$ Treatment of enamines 91 with camphor sulfonic acid (CSA) or hydrogen chloride produced the transient azacarbenium ion intermediates 92. Migration of one of the adjacent cyclobutane carboncarbon bonds with concomitant $\mathrm{C}=\mathrm{O} \pi$-bond formation furnished protonated azaspirocyclic ketones 93, eventually giving rise to the desired azaspirocyclic ring systems $\mathbf{9 4 a}$ and 94b in $73-89 \%$ yield and in a diastereoselectivity of 2.8:1-14:1, which improved when the reaction was executed at lower temperatures (Scheme 27).

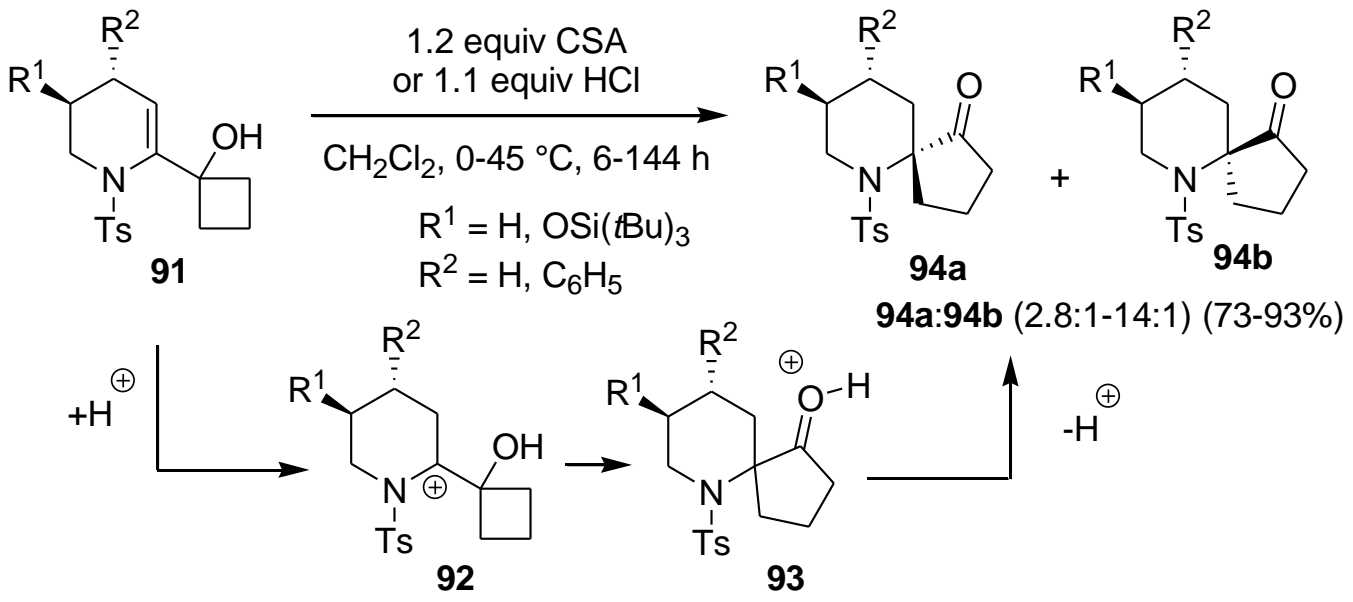

Scheme 27

In a final example, asymmetric spirocyclic diketones 96 have been synthesized via a semipinacol-type 1,2-carbon migration using a cinchona-based primary amine catalyst $97 .{ }^{62}$ Addition of a catalytic amount of $N$-Boc- $L$-phenylglycine (NBLP) and diamine 97 to cyclobutanols 95 afforded spirocyclic diketones 96 in $57-95 \%$ yield and in $86-97 \%$ enantiomeric excess (Scheme 28). The same group have also used chiral phosphoric acid 
catalysts in the asymmetric synthesis of spiroethers via semipinacol rearrangement through activation of a carbonyl group. ${ }^{63}$

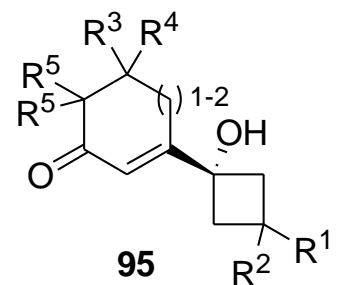

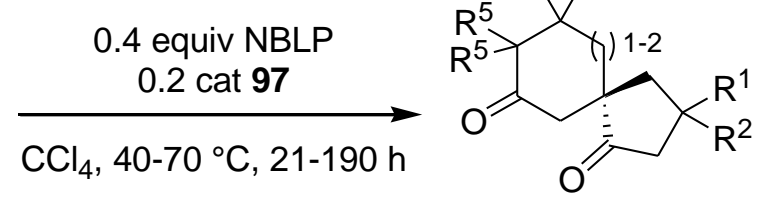

$96(57-95 \%)$

$86-97 \%$ ee

$$
\begin{aligned}
& \mathrm{R}^{1}=\mathrm{H}, \mathrm{C}_{6} \mathrm{H}_{5}, 4-\mathrm{BrC}_{6} \mathrm{H}_{4} ; \mathrm{R}^{2}=\mathrm{H} \\
& \mathrm{R}^{1}-\mathrm{R}^{2}=\left(\mathrm{CH}_{2}\right)_{4-6} \\
& \mathrm{R}^{3}, \mathrm{R}^{4}=\mathrm{H}, \mathrm{Me} ; \\
& \mathrm{R}^{3}-\mathrm{R}^{4}=\left(\mathrm{CH}_{2}\right)_{5} \\
& \mathrm{R}^{5}=\mathrm{H}, \mathrm{Me}
\end{aligned}
$$<smiles>C=CC1CC2CCN1[C@H]([C@H](N)c1ccnc3ccc(OC)cc13)C2</smiles>

97

Scheme 28

\subsection{Halogen/selenium cation-promoted activation}

In addition to acid-catalyzed rearrangements of alkenylcyclobutanols, also halogen and selenium cation-promoted activation has been reported in the literature.

A chlorinative ring homologation of cyclobutanols with one equiv of the potentially explosive $t$-butyl hypochlorite in chloroform has been performed using isopropenylcyclobutanol $\mathbf{6 8}$ as starting material. This reaction provided 2-chloromethyl-2-methylcyclopentanone $\mathbf{9 8}$ in $81 \%$ yield (Scheme 29). ${ }^{50}$ Another chlorinating agent, used for semipinacol type rearrangement reactions, comprised a bleach/acetic acid system which was utilized for the ring expansion of isopropenyl[2.2.1] heptanol. $^{64}$ 


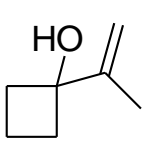

68

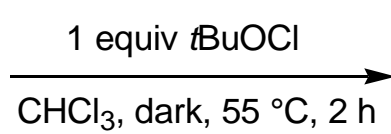

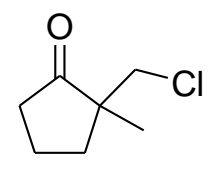

$98(81 \%)$

Scheme 29

The iodonium ion-mediated ring expansion of olefinic cyclobutanols 99 was examined using iodine in the presence of $\mathrm{NaHCO}_{3}$ or by means of $\mathrm{N}$-iodosuccinimide. ${ }^{65}$ In all cases, the reaction proceeded in moderate to high yields, and the triethylsilyl ether $\left(\mathrm{R}^{1}=\right.$ TES) gave a slightly better result (59-100\% yield of $(S)$-100, no $(R)-\mathbf{1 0 0})$ than the corresponding alcohol $\left(\mathrm{R}^{1}=\mathrm{H}\right) \quad(36-88 \%$ of $(S)-\mathbf{1 0 0}$ and $0-47 \%$ of $(R)-\mathbf{1 0 0})$ (Scheme 30). Although no stereoselectivity was observed utilizing monosubstituted substrates $\left(\mathrm{R}^{2}=\mathrm{H}\right)$ giving a mixture of $(S)-\mathbf{1 0 0}$ and $(R)-\mathbf{1 0 0}$, complete stereoselectivity was observed starting from geminally substituted substrates $\left(\mathrm{R}^{2} \neq \mathrm{H}\right)$ to afford cyclopentanone $(S)-\mathbf{1 0 0}$ as the sole product.

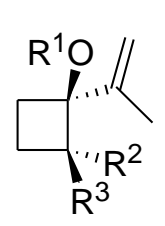

99

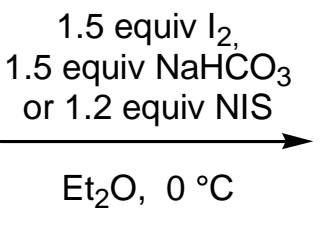

$\mathrm{R}^{1}=\mathrm{H}$, TES; $\mathrm{R}^{2}=\mathrm{H}, \mathrm{CH}_{2} \mathrm{OTBS}$

$\mathrm{R}^{3}=\left(\mathrm{CH}_{2}\right)_{6} \mathrm{Me}, \mathrm{Ph},\left(\mathrm{CH}_{2}\right)_{3} \mathrm{CH}=\mathrm{CHCO}_{2} \mathrm{Me}$, $\left(\mathrm{CH}_{2}\right)_{3} \mathrm{C} \equiv \mathrm{CCO}_{2} \mathrm{Me}$

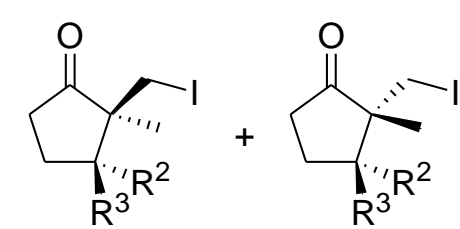

$(S)-100(36-100 \%)(R)-100(0-47 \%)$

Scheme 30

In analogy with the acid-catalyzed rearrangement of vinylcyclobutanols 81 obtained via reaction of cyclobutanone $\mathbf{8 0}$ with the 2-litho derivative of 2,3-dihydrothiophene (Scheme $24),{ }^{54}$ a bromonium ion-promoted rearrangement of vinylcyclobutanol $\mathbf{1 0 1}$ has been reported. ${ }^{66}$ Vinylcyclobutanol 101 was synthesized by addition of 5-lithio-2,3-dihydrofuran to 
cyclobutanone 80 in $\mathrm{THF}$ at $-78{ }^{\circ} \mathrm{C}$. Rearrangement of $\mathbf{1 0 1}$ was executed with $\mathrm{N}$ bromosuccinimide (NBS) in the presence of an acid scavenger, propylene oxide, to give spirocyclic ketone 103, exclusively, in $96 \%$ yield through intermediate bromonium ion $\mathbf{1 0 2}$ (Scheme 31). This $\mathrm{N}$-bromosuccinimide promoted ring expansion methodology has also been used in the formation of functionalized azaspirocyclic cyclopentanones such as compounds 94 (Scheme 27). ${ }^{67}$

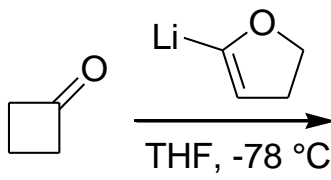

80

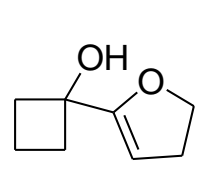

101

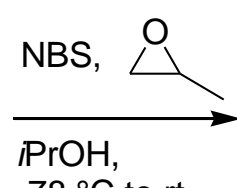

$-78^{\circ} \mathrm{C}$ to rt

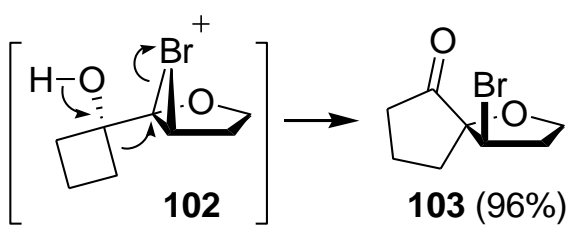

Scheme 31

Allylic alcohols were found to undergo a semipinacol type rearrangement induced by a halogen cation generated from the chloramine- $\mathrm{T} / \mathrm{ZnX} \mathrm{X}_{2}$ combination, which provided a highly efficient and stereoselective method for the preparation of $\alpha$-quaternary $\beta$-bromoketones. It was presumed that the halogen anion in $\mathrm{ZnX}_{2}$ was oxidized to a halogen cation by chloramine- $\mathrm{T}$ and existed in the form of $\mathrm{XCl}$. An electrophilic addition of $\mathrm{X}^{+}$, released from $\mathrm{XCl}$, to the double bond occurred with concomitant 1,2-migration in a transition state geometry resembling that of an ordinary nucleophilic substitution proceeding with inversion of configuration. Using this methodology, 1-cyclopent-1-enylcyclobutanol 104 was converted into 6-bromospiro[4.4]nonan-1-one $\mathbf{1 0 5}$ in $94 \%$ yield in the presence of $\mathrm{ZnBr}_{2}$ (Scheme 32). ${ }^{68}$ $\mathrm{ZnCl}_{2}$ and $\mathrm{ZnI}_{2}$ were also used in the same reaction to prepare other $\beta$-haloketo compounds.

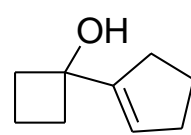

104
1) chloramine- $\mathrm{T}, \mathrm{ZnBr}_{2}$, $\mathrm{MeCN}, \mathrm{rt}, 5 \mathrm{~min}$

2) rt, $1 \mathrm{~min}$

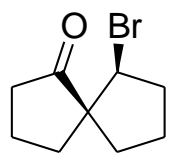

$105(94 \%)$ 


\section{Scheme 32}

Another application of this method involved the synthesis of pseudohelical hydrocarbons of four- and five-membered rings (Scheme 33). ${ }^{69}$ Addition of 1-lithiocyclopentene 107 and 1lithiocyclobutene 110, respectively, to dispiroketone 106 led to allylic alcohols 108 and 111 in 82 and 64\% yield, respectively, which were regio- and stereoselectively converted into cyclopentanones 109 and 112 by reaction with 1.2 equiv of chloramine-T and 1.2 equiv of $\mathrm{ZnBr}_{2}$ in acetonitrile at room temperature in $82 \%$ and $66 \%$ yield, respectively.

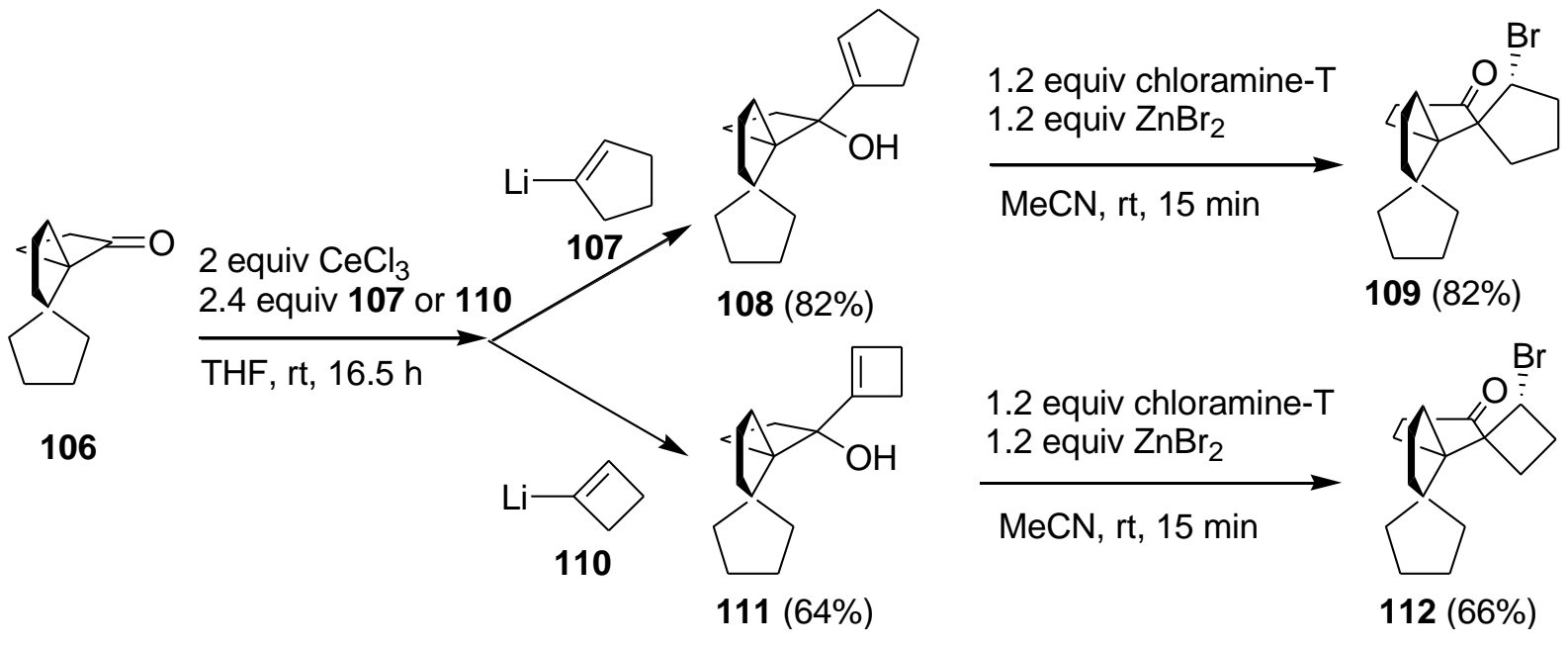

Scheme 33

A last example of cation-promoted ring expansion of vinylcyclobutanols involved the rearrangement of selenonium ion 113, in analogy with the bromonium ion rearrangement in Scheme $31{ }^{54 \mathrm{~b}}$ When vinylcyclobutanol $\mathbf{8 1}$ was treated with one equivalent of phenylselenenyl chloride in isopropylalcohol and propylene oxide (ratio 3:2), spirocyclic ketone 114 was synthesized in $70 \%$ yield (Scheme 34 ). 


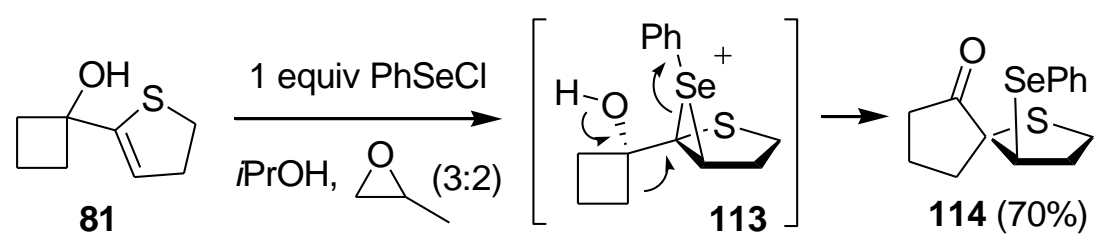

Scheme 34

\section{$2.3 \quad$ Metal-promoted activation}

The electrophilic activation of an alkene by coordination to an electron-deficient metal ion toward nucleophilic attack is fundamental to organometallic chemistry, both conceptual as in synthetic applications. ${ }^{70}$ Mercury- and palladium-promoted ring expansion reactions of alkenylcyclobutanols are well investigated reactions triggered by release of strain in fourmembered ring systems. ${ }^{71}$ These useful methodologies for the construction of five-membered ring systems have been successfully applied in the synthesis of natural products. $^{72}$ In the following section, distinction will be made between mercury-promoted, palladium-promoted ring expansion and thallium promoted reactions of cyclobutane derivatives toward fivemembered ring systems.

It should be noted that the true nature of the electrophilic species resulting from metalpromoted activation of alkenes has not always been defined accurately in the papers described below. Nonetheless, the intermediacy of cyclobutylmethylcarbenium ion-type species can be assumed in order to explain the observed reactivity.

\subsubsection{Mercury-promoted activation}


The mercury(II) ion-mediated ring expansion of 1-alkenyl-1-cyclobutanols $\mathbf{1 1 5}$ led to cyclopentanones 118 (Scheme 35), ${ }^{73}$ which are of synthetic importance because $\beta$-mercurio cycloalkanones may undergo further ring expansion or carbon-carbon bond formation via free radical chain reactions ${ }^{74}$ along with the conversion into $\alpha$-methylene cycloalkanones or $1,4-$ dicarbonyl compounds. ${ }^{75}$ Ring expansion reactions of trimethylsilyl ethers of 1-vinyl and 1propenylcyclobutanols 115 with $\mathrm{Hg}\left(\mathrm{OCOCF}_{3}\right)_{2}$ in dichloromethane at room temperature gave the synthetically useful $\alpha$-methylenecyclopentanones 118 in $68-82 \%$ yield via $\pi$-complex intermediates 116 after demercuration of 117 with aqueous sodium carbonate. For unsymmetrical substrates, and as expected, the most substituted alkyl group migrated preferentially.

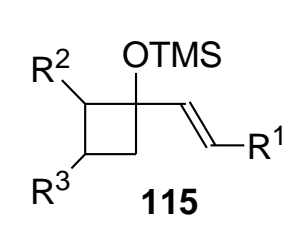

1) 1.3 equiv $\mathrm{Hg}\left(\mathrm{OCOCF}_{3}\right)_{2}$,
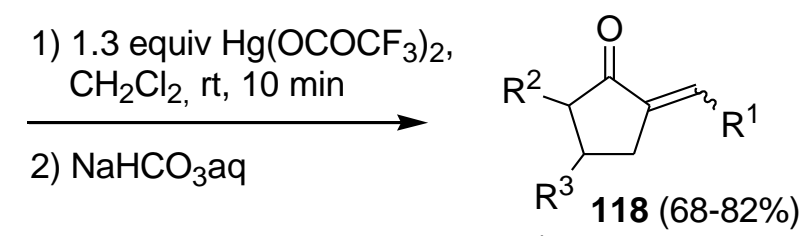

$$
\begin{aligned}
& \mathrm{R}^{1}=\mathrm{H}, \mathrm{Me} ; \mathrm{R}^{3}=\mathrm{H}, \mathrm{Ph} \\
& \mathrm{R}^{2}=\mathrm{H}, \mathrm{s}_{\mathrm{tBu}}
\end{aligned}
$$$$
\mathrm{R}^{1}=\mathrm{Me} ; \mathrm{E} / \mathrm{Z} 82 / 18
$$
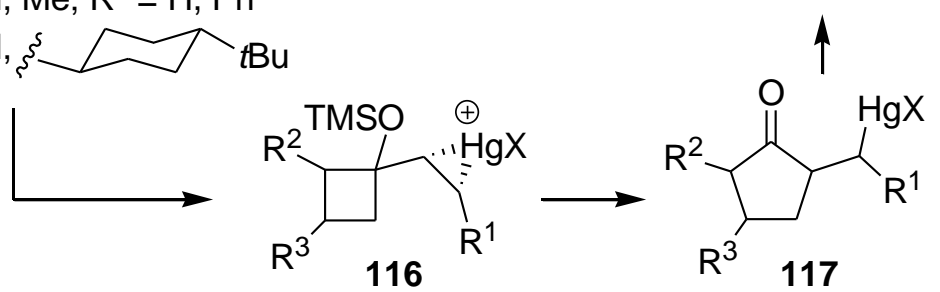

Scheme 35

\subsubsection{Palladium-promoted activation}

The palladium(II)-catalysed conversion of terminal olefins into methyl ketones by $\mathrm{PdCl}_{2^{-}}$ $\mathrm{CuCl}_{2}-\mathrm{O}_{2}-\mathrm{H}_{2} \mathrm{O}$ has been known for some time and is analogous to the Wacker process. ${ }^{76} \mathrm{~A}$ conversion of methylenecyclobutanes $\mathbf{1 1 9}$ into cyclopentanones $\mathbf{1 2 0}$ in 65 to $82 \%$ yield 
comprised a special case of rearrangement based on the reaction conditions of this Wacker oxidation (Scheme 36$){ }^{77}$

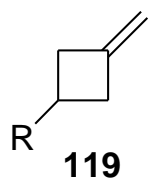

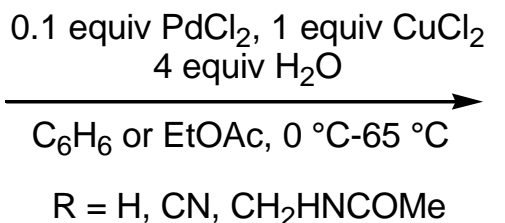

Scheme 36

The reaction of 1-vinyl-1-cyclobutanols 121 with one equivalent of bis(benzonitrile)palladium dichloride in THF quickly and smoothly gave cyclopentenones $\mathbf{1 2 2}$ in one hour at $25{ }^{\circ} \mathrm{C}$ (Scheme 37). ${ }^{78}$ However, when two equivalents of benzoquinone were added, only a catalytic amount of palladium (5 mol\%) was needed to obtain the desired cyclopentenone $\mathbf{1 2 2}$, although reflux conditions were necessary for 2.5 days in THF. The two equivalents of added benzoquinone are responsible for the regeneration of the active catalyst. A plausible mechanistic pathway is given in Scheme 38 using intermediates $\mathbf{1 2 5}$ and $\mathbf{1 2 6}$ for the formation of cyclopentanone $\mathbf{1 2 7}$ and subsequently cyclopentenone $\mathbf{1 2 9}$ through intermediate 128. Accordingly, several 1-vinyl-1-cyclobutanols $\mathbf{1 2 1}$ were rearranged into the corresponding 2-methyl-cyclopentenones 122 in 16-67\% yield (Scheme 37) applying the optimized conditions (vide supra). ${ }^{78}$ The reaction with substrate $\mathbf{1 2 1}\left(\mathrm{R}^{1}=\mathrm{H}, \mathrm{R}^{2}=\mathrm{OEt}, \mathrm{R}^{3}=\right.$ H) produced a substantial amount of the diastereomeric 4-ethoxy-2-methylcyclopentanone $123(42 \%)$ next to $21 \%$ of 4-ethoxy-2-methylcyclopentenone 122 , even in the presence of a ten-fold excess of benzoquinone. This reaction provided useful building blocks for prostaglandin synthesis. 

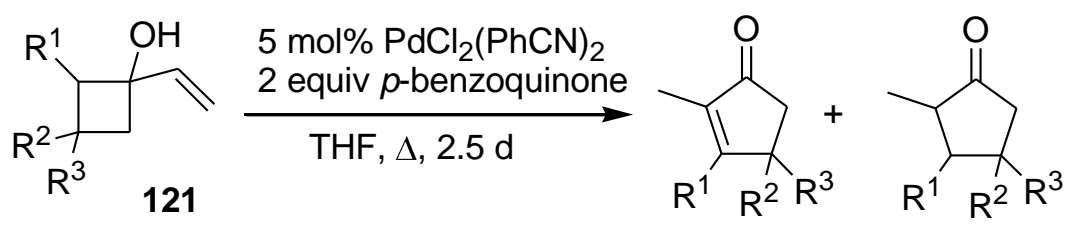

$\mathrm{R}^{1}=\mathrm{H}, \mathrm{R}^{2}=\mathrm{Ph},\left(\mathrm{CH}_{2}\right)_{4} \mathrm{CH}_{3}$, OEt

$\mathrm{R}^{1}-\mathrm{R}^{2}=\left(\mathrm{CH}_{2}\right)_{3},\left(\mathrm{CH}_{2}\right)_{4},\left(\mathrm{CH}_{2}\right)_{5}$

$\mathrm{R}^{3}=\mathrm{H}, \mathrm{Me}$

$122(16-67 \%) 123\left(R^{1}=H, R^{2}=\right.$

OEt, $\left.R^{3}=H\right)(42 \%)$

\section{Scheme 37}<smiles>CCCOc1ccc(O)cc1</smiles>

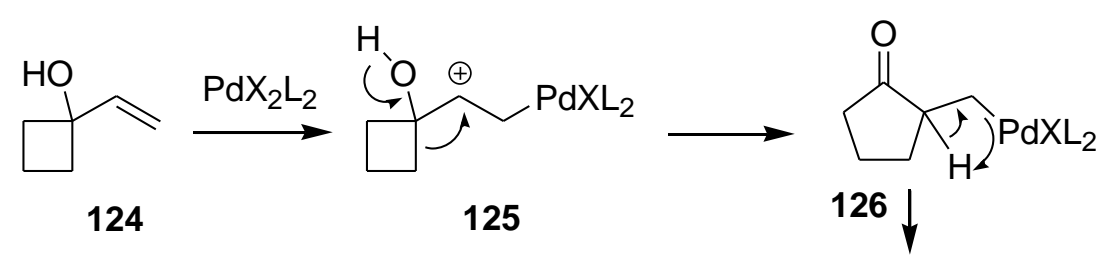

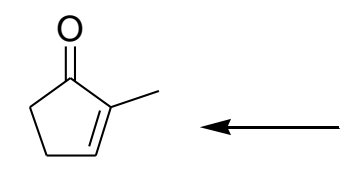

129<smiles>CC1(P)CCCC1=O</smiles>

128

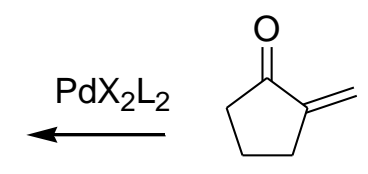

127

Scheme 38

The above-described method was used to synthesize the potential precursor $\mathbf{1 3 1}$ of pentalenolactone- $\mathrm{G}$ and $-\mathrm{H}$ antibiotics without the need to cleave the $\mathrm{Me}_{3} \mathrm{SiO}$ group in 130 prior to the treatment with $\mathrm{PdCl}_{2}\left(\mathrm{PhCN}_{2}\right){ }^{79}$ Treatment of ethyl 2-(3,3-dimethyl-4-oxo-7trimethylsilyloxy-7-vinylbicyclo[3.2.0]hept-1-yl)acetate 130, in a ratio of stereoisomers 12:1, with 3.3 mol\% of bis(benzonitrile)palladium(II) chloride and two equiv of $p$-benzoquinone in THF for three hours under reflux afforded ethyl 2-(3,3-dimethyl-8-methylidene-4,7dioxobicyclo[3.3.0]oct-1-yl)acetate $\mathbf{1 3 1}$ in $72 \%$ yield (Scheme 39). 


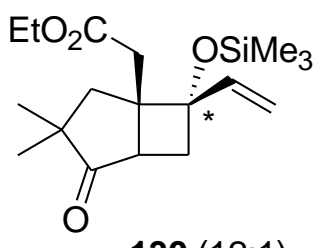

$130(12: 1)$

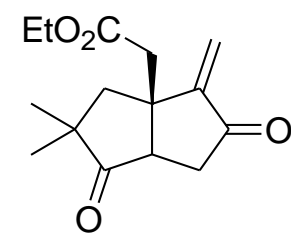

$131(72 \%)$

Scheme 39

A pseudoguaianolide-like structure was synthesized using a palladium-mediated ring expansion for the synthesis of the cyclopentanone ring (Scheme 40$){ }^{80}$ Reaction of tricyclic compound 132 with three mol\% of bis(benzonitrile)palladium(II) chloride in tetrahydrofuran at reflux temperature resulted in a smooth rearrangement to provide the tricyclic $\alpha$ methylenecyclopentanone $\mathbf{1 3 5}$ in $95 \%$ yield. The proposed mechanism involved the formation of an enolate $\mathbf{1 3 4}$ which preceded the construction of the cyclopentanone ring, although it is not clear how this process can be catalytic in palladium according to the suggested pathway. The obtained tricycle $\mathbf{1 3 5}$ was functionalized into analogues of helenalin, a typical pseudoguaianolide sesquiterpene.

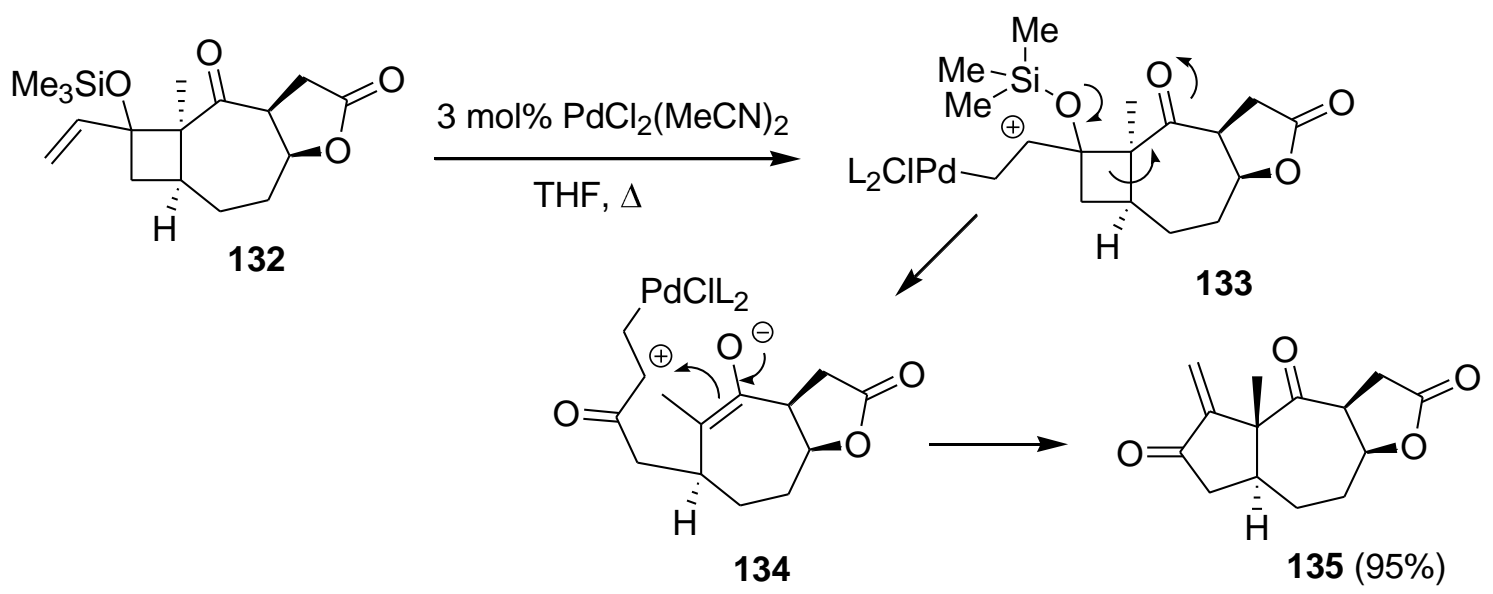

Scheme 40 
A special case involved the palladium-catalyzed ring expansion of vinyl oxaspirohexanes. ${ }^{81}$ When vinyl oxaspirohexanes 136 were treated with five mol\% of $\mathrm{Pd}\left(\mathrm{PPh}_{3}\right)_{4}$ in the presence of one equiv of 4-nitrophenol in tetrahydrofuran at room temperature or at reflux for one to three hours, the corresponding 2-alkylidenecyclopentanones 138 were obtained in 73-90\% yield (Scheme 41). $\operatorname{Pd}(0)$ activated the double bond, forming a $\pi$-allyl palladium cationic complex 137, which rearranged to the corresponding cyclopentanone. When the migrating group was a secondary alcohol, the reaction could be executed at room temperature. Furthermore, the presence of a methyl vinyl group $\left(\mathrm{R}^{1}=\mathrm{Me}\right)$ was expected to stabilize the $\pi$-allyl Pd-complex but, as a result, the reaction proceeded slowly and required heating for three hours. In the case of a tertiary migrating group $\left(\mathrm{R}^{2}, \mathrm{R}^{3}=\mathrm{Me}\right.$ or $\left.\mathrm{R}^{2}-\mathrm{R}^{3}=-\left(\mathrm{CH}_{2}\right)_{2} \mathrm{CH}(t \mathrm{Bu})\left(\mathrm{CH}_{2}\right)_{2}-\right)$, the reaction was completed almost instantly ( 0.2 hours at room temperature) under the same reaction conditions, yielding only 2-vinylcyclopentanones 139 in $87-88 \%$ yield without migration of the double bond (Scheme 41).

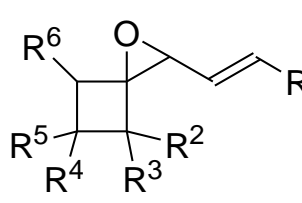

136
$5 \mathrm{~mol} \% \mathrm{Pd}\left(\mathrm{PPh}_{3}\right)_{4}$

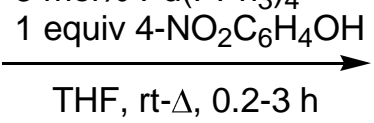

THF, rt- $\Delta, 0.2-3 \mathrm{~h}$

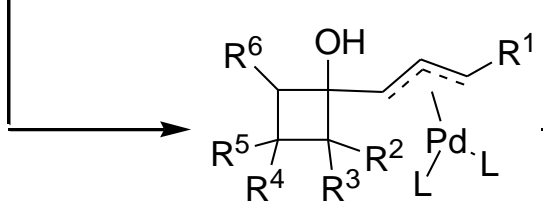

137
$\mathrm{R}^{4}$

$R^{5}$

$138(73-90 \%)$

$R^{1}, R^{2}, R^{3}, R^{4}=H, M e ;$

$\mathrm{R}^{5}=\mathrm{H}, \mathrm{Ph} ; \mathrm{R}^{6}=\mathrm{H}$;<smiles>[R]C/C=C1/C(=O)CC([R7])([R7])C1([R7])[R7]</smiles>

or

$\mathrm{R}^{5}-\mathrm{R}^{6}=\left(\mathrm{CH}_{2}\right)_{3},\left(\mathrm{CH}_{2}\right)_{4}$

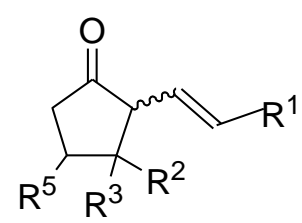

$139(87-88 \%)$

$\mathrm{R}^{1}=\mathrm{H} ; \mathrm{R}^{2}, \mathrm{R}^{3}=\mathrm{Me}$ or

$\mathrm{R}^{2}-\mathrm{R}^{3}=\left(\mathrm{CH}_{2}\right)_{2} \mathrm{CH}(\mathrm{tBu})\left(\mathrm{CH}_{2}\right)_{2}$;

$\mathrm{R}^{5}=\mathrm{H}, \mathrm{Ph}$

\section{Scheme 41}

In the enantioselective total synthesis of (+)-laurene 142, the five-membered ring was obtained via a palladium-mediated ring enlargement of a cyclobutane system (Scheme 42). ${ }^{82}$ 
The triethylsilyl (TES) ethers 140a and 140b were subjected to ring expansion in the presence of a catalytic amount of bis(acetonitrile)palladium(II) chloride and $p$-benzoquinone in tetrahydrofuran at reflux temperature for two hours to give the $\alpha$-methylenecyclopentanone 141 in $86 \%$ or $70 \%$ yield, respectively, as the precursor for (+)-laurene $\mathbf{1 4 2 .}$
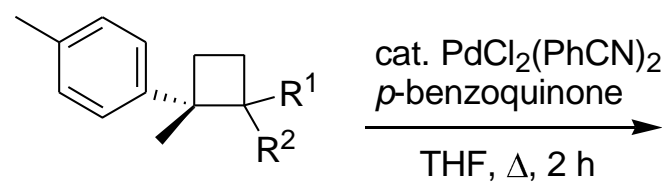

140a: $R^{1}=\cdot \cdot$ OTES $R^{2}=$

140b: $R^{1}=$-OTES $R^{2}=$

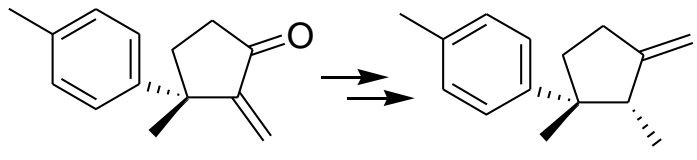

141

$142(+)-($ laurene)

$(86 \%$ from $140 a$ $70 \%$ from $140 \mathrm{~b})$

Scheme 42

A number of polycyclic compounds possessing a hydrindane (hexahydroindane) skeleton are found in nature ${ }^{83 a}$ and are important synthons for a variety of natural products. ${ }^{83 b}$ Several halogenated terpenes having such a ring system, for example oppositol $\mathbf{1 4 3}^{84}$ and iriediol 144, ${ }^{85}$ have been isolated from marine sources (Figure 2).
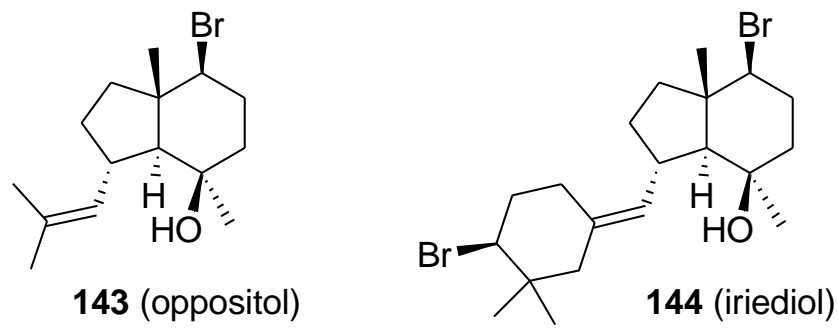

Figure 2

A new route to a hydrindane ring system was developed using a palladium-mediated ring expansion of alkenic cyclobutanols 145 in 1,2-dimethoxyethane (DME) to form a palladium- 
complex, followed by an insertion reaction and subsequent $\beta$-elimination to afford the hydrindan silyl ether 146 in $29 \%$ yield (Scheme 43). ${ }^{71 e, 86}$ The palladium reagent, bis(acetonitrile)palladium(II) chloride, was added in one equivalent. Desilylation of the resulting silyl ether with tetra- $n$-butylammonium fluoride in THF furnished the hydrindane alcohol 147 in $72 \%$.

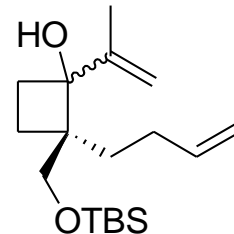

145

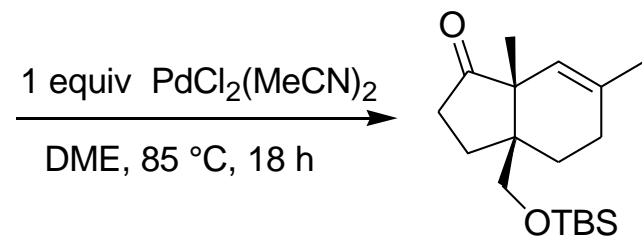

$146(29 \%)$
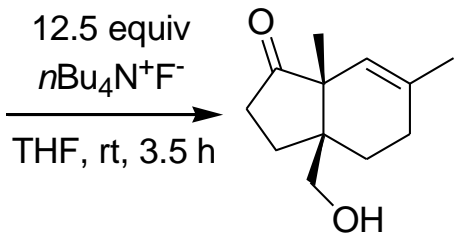

$147(72 \%)$

Scheme 43

The same authors described a palladium-mediated ring expansion of 1-vinylcyclobutanol 148 in the total synthesis of (-)-aplysin 150 and (-)-debromoaplysin $151 .^{72 a}$ The first natural product is a halogenated sesquiterpene, isolated from the sea hare, Aplysia kurodai. (-)Aplysin displays antifeedant properties that helps to protect the mollusk from raptorial advances. The co-occurrence of (-)-debromoaplysin, the unhalogenated form, suggests that this might function as an antioxidant and scavenger of reactive halogens. The silyl ether $\mathbf{1 4 8}$ was subjected to 1.1 equivalents of bis(acetonitrile)palladium(II) chloride in THF at reflux temperature for two hours to give the unsaturated cyclopentanone 149 in $59 \%$ yield. However, the ring expansion reaction was more effective when 0.9 equivalents of palladium(II) acetate and 0.9 equivalents of triphenylarsine were used in dichloromethane at room temperature for three hours (Scheme 44), resulting in $\alpha$-methylidenecyclopentanone 149 in $89 \%$ yield. This compound 149 was also used as a precursor for the synthesis ${ }^{87}$ of (-)-filiformin 152 and its debromo analogue, (-)-debromofiliformin 153, which are known marine sesquiterpenes. ${ }^{88}$ 


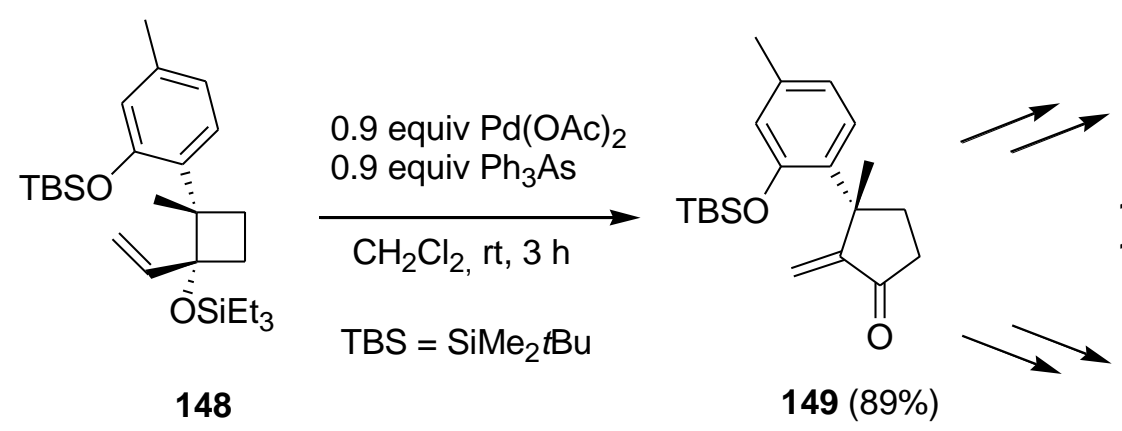

148
0.9 equiv $\mathrm{Pd}(\mathrm{OAc})_{2}$

equiv $\mathrm{Ph}_{3} \mathrm{As}$

$149(89 \%)$<smiles>[R]c1cc2c(cc1C)OC1(C)C(C)CCC1(C)C2</smiles>

150 (-)-aplysin $(\mathrm{R}=\mathrm{Br})$

151 (-)-debromoaplysin $(\mathrm{R}=\mathrm{H})$<smiles>[R]c1cc2c(cc1C)O[C@]1(C)CC[C@]2(C)C1</smiles>

152 (-)-filiformin $(\mathrm{R}=\mathrm{Br}$ )

$153(-)$-debromofiliformin $(\mathrm{R}=\mathrm{H})$

Scheme 44

The Nemoto group ${ }^{89}$ developed an efficient synthesis of A-ring aromatic trichotecanes $\mathbf{1 5 6}$ since such compounds have been shown to possess significant in vivo antileukemic activity. ${ }^{90}$ In this approach, triethylsilyl ethers of 1-vinylcyclobutanols 154 were subjected to a palladium-mediated ring expansion, and it was found that the reaction proceeded regioselectively to give 1-methylidenecyclopentanones $\mathbf{1 5 5}$ as the sole products in $63 \%$ for the methoxymethyl (MOM)-ether and $78 \%$ for the trimethylsilylethoxymethyl (SEM)-ether (Scheme 45). Cyclopentanones $\mathbf{1 5 5}$ were subsequently used as substrates for the synthesis of trichotecanes 156.<smiles></smiles>

154
1.1 equiv $\mathrm{PdCl}_{2}(\mathrm{MeCN})_{2}$ 0.7 equiv $\mathrm{Pd}(\mathrm{OAc})_{2}$ THF for $\mathrm{R}=\mathrm{MOM}$

1.1 equiv $\mathrm{PdCl}_{2}$ 2 equiv $\mathrm{Cu}(\mathrm{OAc})_{2} \cdot \mathrm{H}_{2} \mathrm{O}$ THF/MeCN for $\mathrm{R}=\mathrm{SEM}$

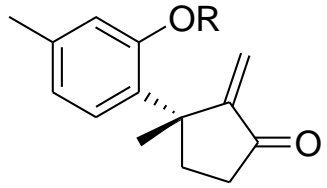

$155(63 \%)(\mathrm{R}=\mathrm{MOM})$

$(78 \%)(\mathrm{R}=\mathrm{SEM})$

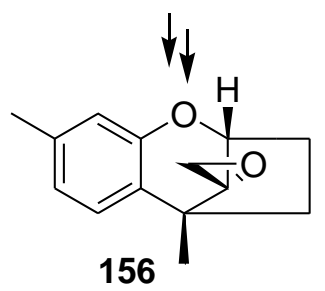

Scheme 45 
In addition, a new route to racemic 4-deoxyverrucarol 159 via a palladium-mediated ring expansion has been developed. ${ }^{72 \mathrm{~d}}$ This rearrangement of 1-vinylcyclobutanol 157 to the corresponding $\alpha$-methylidenecyclopentanone $\mathbf{1 5 8}$ was executed in $90 \%$ yield by means of 1.6 equiv of $\mathrm{Pd}(\mathrm{OAc})_{2}$ in tetrahydrofuran at room temperature for eight hours (Scheme 46). The asymmetric synthesis of 4-deoxyverrucarol 159 was carried out in 2000 by the same group. ${ }^{91}$

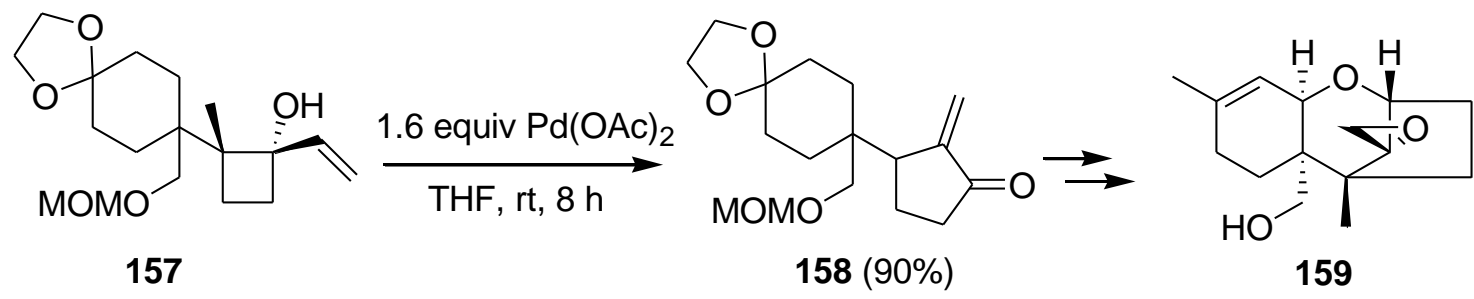

Scheme 46

As an extension of the study of trichothecanes, Nemoto and Ihara reported the synthesis of racemic $( \pm)$-scirpene 162 through a palladium-mediated ring expansion of vinylcyclobutanols 160 as the key step to prepare the precursor 161 (Scheme 47). ${ }^{92}$ The desired rearrangement was performed using one equivalent of $\mathrm{Pd}\left(\mathrm{Cl}_{2}\right)(\mathrm{MeCN})_{2}$ in the presence of $p$-benzoquinone as an oxidizing agent in $N, N$-dimethylacetamide (DMA) as solvent. The $\alpha$ methylidenecyclopentanone $\mathbf{1 6 1}$ was obtained in $62 \%$ yield.

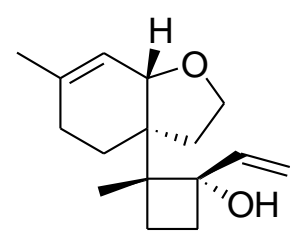

160

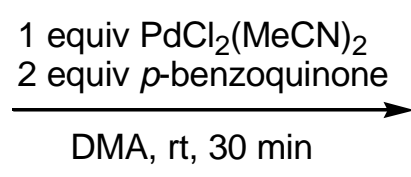

$161(62 \%)$

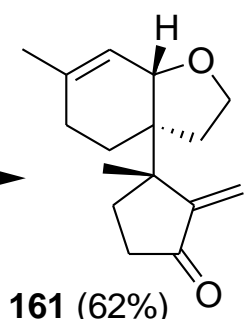

(1)

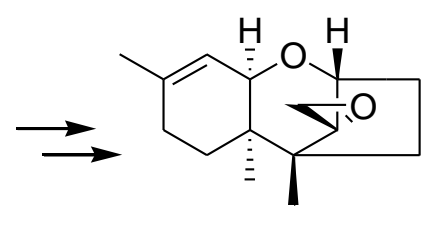

$162( \pm)$-scirpene

Scheme 47 
A cyclic cascade carbopalladation has been reported using previously described methods to synthesize benzo- and naphthohydrindans in a stereoselective manner. ${ }^{71 \mathrm{~g}}$ These hydrindans could be potential intermediates for the synthesis of $\mathrm{A}$-nor steroids and $\mathrm{C}_{11}-\beta$-substituted estradiols. Different palladium reagents such as $\mathrm{PdCl}_{2}(\mathrm{MeCN})_{2}, \quad \operatorname{Pd}(\mathrm{OAc})_{2}\left(\mathrm{AsPh}_{3}\right)_{2}$, $\mathrm{Pd}(\mathrm{OAc})_{2}\left(\mathrm{PPh}_{3}\right)_{2}, \mathrm{Pd}(\mathrm{OAc})_{2}$ and $\mathrm{PdCl}_{2}\left(\mathrm{PPh}_{3}\right)_{2}$ were tested in different solvents at room temperature for 10-144 hours, providing useful entries into A-nor steroids $\mathbf{1 6 4}$ or equilenin type steroids 165 through ring expansion of the cyclobutanol ring system in 163 (Scheme 48). This strategy was used in the synthesis of (+)-equilenin with $60 \%$ yield for the ring expansion of isopropenylcyclobutanol. ${ }^{72 c, 93}$<smiles>C=Cc1c(C2CCC2(O)C(=C)C)ccc2ccccc12</smiles>

163

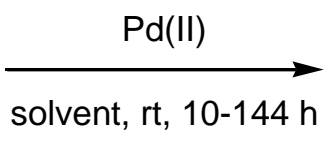

benzo-derivatives $164(15-53 \%)$ naphtho-derivatives 165 (46-81\%)

\section{Scheme 48}

Nonlinear triquinane type building blocks were synthesized by means of metal-controlled skeletal rearrangements, type Wagner-Meerwein migration. ${ }^{94}$ Several metal reagents have been evaluated for the rearrangement of pentacyclic vinylcyclobutane 166. The thallium(III) and mercury(II) salts, being strong, soft electrophiles, favor migration of the more substituted carbon (path a), suggesting an electronically controlled process. By contrast, $\mathrm{Pd}(\mathrm{II})$, a transition metal, clearly favors path $\mathrm{b}$ (Scheme 49). When 1.03 equiv of thallium(III) nitrate trihydrate was used, $\alpha$-methylidenecyclopentanone $\mathbf{1 6 7}$ was obtained in $76 \%$ yield next to $\mathbf{1 7 0}$ in $12 \%$ yield. Changing the reagent to 0.94 equiv of mercury(II) nitrate monohydrate afforded a lower yield of $\mathbf{1 6 7}(52 \%)$ besides $13 \%$ of $\mathbf{1 7 0}$ and $23 \%$ of $\mathbf{1 6 8}$. When a stoichiometric 
reaction of vinylcyclobutanol $\mathbf{1 6 6}$ with palladium(II) nitrate was executed, 54\% of cyclopentenone $\mathbf{1 7 1}, 36 \%$ of $\mathbf{1 6 7}$ and $2 \%$ of $\mathbf{1 7 0}$ and $2 \%$ of $\mathbf{1 6 9}$ were obtained. On the other hand, a catalytic reaction of $\mathbf{1 6 6}$ with five mol\% of palladium(II) nitrate in the presence of three equiv of copper(II) nitrate afforded $60 \%$ of $\mathbf{1 7 1}$ and only $13 \%$ of $\mathbf{1 6 7}$, next to $3 \%$ of $\mathbf{1 7 0}$ and 169. The last reagent that was evaluated was bis(benzonitrile)palladium(II) chloride. If eight mol\% of this reagent was added in the presence of two equiv of $p$-benzoquinone, $72 \%$ of $\alpha$-methylidenecyclopentanone 169 was obtained, next to $12 \%$ of $\mathbf{1 6 7}, 11 \%$ of $\mathbf{1 7 1}$ and $2 \%$ of 170.

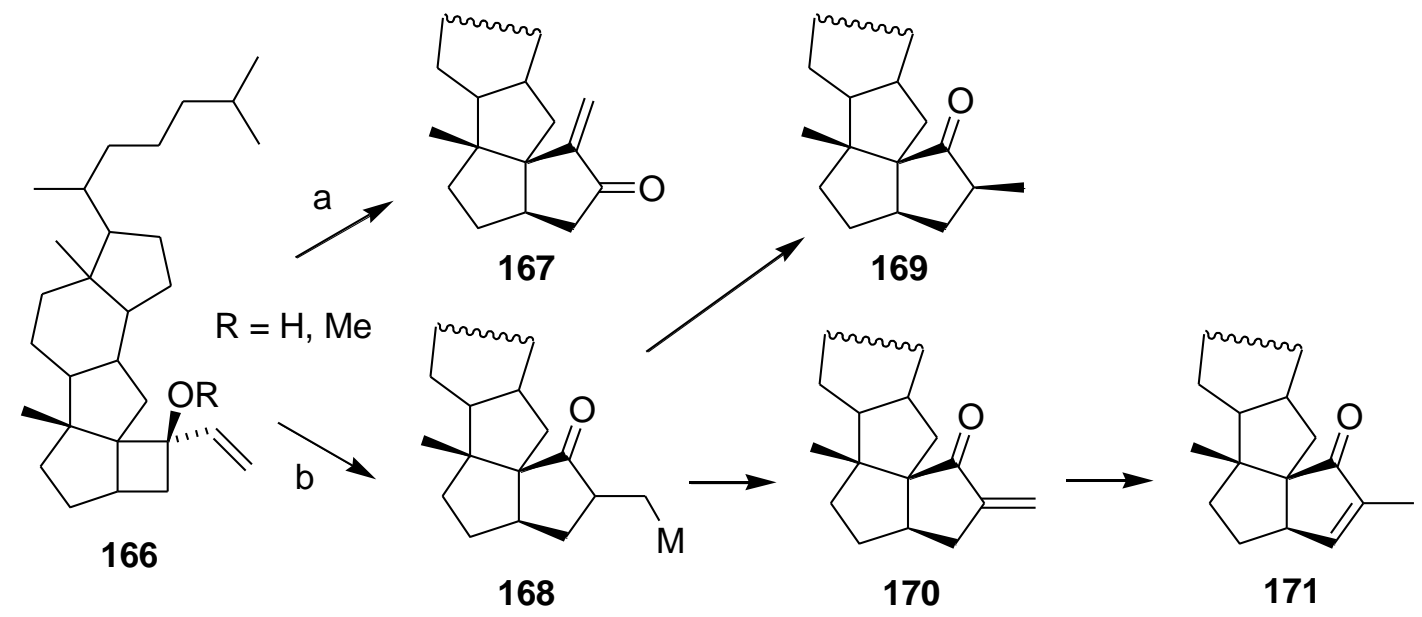

catalyst: $\mathrm{Tl}\left(\mathrm{NO}_{3}\right)_{3} \cdot 3 \mathrm{H}_{2} \mathrm{O}, \mathrm{Pd}\left(\mathrm{NO}_{3}\right)_{2}, \mathrm{Hg}\left(\mathrm{NO}_{3}\right)_{2} \cdot \mathrm{H}_{2} \mathrm{O}, \mathrm{PdCl}{ }_{2}(\mathrm{PhCN})_{2}, \mathrm{Cu}\left(\mathrm{NO}_{3}\right)_{2}$ $\mathrm{M}=$ metal complex

\section{Scheme 49}

In addition to the previous studies, the first ring expansion of $\alpha$-heteroatom-substituted 1vinylcyclobutanols was examined. ${ }^{95}$ When seven mol\% of bis(acetonitrile)palladium(II) chloride and two equivalents of $p$-benzoquinone in tetrahydrofuran were added to $\alpha$-alkoxy-1vinyl-1-cyclobutanol 172, 68\% of cyclopentenone 173 was obtained and no $\alpha$ methylidenecyclopentanone $\mathbf{1 7 4}$ was recovered (Scheme 50). ${ }^{79}$ Changing the catalyst from palladium(II) chloride to palladium(II) acetate allowed the isolation of $\alpha$ - 
methylidenecyclopentanones 174. With one equiv of 2,3-dichloro-5,6-dicyanoquinone (DDQ) as a reoxidizing agent and tetrahydrofuran as the solvent only ten mol\% of palladium(II) acetate was required to produce $\alpha$-methylidenecyclopentanones 174 in 67 to $84 \%$ yield.

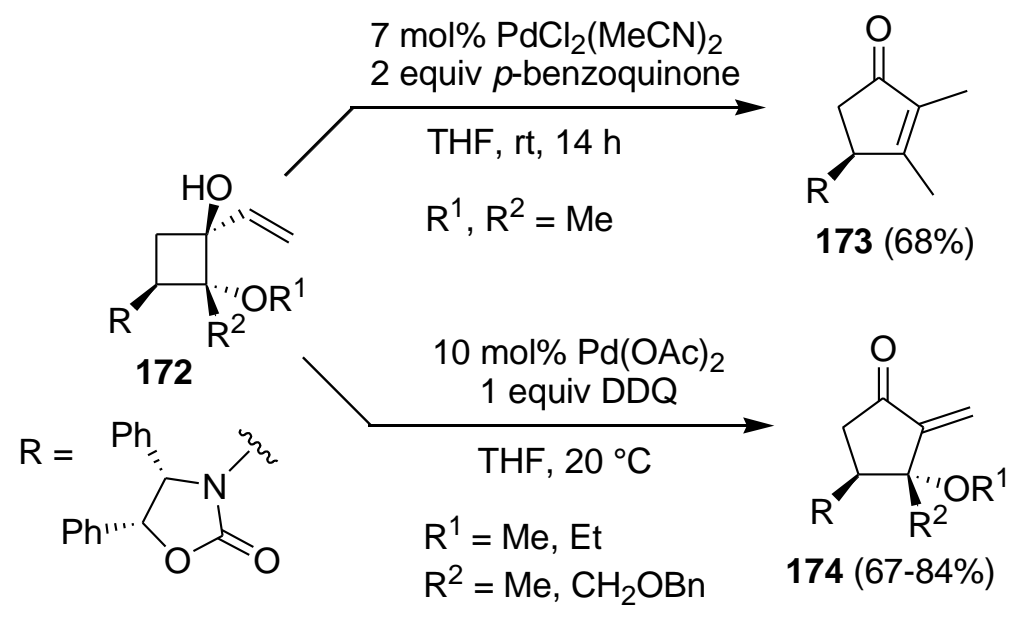

Scheme 50

A special case has been reported by Uemura et al. ${ }^{96}$ The authors described the ring expansion of vinylcyclobutanols in which the less substituted carbon atom performed the ring rearrangement instead of the more substituted one. Bicyclic cyclobutanols 175 having an angular substituent, which blocks $\beta$-hydrogen elimination, were reacted with $10 \mathrm{~mol} \%$ of $\mathrm{Pd}(\mathrm{OAc})_{2}$ in the presence of pyridine and molecular sieves in toluene at $80{ }^{\circ} \mathrm{C}$ under $\mathrm{O}_{2^{-}}$ atmosphere for 18-48 hours to afford the corresponding cyclopentanones 179 in $62-67 \%$ yield (Scheme 51). The results showed that an alkylpalladium intermediate 177, which is formed by $\beta$-carbon elimination from a palladium alcoholate 176, underwent cyclization in the 5-exo mode to an intermediate $\mathbf{1 7 8}$, followed by $\beta$-hydrogen elimination to give an $\alpha$ methylidenecyclopentanone 179. In this case, no initial palladium-assisted activation of the olefinic moiety took place. 


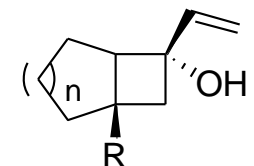

175

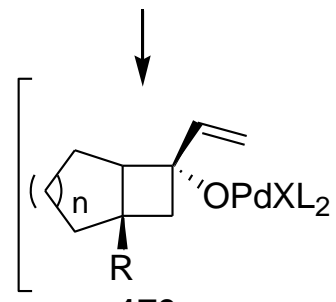

176

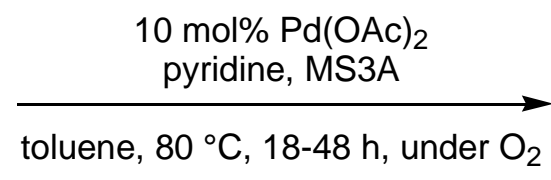

$\mathrm{R}=\mathrm{Me}, \mathrm{Ph} ; \mathrm{n}=1,2$

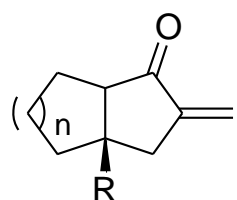

$179(62-67 \%)$ $\beta$-carbon elimination

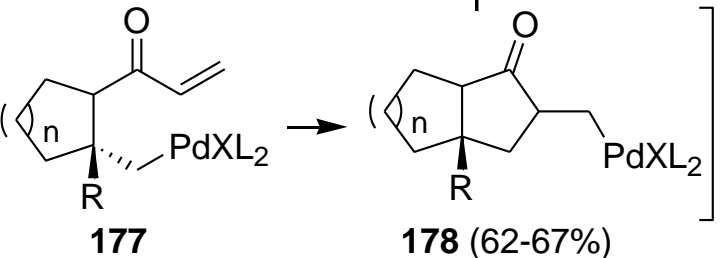

Scheme 51

A last ring expansion of vinylcyclobutanols using a palladium catalyst has been reported by the Trost group. ${ }^{97}$ Exposing vinylcyclobutanols $\mathbf{1 8 0}$ to $2.5 \mathrm{~mol} \%$ of a $\operatorname{Pd}(0)$ catalyst, i.e. $\mathrm{Pd}_{2}(\mathrm{dba})_{3} \cdot \mathrm{CHCl}_{3}$, in the presence of seven mol\% of Trost ligand $(R, R)-\mathbf{1 8 2}$ (Figure 3 ) and two to $100 \mathrm{~mol} \%$ of tetramethylguanidine (TMG) as a base led to smooth ring expansion affording $\alpha$-vinylcyclopentanones $\mathbf{1 8 1}$ in $52 \%$ to quantitative yield and 69-93\% ee (Scheme 52). When the amount of TMG was increased from two to $100 \mathrm{~mol} \%$, the $e e$ increased from 77 to $89 \%$ but at the expense of conversion from quantitative yields down to $52 \%$ yield.

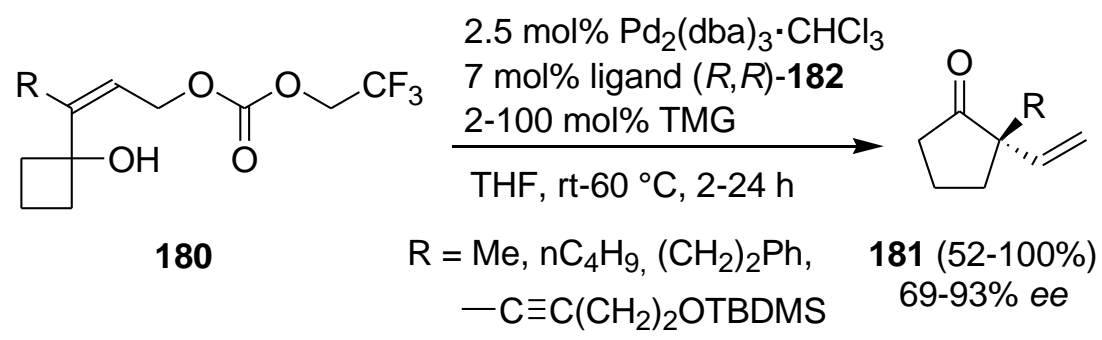

Scheme 52 


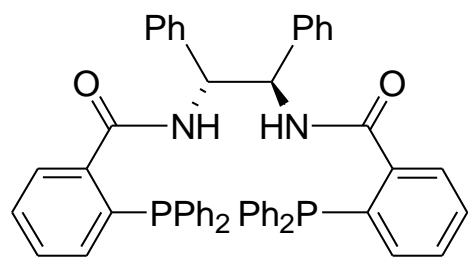

$(R, R)$-ligand 182

Figure 3

\subsubsection{Thallium-promoted activation}

Oxythallation of alkenes with thallium(III) reagents, a reaction which closely resembles the well-known oxymercuration, is a unique method for the preparation of organothallium compounds which are produced in high regio- and stereoselectivity. Also, because the thallium moiety undergoes facile substitution by various functional groups, useful intermediates for further elaboration could be obtained. $^{98}$

Ring expansion of 3-methylenecyclobutanecarbonitrile 183 has been executed via a thallic oxidation. ${ }^{99}$ Treatment of methylenecyclobutane 183 with 1.1 equiv of thallium(III) nitrate trihydrate in 1,2-dimethoxyethane at room temperature for 12 hours afforded 3cyanocyclopentanone 186 in $81 \%$ yield (Scheme 53). The mechanism involved initial formation of a cyclic thallonium ion 184, followed by trans attack of water to give an intermediate $\mathbf{1 8 5}$ in which the thallium can function as a leaving group. ${ }^{100}$

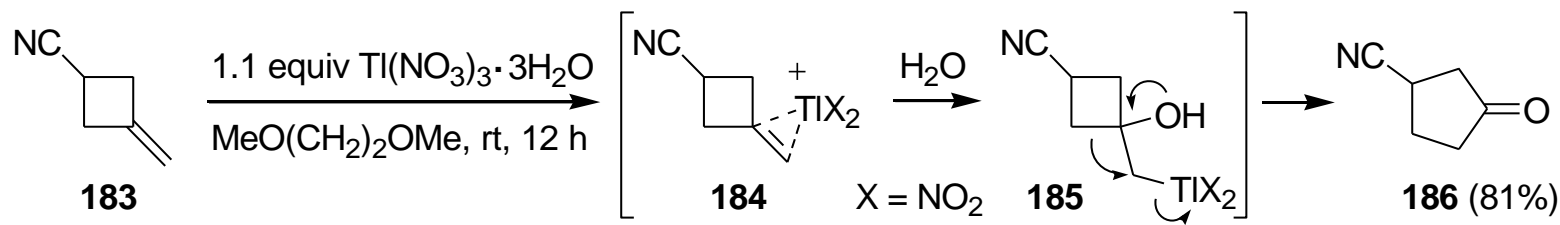

Scheme 53 
Alternatively, thallium ion-mediated ring expansions of 1-alkenyl-1-cyclobutanols 187 were envisioned using cationic species (i.e. $\left.\mathrm{Tl}\left(\mathrm{CF}_{3} \mathrm{COO}\right)_{2}{ }^{+}\right)$, generated from thallium(III) trifluoroacetate. ${ }^{101}$ When trimethylsilylated cyclobutanols $\mathbf{1 8 7}$ were treated with $\mathrm{Tl}\left(\mathrm{OCOCF}_{3}\right)_{3}$ in acetonitrile at room temperature for 30 minutes, an electrophilic attack across the carbon-carbon double bond generated thallium intermediates 188, which subsequently rearranged to the ring-expanded cyclic ketones 190 containing an $\alpha$-methylene substituent. The hydroxy group of cyclobutanols 187 was trimethylsilylated because these ring expansions afforded better yields in comparison with the use of the corresponding alcohols.

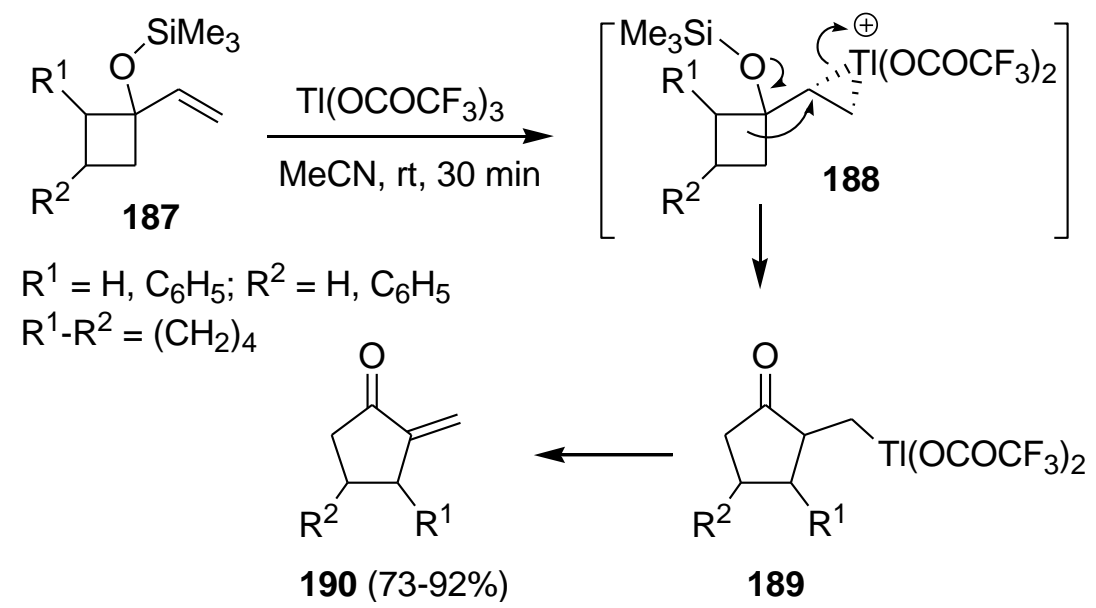

Scheme 54

The thallic oxidation with $\mathrm{Tl}\left(\mathrm{NO}_{3}\right)_{3}$ has been used to rearrange diene 191 to the corresponding syn-3'-spirocyclopentanone $\quad \mathbf{1 9 2} .^{102} \quad$ Treatment $\quad$ of 'synmethylenespiro[bicyclo[2.2.1]heptene-7,1'-cyclobutanyl] 191 with one equiv of thallium(III) nitrate trihydrate in tetrahydrofuran at $3{ }^{\circ} \mathrm{C}$ for $45 \mathrm{~min}$ afforded syn-3'-spirocyclopentanone 
192 in a very low yield of $11 \%$ (Scheme 55). No explanation for this low yield was provided by the authors.

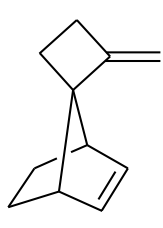

191

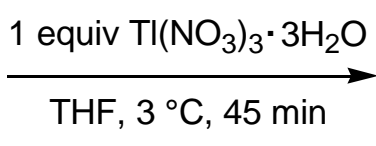

THF, $3{ }^{\circ} \mathrm{C}, 45 \mathrm{~min}$

$192(11 \%)$

Scheme 55

\subsection{Conjugated double bond (1,3-dienyl group) activation}

Palladium-catalyzed ring expansion reactions of (Z)-1-(1,3-butadienyl)cyclobutanols with aryl iodides have been reported as a novel cascade ring rearrangement process. ${ }^{103}$ The reaction proceeds in a stereospecific manner to produce (Z)-2-(3-aryl-1-propenyl)cyclopentanones. Treatment of 1,3-dienylcyclobutanols 193 with 1.5 equiv of an iodo arene in the presence of five mol\% of $\mathrm{Pd}_{2}(\mathrm{dba})_{3}, 20 \mathrm{~mol} \%$ of $\mathrm{P}(o-\mathrm{Tol})_{3}$ and two equiv of $\mathrm{Ag}_{2} \mathrm{CO}_{3}$ in toluene for 2-13 hours at $45{ }^{\circ} \mathrm{C}$ afforded a mixture of cyclopentanones 194 and 195 in 53 to $91 \%$ yield and in a product ratio of 9.3-4.2:1, or 194 as the only formed product (Scheme 56).

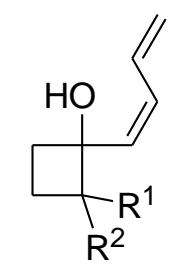

193
1.5 equiv Arl $5 \mathrm{~mol} \% \mathrm{Pd}_{2}(\mathrm{dba})_{3} \cdot \mathrm{CHCl}_{3}$ $20 \mathrm{~mol} \% \mathrm{P}(\mathrm{O}-\mathrm{Tol})_{3}$ 2 equiv $\mathrm{Ag}_{2} \mathrm{CO}_{3}$, toluene, $45^{\circ} \mathrm{C}, 2-13 \mathrm{~h}$ $\mathrm{R}^{1}=$ pentyl, $\mathrm{CH}_{2} \mathrm{OSitBu}\left(\mathrm{C}_{6} \mathrm{H}_{5}\right)_{2}$ $\mathrm{R}^{2}=$ pentyl, Me or $\mathrm{R}^{1}-\mathrm{R}^{2}=\left(\mathrm{CH}_{2}\right)_{5}$ $\mathrm{Ar}=2-\mathrm{MeOC}_{6} \mathrm{H}_{4}$, 2-tolyl, $\mathrm{C}_{6} \mathrm{H}_{5}$, 4- $\mathrm{NO}_{2} \mathrm{C}_{6} \mathrm{H}_{4}$ and others

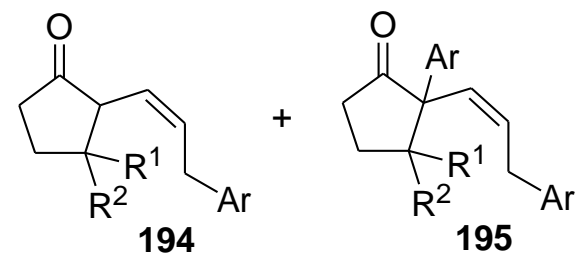

$194: 195(1: 0)$ to $(9.3-4.2: 1)(53-91 \%)$

Scheme 56 


\section{Ring expansion of cyclobutylmethylcarbenium ions through activation of an allene}

Allenylcyclobutanols are versatile initiators for the synthesis of cyclopentanones. Two types of ring expansion reactions are described, one by means of acid activation and one by means of metal-promoted ring rearrangement. Palladium and ruthenium catalysts are used very frequently for the synthesis of a five-membered carbon skeleton.

\subsection{Acid-promoted activation}

In contrast to metal-promoted activation, very few examples are known regarding the acidmediated activation of allenylcyclobutanols.

Allenylcyclobutanol 196, synthesized by addition of 1-lithio-1-methoxyallene across benzocyclobutanone, on treatment with trifluoroacetic acid in a 1:1 tetrahydrofuran/water mixture underwent a hydrolysis-ring expansion providing 2-hydroxy-2-vinylindan-1-one 197 in $83 \%$ yield (Scheme 57). ${ }^{104}$

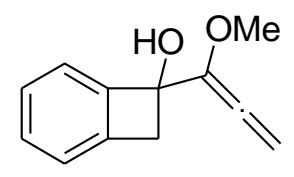

196

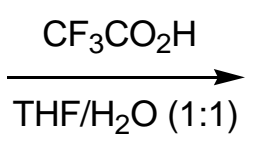

Scheme 57

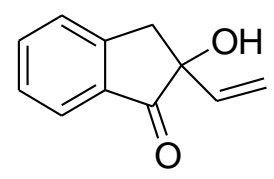

$197(83 \%)$ 


\subsection{Metal-promoted activation}

\subsubsection{Palladium-promoted activation}

Carbopalladation has emerged as an important method for the preparation of a wide range of molecular frames. Both intermolecular ${ }^{105}$ and intramolecular ${ }^{106}$ carbopalladation of allenes comprise attractive approaches in that respect. Palladium-promoted ring expansion reactions of allenylcyclobutanols are well investigated reactions triggered by release of the strain of the four-membered ring systems. ${ }^{107}$ A possible general mechanism is given in Scheme $58 .{ }^{107 \mathrm{c}}$ This reaction enables the formation of a carbon-carbon bond along with the expansion of the four-membered ring system via $\pi$-allylpalladium intermediates 199 in a one-pot process, and thereby constitutes a potentially useful synthetic method for the efficient preparation of natural products.

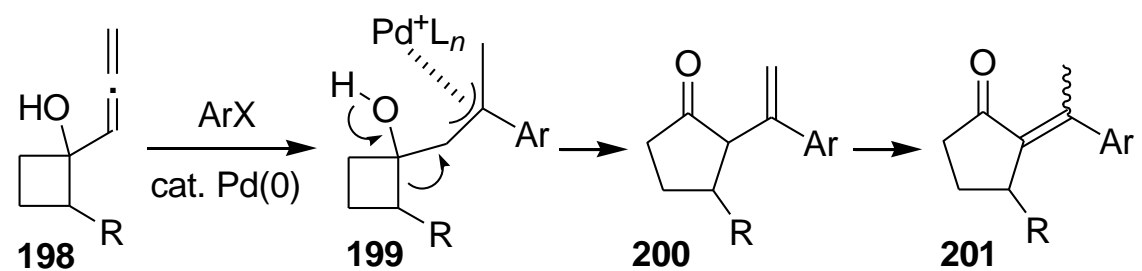

Scheme 58

Applying this methodology, Fukumoto et al. reported an intermolecular version of a carbopalladation reaction and subsequent ring expansion of allenylcyclobutanols $\mathbf{2 0 2}$ giving rise to the direct formation of substituted cyclopentanones, both the conjugated form $\mathbf{2 0 3}$ (62$100 \% E, 0-38 \% Z)$ and the less stable unconjugated form $204(0-48 \%)$ depending on the $\beta$ substituent and the reaction conditions (Scheme 59). ${ }^{107 \mathrm{a}}$ 


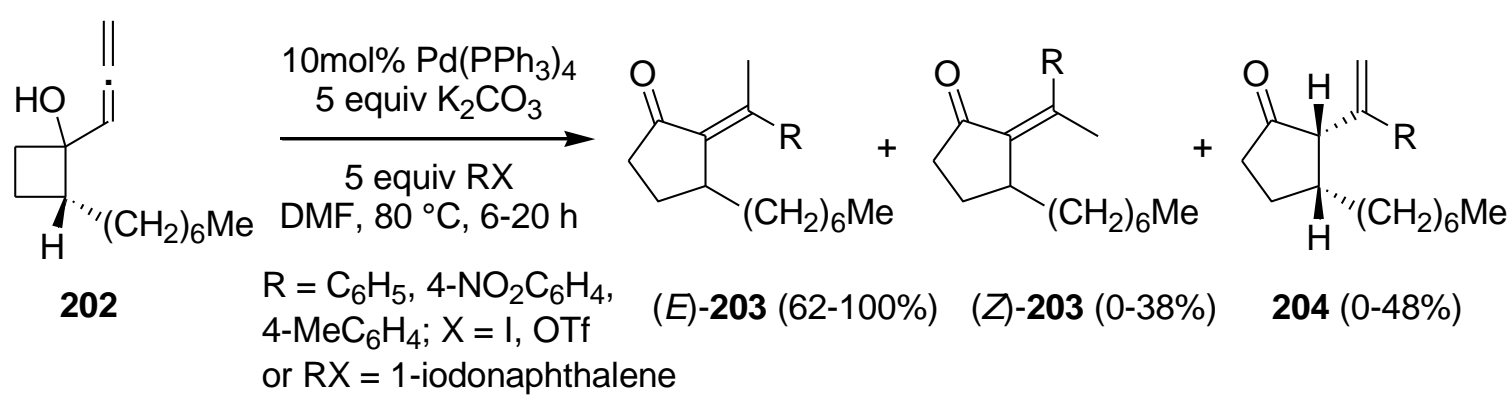

Scheme 59

The same authors also described a novel type of intramolecular palladium-catalyzed cascade reaction for the synthesis of bicyclo[5.3.0] and bicyclo[6.3.0] frameworks. ${ }^{107 a}$ The ring transformation of $\pi$-allylpalladium 206, in situ generated by intramolecular carbopalladation of 205, was accompanied by strain release of the cyclobutane ring to give directly the fused bicyclo[ $n+3.3 .0]$ ring system 207 (Scheme 60).

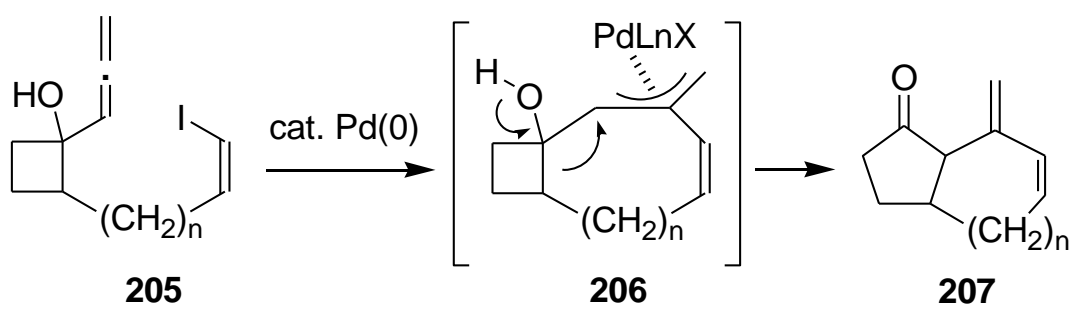

Scheme 60

This intramolecular carbopalladation reaction was executed on two substrates in which the allene and vinyl iodide units were tethered by four- and five-carbon chains (Scheme 61). ${ }^{107 a}$ The cascade reaction starting from 201 or 204 enabled the synthesis of bicyclo[5.3.0]decenone $\mathbf{2 0 2}$ in 67\% yield, tricyclic compound $\mathbf{2 0 3}$ in $80 \%$ yield, 2,8dimethylbicyclo[6.3.0] undeca-1,3-diene-11-one 205 in 34\% yield or 2-methylidene-1,8dimethylbicyclo[6.3.0] undeca-3-ene-11-one 206 in 24\% yield, depending on the chosen starting isomer and the selected reaction temperature. 
<smiles>[R]C1(C=C=C)CCC1(C)CC/C=C\I</smiles>

208a: $\mathrm{R}=-\mathrm{OH}$

208b: $\mathrm{R}=\cdots \cdot \cdots \mathrm{OH}$<smiles>[R]C1(C=C)CCC1(C)[Y10]C/C=C\I</smiles>

211a: $\mathrm{R}=-\mathrm{OH}$

211b: $\mathrm{R}=\cdots \mathrm{\cdots} \mathrm{OH}$

$$
\underset{\text { toluene } \mathrm{A}=1}{\stackrel{\mathrm{Ag}_{2} \mathrm{CO}_{3}, \mathrm{Pd}\left(\mathrm{PPh}_{3}\right)_{4}}{\longrightarrow}}
$$

$\underset{\text { toluene } \mathrm{n}=2}{\stackrel{\mathrm{Ag}_{2} \mathrm{CO}_{3}, \mathrm{Pd}\left(\mathrm{PPh}_{3}\right)_{4}}{\longrightarrow}}$

212

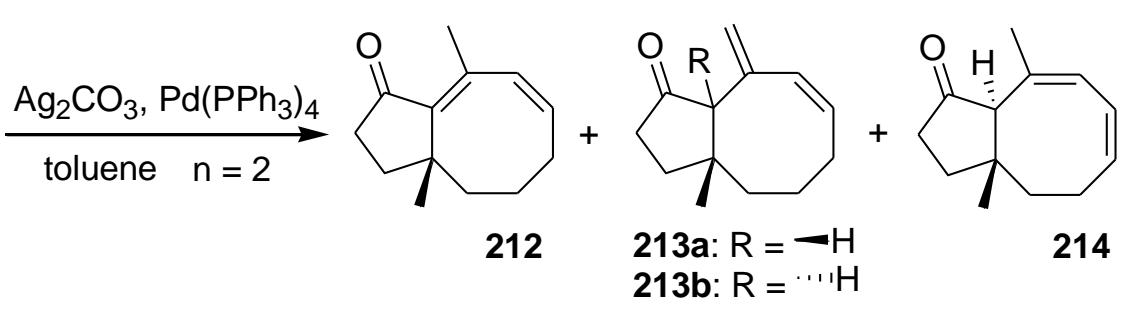

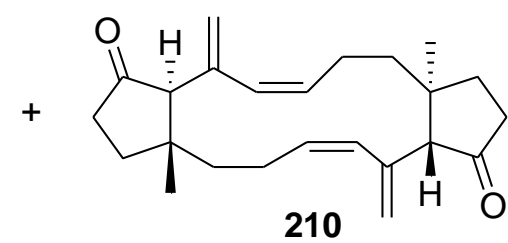

208a: rt: 209:210 (0:100) (80\%)

$80^{\circ} \mathrm{C}: 209: 210(100: 0)(63 \%)$

208b: $80{ }^{\circ} \mathrm{C}$ : $209: 210$ (100:0) (67\%)

211a: $80^{\circ} \mathrm{C}$ : 212:213:214 (48:22(a),23(b):7) (81\%)

$\Delta:$ 212:213:214 (62:0:38) (53\%)

211b: $80^{\circ} \mathrm{C}$ : 212:213:214 (0:100:0) (24\%)

$\Delta:$ 212:213:214 (100:0:0) (34\%)

Scheme 61

A major restriction of the above-described method involved double bond isomerization to give more stable $\alpha, \beta$-unsaturated cyclopentenones. A stereoselective synthesis of $\alpha$-substituted cyclopentanones $\mathbf{2 1 6}$ with quaternary carbon stereocentres has been reported by Ihara and coworkers by introducing a substituent at the allenyl moiety to suppress the isomerization of the products. ${ }^{107 b, \mathrm{c}}$ The stereochemistry of the reaction was controlled by the conformation of the $\pi$-allylpalladium complex during the ring expansion reaction. By choosing the reaction conditions, e.g. time and temperature, the rearrangement of cyclobutanol 215 proceeded in a stereospecific manner to give compounds $\mathbf{2 1 6}$ bearing a quaternary carbon stereocentre with high diastereoselectivity in 31 to $89 \%$ yield (Scheme 62). 


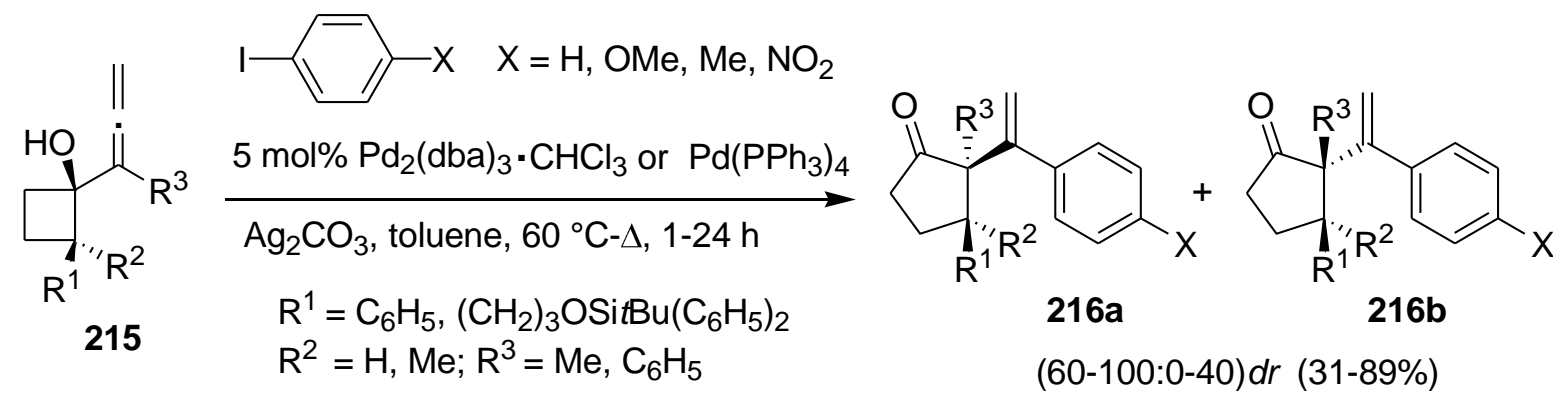

Scheme 62

The asymmetric Wagner-Meerwein shift of allenylcyclobutanols $\mathbf{2 1 7}$, catalyzed by palladium, provided a general way to synthesize cyclopentanones 218 with an $\alpha$-chiral $O$-tertiary centre using Trost ligands for the palladium catalyst. ${ }^{108}$ The combination of benzoic acid and triethylamine gave the fastest reaction and was the key to good reactivity and selectivity. For unsubstituted cyclobutanols $217\left(\mathrm{R}^{\prime}=\mathrm{H}\right)$, the highest reactivity was obtained at $30{ }^{\circ} \mathrm{C}$ with ligand 182 (Figure 3) to obtain cyclopentanones 218 (78-100\% yield, 84-92\% ee), from which one derivative was used to determine the absolute configuration by transforming it into transkumausyne or bisabolangelone (Scheme 63). ${ }^{109}$ 3,3-Disubstituted cyclobutanols 217 (R' $\neq$ H) were converted into cyclopentanones 218 in high yield (80-95\%) at $60{ }^{\circ} \mathrm{C}$ with ligand 219 (Figure 4) in an enantiomeric excess of 92-95\% (Scheme 63).

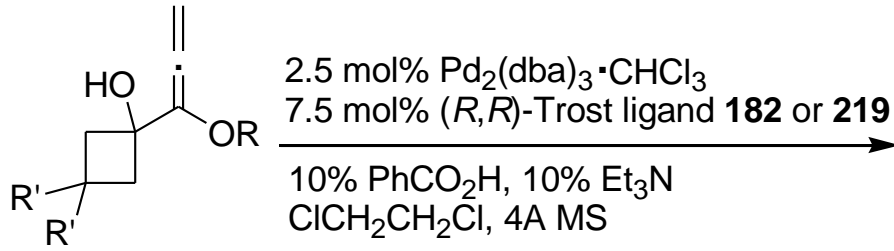

217<smiles>[R]C1([R])CC(=O)[C@](O)(C=C)C1</smiles>

218

$\mathrm{R}^{\prime}=\mathrm{H} ; 30^{\circ} \mathrm{C}$, ligand 182

ligand 182: 218 (78-100\%), (84-92\% ee)

$\mathrm{R}^{\prime}=\mathrm{Ph}, \mathrm{Et},\left(\mathrm{CH}_{2}\right)_{4},\left(\mathrm{CH}_{2}\right) \mathrm{CO}_{2} \mathrm{Et} ; 60^{\circ} \mathrm{C}$, ligand 219 ligand 219: 218 (80-95\%), (92-95\% ee)

$\mathrm{R}=\mathrm{Bn}, \mathrm{PMB},\left(\mathrm{CH}_{2}\right)_{10} \mathrm{Me}$, allyl, $\left(\mathrm{CH}_{2}\right)_{2}(\mathrm{CH})_{2} \mathrm{Me}$

\section{Scheme 63}




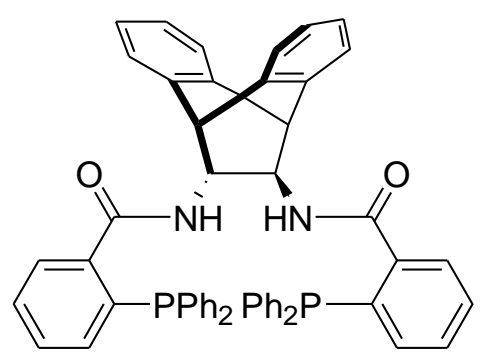

$(R, R)$-ligand 219

Figure 4

The above-described palladium-catalyzed method was applied to 3-monosubstituted allenylcyclobutanols 220 as substrates (Scheme 64). ${ }^{110}$ Because the diastereomeric mixtures resulting from the allene additions to cyclobutanone were not completely separable, the ring expansion was conducted with the enriched diastereomeric mixture of allenylcyclobutanols, obtained after chromatography on silica gel. The corresponding cyclopentanones 221 were obtained in $68-88 \%$ yield with a $d r$ of $4.2-14: 1$ and an enantiomeric excess of $82-90 \%$.
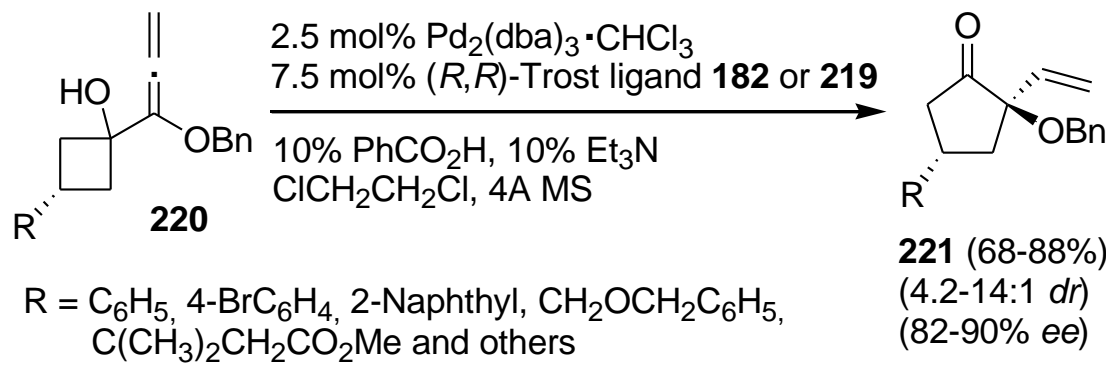

$221(68-88 \%)$

$(4.2-14: 1 d r)$

$(82-90 \%$ ee)

Scheme 64

\subsubsection{Ruthenium- or gold-promoted activation}

In contrast to palladium-promoted ring expansion reactions, only few examples are known concerning ring expansion reactions of cyclobutanols using other transition metals. 
Ihara et al. reported a ruthenium-catalyzed ring expansion of 1-allenylcyclobutanols 222 with $\alpha, \beta$-unsaturated carbonyl compounds $\mathbf{2 2 3}$ under conditions similar to those described by Trost et al. for cycloetherifications. ${ }^{111}$ The reaction mechanism postulated the formation of a $\pi$ allylruthenium intermediate followed by nucleophilic attack of the internal hydroxy group. This reaction enabled the one-pot synthesis of $\alpha$-substituted cyclopentanones 224 using $\left[\mathrm{CpRu}(\mathrm{MeCN})_{3}\right] \mathrm{PF}_{6}$ as a catalyst. ${ }^{112}$ If cerium(III) chloride was added to the reaction mixture, according to the method of Trost and Pinkerton, ${ }^{111 \mathrm{~b}}$ bicyclic hemiacetals were formed as side products. Without the cerium additive, the allenylcyclobutanols $\mathbf{2 2 2}$ were exclusively transformed to cyclopentanones 224 in 63 to $90 \%$ yield with dimethylformamide as the best suitable solvent (Scheme 65).

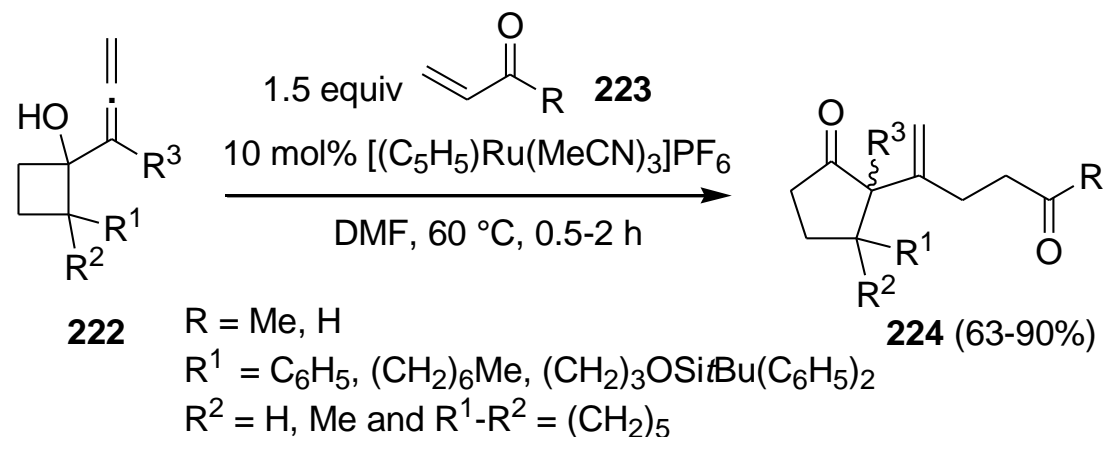

Scheme 65

It should be noted that a rhodium(I)-catalyzed rearrangement of allenylcyclobutanols has been reported by Cramer and co-workers as well. ${ }^{113}$ In contrast to ruthenium- and palladiumcatalyzed ring expansions of allenylcyclobutanols, the final products obtained were cyclohexenones instead of cyclopentanones.

Recently, a gold(I)-catalyzed intramolecular rearrangement of allenylcyclobutanols has been reported. ${ }^{114}$ Treatment of allenylcyclobutanols 225 with $5 \mathrm{~mol} \%$ of $\left(\mathrm{Ph}_{3} \mathrm{P}\right) \mathrm{AuCl}$ and $5 \mathrm{~mol} \%$ 
of AgOTf in dichloromethane at $40{ }^{\circ} \mathrm{C}$ furnished 1-vinyl-3-oxabicyclo[3.2.1] octan-8-ones 228 in $52-85 \%$ yield as single stereoisomers (Scheme 66). Coordination of the cationic gold(I)catalyst to the internal double bond of the allene moiety in $\mathbf{2 2 6}$ triggered a ring expansion through a Wagner-Meerwein shift, ${ }^{110}$ and produced vinyl gold intermediates 227. A subsequent protodemetalation liberated the catalyst and released the bridged compounds $\mathbf{2 2 8}$.<smiles>[R7]C([R7])=C1COC[C@H]2CC([R20])[C@H]12</smiles>

$$
\mathrm{R}^{1}=\mathrm{C}_{6} \mathrm{H}_{5}, 4-\mathrm{MeC}_{6} \mathrm{H}_{4}, 4-\mathrm{MeOC}_{6} \mathrm{H}_{4} \text {, }
$$$$
3,4,5-(\mathrm{MeO})_{3} \mathrm{C}_{6} \mathrm{H}_{2}, 3-\mathrm{BnOC}_{6} \mathrm{H}_{4}, \mathrm{C}_{7} \mathrm{H}_{15}
$$$$
\mathrm{R}^{2}=\mathrm{C}_{6} \mathrm{H}_{5}, 4-\mathrm{MeC}_{6} \mathrm{H}_{4}, 4-\mathrm{ClC}_{6} \mathrm{H}_{4} \text {, }
$$$$
4-\mathrm{FC}_{6} \mathrm{H}_{4}, 4-\mathrm{MeOC}_{6} \mathrm{H}_{4}
$$

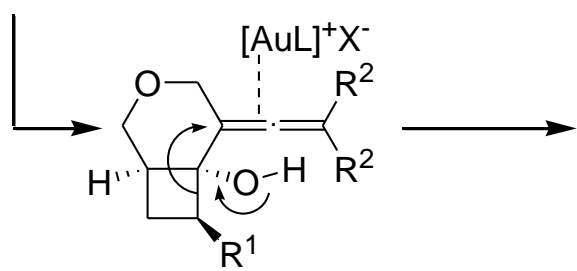

226

$$
\begin{gathered}
5 \mathrm{~mol} \%\left(\mathrm{Ph}_{3} \mathrm{P}\right) \mathrm{AuCl} \\
5 \mathrm{~mol} \% \mathrm{AgOTf}
\end{gathered}
$$

$$
228(52-85 \%)
$$

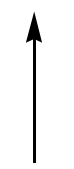

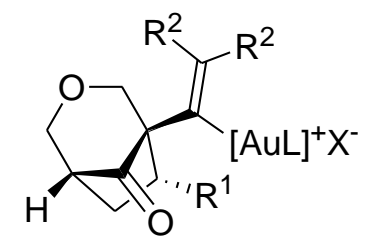

$227(52-85 \%)$

Scheme 66

\section{Ring expansion of cyclobutylmethylcarbenium ions through activation of an alkynyl substituent}

Metal-promoted ring expansion reactions of alkynylcyclobutanols comprise well investigated reactions triggered by release of the strain of the four-membered ring systems. ${ }^{115}$ Three different metals can be used for synthesis of the corresponding cyclopentanones by means of a semipinacol rearrangement, i.e. palladium, ruthenium or gold. 


\subsection{Palladium-promoted activation}

Propargylic compounds exhibit versatile reactivity in the presence of palladium complexes, affording a variety of applications in the field of palladium-catalysed reactions. ${ }^{116}$ This approach has been used for the conversion of alkynylcyclobutanols to the corresponding cyclopentanones. The key step in these reactions is the formation of a $\pi$ propargyl/allenylpalladium complex by facile elimination of a leaving group, which furthermore reacts with other compounds such as soft nucleophiles to lead to a variety of substituted products. ${ }^{117}$

A novel type of palladium-catalyzed cascade ring expansion reaction of 1-(3methoxycarbonyloxy-1-propynyl)cyclobutanols with phenols has been reported in that respect. ${ }^{118}$ This reaction generated a carbon-oxygen bond to afford cyclopentanones in a onepot process. When trans-cyclobutanols 229 were reacted with 1.2 equivalents of different substituted phenols, trans-cyclopentanones 231 were obtained in 80 to $98 \%$ yield (Scheme $67) .118 \mathrm{a}$

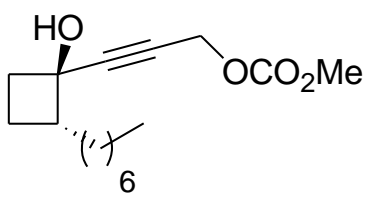

trans-229

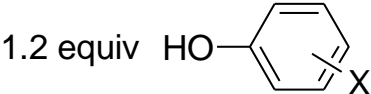

$\mathrm{X}=4$-OMe, 4-Me, 2-OMe

2,4,6-trimethyl

$5 \mathrm{~mol} \% \mathrm{Pd}_{2}(\mathrm{dba})_{3} \cdot \mathrm{CHCl}_{3}$ 20 mol\% dppe; 1,4-dioxane $80^{\circ} \mathrm{C}, 1-2 \mathrm{~h}$

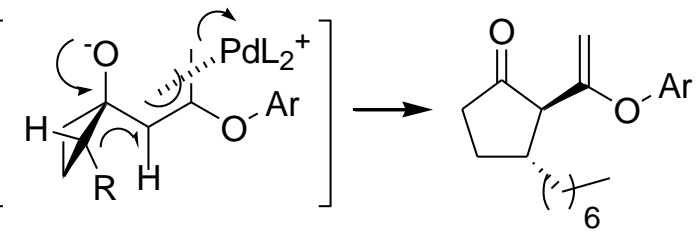

230

trans-231 (80-98\%)

Scheme 67 
In analogy with the rearrangement of trans-cyclobutanols 229, cis-2-(1aryloxyvinyl)cyclopentanones $\mathbf{2 3 1}$ were mainly obtained from the diastereomeric ciscyclobutanols 229 when subjected to the same reaction conditions (Scheme 68). ${ }^{118 a}$ However, these compounds $\mathbf{2 3 1}$ were very unstable due to steric interaction and easily isomerized to 1alkylidenecyclopentanones $\mathbf{2 3 3}$. This reaction generally proceeded in high yields (92-97\%), except in the case of 4-nitrophenol (70\% yield).

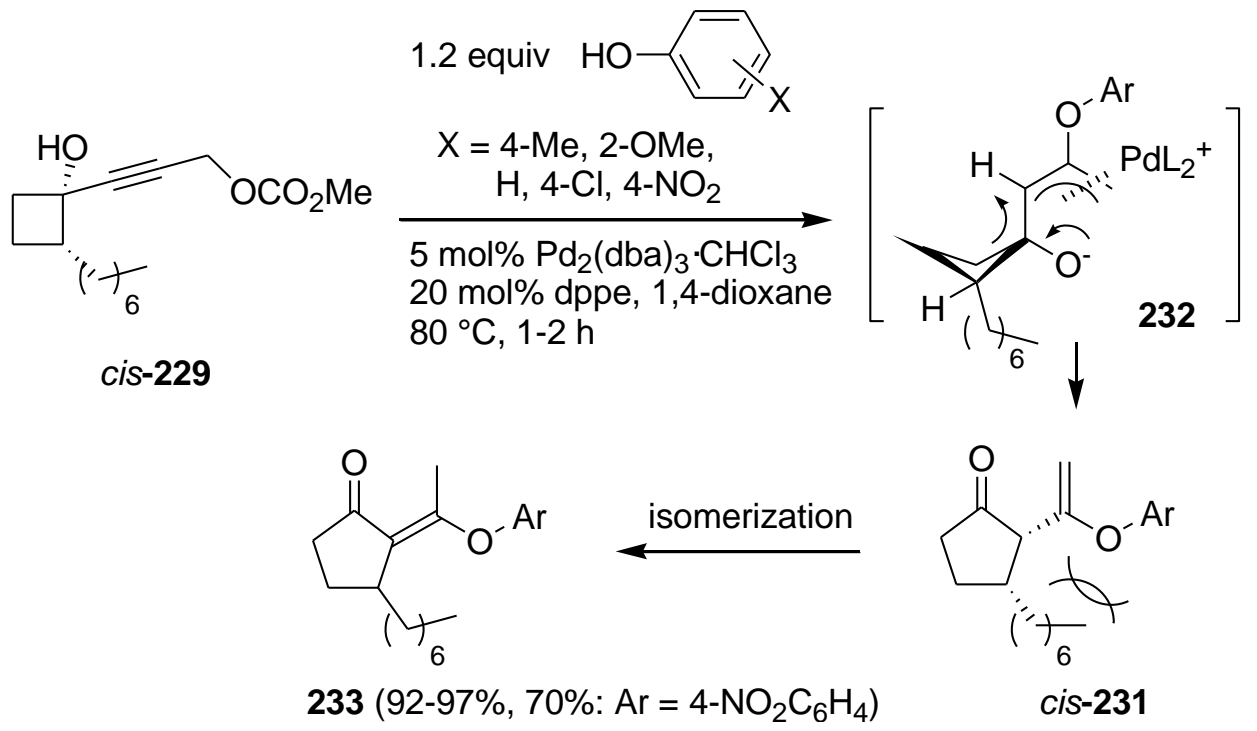

\section{Scheme 68}

Also other nucleophiles besides substituted phenols have been evaluated. ${ }^{118 c}$ For example, imides were found to be suitable reagents in the reaction with propargylic carbonates. When 1-(3-methoxycarbonyloxy-1-propynyl)cyclobutanol 234 was reacted with 1.2 equivalents of various imides in the presence of five mol\% of $\mathrm{Pd}_{2}(\mathrm{dba})_{3} \cdot \mathrm{CHCl}_{3}$ and $20 \mathrm{~mol} \%$ of dppe in dioxane at $100{ }^{\circ} \mathrm{C}$, the corresponding imidyl-substituted alkylidenecyclopentanones 235 were obtained in 34 to 53\% yield (Scheme 69). The imides used were succinimide, phthalimide and benzo[de]isoquinoline-1,3-dione. 


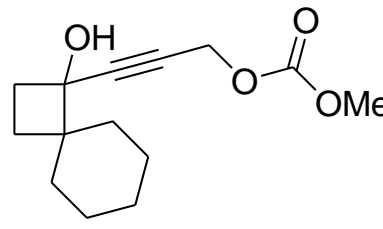

234
1.2 equiv $\mathrm{HN}(\mathrm{COR})_{2}$ $5 \mathrm{~mol} \% \mathrm{Pd}_{2}(\mathrm{dba})_{3} \cdot \mathrm{CHCl}_{3}$

20 mol\% dppe dioxane, $18-96 \mathrm{~h}, 100^{\circ} \mathrm{C}$

$235(34-53 \%)$

\section{Scheme 69}

2-Arylidene- and 2-alkenylidenecyclopentanones have been synthesized by a palladiummediated cross-coupling of aryl and vinyl halides to 1-(1-alkynyl)cyclobutanols, respectively. ${ }^{119}$ When 1-alkynylcyclobutanols 236 were treated with two equiv of an aryl or vinylic iodide, ten mol\% of $\mathrm{Pd}(\mathrm{OAc})_{2}, 20 \mathrm{~mol} \%$ of $\mathrm{PPh}_{3}$, two equiv of diisopropylethylamine and two equiv of $n \mathrm{Bu} 4 \mathrm{NCl}$ in $\mathrm{DMF}$ at $80{ }^{\circ} \mathrm{C}$, a variety of highly substituted 2alkylidenecyclopentanones 239, 240 and 241 were synthesized regio- and stereoselectively in moderate to good yields (35-74\%) (Scheme 70).

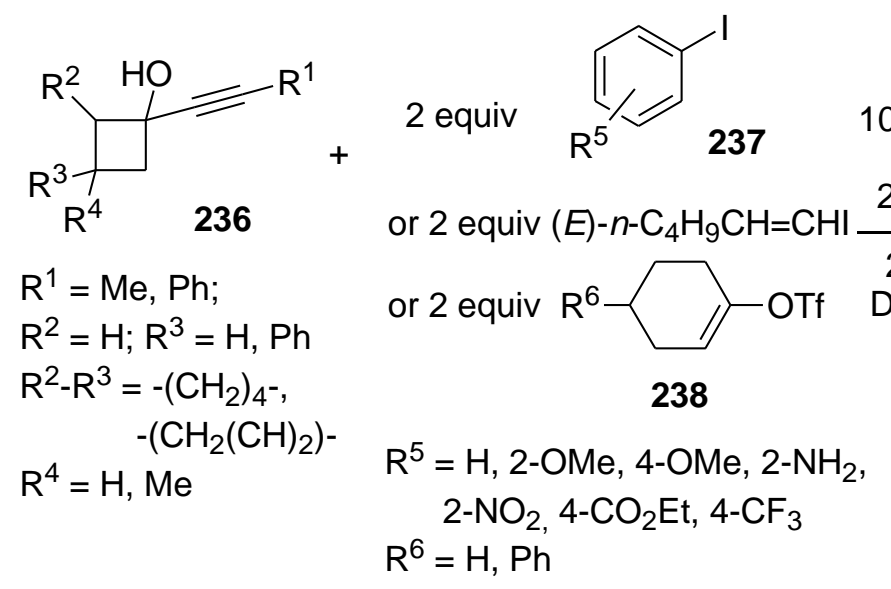<smiles>[R7]C(=C1C(=O)CC([R8])([R])C1[R7])c1ccc(P)cc1</smiles>

$239(52-74 \%)$<smiles>[Z16]C=CC([R7])=C1CCCC1=O</smiles>

$240(35-40 \%)$<smiles>[R7]C(C1=CCC([R6])CC1)=C1CCCC1=O</smiles>

$241(35 \% E$ and $35 \%$ Z)

Scheme 70 
In accordance with the cascade insertion-ring expansion reaction of allenylcyclobutanols with aryl iodides, ${ }^{107 a, b}$ a tandem addition-ring expansion reaction of 1-alkynyl cyclobutanols under hydroarylation conditions has been reported. ${ }^{120}$ Treatment of cyclobutanols 242 with two equiv of an aryl iodide 237, five mol\% of $\mathrm{Pd}(\mathrm{OAc})_{2}$, five mol\% of $\mathrm{PPh}_{3}$ and five equiv of triethylamine in acetonitrile for 24 hours at $80{ }^{\circ} \mathrm{C}$ afforded 2-arylidenecyclopentanones 243 in $30-75 \%$ yield (Scheme 71$).{ }^{120 b}$
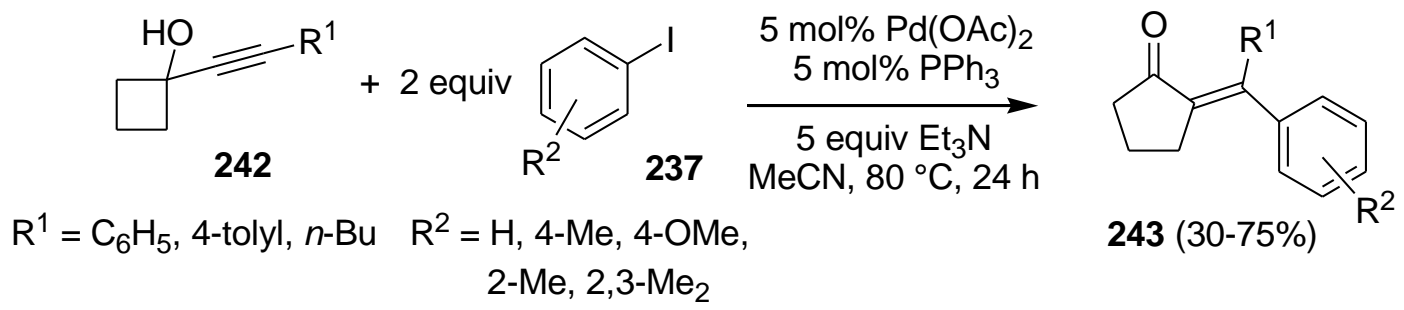

2-Me, 2,3-Me 2

Scheme 71

\subsection{Ruthenium-promoted activation}

The previously described ring rearrangements were triggered by palladium catalysts. On the other hand, a novel type of ring expansion reaction of alkynylcyclobutanols, triggered by a ruthenium catalyst, has been described by Ihara et al. ${ }^{121}$ This reaction involved a dimerization process to obtain unsaturated cyclopentanones 250. It was supposed that the key reaction intermediate was a ruthenacycle $\mathbf{2 4 6}$, which was formed by coordination of a ruthenium catalyst with two molecules of alkynylcyclobutanol 244. An equilibrium between complex 246 and zwitterionic intermediate 247 induced ring rearrangement, followed by ring opening of the ruthenacycle $\mathbf{2 4 8}$ to form an alkenyl ruthenium hydride 249. Finally, reductive elimination of ruthenium from complex $\mathbf{2 4 9}$ produced a ring expanded dimeric compound $\mathbf{2 5 0}$ together with regenerated ruthenium catalyst (Scheme 72). 


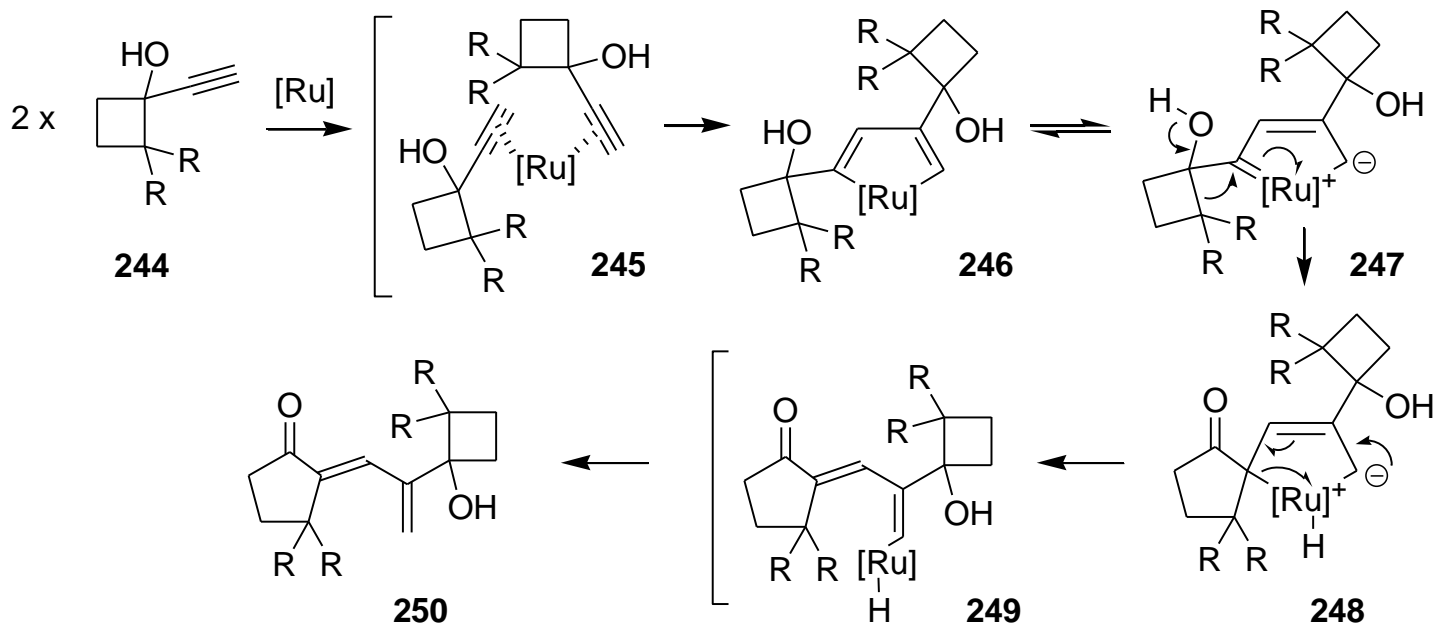

Scheme 72

As an example of this approach, alkynylcyclobutanol 251 was subjected to ten mol\% of $\mathrm{CpRu}(\mathrm{MeCN})_{3} \mathrm{PF}_{6}$ in $0.5 \mathrm{M}$ of $\mathrm{DMF}$ at $60{ }^{\circ} \mathrm{C}$ for one hour to obtain the ring expanded dimer 252 in 52\% yield (Scheme 73). The triethylsilylated (TES) product afforded the same dimeric compound 252 under similar reaction conditions but in lower yield (31\%), even after a reaction time of ten hours.

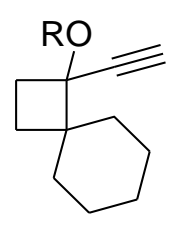

251

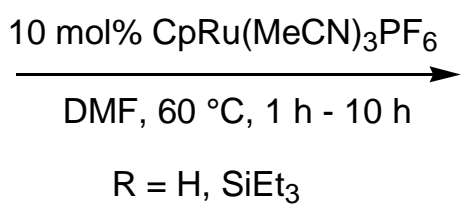

$\mathrm{R}=\mathrm{H}, \mathrm{SiEt}_{3}$

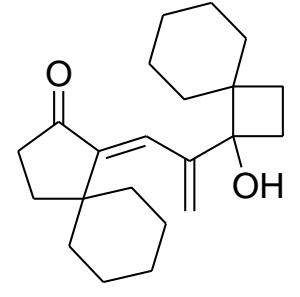

$252(31$ or $52 \%)$

\section{Scheme 73}

Additionally, a ruthenium-catalyzed cascade ring expansion reaction through 1,2rearrangement of 1-ethynylcyclobutanols followed by carbon-carbon bond formation with 3butene-2-one via a one-pot process has been developed to afford 2-alkylidenecyclopentanones 
in 45 to $71 \%$ total yield (Scheme 74$).{ }^{122}$ The stereoselective synthesis of the $Z$ - and $E$-isomers of the latter 2-alkylidene cyclopentanones $\mathbf{2 5 3}$ has been achieved using the appropriate ruthenium catalysts. When $\mathrm{CpRu}\left(\mathrm{PPh}_{3}\right)_{2} \mathrm{Cl}$ was used, the major isomer obtained was $(Z)-2-$ alkylidenecyclopentanone (Z)-253 in 33-43\% yield besides (E)-2-alkylidenecyclopentanone (E)-253 as the minor isomer in 9-26\% yield. On the other hand, when $\mathrm{CpRu}(\mathrm{MeCn})_{3} \mathrm{PF}_{6}$ was added to 1-ethynylcyclobutanols $\mathbf{2 4 4}$, the major isomer isolated was $(E)-\mathbf{2 5 3}$ in $33-54 \%$ yield and the minor isomer (Z)-253 in 3-23\% yield. Only the reaction with a cyclobutanol derivative possessing coordinative 2,2-bis(methoxymethyl) substituents gave (E)-2alkylidenecyclopentanone $(E)-\mathbf{2 5 3}$ as the major isomer for both above-mentioned ruthenium catalysts in 46 to $57 \%$ yield, next to 3-7\% yield for the (Z)-isomer of cyclopentanone 253.

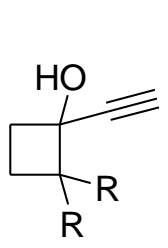

244<smiles>CC(=O)C=CC=[13O]</smiles>

a) $10 \mathrm{~mol} \% \mathrm{CpRu}\left(\mathrm{PPh}_{3}\right)_{2} \mathrm{Cl}$ or b) $\mathrm{CpRu}(\mathrm{MeCN})_{3} \mathrm{PF}_{6}$ $15 \mathrm{~mol}_{\%} \mathrm{CeCl}_{3}$ toluene, $80^{\circ} \mathrm{C}, 1-3 \mathrm{~h}$

$\mathrm{R}=\mathrm{CH}_{2} \mathrm{CH}\left(\mathrm{CH}_{3}\right)_{2}, \mathrm{CH}_{2} \mathrm{OMe}, \mathrm{H}$ $\mathrm{R}-\mathrm{R}=\left(\mathrm{CH}_{2}\right)_{5}$

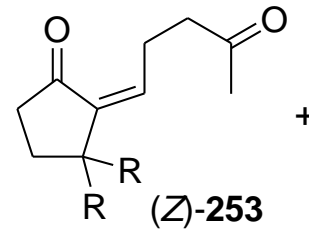

a) $(33-43 \%)$
b) $(3-23 \%)$
a-b) $(3-7 \%)$<smiles>[R]C1([R])CCC(=O)/C1=C/CCC(C)=O</smiles>

a) $(9-26 \%)$

b) $(33-54 \%)$ a-b) $(46-57 \%)$

Scheme 74

\subsection{Gold-promoted activation}

Cationic gold(I) complexes are capable of catalyzing ring expansion reactions by promoting migration of nucleophilic $\sigma$-bonds to alkynes. ${ }^{123} 1$-Alkynylcyclobutanols 254 were found to be viable substrates for gold(I)-catalyzed ring rearrangements to synthesize $\alpha$ - 
alkylidenecyclopentanones 256, in which coordination of a cationic gold(I) catalyst to the alkyne moiety (intermediate 255) induced a 1,2-alkyl shift (Scheme 75).

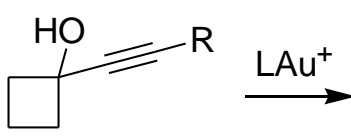

254

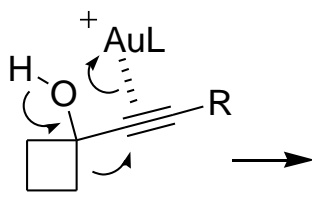

255

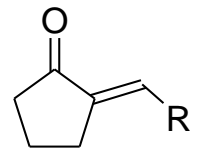

256

Scheme 75

In a first example, alkynylcyclobutanols 257 were subjected to one or two mol\% of a (4trifluoromethylphenyl)phosphine gold(I) catalyst and $\mathrm{AgSbF}_{6}$ in dichloromethane for 10 to 24 hours at room temperature. The subsequent rearrangement afforded $\alpha$ methylidenecyclopentanones 258 in 66 to $82 \%$ yield (Scheme 76) with selective migration of the more substituted carbon atom of the cyclobutanol system.

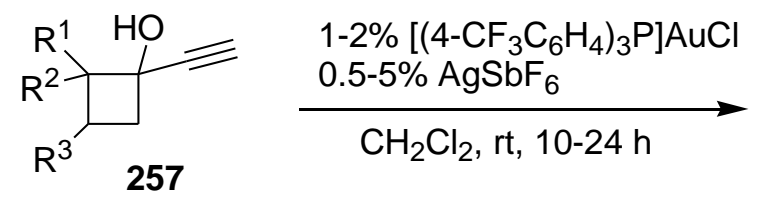

$\mathrm{R}^{1}=\mathrm{CH}_{2} \mathrm{tBu} ; \mathrm{R}^{2}=\mathrm{H} ; \mathrm{R}^{3}=\mathrm{H}$

$R^{1}-R^{2}=\left(\mathrm{CH}_{2}\right)_{6},\left(\left(\mathrm{CH}_{2}\right)_{2} \mathrm{CMe}_{2}\left(\mathrm{CH}_{2}\right)_{2}\right) ; \mathrm{R}^{3}=\mathrm{H}$

$\mathrm{R}^{1}=\mathrm{H} ; \mathrm{R}^{2}-\mathrm{R}^{3}=\left(\mathrm{CH}_{2}\right)_{4}$

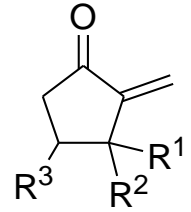

$258(66-82 \%)$

Scheme 76

In a second approach, treatment of the acetate derivative of 1-(3hydroxypropynyl)cycloalkanol $259(\mathrm{R}=\mathrm{Ac})$ with one mol\% of $\mathrm{Au}\left(\mathrm{PPh}_{3}\right) \mathrm{OTf}$ pre-catalyst in dichloromethane at room temperature for one hour furnished cyclopentanone $\mathbf{2 6 0}$ in an excellent yield of $96 \%$ (Scheme 77). ${ }^{124}$ This direct ring expansion occurred without $[3,3]-$ 
rearrangement. Changing the protecting group from acetate to $t$-butyloxycarbonyl (Boc), benzoyl (Bz) or pivaloyl (Piv), however, led to faster [3,3]-rearrangement and completely diverted the reaction into rearrangement followed by cycloisomerization, giving spirofurans $\mathbf{2 6 2}$ in $60-68 \%$ yield through an allenyl intermediate $\mathbf{2 6 1}$ without isolation of cyclopentanones.

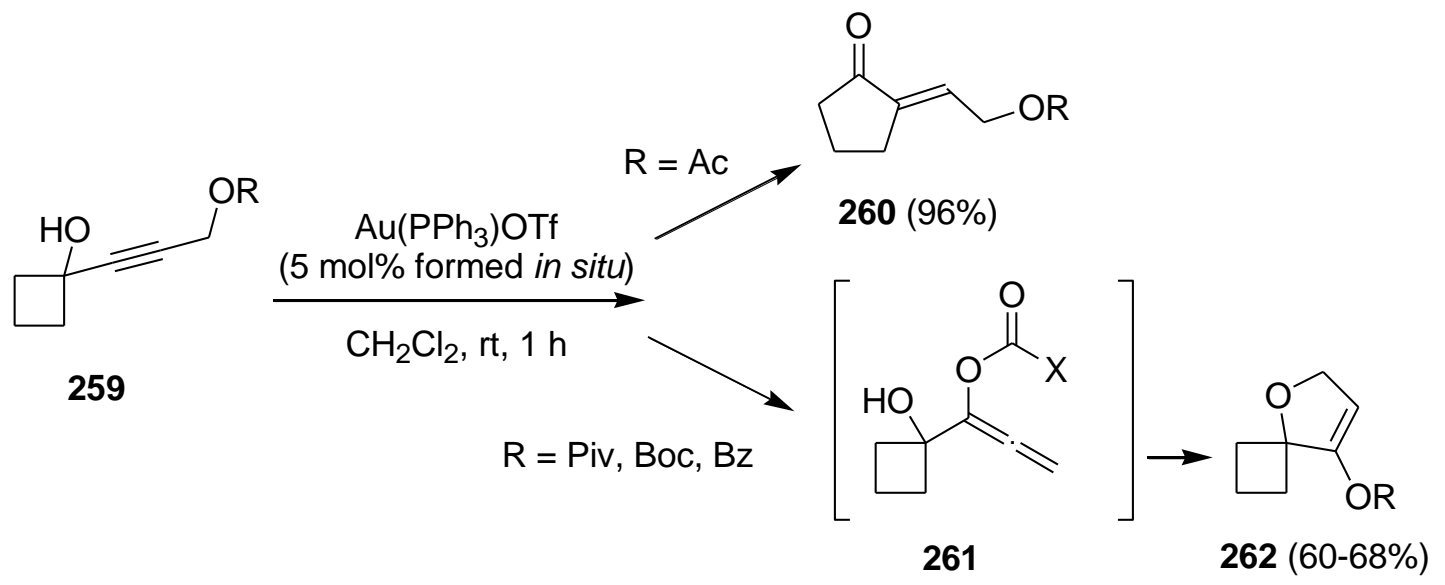

Scheme 77

\section{Ring expansion of cyclobutylmethylcarbenium ions through activation of a carbonyl group}

Another method by which a carbenium ion can be generated comprises protonation or activation by means of a Lewis acid of a carbonyl compound 263 (Scheme 78). The oxygenstabilized cyclobutylmethylcarbenium ions $\mathbf{2 6 5}$, thus formed, subsequently rearrange to give cyclopentylcarbenium ions 266. Several examples, based on this principle, will be discussed in the following paragraphs using a broad scale of acids or Lewis acids, such as $p$ toluenesulfonic acid, hydrogen chloride, aluminium(III) chloride or bromide, silica, camphor 
sulfonic acid, and several others. Also two special cases are described, i. e. a $\mathrm{Co}_{2}(\mathrm{CO})_{8}$ catalyzed ring expansion and activation of a conjugated carbonyl system.<smiles>[R]C(=O)C1CCC1</smiles>

263

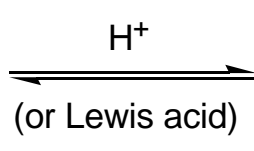

(or Lewis acid)<smiles>[R]C(=O)C1CCC1</smiles>

264

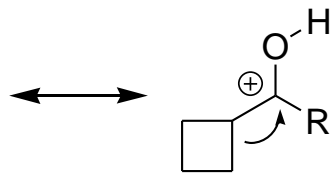

265

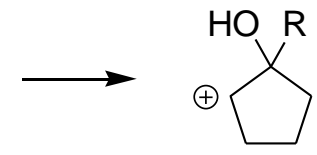

266

Scheme 78

\subsection{Direct activation}

Propellanes containing one cyclobutane ring, i. e. [m.n.2]propellanes (m,n > 2), have been studied in terms of their reactivity toward acid treatment to give ring rearranged products. ${ }^{125}$ An example of this pathway comprised the synthesis of 3,4-dimethyltricyclo[3.3.3.0]undecan2-one 271. A mixture of trans-isomers $\mathbf{2 6 8}$, originating from cycloaddition of 2-butene across bicyclic enone 269, when treated with 0.4 equiv of $p$-toluenesulfonic acid in benzene at reflux for eight hours, underwent two Wagner-Meerwein shifts to yield tricyclo[3.3.3.0]undecane-2one 271 in $82 \%$ overall yield from enone 267 via carbenium intermediate 269 and 270 (Scheme 79). ${ }^{125 \mathrm{~d}}$ Only trans-isomer 271 was isolated after rearrangement, and the transrelationship was ascertained by recovering trans-271 unchanged after treatment with $\mathrm{NaOMe}$ in $\mathrm{MeOH}$ at reflux. Under the same ring expansion conditions, the synthesis of tricyclo[4.3.3.0]dodecane-7-one from bicyclo[4.4.0]dec-1-en-2-one and ethylene has been reported in $95 \%$ yield as well as another propellane-like skeleton. ${ }^{125 \mathrm{~d}}$ In general, the acidcatalyzed rearrangement of cyclobutyl ketones involved in polycyclic ring systems such as [m.n.2]propellanes is known as the Cargill reaction ${ }^{125 e}$ and has been used in the synthesis of natural products ${ }^{2 \mathrm{~g}}$ and several other compounds. ${ }^{126}$ 


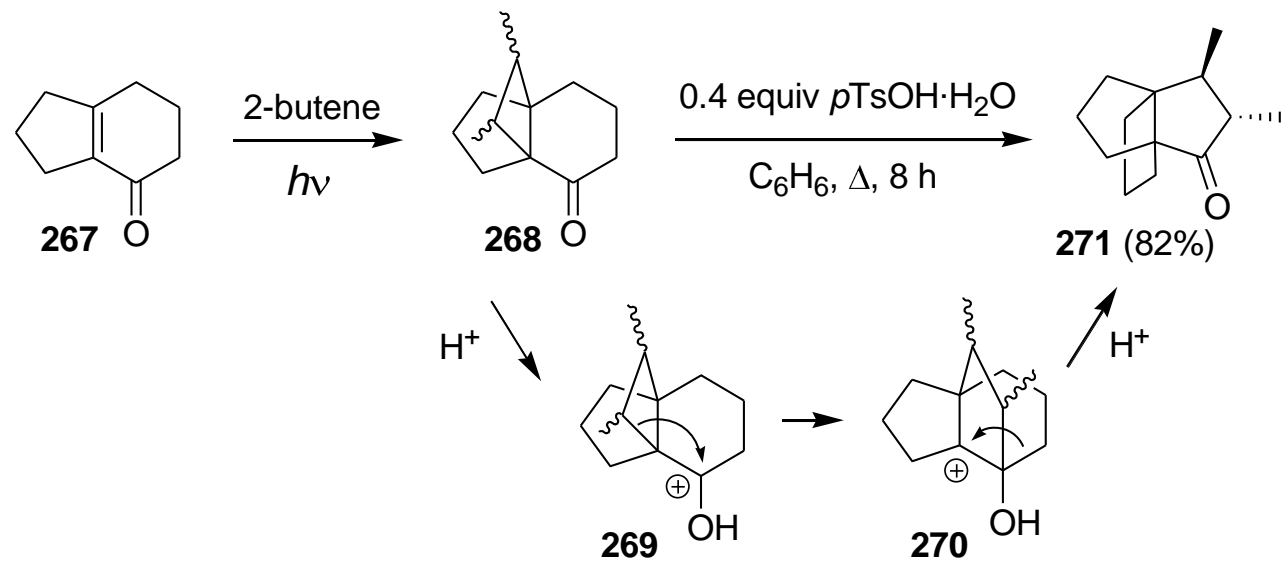

Scheme 79

In a short synthesis of (+)-isophyllocladenone $\mathbf{2 7 5}$, the five-membered ring was obtained via ring rearrangement of an $\alpha$-methylidenecyclobutane ring. ${ }^{127}$ To this end, compound 272 rearranged to (+)-isophyllocladenone $\mathbf{2 7 5}$ in $50 \%$ yield when treated with a large amount of $p$ toluenesulfonic acid (1:1 by weight) in benzene at reflux temperature for three hours through skeletal reorganization via intermediates 273 and 274 (Scheme 80).

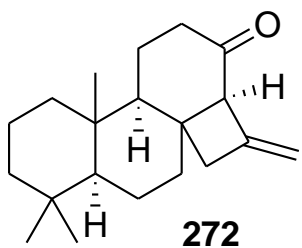

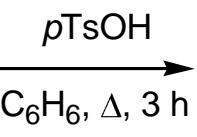<smiles>C=C1CC23CCC4C(C)(C)CCCC4(C)C2CCC(O)C1C3</smiles>

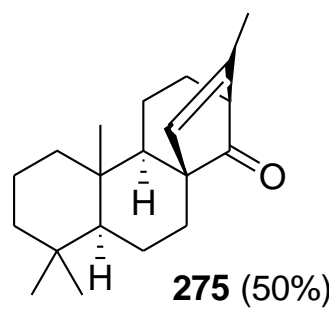

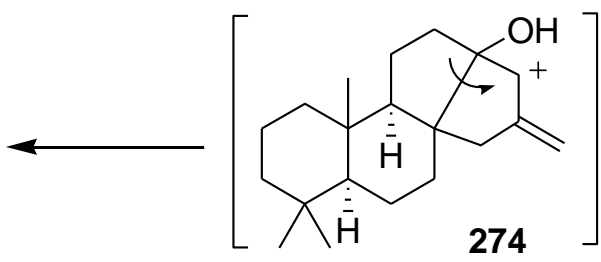

Scheme 80 
In studies on the preparation of sesquiterpenes, a synthesis of tricyclic compound 277 has been reported by reaction of tricyclic ketone 276 with 2.5 equiv of $p$-toluenesulfonic acid in benzene at reflux for five days to afford the corresponding ring expanded ketone 277 in quantitative yield (Scheme 81). ${ }^{128}$

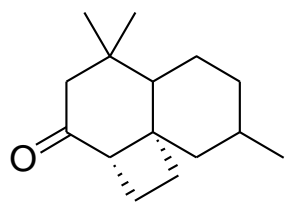

276

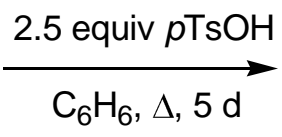

$\mathrm{C}_{6} \mathrm{H}_{6}, \Delta, 5 \mathrm{~d}$

Scheme 81

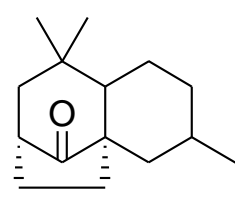

$277(100 \%)$

As an alternative racemic route to the tricyclic sesquiterpene isocomene 36, Pirrung reported a synthesis via a cyclobutyl carbinyl ketone rearrangement. ${ }^{42 b}$ The first synthesis by Pirrung was already described in this review in section $2.1 .2 .^{42}$ Using the Cargill rearrangement, ${ }^{125 b}$ 278 was treated with 1.2 equiv of $p \mathrm{TsOH}$ in benzene under reflux to provide $\mathbf{2 7 9}$ and $\mathbf{2 8 0}$ in 75 and $15 \%$ yield, respectively, after column chromatography (Scheme 82). However, the more obvious precursor to isocomene $\mathbf{3 6}$ was the minor product. Yet, using the conversions of [3.3.0]- and [3.2.1]bicyclooctane carbenium ions $\mathbf{2 8 3}$ and $\mathbf{2 8 5}$ in the Cargill reaction (Scheme 83), compound 279 was treated with an excess of MeLi in tetrahydrofuran at reflux to give a mixture of tertiary alcohols in quantitative yield. Upon treatment with formic acid at room temperature, the crude mixture of alcohols was transformed into isocomene $\mathbf{3 6}$ in $70 \%$ yield (Scheme 82). 


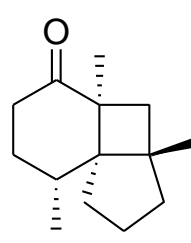

278
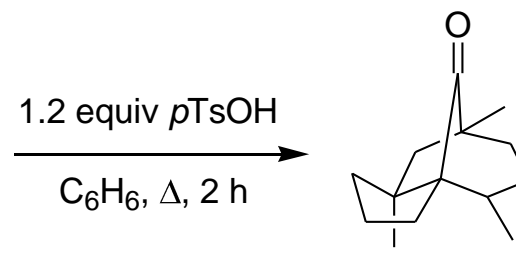

$279(75 \%)$

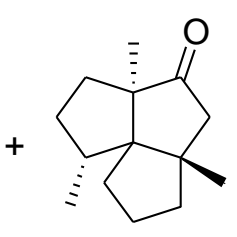

$280(15 \%)$

1) excess MeLi, THF, $\Delta$

2) $\mathrm{HCOOH}, \mathrm{rt}$

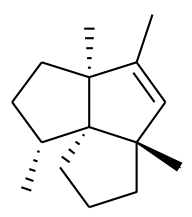

36 (70\%)

\section{Scheme 82}

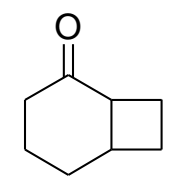

281

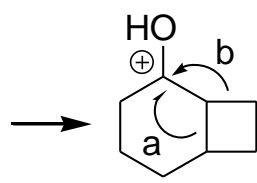

282

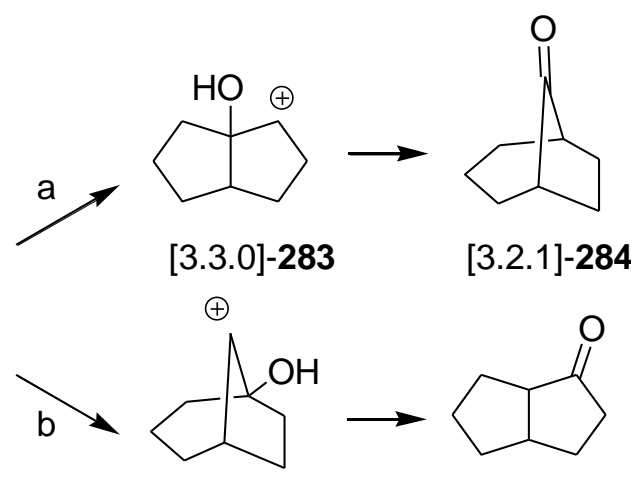

[3.2.1]-285
[3.3.0]-286

Scheme 83

When 1-alkanoyl-1-(p-tolylsulfanyl)cyclobutanes 287 were treated with one or two equiv of aluminium(III) chloride in toluene, hexane or chlorobenzene at room temperature, 2-alkyl-2( $p$-tolylsulfanyl)cyclopentanones 288 were obtained in 55-90\% yield (Scheme 84). ${ }^{129}$ Other Lewis acids such as aluminium(III) bromide and iron(III) chloride were also effective for this reaction. Boron(III) fluoride etherate and protonic acids (sulfuric acid and perchloric acid) did not catalyse the rearrangement. The mechanism involved coordination of $\mathrm{AlCl}_{3}$ to the carbonyl oxygen, followed by ring expansion to form a sulfur-stabilized carbenium ion, and migration of the alkyl group to the carbenium ion centre with concomitant regeneration of the 
carbonyl function to afford the corresponding cyclopentanones. This reaction was applied to the synthesis of 2-[4-(3-hydroxypropyl)phenyl]-2-cyclopentenone $\mathbf{2 8 9}$ in $84 \%$ yield from $\mathbf{2 8 7}$, which is of interest since the corresponding carboxylic ester was proposed as a key intermediate for the synthesis of 4,5,6,7-tetra-nor-3-8-inter-p-phenylene-11deoxyprostaglandin, a new prostaglandin analogue. ${ }^{129,130}$<smiles>[R]C(=O)C1([R5])CC([R])C1[R]</smiles>

287

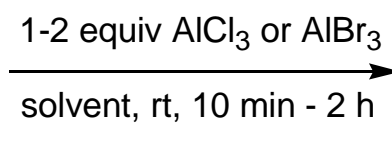

$\mathrm{R}=\mathrm{Tol}, \mathrm{Me} ; \mathrm{R}^{1}=\mathrm{H}, \mathrm{Me}$

$\mathrm{R}^{2}=\mathrm{H}, \mathrm{PhCH}_{2} ; \mathrm{R}^{3}=\mathrm{H}, \mathrm{Me}, \mathrm{Et}, n \mathrm{Bu}, 4-\left(\left(\mathrm{CH}_{2}\right)_{3} \mathrm{OH}\right) \mathrm{C}_{6} \mathrm{H}_{4}$ solvent $=$ toluene, hexane, chlorobenzene<smiles>[R7]C1CC([R5])(S)C(=O)C1[R]C(C)C</smiles>

$288(55-90 \%)$
289 (84\% overall)

$$
\mathrm{R}=\mathrm{Tol} ; \mathrm{R}^{1}=\mathrm{H} ; \mathrm{R}^{2}=\mathrm{H} \text {; }
$$

$\mathrm{R}^{3}=4-\left(\left(\mathrm{CH}_{2}\right)_{3} \mathrm{OH}\right) \mathrm{C}_{6} \mathrm{H}_{4}$

\section{Scheme 84}

In a curious example, slow addition of a slight excess of trichloroacetyl chloride in anhydrous ether to a slurry of activated zinc in an ether solution of bullvalene $\mathbf{2 9 0}$ at room temperature for 12 hours afforded $\alpha, \alpha$-dichlorocyclopentanone 293 in $81 \%$ yield (Scheme 85 ). ${ }^{131}$ The proposed mechanism involved initial formation of an equilibrium mixture of 1,2-cycloadducts 291 and 292 (shown by detailed NMR analysis) via [2+2]-cycloaddition of the olefin with dichloroketene. However, these cycloadducts undergo Lewis acid-catalyzed ring opening and subsequent cyclization with skeletal rearrangement to form the 1,6-adduct 293.

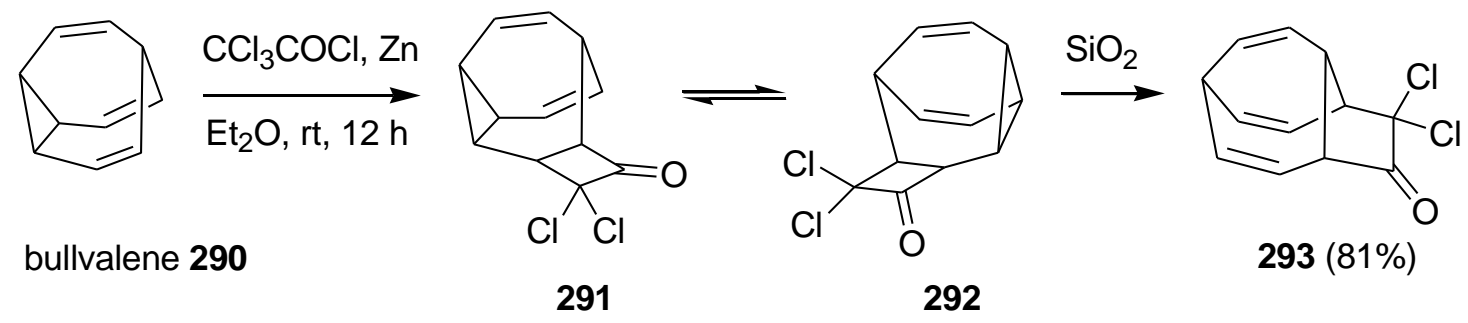

Scheme 85 
The acid-catalyzed rearrangement of [4.3.2]propellanones 294 to tricyclo[4.3.2.0 $0^{1,5}$ undecanols 295 has been reported as a one-step construction of the carbocyclic skeleton of terrecyclic acid A 296, descarboxyquadrone 297 and quadrone 298 (Scheme 86). ${ }^{132}$ These compounds have been shown to display significant biological activities involving antitumor properties. When tricyclic ketone 294 was treated with conc. $\mathrm{HCl}$ in diethyl ether at reflux temperature for 36 hours, diol 295 was isolated in $72 \%$ yield (for $\mathrm{R}^{1}=$ OAc, $\left.\mathrm{R}^{2}=\mathrm{OH}\right)$ or, because of instability $\left(\mathrm{R}^{1}, \mathrm{R}^{2}=\mathrm{H}\right)$, directly converted into the next product of the reaction sequence.

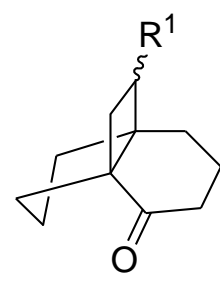

294

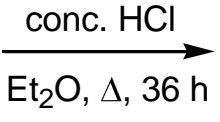

$\mathrm{R}^{1}=\mathrm{OAc}, \mathrm{H}$ $\mathrm{R}^{2}=\mathrm{OH}, \mathrm{H}$

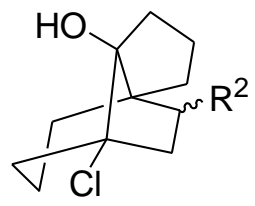

$295(72 \%)$ $\left(\mathrm{R}^{1}=\mathrm{OAc}, \mathrm{R}^{2}=\mathrm{OH}\right)$

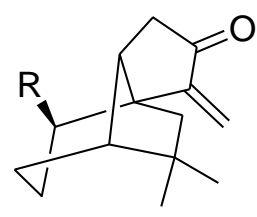

$\mathrm{R}=\mathrm{CO}_{2} \mathrm{H}$ : terrecyclic acid $\mathrm{A} 296$ $\mathrm{R}=\mathrm{H}$ : descarboxyquadrone 297

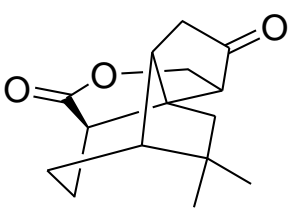

quadrone 298

\section{Scheme 86}

In a short synthesis toward hirsutene 32, the rearrangement of tricyclo[5.4.0.0 $\left.0^{2,6}\right]$ undecane8,11-dione 299 represents the key step for the synthesis of the carbocyclic skeleton. ${ }^{133}$ When 299 was treated with 2.3 equiv of iodotrimethylsilane in dichloromethane for three hours at room temperature, tricyclo[6.3.0.0 $\left.0^{2,6}\right]$ undec-2-ene-3-one $\mathbf{3 0 0}$ was isolated in $95 \%$ yield through rearrangement and a final dehydration step (Scheme 87). ${ }^{133 \mathrm{~b}}$ 
<smiles>CC1(C)CC2C(C1)[C@@H]1C(=O)CCC(=O)C21</smiles>

299

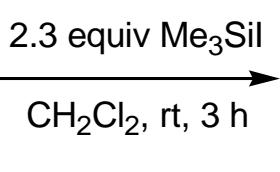<smiles>CC1(C)CC2CC3=C(C(=O)CC3)C2C1</smiles>

$300(95 \%)$

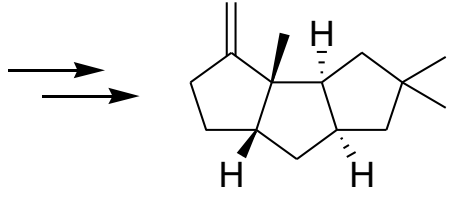

hirsutene 32

Scheme 87

When dispiroketones 301, 302 and $\mathbf{3 0 3}$ were treated with equimolar amounts of a 0.56 molar solution of anhydrous $p$-toluenesulfonic acid in benzene for 14 hours at $20{ }^{\circ} \mathrm{C}$, quantitative conversion into the bicyclic enone $\mathbf{3 0 7}$ was observed. The same conversion was complete within ten minutes at $70{ }^{\circ} \mathrm{C}$, but after 14 hours at $70{ }^{\circ} \mathrm{C}$ the propellanone 310 was formed instead in a quantitative yield (Scheme 88). ${ }^{134}$ These rearrangements proceeded via intermediate $\beta$-hydroxy carbenium ions. These ketones $\mathbf{3 0 1}, \mathbf{3 0 2}$ and $\mathbf{3 0 3}$ were well suited for rearrangement because of the defined dihedral angle relationships favoring stereospecific rearrangements and the possibility of reactions through energetically favorable tertiary carbenium ions as depicted in Scheme $88,{ }^{135}$ besides the pronounced relief of strain associated with $\mathrm{C}_{4}-\mathrm{C}_{5}$ ring enlargements. 


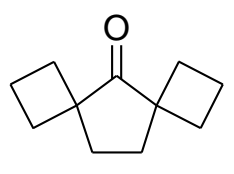

301

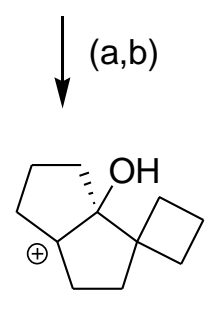

304

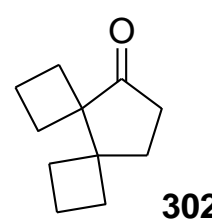

$(a, b)$

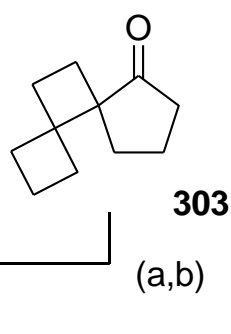

303

$(a, b)$ (a) 1 equiv $0.56 \mathrm{M} \mathrm{pTsOH}$ $\mathrm{C}_{6} \mathrm{H}_{6}, 14 \mathrm{~h}, 20^{\circ} \mathrm{C}$

(b) 1 equiv $0.56 \mathrm{M} \mathrm{pTsOH}$ $\mathrm{C}_{6} \mathrm{H}_{6}, 14 \mathrm{~h}, 70^{\circ} \mathrm{C}$

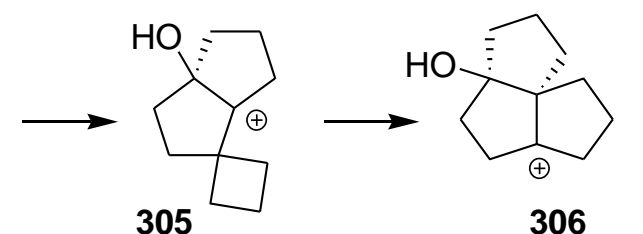

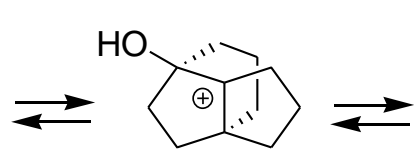

$\mathrm{HO}$<smiles>CC1CCC23C=CC=CC12C3</smiles>

308<smiles>O=C1CCC23C=CC=CC12CCC3</smiles>

$310(100 \%)(b)$

Scheme 88

According to the previous result, reaction of a tetraspiroketone 311 with equimolar amounts of anhydrous p-toluenesulfonic acid in benzene would lead to bispropellanone $\mathbf{3 1 2}$. However, the bridged pentacyclic ketone 315 was isolated instead in 100\% yield (Scheme 89). ${ }^{134 \mathrm{c}}$ The observed reactivity was explained considering the carbenium ion intermediates 313 and 314 en route to ketone $\mathbf{3 1 5}$.

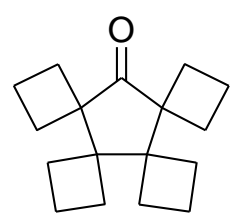

311

1 equiv $0.25 \mathrm{M}$ pTsOH

$\checkmark \mathrm{C}_{6} \mathrm{H}_{6}, 30 \mathrm{~min}, 80^{\circ} \mathrm{C}$

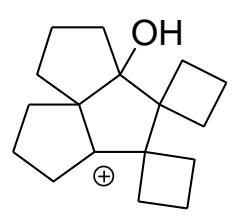

313

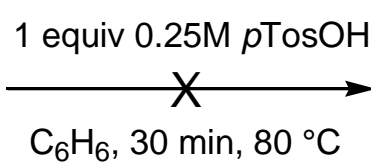

$\mathrm{C}_{6} \mathrm{H}_{6}, 30 \mathrm{~min}, 80^{\circ} \mathrm{C}$

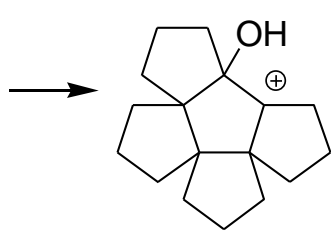

314<smiles></smiles>

312

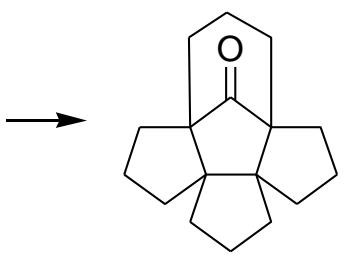

315 (100\%)

Scheme 89 
In a formal reductive ring enlargement, cyclobutanecarboxylic acid $\mathbf{3 1 6}$ has been described to be converted to cyclopentane $\mathbf{3 1 7}$ in $96 \%$ yield through a primary carbenium ion utilizing a mixture of two equiv of sodium borohydride and 12 equiv of triflic acid in diethyl ether (Scheme 90). ${ }^{136}$ In the original paper, the authors mainly focused on adamantine derivatives.

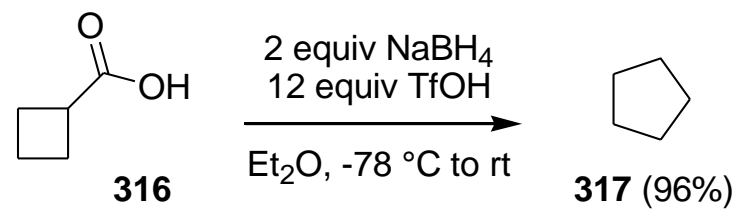

\section{Scheme 90}

Within the study of marine sesquiterpenes, a new pathway (path b) for the rearrangement of $\left(1 S^{*}, 4 S^{*}, 8 R^{*}\right)$-tricyclo[6.3.0.0 $\left.0^{1,4}\right]$ undecan-5-one $\mathbf{3 1 8}$ has been reported under the action of a Lewis acid to give angularly fused triquinane $\mathbf{3 2 5}$ with high selectivity, which is entirely different from the Cargill pathway (path a) (Scheme 91). ${ }^{137}$ Coordination of the carbonyl group to the Lewis acid generated intermediate 322, followed by cleavage of the central cyclobutane bond to yield homoallylcarbinylcarbenium ion 323. A 1,2-hydride shift afforded the carbenium ion 324, which collapsed to give the desired product $\mathbf{3 2 5}$. 


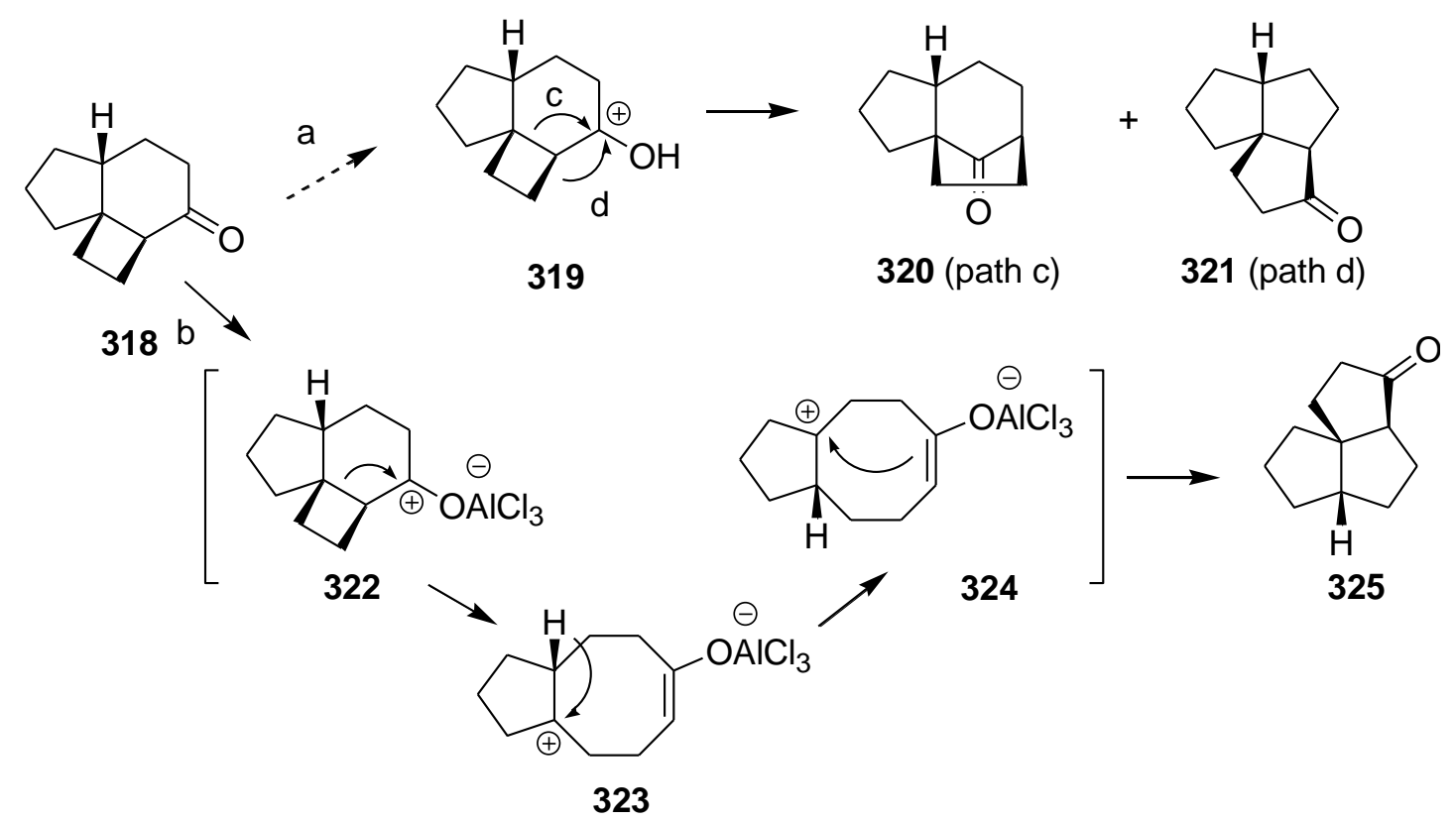

Scheme 91

The utility of this approach was further demonstrated by the total syntheses of ( \pm )-3oxosilphinene 326, ( \pm )-silphiperfol-6-ene 327 and ( \pm )-5-oxosilphiperfol-6-ene 328 (Scheme 92). ${ }^{137}$ The rearrangement of substrates 318 proceeded smoothly using aluminium(III) chloride in dichloromethane at room temperature for 30 minutes to obtain the angular ketones 325 in 55-93\% yield, which could be converted into the desired products.

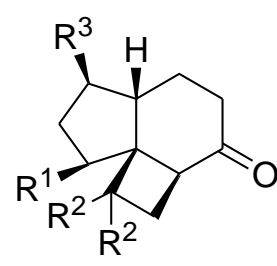

318

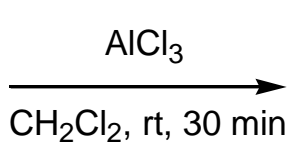

$\mathrm{R}^{1}=\mathrm{H}, \mathrm{Me}$

$\mathrm{R}^{2}=\mathrm{H}, \mathrm{Me}$

$\mathrm{R}^{3}=\mathrm{H}, \mathrm{Me}$

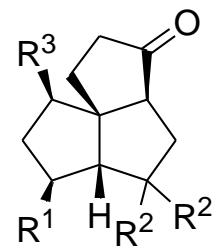

$325(55-93 \%)$

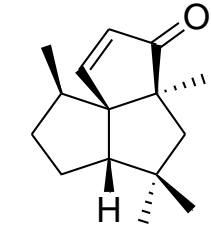

3-oxosilphinene 326

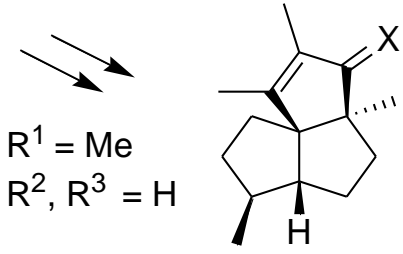

$\mathrm{X}=\mathrm{H}_{2}$ : silphiperfol-6-ene 327

$X=O$ : 5-oxosilphiperfol-6-ene 328

Scheme 92 
The reactivity of 1-alkanoylcyclobutanes toward ring enlargement can be further enhanced by the introduction of an electron-donating hydroxy group at the 1-position. Exposure of the relatively stable 1-(1-oxo-2-propenyl)cyclobutanol 329 (obtained via treatment of 3ethoxycyclobutanone with 1-lithio-1-methoxyallene followed by acid hydrolysis) to the usual aqueous acid conditions (i. e. treatment with trifluoroacetic acid in a $\mathrm{THF} / \mathrm{H}_{2} \mathrm{O}(1: 1)$ solvent mixture) did not rapidly induce ring expansion. However, exposure to $\mathrm{SiO}_{2}$ provided the ring expanded cyclopentanone product 330 as one diastereomer. ${ }^{104 a}$ Treatment of the same cyclobutanol 329 with $\mathrm{ZnBr}_{2}$ in dichloromethane for two hours at room temperature, followed by ten hours under reflux led to cyclopentenone $\mathbf{3 3 1}$ in $45 \%$ yield, presumably via cyclopentanone 330 (Scheme 93).

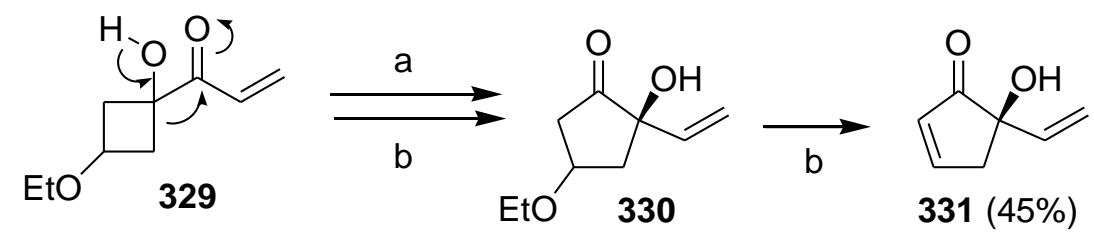

a) $\mathrm{SiO}_{2}$ chromatography

b) 1.9 equiv $\mathrm{ZnBr}_{2}, \mathrm{CH}_{2} \mathrm{Cl}_{2}$, (rt, $\left.2 \mathrm{~h}\right)+(\Delta, 10 \mathrm{~h})$

\section{Scheme 93}

In analogy, the cyclobutyl system $\mathbf{3 3 2}$ rearranged completely to $\alpha$-hydroxycyclopentanone 333 on silica gel chromatography using diethyl ether/hexane (1:5) in 95\% yield (path A, Scheme 94). ${ }^{138 a}$ Furthermore, a nickel-catalyzed enantioselective $\alpha$-ketol rearrangement of 1benzoylcyclobutanol 332 was initiated with two mol\% of $\mathrm{NiCl}_{2}$ and four mol\% of 2,6bis[(4S)-isopropyl-2-oxazolin-2-yl]pyridine $\left(\mathrm{NiCl}_{2} /\right.$ pybox $)$ in methanol for four hours at 25 ${ }^{\circ} \mathrm{C}$, to afford (-)-2-hydroxy-2-phenylcyclopentanone 333 in quantitative yield and in 34\% 
enantiomeric excess without knowing the exact absolute configuration (path B, Scheme $94) .{ }^{138 b}$

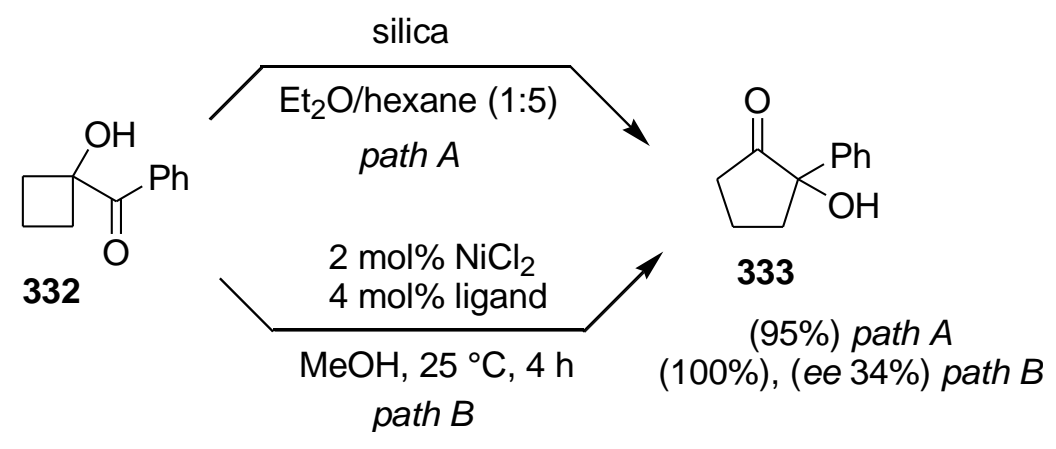

Scheme 94

Ring enlargement of cyclohexene-annelated acylcyclobutanes upon treatment with an appropriate Lewis acid has been reported to afford hydrindanone derivatives. ${ }^{139}$ Ring enlargement of 1-acylbicyclo[4.2.0]oct-3-enes $\mathbf{3 3 4}$ could afford two isomeric ketones $\mathbf{3 3 7}$ and 339 depending on the direction of migration (pathways a and b) (Scheme 95). The formation of $\mathbf{3 3 9}$, however, was unfavorable due to the lower stability of intermediate $\mathbf{3 3 8}$ as compared to carbenium ion 336. The overlap of the $p$-orbital of the carbonyl group and the breaking $\sigma$ orbital of the cyclobutane ring must be maintained during the ring expansion of cyclobutane 334 to carbenium ion intermediate 336. As a result, the acetyl group and the C-6 hydrogen or alkyl group $\left(\mathrm{R}^{2}\right)$ lay in the same plane in the transition state so that the ring enlargement proceeded through conformer 335a or 335b. Since the alkyl group migrated at the same face of the molecule, the main cis-isomer was produced via 335a and hence the steric repulsion between $\mathrm{R}^{2}$ and the carbonyl oxygen, coordinated to the Lewis acid, was larger than the repulsion between the $\mathrm{R}^{2}$ - and $\mathrm{R}^{1}$-group. 


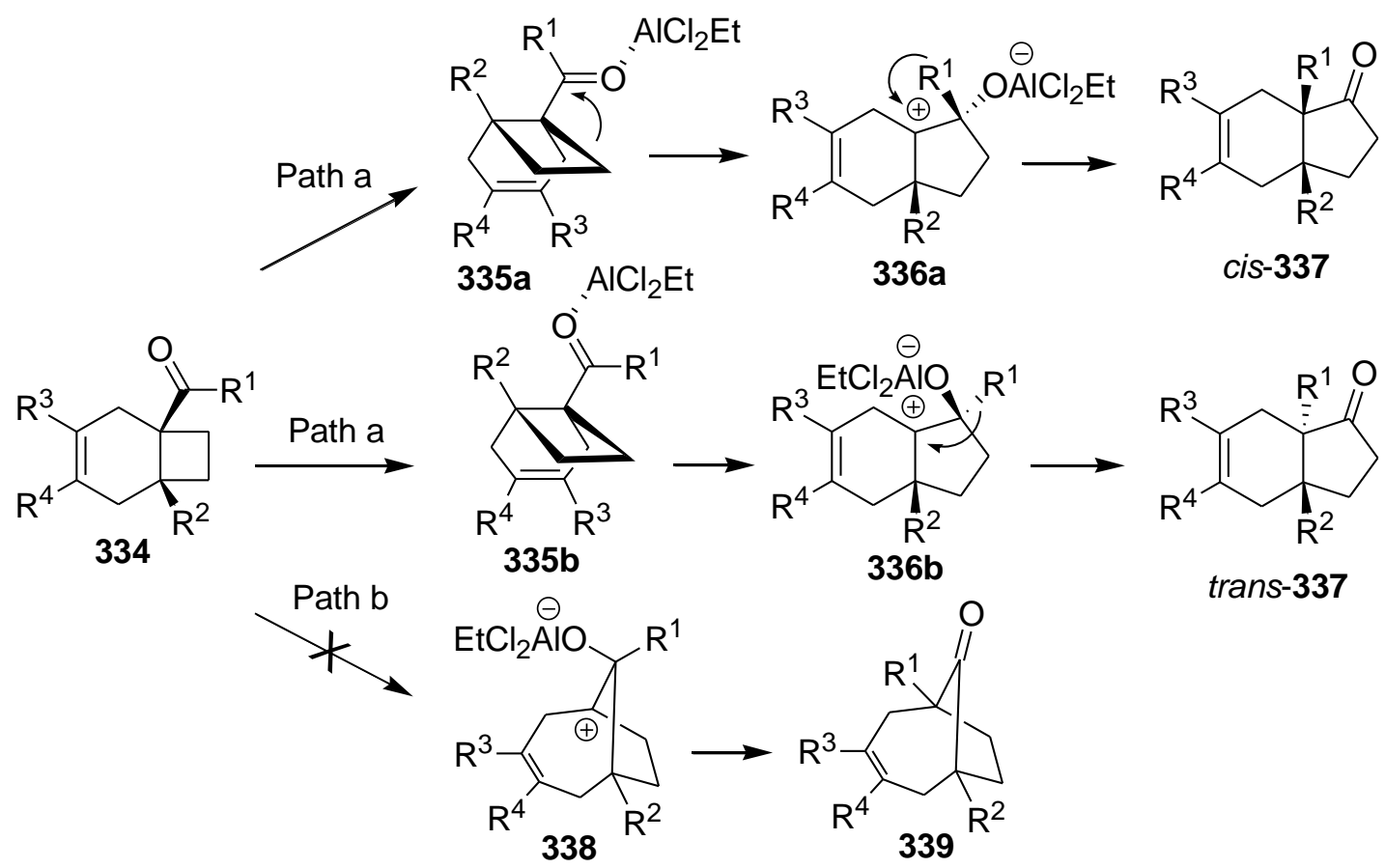

Scheme 95

With 1.1 equiv of ethylaluminium dichloride, as the most efficient Lewis acid, the ring expansion of 1-acylbicyclo[4.2.0]oct-3-enes $\mathbf{3 3 4}$ in dichloromethane gave 6alkylbicyclo[4.3.0]non-3-en-7-ones 337 in good yields (Scheme 96). ${ }^{139}$ When substituted annelated cyclobutyl methylketones $\left(\mathrm{R}^{1}=\mathrm{Me}\right)$ were used, cis-hydrindanones were synthesized in good yield $(67-93 \%)$ with high cis-stereoselectivity $(82-100 \%$ de). With isopropyl and tert-butyl ketones $\left(\mathrm{R}^{1}=i \mathrm{Pr}\right.$, tert-Bu) instead of methyl ketones, a reduced stereoselectivity or even a reversal was observed, according to the steric demand of these substituents.<smiles>[R]C(=O)C12CCCC1([R])C([R])=C([R])C2</smiles>

334

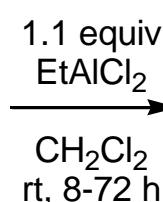

rt, 8-72 h

$\mathrm{R}^{1}=\mathrm{Me}, \mathrm{Pr}$, tert-Bu

$\mathrm{R}^{2}=\mathrm{H}, \mathrm{Me}, \mathrm{Bu} ; \mathrm{R}^{3}=\mathrm{H}$ $\mathrm{R}^{3}-\mathrm{R}^{4}=\mathrm{C}_{4} \mathrm{H}_{4} ; \mathrm{R}^{4}=\mathrm{H}, \mathrm{Me}$<smiles>[R]C1=C([R])CC2([R7])C(=O)CCC2([R7])C1</smiles>
cis-337 $\mathrm{R}^{1}=\mathrm{Me}(67-93 \%)(01: 9-100: 0)$$$
\mathrm{R}^{1}=\operatorname{Pr}(88 \%)(50: 50)
$$$$
R^{1}=\text { tert-Bu (9\%) (16:84) }
$$

\section{Scheme 96}


As part of the synthesis of enantiomerically pure spirocyclic $\alpha, \beta$-butenolides, a bromonium ion- (vide supra, Scheme 31) or oxonium ion-induced rearrangement of carbinol 101 has been developed. ${ }^{54 a, 66,140}$ This oxonium ion-promoted rearrangement was first executed by treatment of carbinol 101, synthesized by the addition of 5-lithio-2,3-dihydrofuran $340\left(R^{1}, R^{2}=H\right)$ to cyclobutanone 80, with different acids to produce the spirocyclic tetrahydrofuranyl ketone $342\left(\mathrm{R}^{1}, \mathrm{R}^{2}=\mathrm{H}\right)$ in $45-87 \%$ yield with excellent selectivity ( $\left.d r 100: 0\right)$. Next to $\mathbf{3 4 2}$, variable quantities (0-14\%) of 1,4-dioxanes 343 and $344\left(R^{1}, R^{2}=H\right)$ in a 1:1 ratio were detected, depending on the used acidic ion exchange resin (Scheme 97). Only when Amberlyst- $15^{66}$ or methanol-free Dowex-50X resin ${ }^{140 \mathrm{~b}}$ was used in dichloromethane at room temperature, no dioxane side product was obtained.

When carbinols $101\left(\mathrm{R}^{1}=\mathrm{H}\right.$, allyl; $\left.\mathrm{R}^{2}=\mathrm{H}, \mathrm{Me}\right)$ were treated with camphor sulfonic acid (CSA) (0.2-1.7 mol\%) in dichloromethane at room temperature for 30 minutes to two hours, spiro ketones $\mathbf{3 4 2}$ were obtained in 67 to $89 \%$ yield in a diastereomeric ratio ranging from $3.9: 1$ to $1: 1.5 .^{141}$

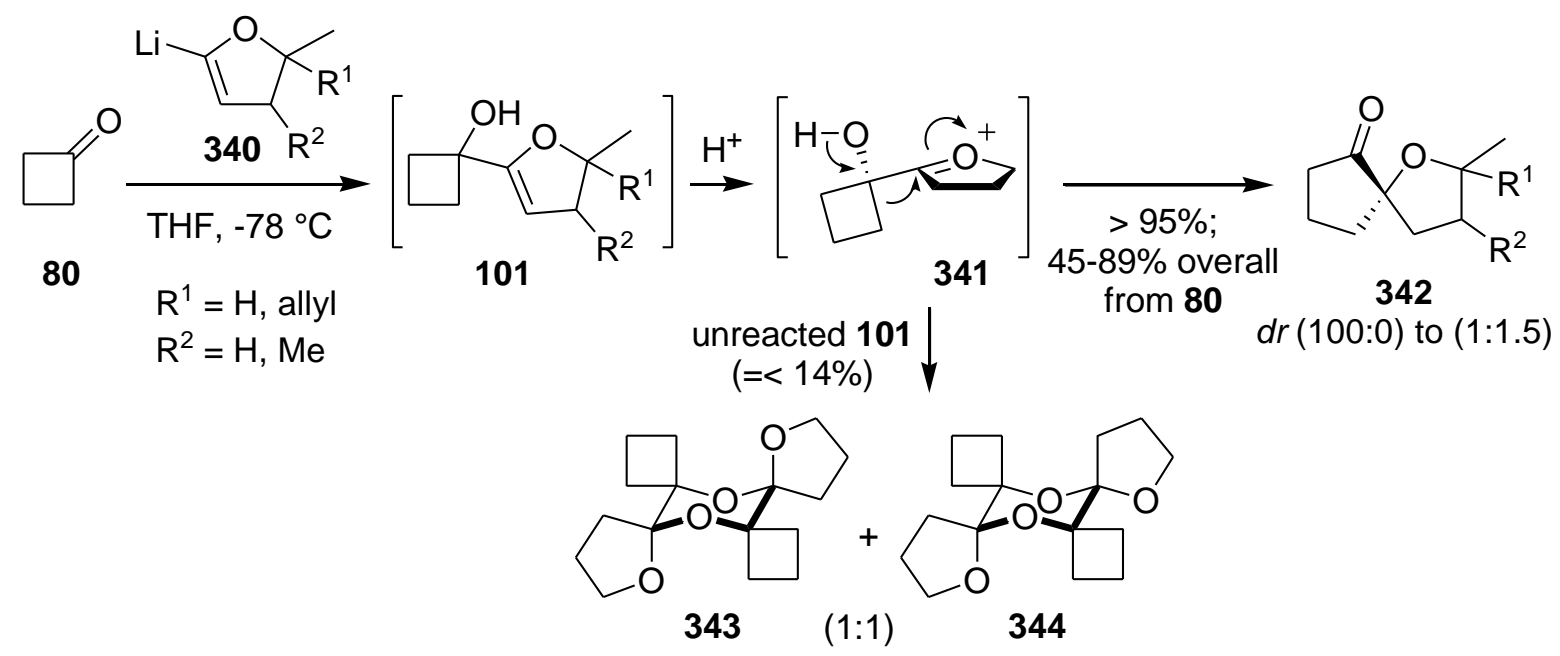

Scheme 97 
In the field of carbohydrate chemistry, the acid-catalyzed rearrangement of dihydropyranylcarbinols such as $\mathbf{3 4 5}$ to spirocyclic bis- $C, C$-glycosides $\mathbf{3 4 7}$ and $\mathbf{3 4 9}$ has been examined and proved to be highly diastereoselective. ${ }^{141,142}$ This efficient process resulted in the generation of a new stereogenic centre by means of controlled pinacol-like 1,2-migration to a cyclic oxonium ion. When glycols $\mathbf{3 4 5}$, substituted with a leaving group in the allylic C(4) position, were subjected to acidic conditions, two intermediates 346 and 348 could be formed, resulting in spirocyclic compounds 347 and 349, respectively. While the generation of intermediate 346 qualified as a potentially reversible process, the formation of $\mathbf{3 4 8}$ is essentially irreversible (Scheme 98). ${ }^{142}$

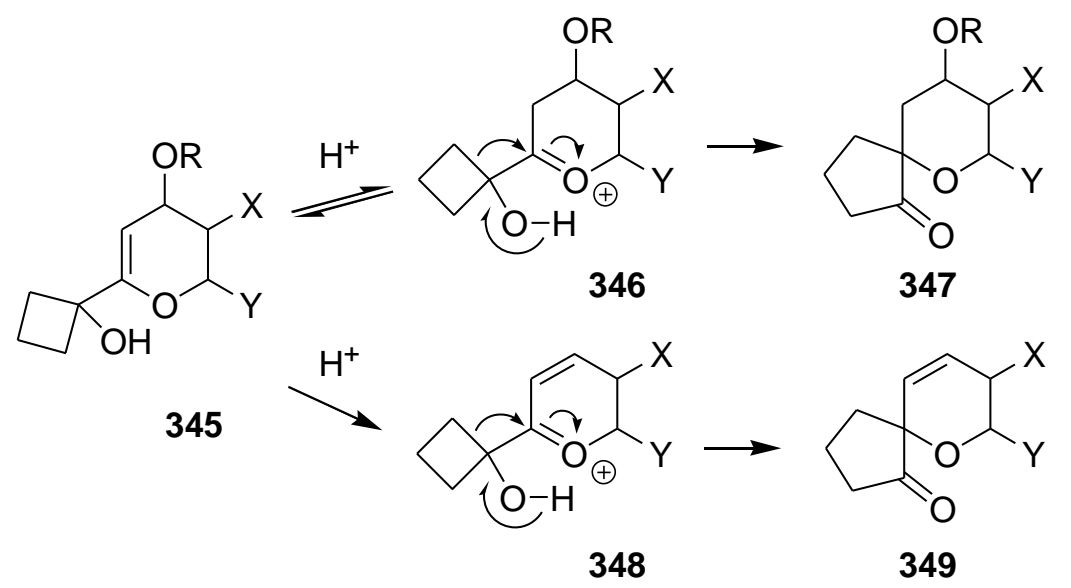

\section{Scheme 98}

In another example, simple substitution of the dihydropyran ring with one or two alkyl groups engendered sufficient inductive electron donation to reduce the potential for isomerization significantly, ${ }^{141}$ although cyclobutanol derivatives still underwent ring expansion at a rate to be synthetically useful. In that respect, treatment of cyclobutanols $\mathbf{3 5 0}$ with a catalytic amount of camphorsulfonic acid (CSA) in dichloromethane at room temperature for 0.5 to four hours resulted in spirocyclic bis- $C, C$-glycosides $\mathbf{3 5 1}$ and $\mathbf{3 5 2}$ in 50-80\% and 14-38\% yield, respectively (Scheme 99). ${ }^{142 b}$ 
<smiles>[R]C1C=C(C2(O)CCC2)O[C@H]([R])[C@@H]1[R]</smiles>

350

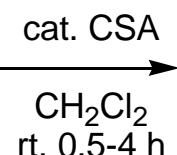
rt, $0.5-4 \mathrm{~h}$<smiles>[R]C1C[C@@]2(CCCC2=O)O[C@H]([18F])[C@@H]1[R]</smiles>

$351(50-80 \%)$<smiles>[R]C1C[C@]2(CCCC2=O)O[C@@H]([R])[C@@H]1[R]</smiles>

352 (14-38\%)

$\mathrm{R}^{1}=\mathrm{H}, \mathrm{Me}$, OTIPS, OTBS

$\mathrm{R}^{2}=\mathrm{H}$, OTIPS, OTBS

$\mathrm{R}^{3}=\mathrm{CH}_{2}$ OTIPS, Me, $\mathrm{H}$

\section{Scheme 99}

Although based on a different reaction mechanism, the samarium(II)-induced ring expansion of 1,2-cyclobutanedicarboxylates $\mathbf{3 5 3}$ to cyclopentanones 354 is worth mentioning (Scheme 100). ${ }^{143}$ Also, a single isomer 356 was obtained in the ring expansion of tricyclic compound $\mathbf{3 5 5}$ in $38 \%$ yield. It should be noted that the reaction of this rearrangement proceeded via a tandem reductive fragmentation-Dieckmann condensation.

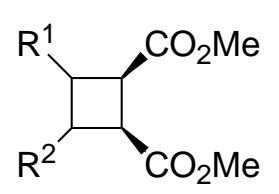

353

$\mathrm{R}^{1}-\mathrm{R}^{2}=\left(\mathrm{CH}_{2}\right)_{3},\left(\mathrm{CH}_{2}\right)_{4},\left(\mathrm{CH}_{2}\right)_{5},\left(\mathrm{CH}_{2}\right)_{6}$ $\mathrm{R}^{1}, \mathrm{R}^{2}=\mathrm{Ph}$

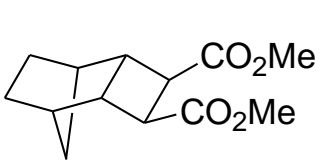

355

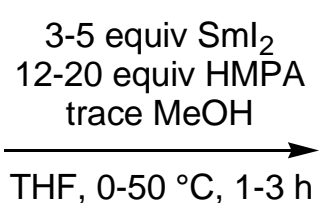

THF, $0-50{ }^{\circ} \mathrm{C}, 1-3 \mathrm{~h}$

3 equiv $\mathrm{Sml}_{2}$

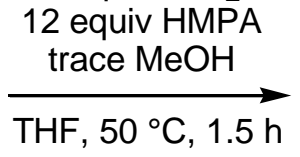

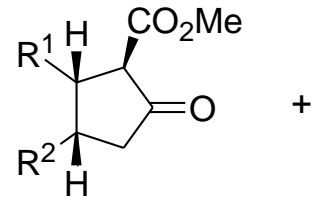

cis-354<smiles>[R]C1CC(=O)C(C(C)=O)[C@H]1[R]</smiles>

trans-354 cis-354:trans-354 (39-79\%) (1-3.8:1-1.5)<smiles>COC(=O)C1C(=O)CC2C3CCC(C3)C12</smiles>

Scheme 100

Ring expansion of cyclobutanecarboxaldehyde $357\left(\mathrm{R}^{1}, \mathrm{R}^{2}=\mathrm{Me}, \mathrm{R}^{3}=i \mathrm{Pr}\right)$ was executed upon treatment with 1.2 equiv of $\mathrm{AlCl}_{3}$ in dichloromethane at $0{ }^{\circ} \mathrm{C}$ for nine hours through 
successive 1,2-shifts of a tertiary alkyl group and a hydride to synthesize 2benzoyloxycyclopentanone 358 in $61 \%$ yield (Scheme 101). ${ }^{144}$ The same authors reported the ring expansion of bicyclic compound $359\left(\mathrm{R}^{1}=\mathrm{Me}, \mathrm{R}^{2}-\mathrm{R}^{3}=\left(\mathrm{CH}_{2}\right)_{3} \mathrm{C}\left(\mathrm{CH}_{3}\right)_{2}\right)$ by treatment with two equiv of $\mathrm{Bu}_{4} \mathrm{NF} \cdot 3 \mathrm{H}_{2} \mathrm{O}$ through hydrolysis and subsequent 1,2-shift of a tertiary alkyl group to afford 2-hydroxycyclopentanone $\mathbf{3 5 9}$ as a chiral intermediate in the enantioselective total synthesis of 4a-methylhydrofluorene diterpenoids such as (-)-taiwaniaquinol B $\mathbf{3 6 0}$ (Scheme 101). ${ }^{144 a}$
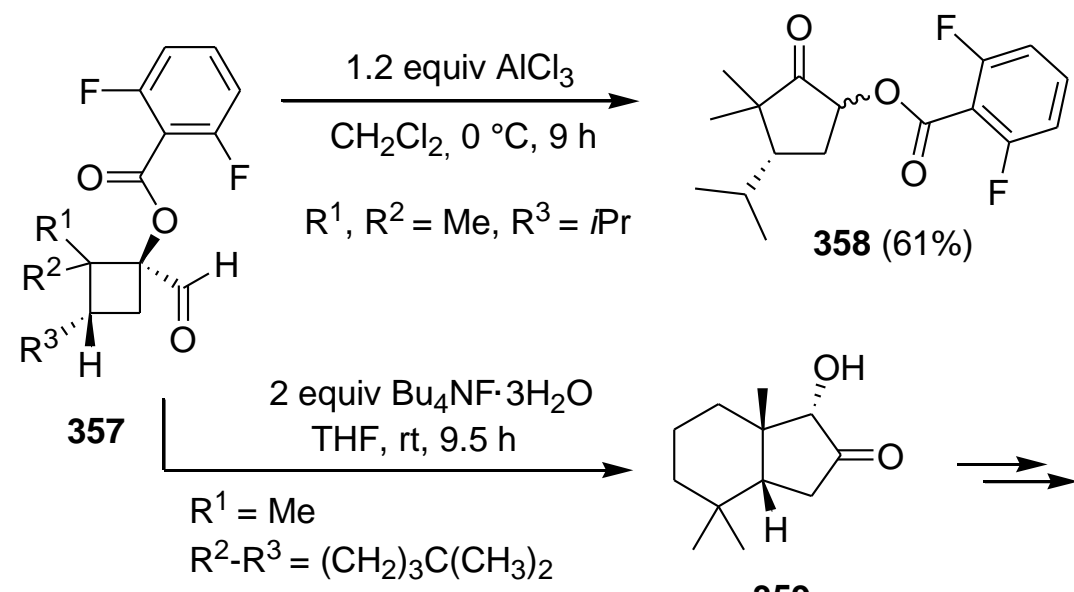

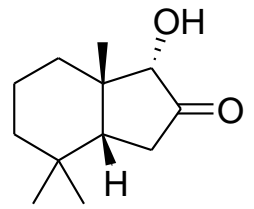

359

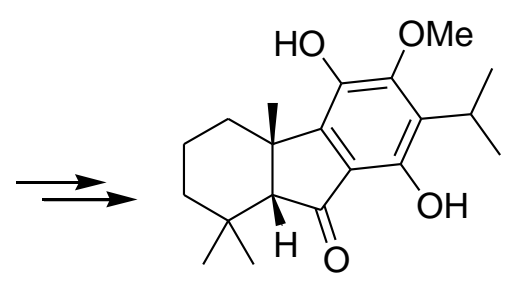

(-)-taiwaniaquinol B 360

Scheme 101

\subsection{Special cases}

Although essentially based on a cyclobutane to cyclopentane ring enlargement through activation of a carbonyl moiety, the following examples deviate from a simple and direct carbonyl activation approach and are therefore discussed in a separate section.

The cobalt carbonyl-catalyzed ring expansion of cyclobutanone $\mathbf{3 6 1}$ to 1,2bis(diethylmethylsiloxy)cyclopentene $\mathbf{3 6 5}$ with diethylmethylsilane and carbon monoxide (50 
atm) comprised the first example of the catalytic incorporation of carbon monoxide into a simple ketonic C-C bond. ${ }^{145}$ The ring-enlargement mechanism, as shown in Scheme 102, for the rearrangement of cyclobutanones 361 to cyclopentenes 365 , also involved a cyclobutylmethyl to cyclopentylcarbenium ion rearrangement. There was evidence that $\mathrm{MeEt}_{2} \mathrm{SiCo}(\mathrm{CO})_{4}$ was involved in the reaction, generated in situ in the trialkylsilane/carbon monoxide/dicobaltoctacarbonyl system. In addition to the ring strain of cyclobutanes, the high oxygenophilicity of silicon implied a strong driving force for this reaction. Addition of three equiv of diethylmethylsilane, 0.04 equiv of dicobaltoctacarbonyl, 0.04 equiv of triphenylphosphine and carbon monoxide (50 atm) to cyclobutanone 361 in benzene at 110$175{ }^{\circ} \mathrm{C}$ for 20 hours afforded the corresponding disiloxycyclopentenes $\mathbf{3 6 5}$ in $73-95 \%$ yield through formation of intermediates $\mathbf{3 6 2}, \mathbf{3 6 3}$ and $\mathbf{3 6 4}$ (Scheme 102).

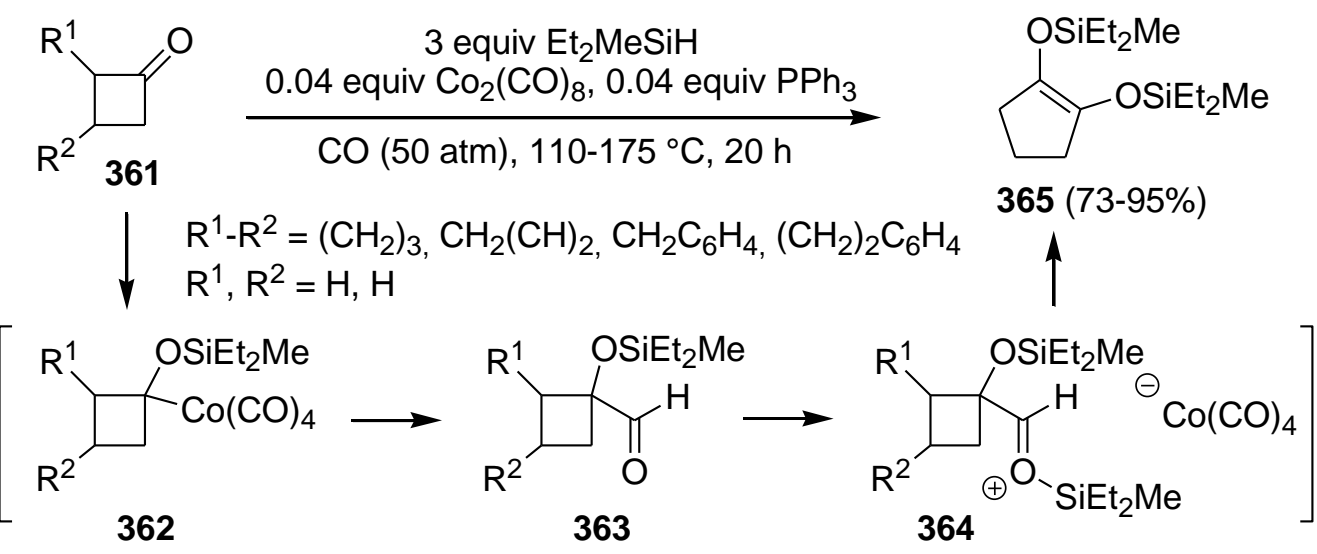

Scheme 102

Bicyclo[3.3.0]oct-1-en-3-ones 368, obtained from spirocyclobutanes 365, were applied in the synthesis of racemic 1-desoxyhypnophilin. ${ }^{146}$ When enaminonitriles 365 were treated with phosphoric acid in aqueous acetic acid at reflux temperature for one hour, the corresponding cyclopentenones $\mathbf{3 6 8}$ were obtained in $62-99 \%$ yield. In a plausible mechanism, the acidic hydrolysis of the enamine function of $\mathbf{3 6 5}$ first gave enones 366. Protonation of the carbonyl 
oxygen of enones 366, followed by rearrangement of the cyclobutane ring furnished bicyclo[3.3.0] ]octenones $\mathbf{3 6 7}$ which, upon tautomerization, produced bicyclic enones $\mathbf{3 6 8}$.

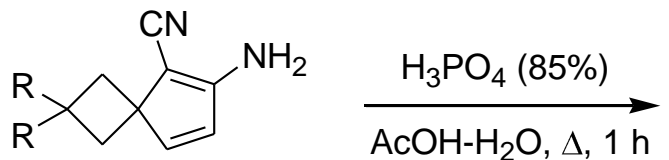

365

$\mathrm{R}=\mathrm{H}, \mathrm{CH}_{2} \mathrm{OEt}$

$\mathrm{R}, \mathrm{R}=\mathrm{CH}_{2} \mathrm{OC}\left(\mathrm{CH}_{3}\right)_{2} \mathrm{OCH}_{2}$

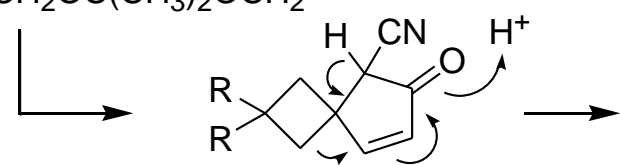

366

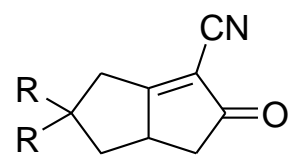

$368(62-99 \%)$

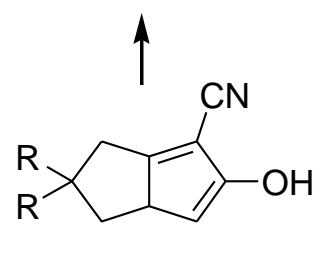

367

Scheme 103

When enaminonitriles 369 were subjected to the same reaction conditions as described before, not the expected 2-cyano-4-alkyl- or 4-arylbicyclo[3.3.0]oct-1-en-3-ones were obtained but instead 2-alkyl- or 2-arylbicyclo[3.3.0]oct-1-en-3-ones 373 were isolated in 53-99\% yield. ${ }^{146}$ A plausible mechanism for the formation of these compounds is provided in Scheme 104. First, acidic hydrolysis of the enamine moiety of $\mathbf{3 6 9}$ gave enones $\mathbf{3 7 0}$. Subsequently the ring expansion of the cyclobutane ring took place as described above (Scheme 103) to give 2cyano-4-alkyl- or 4-arylbicyclo[3.3.0]oct-1-en-3-ones 371. Migration of the double bond in 371 occurred under the acidic conditions to afford enone 372, in which the cyano group was hydrolyzed followed by decarboxylation to provide compounds 373 . 


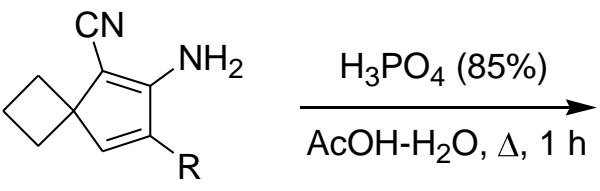

369

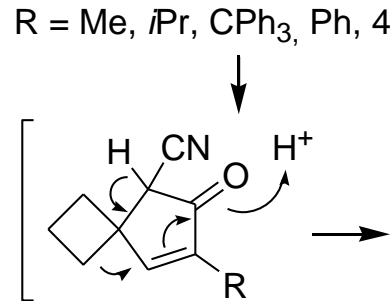

370

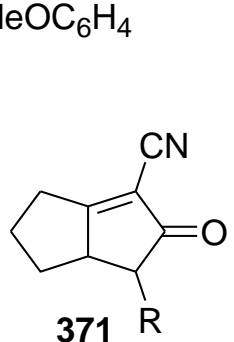

$371 \mathrm{R}$<smiles>[R]C1=C2CCCC2CC1=O</smiles>

$373(53-99 \%)$<smiles>[R]C1=C2C[C@@H](C)CC2C(C#N)C(=O)C1[18OH]</smiles>

Scheme 104

\section{Formation of cyclobutylmethylcarbenium ions through expulsion of a leaving group}

Different kinds of leaving groups, e.g. halogens, nitrogen gas, a nitro group, activated hydroxy and alkoxy groups, and sulfur and selenium groups, can be used to form and induce ring expansion of cyclobutylmethylcarbenium ions with ring strain as a driving force. Several examples of syntheses based on this approach are described in this section.

\subsection{A halogen atom as leaving group}

\subsubsection{Cyclobutylmethyl chlorides}

The ethyl dichloroacetate anion, cathodically generated from ethyl trichloroacetate, was added across cyclobutanone 80 in DMF at $0{ }^{\circ} \mathrm{C}$ to yield cyclopentanone 375 in $43 \%$ yield (Scheme 
105). ${ }^{147}$ The formation of this cyclopentanone was conceived by a ring expansion reaction of the adduct 374, taking advantage of the electrophilicity of the dihalogenated carbon atom.

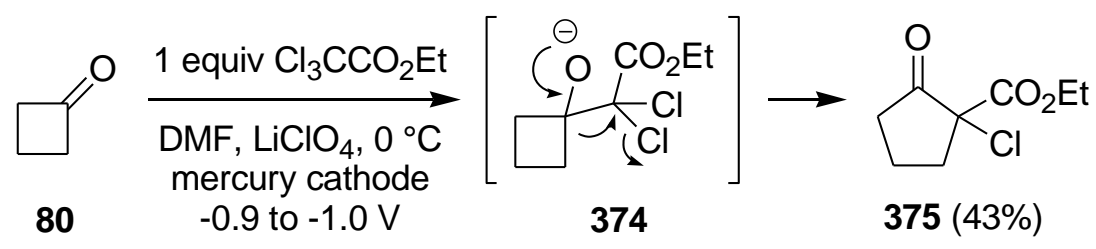

Scheme 105

In the synthesis of the regioisomer of $\beta$-cuparenone 379, Krief and co-workers reported a rearrangement of chlorohydrin $\mathbf{3 7 7}$, synthesized from epoxide $\mathbf{3 7 6}$ with beryllium(II) chloride (Scheme 106). ${ }^{148}$ Treatment of this chlorohydrin 377 with silver tetrafluoroborate in the presence of aluminium oxide at $20{ }^{\circ} \mathrm{C}$ for 15 hours afforded cyclopentanone 378 and a small fraction of $\beta$-cuparenone 379 in a ratio of 95:5. An overall yield of $75 \%$ was assigned to cyclopentanone $\mathbf{3 7 8}$ starting from epoxide $\mathbf{3 7 6}$.<smiles>Cc1ccc(C2(C)C(C)(C)CC23CO3)cc1</smiles>

376

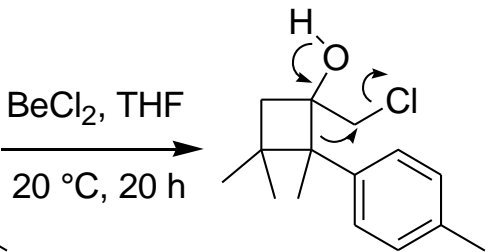

377

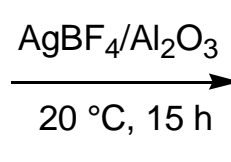
$20^{\circ} \mathrm{C}, 15 \mathrm{~h}$

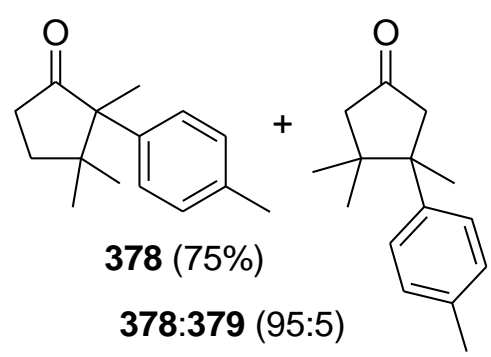

$\beta$-cuparenone 379

Scheme 106

In another approach, a one-carbon homologation of ketones to $\alpha$-sulfinyl ketones using (chloromethyl)phenylsulfoxide has been reported. $^{149}$ Treatment of (chloromethyl)phenylsulfoxide with 1.2 equiv of lithium diisopropylamide (LDA) in 
tetrahydrofuran at $-60{ }^{\circ} \mathrm{C}$ formed a carbanion, which was reacted with cyclobutanone 80 to give adduct $\mathbf{3 8 0}$ as a single isomer in $92 \%$ yield (Scheme 107). This adduct $\mathbf{3 8 0}$ was treated with three equiv of LDA in tetrahydrofuran at -60 to $-50{ }^{\circ} \mathrm{C}$ for 1.5 hours to afford $\alpha$-sulfinyl cyclopentanone $\mathbf{3 8 1}$ in $95 \%$ yield as a mixture of two inseparable diastereomers in a 4:1 ratio. The previous method was applied to the one-carbon ring expansion of cyclic ketones to cyclic ketones bearing an alkyl substituent. ${ }^{150}$ Addition of the carbanion of (1-chloroalkyl)-ptolylsulfoxide to cyclobutanone $\mathbf{8 0}$ afforded chloro alcohol $\mathbf{3 8 2}$ in 91\% yield (Scheme 107). When five equiv of $t \mathrm{BuLi}$ were added to the chloro alcohol 382 in tetrahydrofuran at $-70{ }^{\circ} \mathrm{C}$, the rearrangement afforded 1-decylcyclopentanone $\mathbf{3 8 3}$ in $60 \%$ yield.

The same authors used the previous ligand exchange reaction of sulfoxides for the synthesis of $\alpha$-chloroketones from carbonyl compounds with one-carbon homologation. ${ }^{151}$ When (dichloromethyl)phenylsulfoxide was treated with LDA in tetrahydrofuran at $-60{ }^{\circ} \mathrm{C}$ followed by cyclobutanone addition, adduct 384 was synthesized in 90\% yield (Scheme 107). The chloro alcohol 384 was treated with three equiv of $\mathrm{EtMgBr}$ in tetrahydrofuran at -78 to $-45^{\circ} \mathrm{C}$ for $1.5 \mathrm{~h}$ to synthesize $\alpha$-chlorocyclopentanone $\mathbf{3 8 5}$ in $63 \%$ yield. In this case, a Grignard reagent $(\mathrm{EtMgBr})$ was used for the ligand exchange reaction of the sulfoxides. Apparently, different approaches can be applied for the conversion of cyclobutanone $\mathbf{8 0}$ into cyclopentanones, in which either cationic or anionic intermediates intervene. 


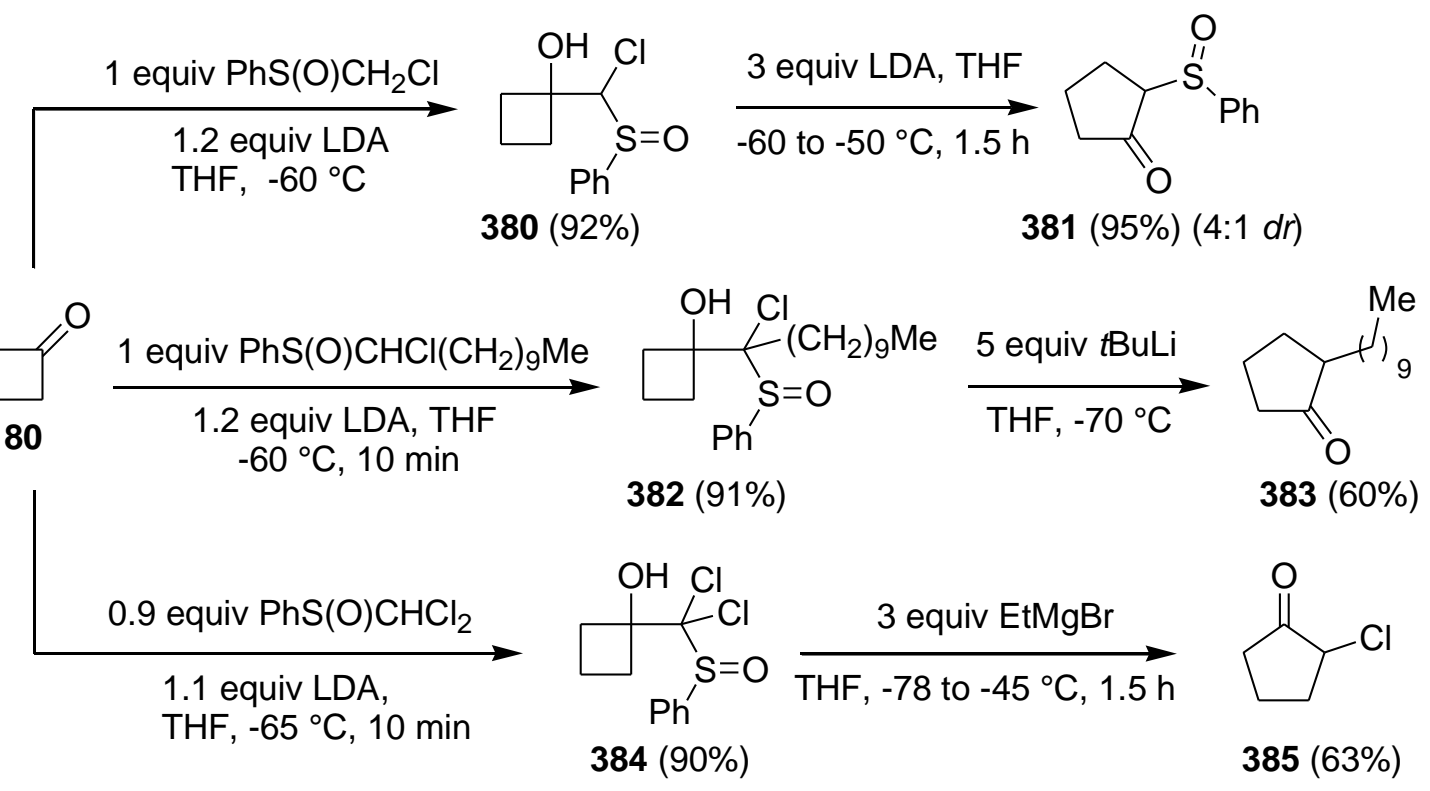

Scheme 107

Treatment of cyclic tert-trihalomethylcarbinols with $\mathrm{CrCl}_{2}$ in THF/HMPA in the presence of aryl or aliphatic aldehydes initiated a cascade sequence of one-carbon ring expansion olefination, affording conjugated exocyclic ketones. ${ }^{152}$ As a specific example, exposure of cyclobutyl carbinol 386 to six equiv of $\mathrm{CrCl}_{2}$ and one equiv of benzaldehyde in THF/HMPA for four hours at $40{ }^{\circ} \mathrm{C}$ afforded (E)-2-benzylidenecyclopentanone $\mathbf{3 8 7}$ in $63 \%$ yield (Scheme 108).

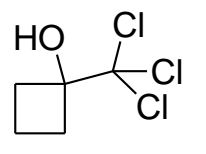

386

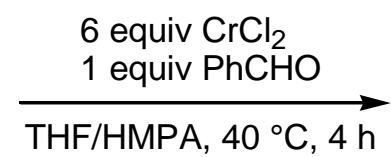

THF/HMPA, $40^{\circ} \mathrm{C}, 4 \mathrm{~h}$<smiles>O=C1CCCC1=Cc1ccccc1</smiles>

$387(63 \%)$

\section{Scheme 108}

Two plausible mechanistic pathways were disclosed (Scheme 109). ${ }^{152}$ Initial metalation of the trihalomethyl moiety generated the key dihalochromium intermediate 388. A second metalation led to $\mathbf{3 8 9}$, which rearranged to dichromium ketone 390 . This ketone 390 was 
expected to add rapidly to the aldehyde and to collapse to the final product $\mathbf{3 9 2}$. Alternatively, $\alpha$-elimination of 388 formed carbene 393 and hence $\alpha$-haloenol 394, its rearrangement product. Addition of the aldehyde culminated in $\mathbf{3 9 2}$ via reduction of adduct $\mathbf{3 9 5}$.

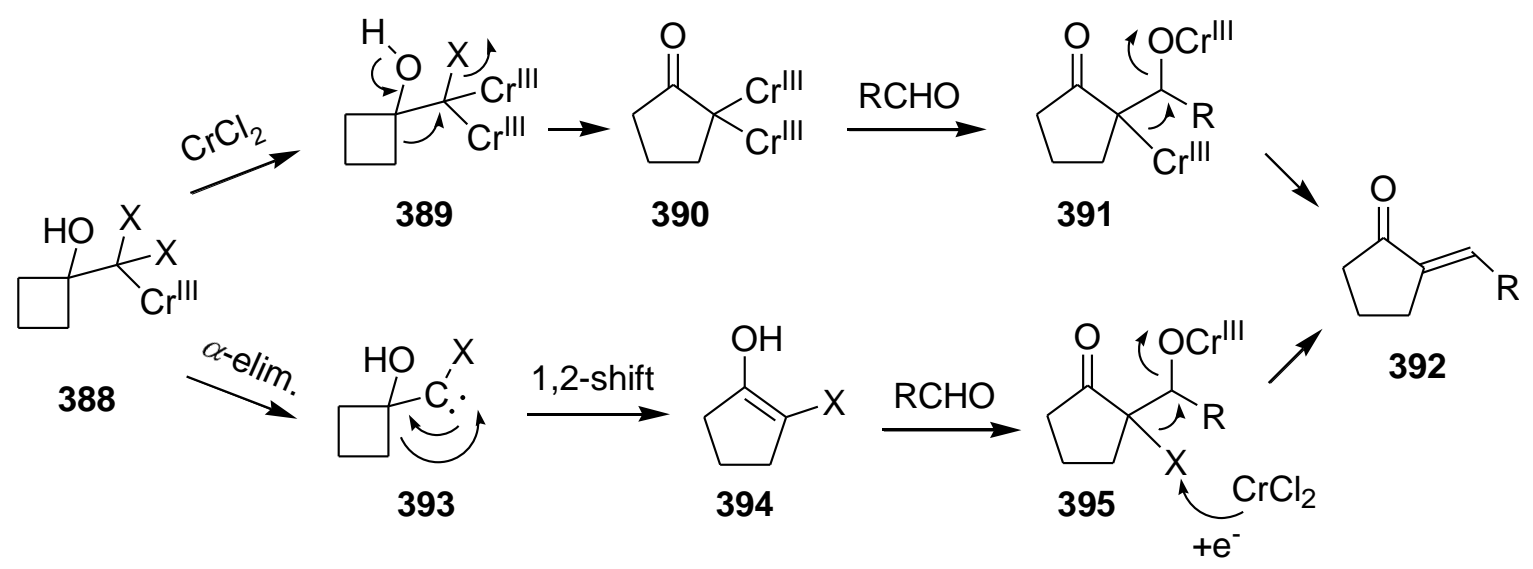

Scheme 109

A domino $\lambda^{3}$-iodination - 1,4-halogen shift - ring enlargement reaction of 5-chloro- or 5bromopent-1-ynes 396 took place when the starting material was treated with two equiv of 4(difluoroiodo)toluene in the presence of 1.5 equiv of $\mathrm{BF}_{3} \cdot \mathrm{Pr}_{2} \mathrm{O}$ in chloroform at $-60{ }^{\circ} \mathrm{C}$ to room temperature for five hours with an additional five hours at room temperature (Scheme 110). ${ }^{153}$ This domino reaction afforded (E)-3-cyclopentyl-2-halopropenyliodinanes 401 stereoselectively in $87-89 \%$ yield. A mechanistic rationale based on the formation and transformation of intermediates $397,398,399$ and $\mathbf{4 0 0}$ was provided by the authors. 


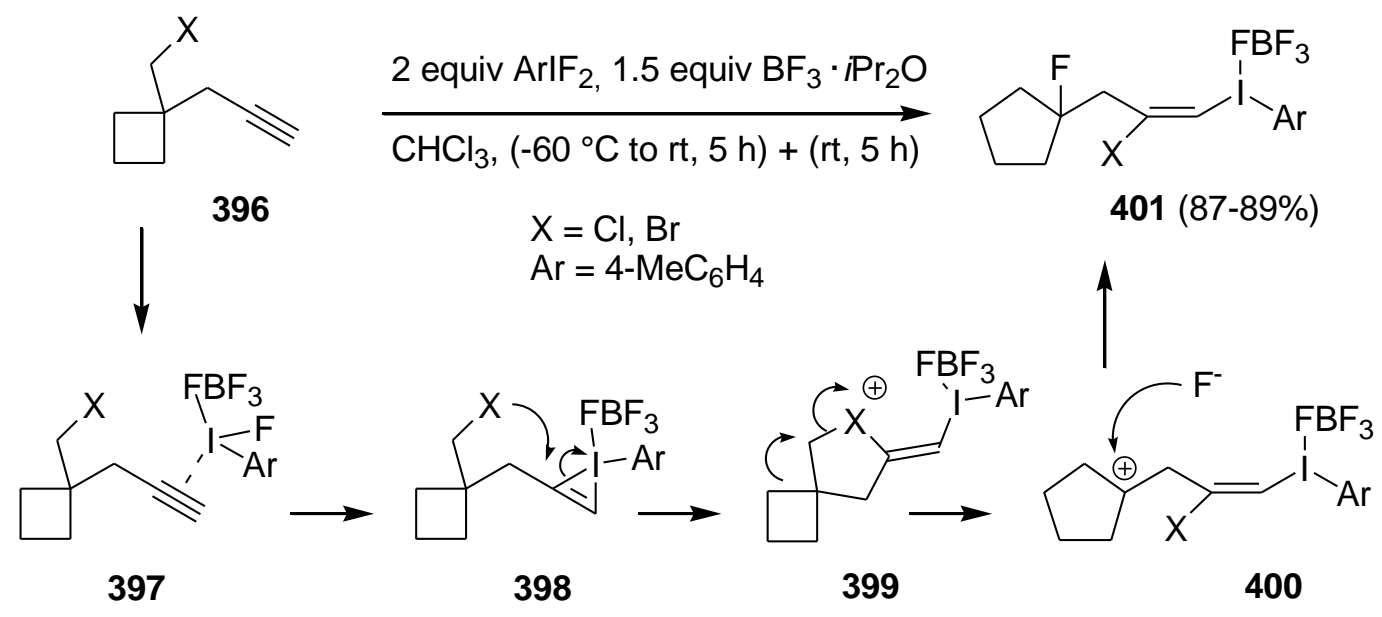

Scheme 110

\subsubsection{Cyclobutylmethyl bromides}

\subsubsection{Rearrangement of oxaspiro[2.3]hexanes using $\mathrm{LiBr}$}

Ring enlargement of cyclobutanones by means of the rearrangement of spiroannelated oxiranes has been developed by Trost and Latimer as an important step in gibberellin

synthesis (Scheme 111). ${ }^{154}$ Treatment of cyclobutanone $\mathbf{4 0 2}$ with 2.6 equiv of dimethylsulfonium methylide gave $\mathbf{4 0 3}$, and subsequent treatment with 1.2 equiv of lithium bromide in benzene containing 1.2 equiv of HMPA produced ketone $\mathbf{4 0 5}$ in $65 \%$ yield. The cyclobutane to cyclopentane ring expansion proceeded through initial ring opening of epoxide 403 by bromide toward the oxyanion of 1-(bromomethyl)cyclobutanol 404, followed by skeletal rearrangement to furnish cyclopentanone 405. Alternatively, conversion of substrates 402 to epoxide 403 via $m$ CPBA epoxidation of the Wittig olefination product 406, followed by rearrangement, gave spirocompound $\mathbf{4 0 5}$ in $78 \%$ overall yield. The latter procedure, although one step longer, proceeded in higher yield. 


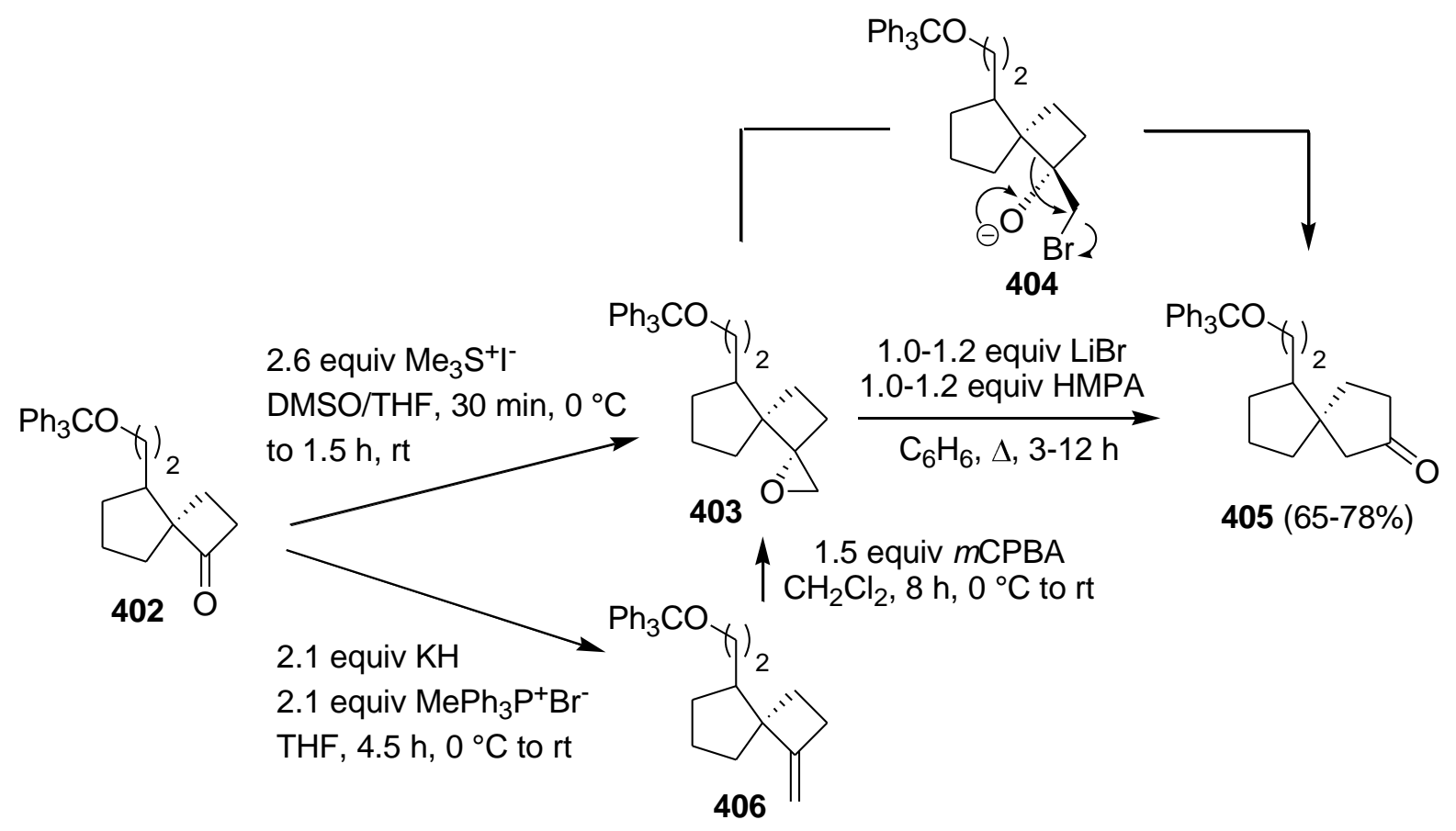

Scheme 111

The same type of epoxide-carbonyl rearrangement was executed in the synthesis of $( \pm)$ modhephene 410. ${ }^{155}$ The ring expansion of $\mathbf{4 0 7}$ was carried out in the same manner using lithium bromide and hexamethylphosphoramide in benzene at $80{ }^{\circ} \mathrm{C}$, affording the desired ketone $\mathbf{4 0 8}$ in $86 \%$ yield, together with a small amount $(9 \%)$ of the regioisomer $\mathbf{4 0 9}$ (Scheme 112).

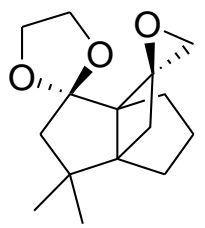

407

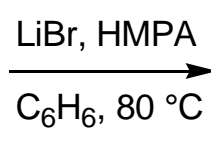

$\mathrm{C}_{6} \mathrm{H}_{6}, 80^{\circ} \mathrm{C}$

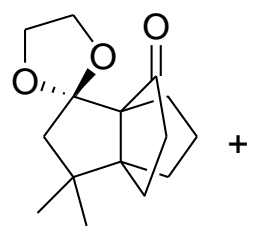

$408(86 \%)$

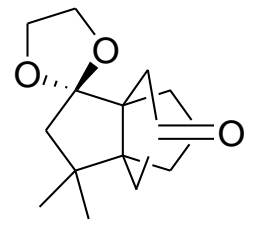

$409(9 \%)$

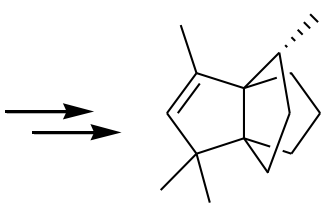

modhephene $\mathbf{4 1 0}$

Scheme 112

The same authors also published an alternative synthesis of ( \pm )-isocomene 36 (Figure 5). The second five-membered ring was synthesized in $81 \%$ yield applying the same reaction 
conditions ( $\mathrm{LiBr}$, HMPA, benzene, $80{ }^{\circ} \mathrm{C}$ ) from the corresponding epoxide. ${ }^{156}$ On the other hand, Wenkert and Arrhenius used LiI in tetrahydrofuran at room temperature for 24 hours for the synthesis of the third five-membered ring of isocomene $\mathbf{3 6}$ in $91 \%$ yield, also starting from the corresponding epoxide. ${ }^{157}$ Two other syntheses of isocomene have previously been described, one using the acid-promoted activation of a vinylcyclobutane (Scheme 10) and one via a cyclobutyl carbinyl ketone rearrangement (Scheme 82 ), both reported by Pirrung. ${ }^{42}$ Pirrung has also described a ring expansion of an epoxide ( $\mathrm{LiBr}, \mathrm{HMPA}$, benzene, $\left.80{ }^{\circ} \mathrm{C}\right)$ in $85 \%$ yield in the synthesis of the precursor of the methyl ester of pentalenolactone $\mathrm{G} \mathbf{4 1 1}$ (Figure 5). ${ }^{158}$

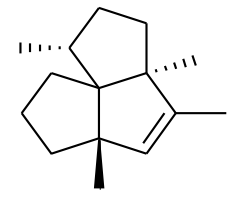

isocomene 36

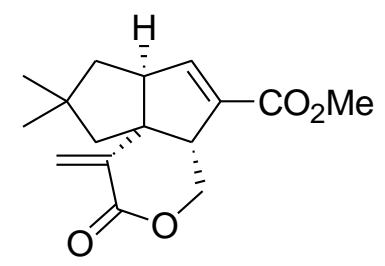

411

Figure 5

Research on the chelation-controlled regioselective epoxide-carbonyl rearrangement has been effected on 1-oxaspirohexane derivatives, giving difunctionalized bicyclo[3.3.0]octan-2-ones 414 (Scheme 113). ${ }^{159}$ When epoxides 412 were subjected to one equiv of lithium bromide and one equiv of hexamethylphosphoramide in benzene at reflux temperature, migration of the less substituted carbon occurred, whose selectivity is controlled by chelation of oxygen to the lithium cation. This process afforded 2,8-disubstituted diquinanes 414 in high selectivity (96100:0-4) in 75 to $94 \%$ yield. In contrast, the anti-epoxy acetal 412 did not afford 414 but gave 415 as the only ring expanded product in $24 \%$ yield, together with the macrocyclic enol ether 416 in $54 \%$ yield. $^{159}$ 


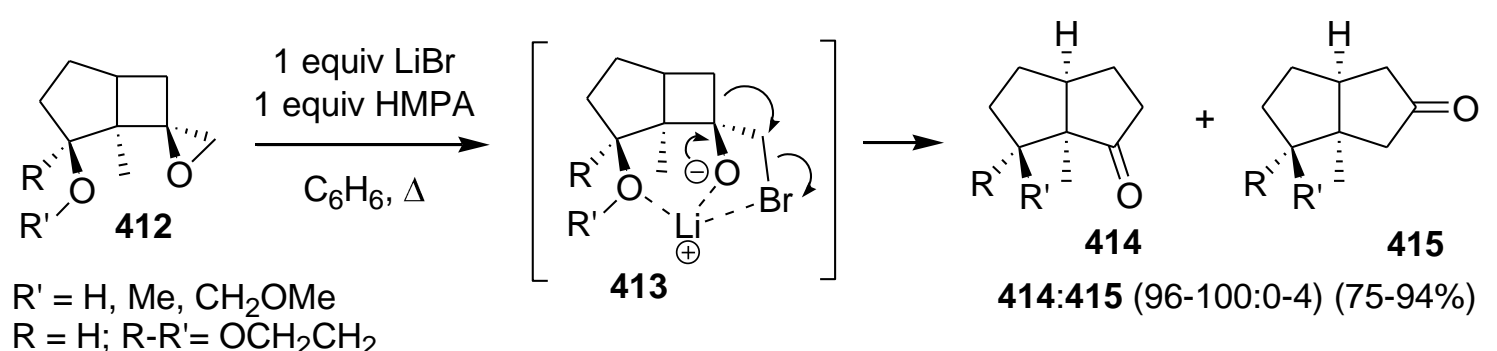

$\mathrm{R}=\mathrm{H} ; \mathrm{R}-\mathrm{R}^{\prime}=\mathrm{OCH}_{2} \mathrm{CH}_{2}$

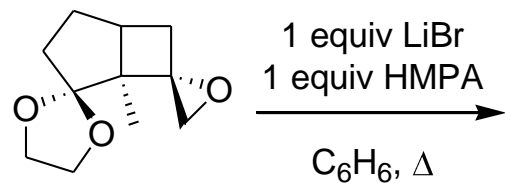

412

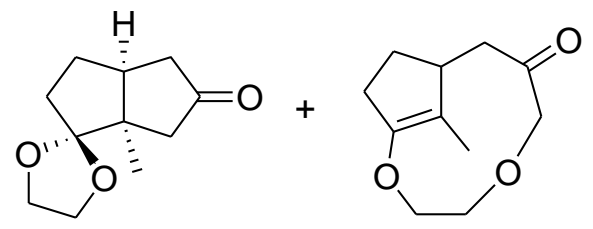

$415(24 \%)$
$416(54 \%)$

Scheme 113

\subsubsection{Other methods}

A ring expansion of a 1-(dibromomethyl)cyclobutanol derivative has been reported by Vedejs and Larsen as part of a synthetic pathway to fulvinic acid $\mathbf{4 2 0} .{ }^{160}$ When cyclobutanone $\mathbf{4 1 7}$ was treated with $\mathrm{CH}_{2} \mathrm{Br}_{2}$ in the presence of LDA, cyclobutyl carbinol 418 was obtained in $84 \%$ yield (Scheme 114). ${ }^{160 \mathrm{~b}}$ Rearrangement by means of $n \mathrm{BuLi}$ and $\mathrm{Me}_{3} \mathrm{SiCl}$ yielded the ring expanded product $\mathbf{4 1 9}$ in $85 \%$ yield which could be converted into fulvinic acid $\mathbf{4 2 0}$ through ozonolysis of the olefinic moiety.

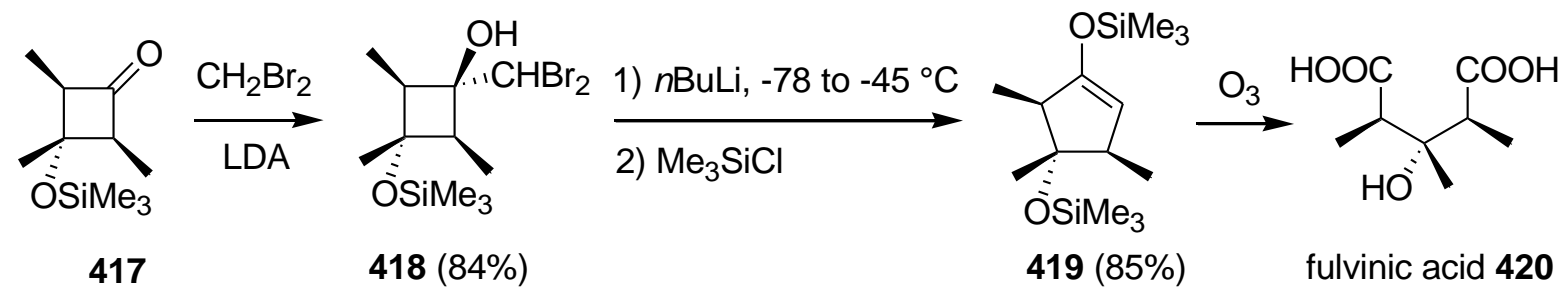

Scheme 114 
A $\mathrm{Ag}^{+}$-induced solvolysis of 2-bromomethyl-2-hydroxycyclobutanones $\mathbf{4 2 2}$, obtained via photocyclisation of $\alpha$-bromomethyl-1,2-diketones $\mathbf{4 2 1}$, provided a route to 4 -substituted and 4,5-disubstituted cyclopentane-1,3-diones $\mathbf{4 2 3} .{ }^{161}$ In that respect cyclobutanones $\mathbf{4 2 2}$ were treated with 1.2 equiv of silver nitrate in aqueous acetic acid $(1: 1)$ at $0{ }^{\circ} \mathrm{C}$ for four to six hours, after which a solution of 0.6 equiv of lithium bromide and 0.9 equiv of sodium acetate were added, giving rise to the corresponding cyclopentanones $\mathbf{4 2 3}$ in 35-72\% yield (Scheme 115).

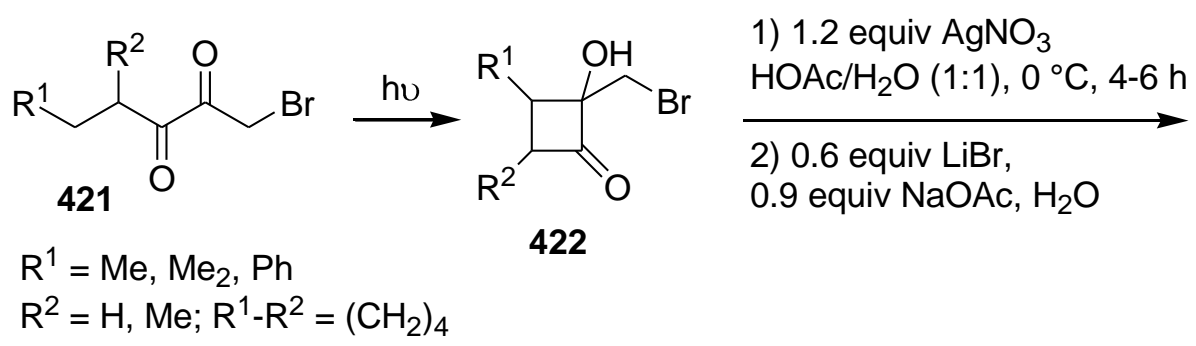

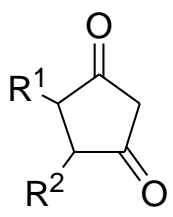

$423(35-72 \%)$

\section{Scheme 115}

In a final example, the formation of a cyclopentane annelated isoquinolone from a spirocyclobutane dihydroisoquinolone was executed by silver tetrafluoroborate addition. ${ }^{162}$ The bromomethylcyclobutane derivative $\mathbf{4 2 4}$, prepared photochemically by bromination using $\mathrm{N}$-bromosuccinimide, underwent ring enlargement upon treatment with 1.4 equiv of silver tetrafluoroborate in dichloromethane at room temperature for four hours to provide tetrahydrophenanthridin-6(5H)-one $\mathbf{4 2 5}$ in $90 \%$ yield (Scheme 116).<smiles>O=C1NC2(CCC2)CC1(Br)CBr</smiles>

424

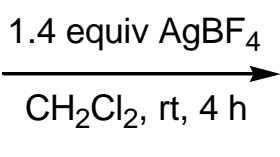

$\mathrm{CH}_{2} \mathrm{Cl}_{2}$, rt, $4 \mathrm{~h}$

Scheme 116<smiles>O=c1[nH]c2c(c3ccccc13)CCC2</smiles>

$425(90 \%)$ 


\subsubsection{Cyclobutylmethyl iodides}

\subsubsection{Rearrangement of oxaspiro[2.3]hexanes using Lil}

According to literature data, direct and regioselective transformation of oxaspirohexanes 426 into cyclopentanones $\mathbf{4 2 8}$ is best achieved using lithium iodide, although also lithium bromide has proven to give excellent results (vide supra). ${ }^{163}$ Mechanistically, the isomerization occurres via initial ring opening of the epoxide by nucleophilic addition of iodide, followed by regioselective migration of the more substituted carbon atom of the cyclobutane ring (Scheme 117).

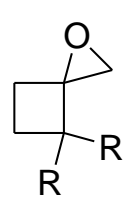

426

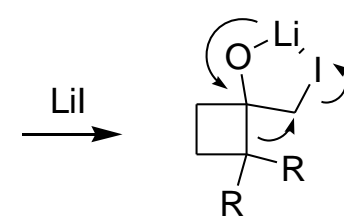

427

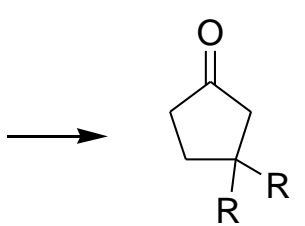

428

Scheme 117

For example, the synthetic sequence towards 6a-carbaprostaglandin $I_{2} 432$ started with the optically active, tricyclic ketone 429 which was ring expanded to ketones 430 and 431 (Scheme 118). ${ }^{164}$ This ring rearrangement was accomplished via the addition of 0.3 equiv of lithium iodide to isomeric spiro epoxides $\mathbf{4 2 9}$ in tetrahydrofuran at room temperature for 45 to $60 \mathrm{~min}$, affording the isomeric cyclopentanones $\mathbf{4 3 0}$ and $\mathbf{4 3 1}$ in $97 \%$ crude yield in a 1:9 ratio. $^{163 \mathrm{~b}}$ 


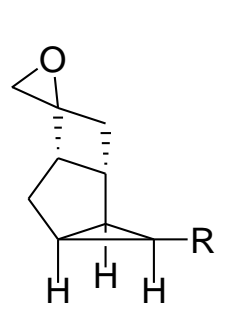

429
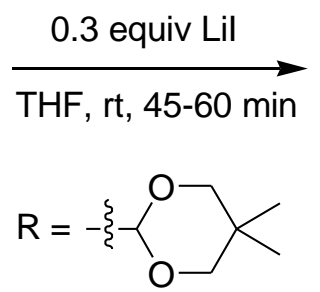

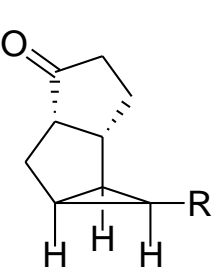

430

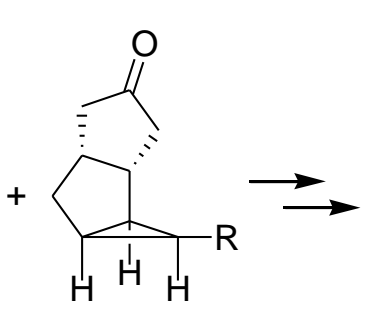

431

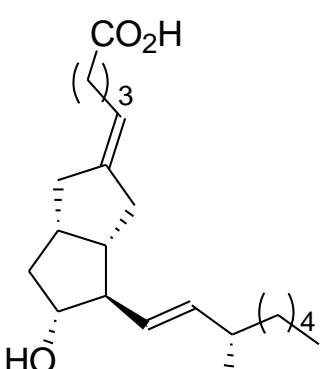

HÖ

430:431 (1:9) (97\% crude yield) 6a-prostaglandin $\mathrm{I}_{2} 432$

In a short synthesis of ( \pm -herbertene 436 , starting from 1-isopropenyl-3-methylbenzene $\mathbf{4 3 3}$, a carbenium ion promoted rearrangement afforded $\beta$-herbertenone $\mathbf{4 3 5}$ as the direct precursor (Scheme 119). ${ }^{57}$ Spiroannelated oxirane 434 , in the presence of a catalytic amount of lithium iodide, rearranged mainly to $\beta$-herbertenone $\mathbf{4 3 5}$ next to a minor amount of the isomer $\mathbf{8 9}$. The exact ratio of isomers $\mathbf{4 3 5}$ and $\mathbf{8 9}$ was not mentioned in the article. A Huang-Minlon reduction of both ketones using hydrazine in the presence of potassium hydroxide led to ( \pm herbertene 436, with an overall yield of $c a$. 30\% from 433. Synthesis of 2,2,3-trimethyl-(3methylphenyl)cyclopentanone $\mathbf{8 9}$, the minor isomer in this synthesis, was already described in the acid-promoted ring expansion of propenylcyclobutanols (Scheme 26). ${ }^{59}$

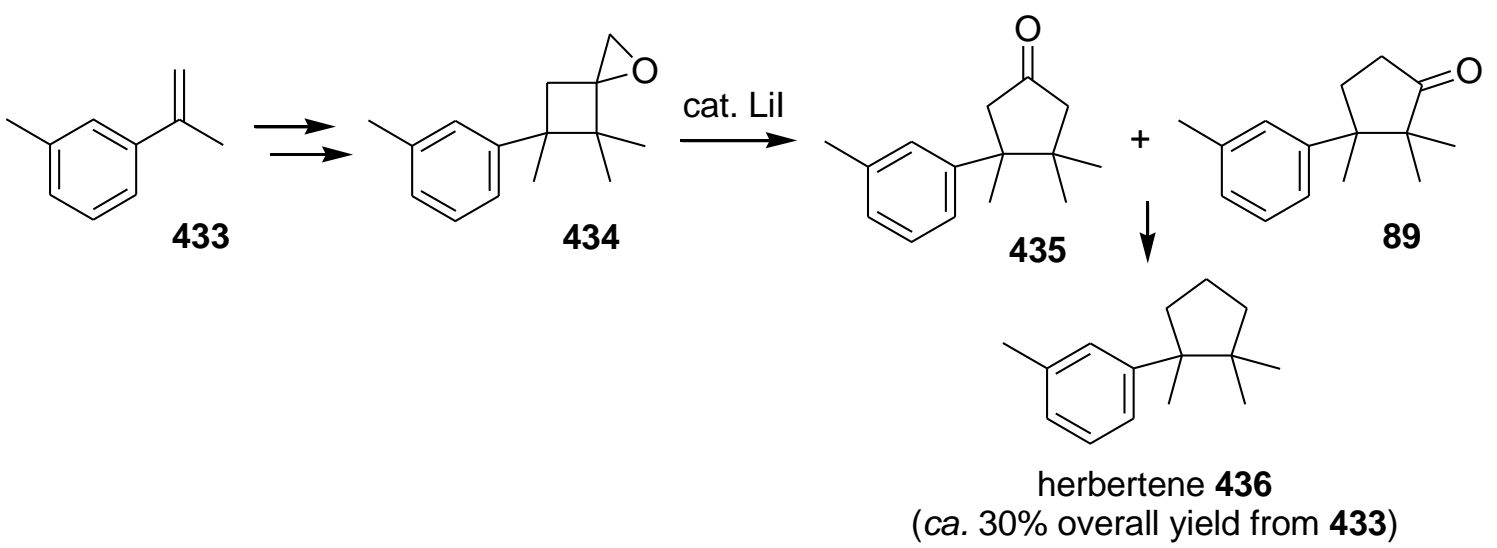

Scheme 119 
The synthetic applicability of this approach was further demonstrated by the synthesis of polyalkylated cyclopentanones 440 in a regioselective way using cyclobutanones 439 and carbonyl compounds 437 as starting material (Scheme 120). ${ }^{165}$ The final step in this approach comprised a ring expansion of epoxides 439 , which was achieved using lithium iodide in dichloromethane at reflux temperature to afford cyclopentanones $\mathbf{4 4 0}$ in 77 to $91 \%$ yield. This was the first example of a ring rearrangement of an epoxide ring bearing one or two alkyl groups. The ring rearrangement proved to be highly regioselective via migration of the more substituted carbon atom of the cyclobutane ring.

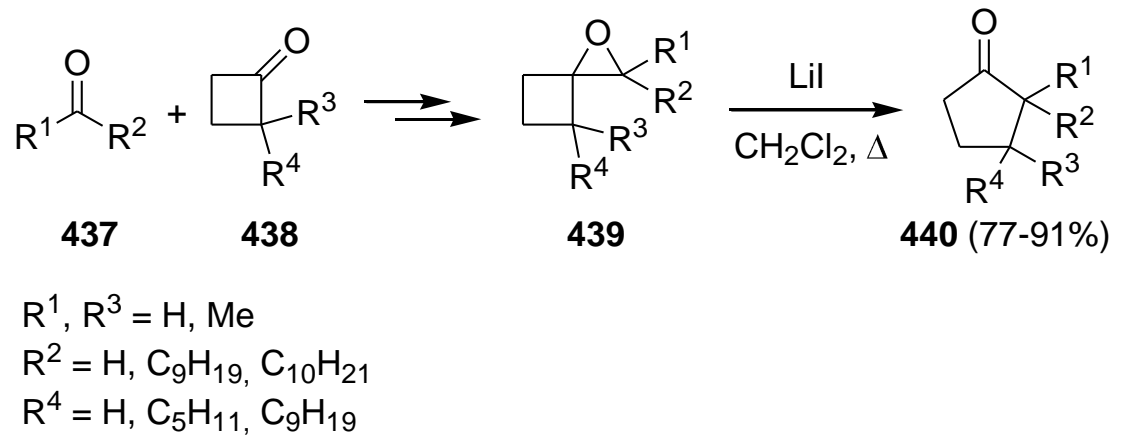

Scheme 120

As mentioned before, Krief and co-workers have also used a spiro epoxide in the synthesis of $\beta$-cuparenone 379 (Scheme 106). ${ }^{148}$ Treatment of the spiro epoxide 376 with lithium iodide in dioxane in the presence of one equiv of 12-crown-4, afforded $\beta$-cuparenone $\mathbf{3 7 9}$ and a small fraction of its regioisomer $\mathbf{3 7 8}$ in a selectivity of 94:6 in 95\% yield. It should be noted that the opposite selectivity was obtained upon treatment of epoxide 376 with $\mathrm{BeCl}_{2}$, as depicted in Scheme 106.

The regioselective synthesis of two bicyclo[3.3.0]octane systems $\mathbf{4 4 3}$ and $\mathbf{4 4 5}$ (carbaprostacyclin precursors) via spirooxiranes $\mathbf{4 4 2}$ and $\mathbf{4 4 4}$, respectively, further 
demonstrated the feasibility of the spiroannelation methodology (Scheme 121). ${ }^{166} \alpha$-Epoxide 442 was synthesized in $90 \%$ yield via the Corey-Chaykovsky method, and subsequent rearrangement of $\mathbf{4 4 2}$ afforded ketone $\mathbf{4 4 3}$ in $68 \%$ yield and its isomer $\mathbf{4 4 5}$ in $10 \%$ yield, after chromatography. The corresponding $\beta$-epoxide 444 was subsequently prepared in $70 \%$ overall yield, from the bicycloheptanone $\mathbf{4 4 1}$ after initial conversion into the analogous methylene derivative using the method of Lombardo, followed by epoxidation. ${ }^{167}$ In direct contrast to the cleavage of the $\alpha$-epoxide 442 , the $\beta$-epoxide 444 underwent a slow, regioselective rearrangement to yield ketone $\mathbf{4 4 5}$ in $71 \%$ accompanied by less than $10 \%$ of ketone $\mathbf{4 4 4}$. The obtained bicyclo[3.3.0]octane framework is a structural unit shared by a variety of sesquiterpenes and many carbocyclic analogues of prostacyclin $\left(\mathrm{PGI}_{2}\right)$.

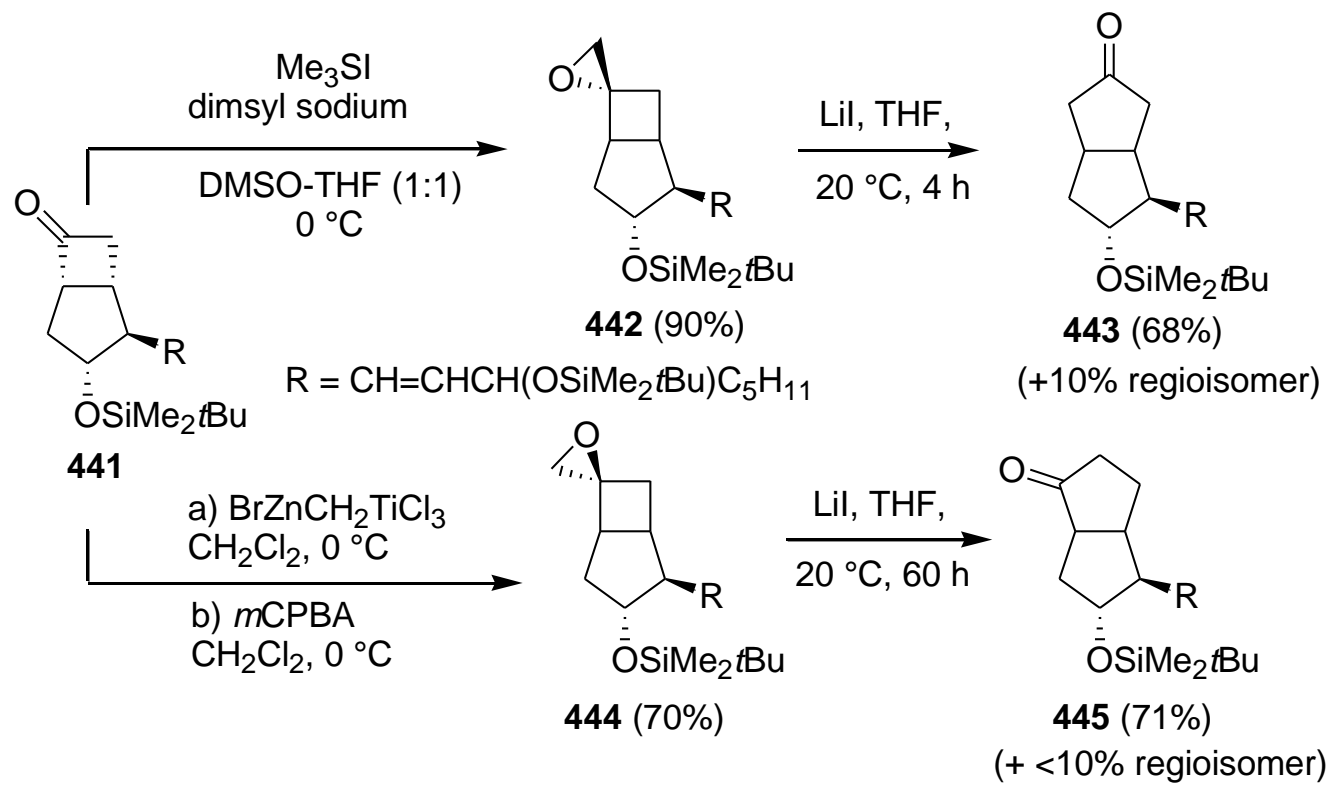

Scheme 121

As part of the synthesis of 13-thiacarbacyclines, used as medicines, lithium iodide was used in the formation of the bicyclo[3.3.0] octanone skeleton (Scheme 122). ${ }^{168}$ When five mol\% of lithium iodide was added to spirooxirane 446 in tetrahydrofuran at room temperature, bicyclo[3.3.0]octanone $\mathbf{4 4 7}$ was isolated. No yield was mentioned for the ring expansion step. 


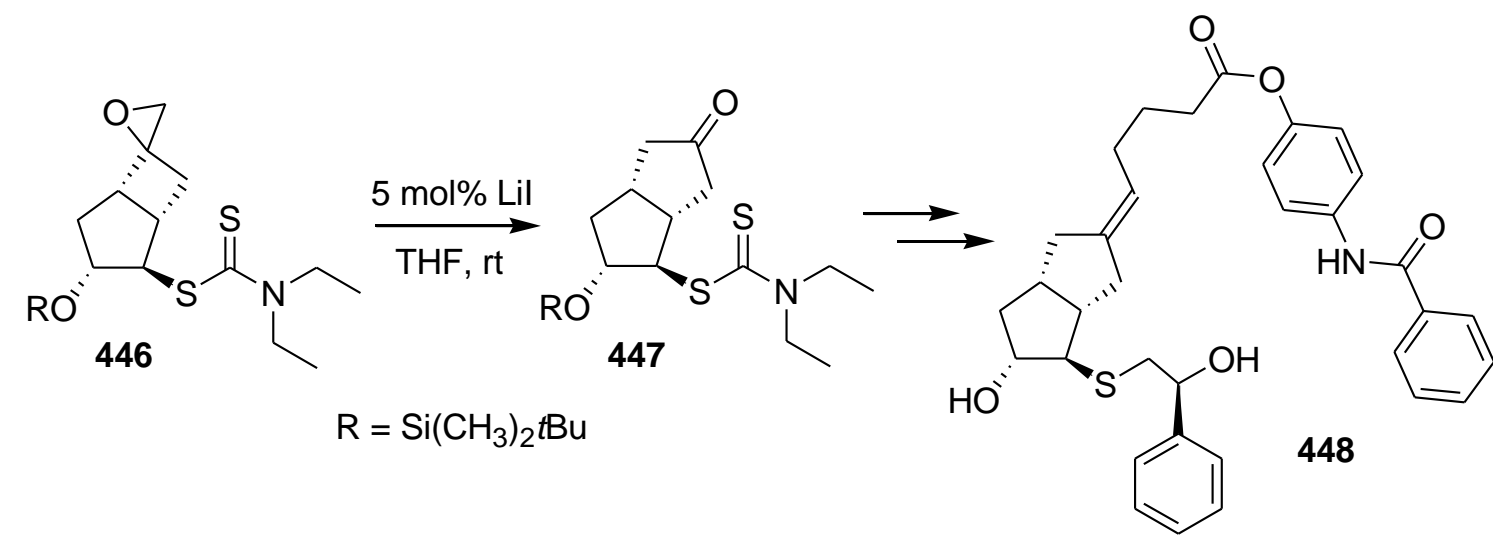

Scheme 122

The ring expansion of oxiranes 449, prepared from 2- $N$-methyl- $N$-tosylcyclobutanones by reaction with dimethylsulfonium methylide, ${ }^{169}$ with a stoichiometric amount of lithium iodide in tetrahydrofuran at reflux temperature for two hours afforded mono- or bicyclic cyclopentenones 450 in $41-96 \%$ yield with $0-92 \%$ ee, resulting from a $\beta$-elimination of $N$ methyl- $N$-tosylamide from a initially formed cyclopentanone. The ring expansion was completely selective with the exception of the bicyclo[4.2.0] octanone systems $\left(\mathrm{R}^{1}-\mathrm{R}^{2}=\right.$ $\left.\mathrm{CH}_{2}(\mathrm{CH})_{2} \mathrm{CH}_{2},\left(\mathrm{CH}_{2}\right)_{4}\right)$, which afforded a side product 451 in $14-41 \%$ yield. The ring expansion of chiral trans-bicyclo[5.2.0]nonane $449\left(\mathrm{R}^{1}-\mathrm{R}^{2}=-\left(\mathrm{CH}_{2}\right)_{5^{-}}\right)$or transbicyclo[6.2.0]decane $449\left(\mathrm{R}^{1}-\mathrm{R}^{2}=\left(\mathrm{CH}_{2}\right)_{6}\right)$ afforded a mixture of cis- and transcyclopentenones $450(85: 15 d r, 98 \%$ ee and 15:85 $d r, 92 \%$ ee, respectively) in 87 to $90 \%$ yield (Scheme 123). 

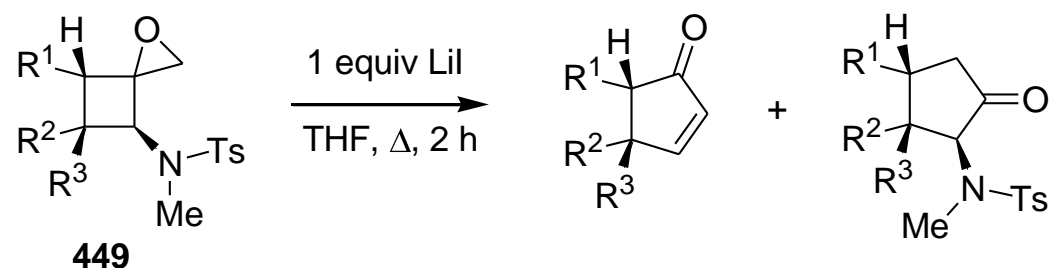

exo:endo 1:1-9:1

$450(41-96 \%)$

$451(14-41 \%)$

ee $(0-92 \%)$

$\mathrm{R}^{1}=\mathrm{H} ; \mathrm{R}^{2}=\mathrm{Ph}, n \mathrm{Bu} ; \mathrm{R}^{3}=\mathrm{H}, \mathrm{Me}$

$\mathrm{R}^{1}-\mathrm{R}^{2}=\mathrm{CH}_{2}(\mathrm{CH})_{2} \mathrm{CH}_{2}$,

$\mathrm{R}^{1}-\mathrm{R}^{2}=\left(\mathrm{CH}_{2}\right)_{3},\left(\mathrm{CH}_{2}\right)_{4}, \mathrm{CH}_{2}(\mathrm{CH})_{2} \mathrm{CH}_{2}$

$\left(\mathrm{CH}_{2}\right)_{4} ; \mathrm{R}^{3}=\mathrm{H}$
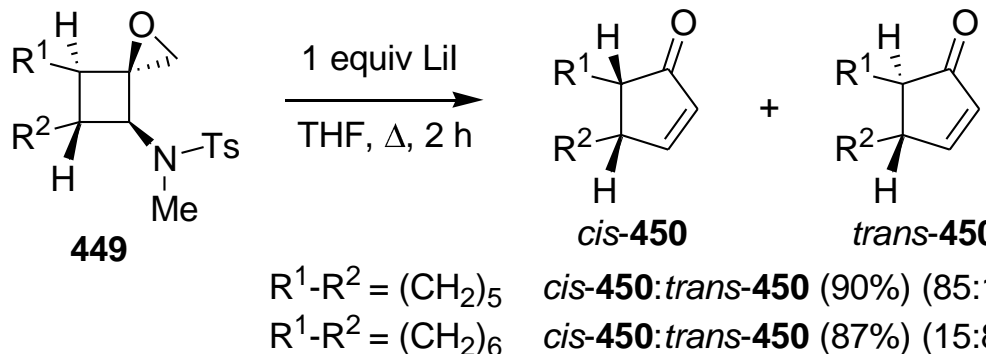

cis-450:trans-450 (90\%) (85:15) ee $98 \%$

cis-450:trans-450 (87\%) (15:85) ee $92 \%$

\section{Scheme 123}

A Lewis acid-promoted one-pot ring expansion of trisubstituted cyclobutanones has been executed starting from 3-substituted 2-methoxy-2-methylcyclobutanones 452 (Scheme 124). ${ }^{170}$ An ylide, generated from trimethyloxo- $\lambda^{4}$-sulfanium iodide $\left(\mathrm{Me}_{3} \mathrm{~S}(\mathrm{O}) \mathrm{I}\right)$ and sodium hydride, served as the $\mathrm{C}_{1}$-equivalent. Addition of cyclobutanones 452 to a solution of $\mathrm{Me}_{3} \mathrm{~S}(\mathrm{O}) \mathrm{I}$ and sodium hydride in dimethylformamide (DMF), followed by addition of three equiv of $\mathrm{Et}_{3} \mathrm{Al}$ at $25{ }^{\circ} \mathrm{C}$ for nine hours, afforded the corresponding cyclopentanones 453 in 0 $18 \%$ yield and cyclopentenones $\mathbf{4 5 4}$ in $29-55 \%$ yield. Replacing $\mathrm{Et}_{3} \mathrm{Al}$ with 0.25 equiv of scandium(III) triflate at $50{ }^{\circ} \mathrm{C}$ for five hours improved the reaction, providing higher yields (54-79\%) for cyclopentanones $\mathbf{4 5 3}$, and little or no alkoxide elimination (0-9\% cyclopentenones $\mathbf{4 5 4 )}$. 


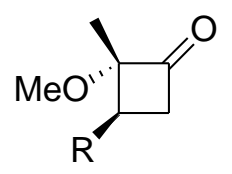

452

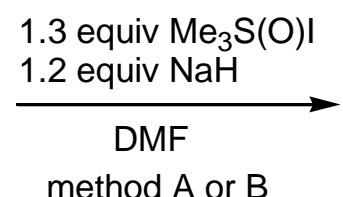

method $A$ or $B$
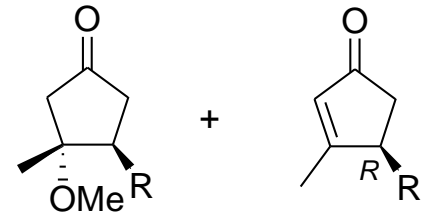
method $\mathrm{A}: 3$ equiv $\mathrm{Et}_{3} \mathrm{Al}, 25^{\circ} \mathrm{C}, 9 \mathrm{~h}$
A: $453(0-18 \%) \quad 454(29-55 \%)$ method B: 0.25 equiv $\mathrm{Sc}(\mathrm{OTf})_{3}$,
B: $453(54-79 \%) 454(0-9 \%)$ $50{ }^{\circ} \mathrm{C}, 5 \mathrm{~h}$<smiles>COCCCN1C(=O)OC(c2ccccc2)C1c1ccccc1</smiles>

Scheme 124

Another example concerning cyclopentanone synthesis through elaboration of spirooxiranes was recently reported. ${ }^{171}$ Chiral diol $(1 R, 3 R)-s y n-455$ was transformed into oxaspirohexane 456 which, by reaction with lithium iodide, gave cyclopentanone 457 in $87 \%$ yield (Scheme 125). This reaction was also the first to report the transformation of a chiral oxaspirohexane to obtain 457 diastereoisomerically pure with no loss of stereochemical integrity through inversion of configuration at the migrating terminus.

Analogous rearrangements have also been executed with lithium iodide in dichloromethane or with $\mathrm{Et}_{2} \mathrm{AlCl}$ in toluene to afford 2-alkyl-2-arylcyclopentanones in 65-99\% yield and in an enantiomeric excess of $70-90 \% .^{172}$

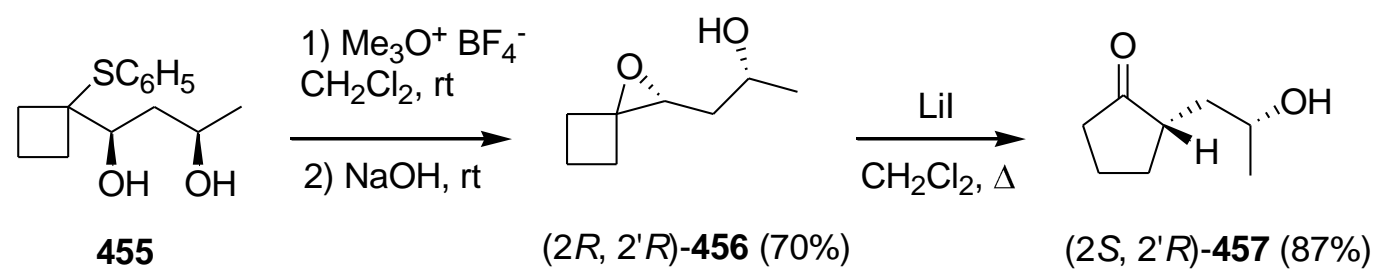

Scheme 125 
A last example involves in the synthesis of pseudohelical hydrocarbons of four- and fivemembered rings. ${ }^{69}$ A sequential ring enlargement via a high temperature methylenation, an epoxidation, and a lithium iodide-induced rearrangement proved necessary to synthesize complex cyclopentanone 460 (Scheme 126). The ring expansion of spirooxirane 459 to cyclopentanone $\mathbf{4 6 0}$ proceeded in $88 \%$ yield by reaction with one equiv of lithium iodide in tetrahydrofuran at 60 to $70{ }^{\circ} \mathrm{C}$ for six hours. All attempts of a direct ring enlargement of $\mathbf{4 5 8}$ with diazomethane failed. The diazomethane type ring expansion will be discussed further in this review.

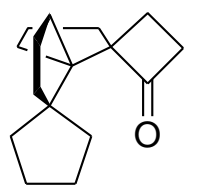

458
1) $\underset{\mathrm{Ph}}{\stackrel{\mathrm{PCPBA}}{ } \mathrm{P}=\mathrm{CH}_{2}}$

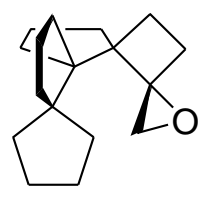

459

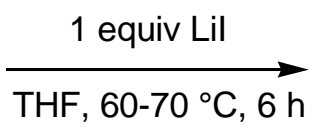

THF, $60-70{ }^{\circ} \mathrm{C}, 6 \mathrm{~h}$

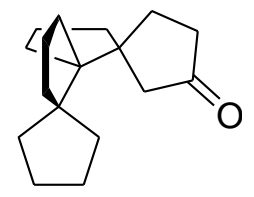

$460(88 \%)$

Scheme 126

\subsubsection{Other methods}

Whereas the majority of literature examples comprise rearrangements of oxaspiro[2.3] hexanes, a few other approaches via transformation of cyclobutylmethyl iodides are known.

In a first example, lithio(iodomethyl)phenylsulfoxide, generated by the reaction of (iodomethyl)phenylsulfoxide with LDA in tetrahydrofuran at $-78{ }^{\circ} \mathrm{C}$, reacted with cyclobutanone $\mathbf{8 0}$ to form adduct $\mathbf{4 6 1}$ in $88 \%$ yield (Scheme 127). ${ }^{173}$ Reaction of the adduct 461 with silver nitrate in $95 \%$ ethanol at $85{ }^{\circ} \mathrm{C}$ for three hours gave compound 381 in $13 \%$ yield, involving the intermediacy of phenylsulfinyl ion 462. Because of the low yield, 
compound 461 was treated with $\mathrm{TiCl}_{4} / \mathrm{Zn}$ in an ether/dichloromethane mixture to synthesize $\alpha$-phenylsulfenylcyclopentanone $\mathbf{4 6 4}$ in $62 \%$ yield, presumably via the intermediate thionium ion 463.

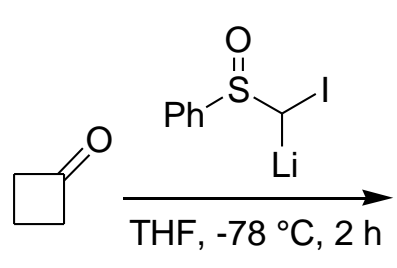

80

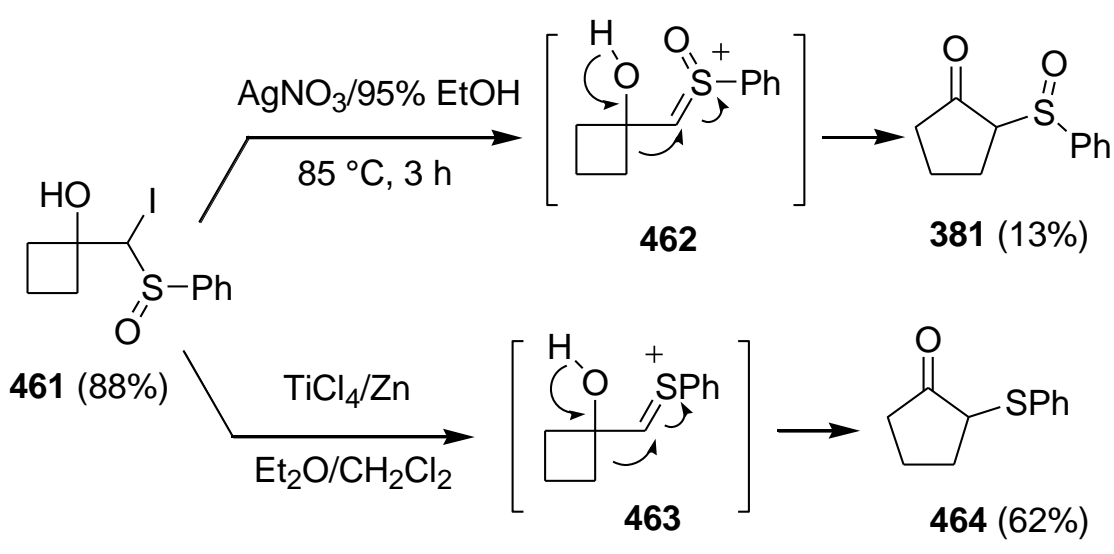

Scheme 127

Alternatively, iodomethylation has been used in the transformation of cyclobutanones $\mathbf{4 6 5}$ to cyclopentanones 466 and $467 .{ }^{174}$ Samarium diiodide-induced iodomethylation of cyclobutanones with diiodomethane provided a simple way for the synthesis of iodohydrins, which underwent ring expansion when exposed to a base. When 3-monosubstituted and 3,3disubstituted cyclobutanones 465 were treated with one equiv of $\mathrm{CH}_{2} \mathrm{I}_{2}$ and 2.1 equiv of $\mathrm{SmI}_{2}$ in tetrahydrofuran at room temperature for $15 \mathrm{~h}$, the corresponding cyclopentanones 466 and $\mathbf{4 6 7}$ were synthesized in 40-88\% yield (Scheme 128). Only with bicyclic cyclobutanones, two regioisomers of cyclopentanone derivatives were produced as a 1:1 mixture $\left(\mathrm{R}^{1}-\mathrm{R}^{2}=\left(\mathrm{CH}_{2}\right)_{4}\right.$ or $\left.\mathrm{CH}_{2} \mathrm{CH}=\mathrm{CHCH}_{2}\right)$ or in a isomer ratio of $97: 3\left(\mathrm{R}^{1}-\mathrm{R}^{2}=\left(\mathrm{CH}_{2}\right)_{5}\right)$. 


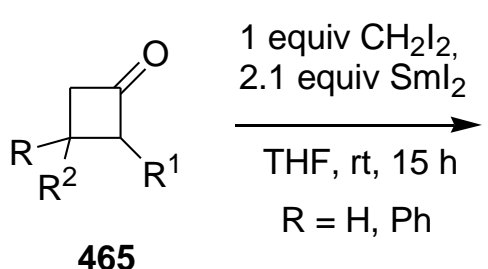

465

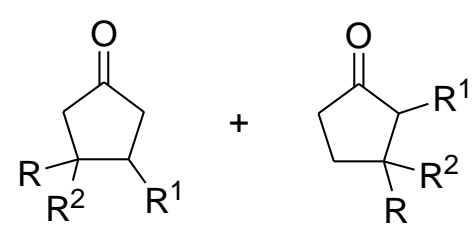

466:467 (40-88\%)

$$
\begin{array}{ll}
\mathrm{R}^{1}=\mathrm{H} ; \mathrm{R}^{2}=\mathrm{Ph}, n \mathrm{Bu}, \text { tert-Bu, Me } & \mathbf{4 6 6 : 4 6 7}(1: 0) \\
\mathrm{R}^{1}-\mathrm{R}^{2}=\left(\mathrm{CH}_{2}\right)_{4}, \mathrm{CH}_{2} \mathrm{CH}=\mathrm{CHCH}_{2} & \mathbf{4 6 6 : 4 6 7}(1: 1) \\
\mathrm{R}^{1}-\mathrm{R}^{2}=\left(\mathrm{CH}_{2}\right)_{5} & \mathbf{4 6 6 : 4 6 7}(97: 3)
\end{array}
$$

Scheme 128

\section{$6.2 \quad N_{2}$ as leaving group}

Numerous examples of cyclobutane to cyclopentane rearrangements are known based on the formation and ring expansion of intermediate cyclobutylmethylcarbenium ions through expulsion of nitrogen gas as a leaving group. Besides a few isolated examples as azide addition across methylenecyclobutanes, the vast majority of papers deal with semipinacoltype rearrangements via diazoalkanes.

\subsubsection{Via azide addition across methylenecyclobutanes}

Methylenecyclobutane $\mathbf{4 6 8}$ has been reported to react with aromatic sulfonyl azides under high pressure at $60{ }^{\circ} \mathrm{C}$ for four days to give the corresponding ring enlarged $N$-sulfonylimines 471 in almost quantitative yield (Scheme 129). ${ }^{175}$ This 1,3-dipolar addition of azides to electron-rich olefins was facilitated by strong electron-withdrawing substituents attached to the azide moiety. The resulting triazolines turned out to be relatively unstable, resulting in the evolution of nitrogen gas spontaneaously or upon gentle heating. This type of ring enlargement is closely related to the Demjanov-Tiffeneau reaction. In a last step, the $\mathrm{N}$ - 
sulfonylimines 471 were hydrolysed to cyclopentanone 428 with aqueous hydrogen chloride in more than $80 \%$ yield.

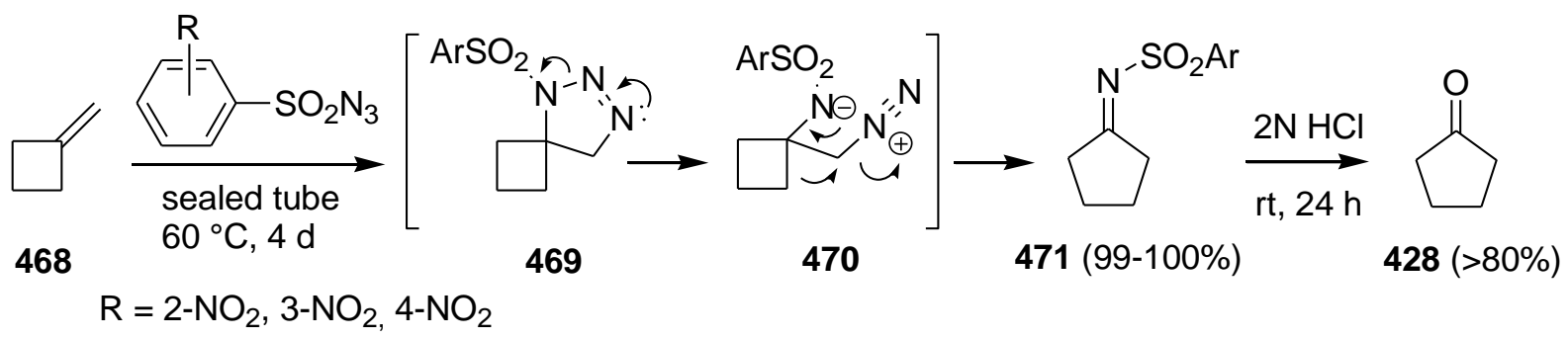

Scheme 129

The same methodology has been used by Fitjer for the synthesis of tetraspiro[2.0.2.0.2.1]tridecan-13-one $\mathbf{4 7 5}$ (Scheme 130). ${ }^{176}$ Treatment of 13cyclopropylidenetetraspiro[2.0.2.0.2.0.2.1]tridecane $\quad \mathbf{4 7 2} \quad$ with $\quad 1.05 \quad$ equiv 4nitrobenzenesulfonyl azide in acetonitrile at reflux for 13 hours afforded tetraspiro[2.0.2.0.2.1]tridecan-13-one $\mathbf{4 7 4}$ in $81 \%$ yield. The corresponding ketone $\mathbf{4 7 5}$ was synthesized in $99 \%$ yield by reaction of $\mathbf{4 7 4}$ with a $5 \%$ potassium hydroxide solution in methanol at reflux temperature for one hour. The same ring enlargement sequence was applied in the synthesis of [3.3.0]propellanes. ${ }^{134 a, b}$

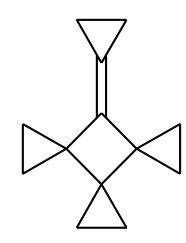

472

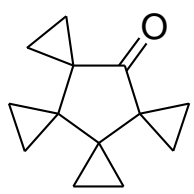

$475(99 \%)$
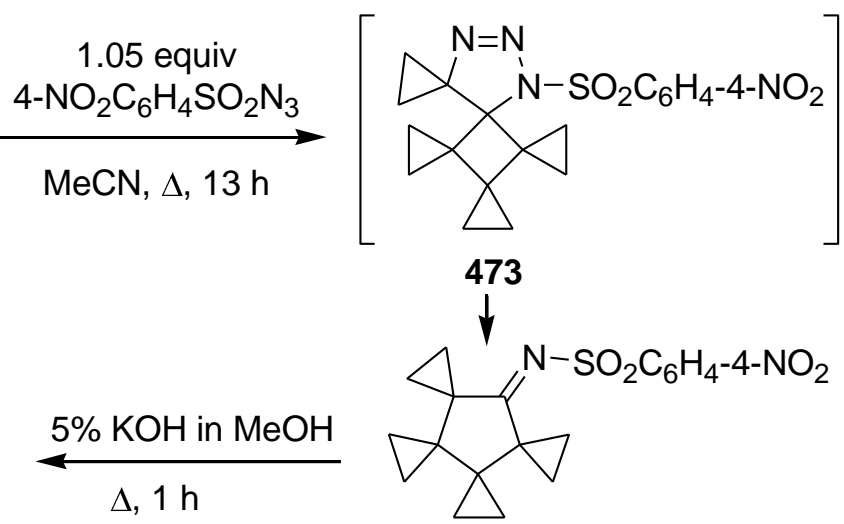

$474(81 \%)$

Scheme 130 


\subsubsection{Semipinacol rearrangement}

\subsubsection{Semipinacol rearrangement of diazonium salts derived from 2- aminoalcohols (Tiffeneau-Demjanov rearrangement)}

Cycloalkylmethylamines $\mathbf{4 7 6}$ can undergo ring expansion upon diazotation, affording cyclic alcohols 478. This kind of reaction, the conversion of an amino to a diazonium group and subsequent ring expansion, is also known as the Demjanov rearrangement (Scheme 131). ${ }^{177,178}$

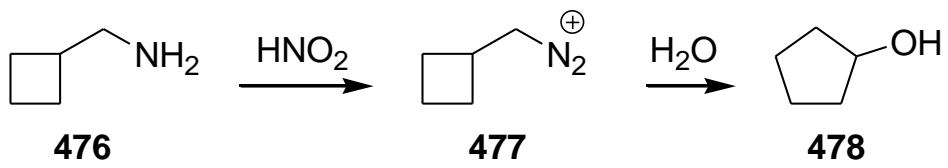

Scheme 131

A semipinacol rearrangement of 6-(aminomethyl)bicyclo[3.2.0]-2-hepten-6-ol 479 has been executed using nitrous acid to afford a mixture of bicyclo[3.3.0]octenones $\mathbf{4 8 1}$ and $\mathbf{4 8 2}$ $(85: 15)$ in $55 \%$ yield (Scheme 132). ${ }^{179}$ This type of reaction, the conversion of an amino to a diazonium group and subsequent carbonyl formation and ring expansion of intermediate $\mathbf{4 8 0}$, is also known as the Tiffeneau-Demjanov rearrangement.

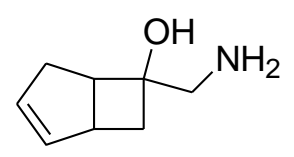

479

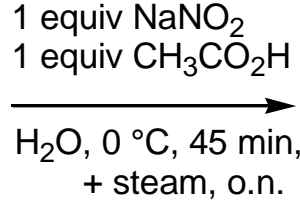

+ steam, o.n.

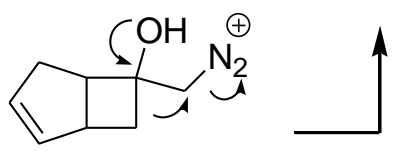

480

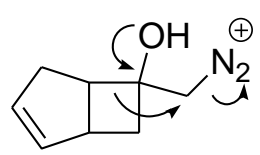

480

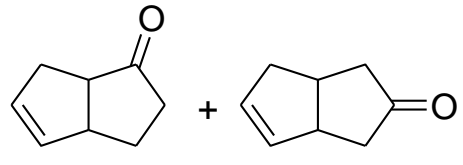

$481: 482(55 \%)(85: 15)$

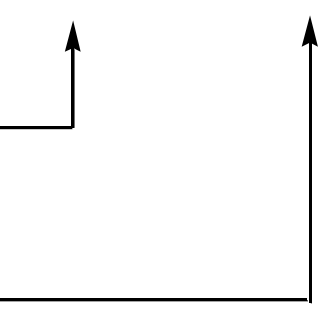




\subsubsection{Semipinacol rearrangement of diazoalkanes}

Among the variety of carbocyclic ring expansions of cyclobutanones to cyclopentanones, the diazomethane methodology is the most extensively used (Scheme 133 ). ${ }^{20,180}$ With a few exceptions, the rearrangement of the intermediate zwitter ion $\mathbf{4 8 3}$ is highly regioselective and only one product is generally isolated, particularly in cases were $\alpha$-chloro- or $\alpha, \alpha$ dichlorocyclobutanones and substituted diazomethanes are used. With unsymmetrical cyclobutanones, diazomethane ring expansions tend to favor migration of the less substituted $\alpha$-carbon and disfavor migration of $\alpha$-positions bearing electronegative halogens. However, other factors including steric effects, ring strain, steric hindrance related to the approach of the diazomethane, and the conformation of the intermediate betaine can influence the regioselectivity of migration, making predictions difficult. Several examples will be described in this section.

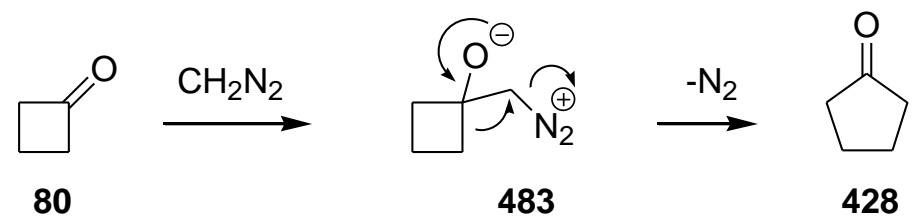

Scheme 133

\subsection{Non-halogenated cyclobutanone derivatives}

In a first example, hydrindanonecarboxylates $\mathbf{4 8 5}$ have been synthesized using the diazoalkane ring expansion method in a highly selective manner (Scheme 134). ${ }^{181}$ Bicyclo[4.2.0]octanones $\mathbf{4 8 4}$ reacted with 1.5 equiv of boron(III) fluoride etherate and ethyl 
diazoacetate in diethyl ether at room temperature for three hours to afford bicylo[4.3.0]nonanones $\mathbf{4 8 5}$ in 70 to $100 \%$ yield.

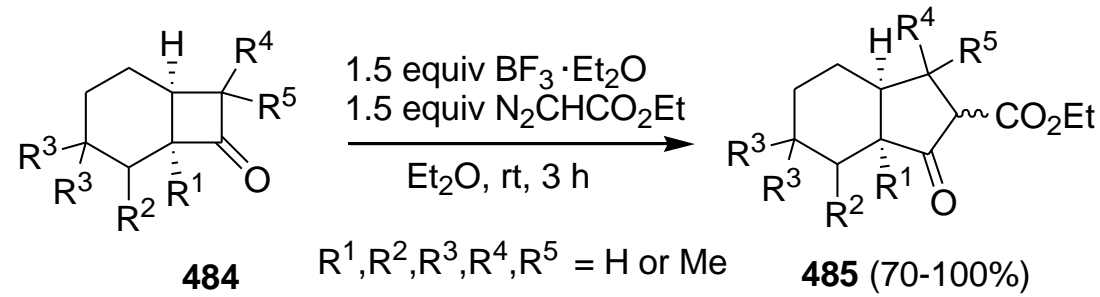

Scheme 134

In research on bicyclooctanes, ring expansion of bicyclo[3.2.0]hept-2-en-6-one 486 using one equiv of diazomethane in the presence of 0.5 equiv of lithium perchlorate in diethyl ether at $-78{ }^{\circ} \mathrm{C}$ for ten minutes and subsequently at room temperature for one hour provided a mixture of two regioisomers $\mathbf{4 8 1}$ and $\mathbf{4 8 2}$ in a $4: 1$ ratio (Scheme 135). ${ }^{182}$ The desired bicyclo[3.3.0]oct-2-en-6-one $\mathbf{4 8 1}$ was isolated from the mixture in $44 \%$ yield. In the absence of a Lewis acid, the observed ratio was approximately $3: 2$.

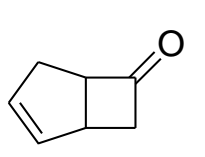

486

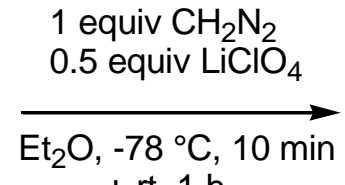

$+\mathrm{rt}, 1 \mathrm{~h}$

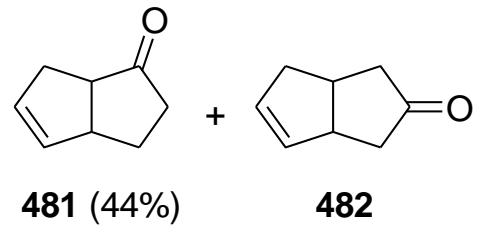

$481: 482(4: 1)$

Scheme 135

Ring expansion of 11-norprostaglandin 487 (11-nor $\mathrm{PGE}_{2}$ ) toward methyl 15 $\alpha$-hydroxy-10oxoprosta-5,13-dienoate 488 and 11-desoxy $\mathrm{PGE}_{2} 489$ was achieved by treatment with diazomethane in a 5:1 diethyl ether/methanol solution at room temperature (Scheme 136). ${ }^{183,184}$ After chromatographic separation, methyl 15 $\alpha$-hydroxy-10-oxoprosta-5,13- 
dienoate $\mathbf{4 8 8}$ was isolated in $50 \%$ yield, together with 11-desoxy $\mathrm{PGE}_{2} \mathbf{4 8 9}$ in $25 \%$ yield. However, this experiment clearly demonstrated that in the case of alkyl substituted cyclobutanones the ring enlargement with diazomethane occurred in good chemical yield but with poor regioselectivity.<smiles>CC(=O)CCC/C=C/C[C@H]1C(=O)C[C@H]1/C=C/[C@H](O)c1ccccc1</smiles><smiles>COC(=O)c1ccccc1</smiles><smiles>CC(=O)CCC/C=C/[C@H]1C(=O)CCC1/C=C/[C@H](O)c1ccccc1</smiles>

$489(25 \%)$

Scheme 136

In another approach, an effort has been made to synthesize prostanoids containing an ether linkage in the lower side-chain as potent anti-ulcer compounds. ${ }^{185}$ Again, the cyclopentanone ring was synthesized via a ring expansion of a suitable cyclobutane precursor. When cyclobutanone 490 was treated with diazomethane in ether and methanol at $0-5{ }^{\circ} \mathrm{C}$, a mixture of regioisomers 491 and 492 was obtained in low yield (19\% 491 and 19\% 492), next to 30\% unreacted starting material 490 (Scheme 137). However, when trimethylsilyldiazomethane was used in the presence of $\mathrm{BF}_{3} \cdot \mathrm{Et}_{2} \mathrm{O}$ in dichloromethane at $-78{ }^{\circ} \mathrm{C}$, the reaction was regioselective, and only isomer 491 was isolated in 52\% yield. 


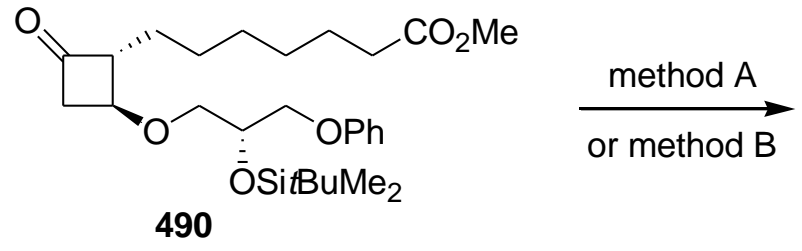

A) $\mathrm{CH}_{2} \mathrm{~N}_{2}, \mathrm{Et}_{2} \mathrm{O}, \mathrm{MeOH}, 0-5^{\circ} \mathrm{C}$

B) $\mathrm{TMSCHN}_{2}, \mathrm{BF}_{3} \cdot \mathrm{Et}_{2} \mathrm{O}, \mathrm{CH}_{2} \mathrm{Cl}_{2},-78{ }^{\circ} \mathrm{C}$

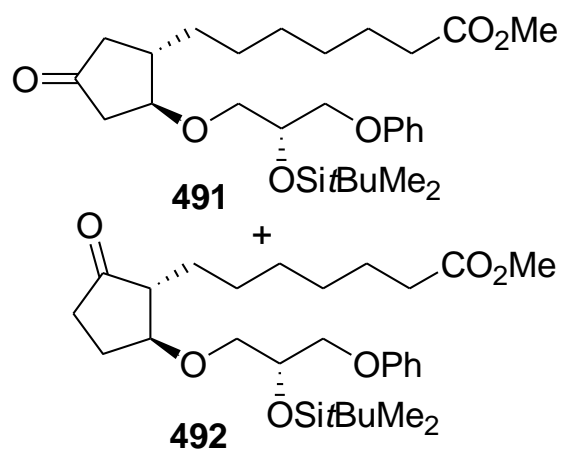

method A: $491: 492: 490(19 \%, 19 \%, 30 \%)$ method B: 491 (52\%)

Scheme 137

Plentiful synthetic routes have been developed toward the preparation of natural products and their derivatives employing the cyclobutanone to cyclopentanone ring expansion reactions with diazoalkanes.

In a first example, Greene et al. reported the total synthesis of natural hirsutic acid C 496 (Scheme 138) through adjustment of a known racemic synthesis (vide infra). ${ }^{186}$ Cyclobutanone 493 was exposed to 2.1 equiv of ethyl diazoacetate and 0.4 equiv of antimony(V) chloride in dichloromethane at $-78{ }^{\circ} \mathrm{C}$ for two hours to afford a regioselective ring expansion, which was followed by deethoxycarbonylation to provide a 98:2 mixture of ketones 494 and 495, from which pure 494 was isolated by silica gel chromatography.

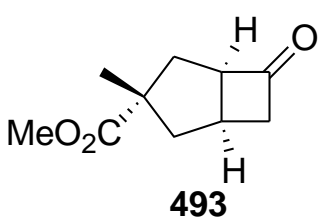

493
1) 2.1 equiv $\mathrm{N}_{2} \mathrm{CHCO}_{2} \mathrm{Et}$ 0.4 equiv $\mathrm{SbCl}_{5}$ $\mathrm{CH}_{2} \mathrm{Cl}_{2},-78^{\circ} \mathrm{C}, 2 \mathrm{~h}$

2) $\mathrm{MeO}\left(\mathrm{CH}_{2}\right)_{2} \mathrm{OMe}, \mathrm{H}_{2} \mathrm{O}$ $\Delta, 48 \mathrm{~h}$

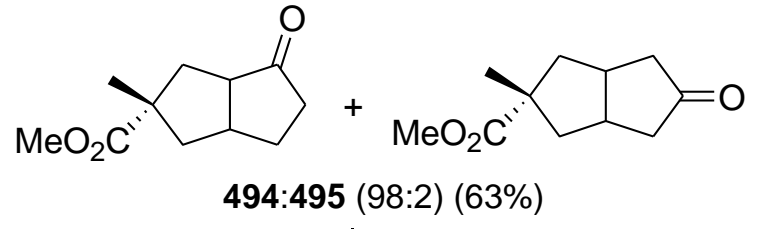

hirsutic acid C 496 
Capnellene 500, the presumed biosynthetic precursor of the capnellane family of nonisoprenoid sesquiterpenes, has received significant synthetic attention due to the cis-anticis tricyclo $\left(6 \cdot 3 \cdot 0.0^{2,6}\right)$ undecane skeletal framework. These compounds also display biological effects similar to those of their terrestrial counterparts, hirsutanes, which possess promising antibacterial and antitumor properties. ${ }^{187}$ In a total synthesis of racemic capnellene $\mathbf{5 0 0}$, the second five-membered ring was formed via a ring rearrangement of 2benzyloxybicyclo[3.2.0]heptane-6-one $497 .^{188}$ To induce the required ring expansion, compound 497 was treated with ethyl diazoacetate in diethyl ether in the presence of boron(III) fluoride etherate at $0{ }^{\circ} \mathrm{C}$ and stirred overnight (Scheme 139). The desired ketoester 498 was formed preferentially along with a small amount of its regioisomer 499 as an inseparable mixture in a total yield of $80 \%$. The exact ratio of the two isomers was not reported in the article.

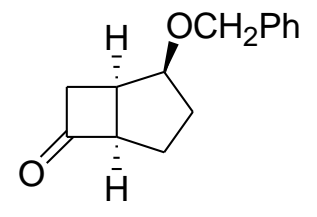

497

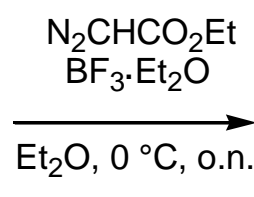

$\mathrm{Et}_{2} \mathrm{O}, 0^{\circ} \mathrm{C}, \mathrm{o.n}$ 
the precursor of capnellene. ${ }^{189}$ The ring expansion was executed via addition of boron(III) fluoride etherate and ethyl diazoacetate to cyclobutanone 501 in diethyl ether at $-28{ }^{\circ} \mathrm{C}$, followed by addition of sodium chloride and dimethylsulfoxide in water at $150{ }^{\circ} \mathrm{C}$ (Scheme 140). However, only a 83:17 ratio of $\mathbf{5 0 2}$ to its regioisomer $\mathbf{5 0 3}$ was obtained. Column chromatography afforded cyclopentanone $\mathbf{5 0 2}$ in $\mathbf{7 3 \%}$ yield, which could be converted into $( \pm)-\Delta^{(9,12)}$-capnellene $\mathbf{5 0 0}$ in one step. A total and selective synthesis of $(-)-\Delta^{(9,12)}$-capnellene $\mathbf{5 0 0}$ and its antipode, based on a ring expansion for the synthesis of the second five-membered ring using ethyl diazoacetate in the presence of antimony(V) chloride, has been reported in 1991. ${ }^{190}$ 2,2,5-Trimethylbicyclo[3.2.0]heptan-6-one rearranged via treatment with ethyl diazoacetate in the presence of antimony(IV) chloride to yield the corresponding 2,2,5trimethylbicyclo[3.3.0]octan-6-one in $85 \%$ yield.

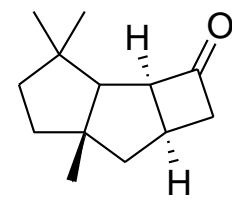

501
1) $\mathrm{BF}_{3} \cdot \mathrm{Et}_{2} \mathrm{O}, \mathrm{N}_{2} \mathrm{CHCO}_{2} \mathrm{Et}$ $\mathrm{Et}_{2} \mathrm{O},-78^{\circ} \mathrm{C}$

2) $\mathrm{NaCl}, \mathrm{Me}_{2} \mathrm{SO}$ $\mathrm{H}_{2} \mathrm{O}, 150^{\circ} \mathrm{C}$

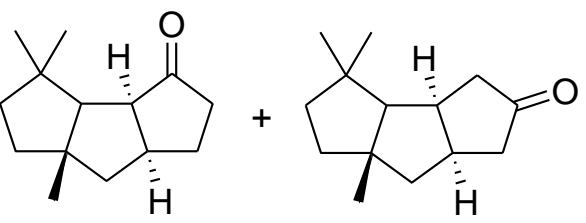

503

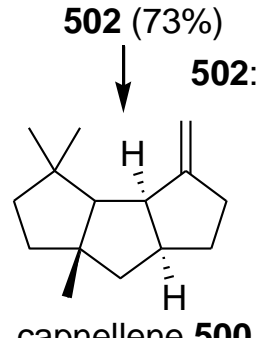

capnellene 500

Scheme 140

A total synthesis of the marine sesquiterpenes $( \pm)$-aplysin $150\left(R^{1}=B r, R^{2}=H\right),( \pm)$ debromoaplysin $151\left(\mathrm{R}^{1}=\mathrm{R}^{2}=\mathrm{H}\right),( \pm)$-aplysinol $506\left(\mathrm{R}^{1}=\mathrm{Br}, \mathrm{R}^{2}=\mathrm{OH}\right),( \pm)$ debromoaplysinol $507\left(\mathrm{R}^{1}=\mathrm{H}, \mathrm{R}^{2}=\mathrm{OH}\right)$, and ( \pm )-isoaplysin $508\left(\mathrm{R}^{1}=\mathrm{H}, \mathrm{R}^{2}=\mathrm{Br}\right)$, has been reported using ethyl diazoacetate for the ring rearrangement. ${ }^{191}$ A first synthesis of aplysin was already described previously (Scheme 44), involving a palladium-promoted ring 
expansion of alkenylcyclobutanols. ${ }^{72}$ Treatment of compounds $\mathbf{5 0 4}$ with 1.5 equiv of ethyl diazoacetate in the presence of 1.5 equiv of boron(III) fluoride etherate in diethyl ether at -10 ${ }^{\circ} \mathrm{C}$ for 30 minutes and subsequently at room temperature for three hours furnished the $\beta$ ketoesters $\mathbf{5 0 5}$ regioselectively in $81-82 \%$ yield, which could be converted into the appropriate sesquiterpene 150, 151 and 506-508 (Scheme 141).

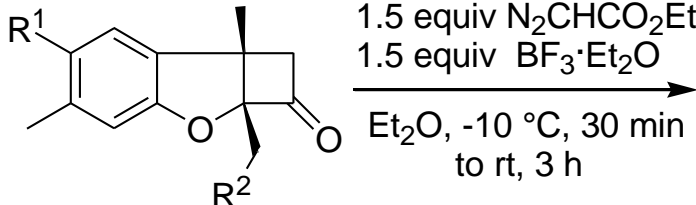

504

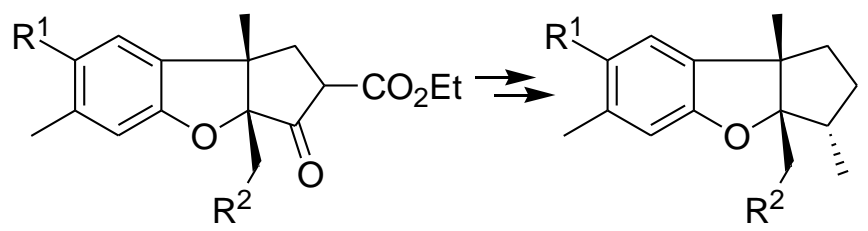

$505(81-82 \%)$

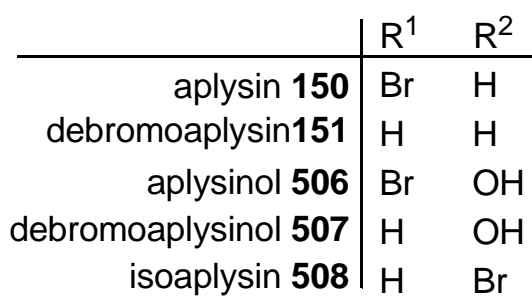

Scheme 141

In research on taxoids, a semipinacol rearrangement using nitrogen gas as a leaving group has been used for the synthesis of a 6-pinanone derivative. ${ }^{192}$ Addition of $5 \mathrm{~mol} \%$ of trifluoroacetic acid to diazolactone $\mathbf{5 0 9}$ in dichloromethane at room temperature, and treatment of the reaction mixture with 1.5 equiv of tert-butyldimethylsilyl chloride in the presence of three equiv of imidazole in dimethylformamide at room temperature afforded lactone $\mathbf{5 1 1}$ in $91 \%$ yield through rearrangement of intermediate $\mathbf{5 1 0}$ (Scheme 142). 


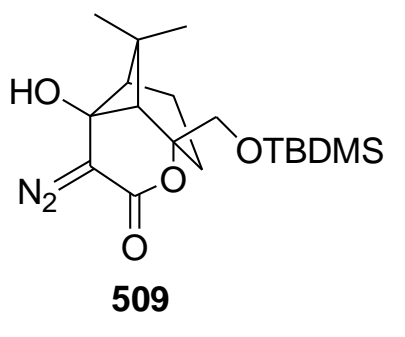

a) $5 \mathrm{~mol} \% \mathrm{CF}_{3} \mathrm{CO}_{2} \mathrm{H}$ $\mathrm{CH}_{2} \mathrm{Cl}_{2}$, rt, $3 \mathrm{~h}$

b) 1.5 equiv $\mathrm{tBu}(\mathrm{Me})_{2} \mathrm{SiCl}$ 3 equiv imidazole DMF, rt, $18 \mathrm{~h}$

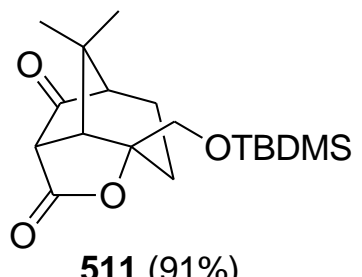

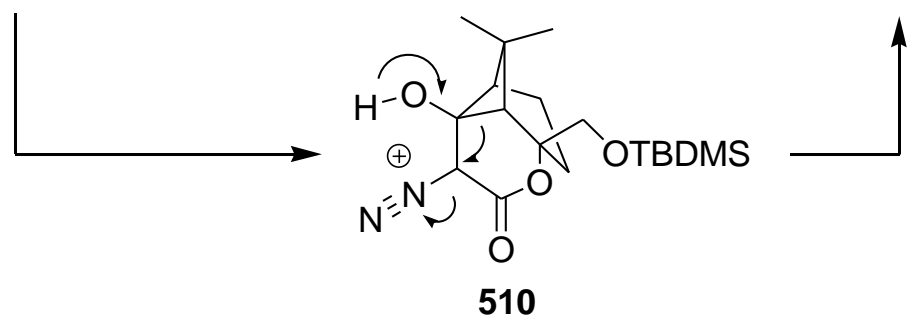

Scheme 142

The ring expansion of $\beta$-substituted $\alpha$-methyl- $\alpha$-methoxycyclobutanones by diazomethane and the influence of the $\beta$-substituent on the regioselectivity has been studied by Reeder and Hegedus (Scheme 143). ${ }^{193} \beta$-Substituted 2-methoxy-2-methylcyclobutanones 512 with the $\alpha$ methyl group in syn-position with regard to the $\beta$-substituent reacted with diazomethane in tetrahydrofuran at $0{ }^{\circ} \mathrm{C}$ to yield cyclopentanones $\mathbf{5 1 3}$ and $\mathbf{5 1 4}$ in 46 to $92 \%$ yield. Migration of the less-substituted $\alpha$-position is favored and electronegative groups suppress migration, and thus ring expansion should strongly favor formation of regioisomer 513. Although this was indeed the case, the observed ratios of $\mathbf{5 1 3}$ to $\mathbf{5 1 4}$ varied from 100:0 to 30:70 depending on the $\beta$-substituent. However, the root cause of this influence was unclear.<smiles>[R]C1CC(=O)[C@]1(C)OC</smiles>
512

$\mathrm{R}=n \mathrm{C}_{4} \mathrm{H}_{9}, \mathrm{TMSCH}_{2},\left(\mathrm{CH}_{2}\right)_{3}$, $\mathrm{C}_{6} \mathrm{H}_{5}, 4-\mathrm{HOC}_{6} \mathrm{H}_{4}, 4-\mathrm{MeOC}_{6} \mathrm{H}_{4}$, and several other examples<smiles>[R]C1CC(=O)C[C@@]1(C)OC</smiles>

$513: 514(46-92 \%)$

(100:0 to $30: 70)$

Scheme 143 
Aminocyclobutanones 515 rearranged to aminocyclopentanones 516 and 517 via a diazomethane ring expansion reaction (Scheme 144). ${ }^{194 a}$ When cyclobutanones 515 were treated with diazomethane, migration of the less substituted carbon predominated toward the formation of cyclopentanones $\mathbf{5 1 6}$ in 69 to $77 \%$ yield, next to the minor isomers $\mathbf{5 1 7}$ in 16 to $19 \%$ yield.

In the field of metal-catalyzed allylic substitution reactions, an analogous ring expansion $\left(\mathrm{R}^{1}\right.$, $\mathrm{R}^{2}=\mathrm{Me}$ ) has been reported in 2002 where the corresponding cyclopentanone was synthesized in $72 \%$ yield. ${ }^{194 c}$

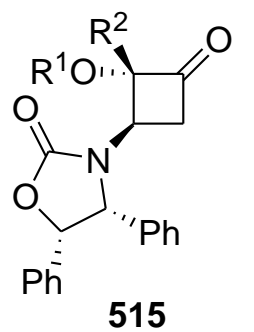

515

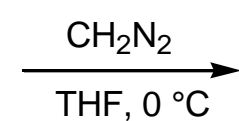

$\mathrm{R}^{1}=\mathrm{Me}, \mathrm{Et}$ $\mathrm{R}^{2}=n-\mathrm{Bu}, \mathrm{CH}_{2} \mathrm{OBn}$<smiles>[R7]C1([R20])C(=O)CC[C@H]1N1C(=O)OC[C@H]1c1ccccc1</smiles>

$\mathrm{Ph} 516(69-72 \%)$<smiles>[R2][C@]1(O)CC(=O)C[C@H]1N1C(=O)O[C@@H](c2ccccc2)[C@H]1c1ccccc1</smiles>

$517(16-19 \%)$

Scheme 144

Structurally challenging pseudohelical hydrocarbons of four-and five-membered rings were synthesized by Widjaja et al. ${ }^{69}$ Enantiopure ketone $\mathbf{5 1 8}$ was subjected to diazomethane to obtain a 55:45 mixture of ring expanded ketones $\mathbf{5 1 9}$ and $\mathbf{5 2 0}$ in $71 \%$ yield, which were reduced via a Wolff-Kishner approach to trispirane $(S)$-521 (Scheme 145). In contrast to cyclobutanone $\mathbf{4 5 8}$ (Scheme 126), which could not be converted directly to the corresponding cyclopentanone using diazomethane, there were no problems detected for this conversion. 


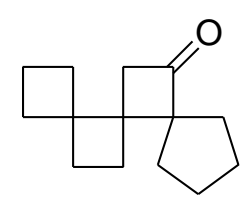

518

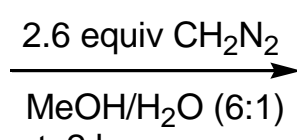

rt, $2 \mathrm{~h}$

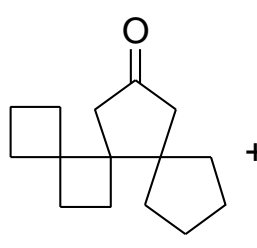

$519: 520(71 \%)(55: 45)$

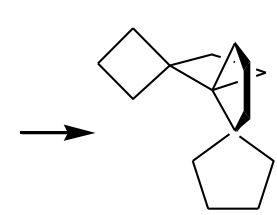

(S)-521 (66\%)

Scheme 145

\subsubsection{2 $\alpha$-Chloro- or $\alpha, \alpha$-dichlorocyclobutanone rearrangements}

Although the above-mentioned ring expansions proceeded quite cleanly to afford the corresponding cyclopentanones, a low degree of regioselectivity in the migration was sometimes observed, especially in cases where unsubstituted diazomethane was used (see for example Scheme 136). However, the presence of $\alpha$-chloro substituent(s) not only accelerates the rate of the reaction, but also favors path a over path $\mathrm{b}$ (Scheme 146). ${ }^{195} \alpha$-Chloro and $\alpha, \alpha$ dichlorocyclobutanones 522 react faster and more regioselectively in the ring enlargement reaction using diazomethane. Epoxide formation is not significant, probably because of the strained nature of the four-membered ring, ${ }^{196}$ in spite of the fact that epoxide formation generally increases with the introduction of electronegative substituents adjacent to the carbonyl. $^{180}$

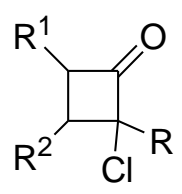

522
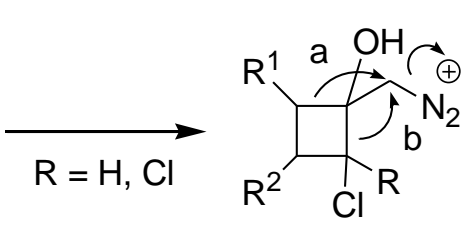

523

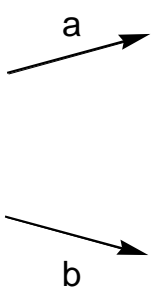<smiles>[R7]C1CC(=O)C([R])(Cl)C1[R2]#[R]</smiles>

525

Scheme 146 
In a first example, the racemic aglycon acetate $\mathbf{5 2 8}$ of loganine, a key compound in alkaloid biosynthesis, was readily prepared by the diazoethane-induced ring enlargement of $\alpha$ chlorocyclobutanone 526. Ring expansion followed by dechlorination afforded bicyclic ketone $\mathbf{5 2 7}$ in $\mathbf{7 2 \%}$ yield as a synthetic precursor for oxaheterocyclic compound $\mathbf{5 2 8}$ (Scheme 147). ${ }^{197}$<smiles>C[SiH2]C1C=C[C@H]2[C@H](Cl)C(=O)[C@@H]12</smiles>

526
1) $\mathrm{MeCHN} / \mathrm{Et}_{2} \mathrm{O} / \mathrm{MeOH}$

2) excess $\mathrm{Zn}, \mathrm{AcOH} / \mathrm{H}_{2} \mathrm{O}$

3) $\mathrm{NaOMe}, \mathrm{MeOH}$<smiles>CC1C(=O)C[C@H]2C=C[C@@H]([AsH3])[C@H]12</smiles>

$527(72 \%)$

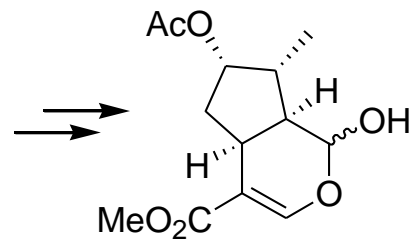

528

\section{Scheme 147}

In order to validate the synthetic applicability of $\alpha, \alpha$-dichlorocyclobutanones for the preparation of cyclopentanones, Greene and Deprés used $\alpha, \alpha$-dichlorocyclobutanones 529, readily available cycloaddition adducts, for the highly regioselective, one-carbon ring expansion reaction with diazomethane to produce the corresponding $\alpha, \alpha$ dichlorocyclopentanones 530. Dechlorination with an excess of $\mathrm{Zn}$ (one "pot") afforded cyclopentanones 531 in 64 to $82 \%$ yield (Scheme 148). ${ }^{195}$ In addition, also the transformation of an $\alpha, \alpha$-dichlorocyclobutanone $\mathbf{5 2 9}$ into an $\alpha$-methylsubstituted cyclopentanone in 74\% yield has been reported utilizing diazoethane, followed by addition of an excess of $\mathrm{Zn} .{ }^{195,198}$<smiles>[R]C1C(=O)C(Cl)(Cl)C1[R]</smiles>

529

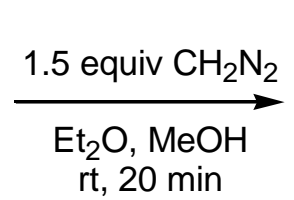

rt, 20 min

$\mathrm{R}=\mathrm{H}, \mathrm{R}^{\prime}=\mathrm{C}_{6} \mathrm{H}_{5}, \mathrm{C}_{8} \mathrm{H}_{17}$

$\mathrm{R}^{-\mathrm{R}^{\prime}}=\mathrm{CH}_{2} \mathrm{CHCH},\left(\mathrm{CH}_{2}\right)_{4},\left(\mathrm{CH}_{2}\right)_{5}$<smiles>[R]C1CC(=O)C(Cl)(Cl)C1P</smiles>

530

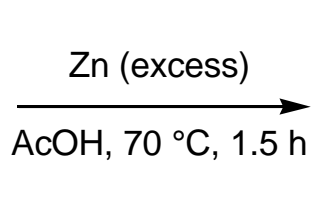

531 (64-82\%)

Scheme 148 
Numerous applications of this diazomethane ring enlargement protocol have been used in the synthesis of natural products. In the racemic synthesis of ( \pm -pentalenene $\mathbf{5 3 2},{ }^{199}$ the least oxidized neutral precursor of pentalenic acid and of a variety of pentalenolactones, as well as the least oxidized neutral triquinane metabolite of Streptomyces griseochromogenes, the second five-membered ring was formed in $52 \%$ overall yield from a bicyclo[3.2.0]heptanone through ring expansion in the presence of diazomethane. Greene et al. reported the synthesis of racemic ( \pm )-hirsutene 32 (Figure 6) with iterative three-carbon annelations, for which the third ring was introduced regioselectively via dichloroketene addition and subsequent ring expansion with diazomethane to form the precursor of $( \pm)$-hirsutene $32 .{ }^{200}$ The same authors accomplished the total synthesis of racemic ( \pm )-hirsutic acid C 496 (Figure 6) and used diazomethane in two ring expansion steps. ${ }^{201}$

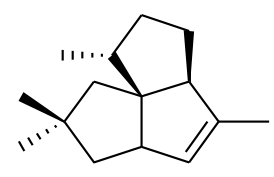

pentalenene 532

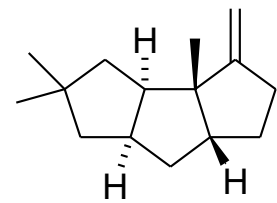

hirsutene 32

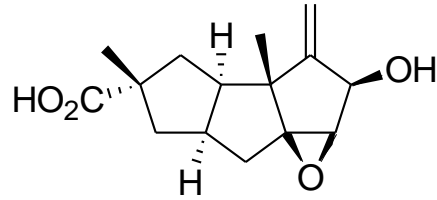

hirsutic acid 496

Figure 6

Furthermore, also in a regioselective synthesis of racemic $\alpha$-cuparenone $\mathbf{8 9}$ and $\beta$-cuparenone 379, the diazomethane ring enlargement protocol has been used successfully. ${ }^{202,203}$ Another synthetic approach to $\alpha$-cuparenone $\mathbf{8 9}$ was already described in this review using an acidpromoted ring rearrangement of a vinylcyclobutanol (Scheme 26). ${ }^{56}$

The regiocontrolled ring expansion of bicyclic cyclobutanones $\mathbf{5 3 3}$ to the corresponding bicyclic cyclopentanones 534 (Scheme 149) was achieved using diazomethane in ether. $\alpha$ - 
Methylidene cyclopentanones $\mathbf{5 3 5}$ were obtained via treatment of bicyclic compounds 534 with tetrabutylammonium fluoride in DMSO in 73 to $96 \%$ overall yield. ${ }^{204}$<smiles>[R]C1C(=O)C(Cl)(CSCC)C1([R])[R]</smiles>

533

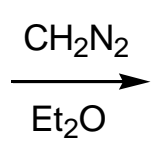

$\mathrm{R}=\mathrm{H}, \mathrm{OH}$

$\mathrm{R}^{1}-\mathrm{R}^{2}=\mathrm{CH}=\mathrm{CH}-\mathrm{CH}_{2}, \mathrm{O}-\left(\mathrm{CH}_{2}\right)_{3},\left(\mathrm{CH}_{2}\right)_{3}$

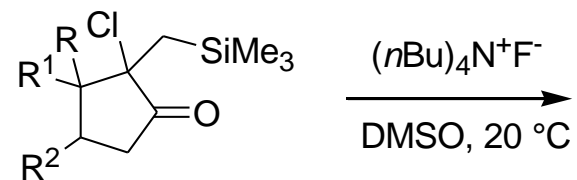

534<smiles>[R]C1CC(=O)C(=C)C1([R])[R]</smiles>

$535(73-96 \%$ overall $)$

Scheme 149

Optically active $\alpha$-chlorocyclopentenones 538 were synthesized in approximately $60 \%$ yield via asymmetric induction during a cycloaddition reaction of dichloroketene with chiral enol ethers 536, followed by ring expansion of the obtained cyclobutanones 537 using diazomethane and $\mathrm{Cr}\left(\mathrm{ClO}_{4}\right)_{2}$ (Scheme 150). ${ }^{205}$ Catalytic hydrogenation in methanol afforded (S)-(-)-cyclopentanones $\mathbf{5 3 9}$ in circa $80 \%$ yield.<smiles>[R]C=CO[R5]</smiles>

536<smiles>[R7]C1C2CC([R])([R])C([R7])(C1[R7])C2[R]</smiles>

$\mathrm{R}=\mathrm{Me}, n \mathrm{C}_{5} \mathrm{H}_{11}, n \mathrm{C}_{8} \mathrm{H}_{17}, \mathrm{C}_{6} \mathrm{H}_{5} \mathrm{CH}_{2} \mathrm{CH}_{2}$

$\mathrm{R}^{1}=\mathrm{H}, \mathrm{Me} ; \mathrm{R}^{2}=\mathrm{Me}, \mathrm{CH}_{2} \mathrm{OtBu}, \mathrm{CH}_{2} \mathrm{SO}_{2} \mathrm{~N}(\mathrm{Pr})_{2}$

$\mathrm{R}^{3}=\mathrm{OH}, \mathrm{OCH}_{2} t \mathrm{Bu} ; \mathrm{R}^{4}=\mathrm{H}, \mathrm{OH}, \mathrm{OCH}_{2} t \mathrm{Bu}, \mathrm{Me} ; \mathrm{R}^{5}=\mathrm{H}, \mathrm{Me}$
$\underset{\mathrm{Cr}\left(\mathrm{ClO}_{4}\right)_{2}}{\stackrel{\mathrm{CH}_{2} \mathrm{~N}_{2}}{\longrightarrow}}$<smiles>[R]C1C=C(Cl)C(=O)C1[PH+]=O</smiles>

538 (ca. 60\%)

$\mathrm{H}_{2}, \mathrm{Pd}-\mathrm{C}$
$\mathrm{MeOH}$

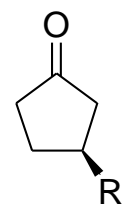

539 (ca. 80\%)

\section{Scheme 150}


Other examples in which the diazomethane ring expansion has been used comprise the synthesis of the precursors of 4-oxo-1,2-cyclopentane dipropanoic acids 540, angularly fused tricyclopentanoids 541, bicyclic compounds 542 and the macrocycles exaltone 543 and the precursor of muscone 544 in quantitative yield, using an excess of diazomethane in diethyl ether in the presence of a catalytic amount of methanol (Figure 7). ${ }^{206}$<smiles>CCCC[C@H]1CC(=O)OC1CCC(=O)O</smiles>

540<smiles>[R]C1CC2=C(CCC=CCC2)C1=O</smiles>

$\mathrm{R}=\mathrm{H}, \mathrm{Me}$<smiles>O=C1CCC23CCCC2CC[C@H]13</smiles>

541

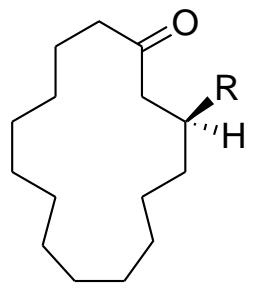

$\mathrm{R}=\mathrm{H}:$ exaltone 543

$\mathrm{R}=\mathrm{Me}$ : muscone 544

Figure 7

Additional illustrations on the use of the diazomethane ring expansion methodology involved the synthesis of the precursor of the monoterpene lactone ( \pm )-boonein $\mathbf{5 4 5 ,},{ }^{207}$ of the precursor of 7-methoxycyclopenta[a]phenalene $\mathbf{5 4 6},{ }^{208}$ and the precursor of 2-hydroxyazulene $\mathbf{5 4 7},{ }^{209}$ but also in the synthesis of the cyclopentenone fragment of (-)-dihydrocryptosporiopsin $\mathbf{5 4 8},{ }^{210}$ and in the key reaction step for an approach to brefeldin A 549 (Figure 8). ${ }^{211}$ 
<smiles>C[C@H]1C(O)C[C@@H]2CCOC(=O)[C@@H]21</smiles>

boonein 545<smiles>COc1c2c(c3cccc4cccc1c43)=CC=C2</smiles>

546<smiles>Oc1cc2cccccc-2c1</smiles>

547<smiles>CCCC1=C(Cl)C(=O)[C@H](Cl)[C@]1(O)C(=O)OC</smiles>

548

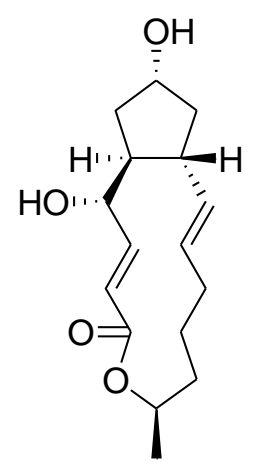

brefeldin A 549

Figure 8

This efficient ring expansion has also been used for the synthesis of novel compounds, as illustrated in Figure 9. The diazomethane ring expansion approach was used in the synthesis of cis-syn-cis-anti tetraquinanedione $\mathbf{5 5 0}$ in $62 \%$ yield as part of experiments in pursuit of pentagonal dodecahedrane. ${ }^{212}$ In similar research on polyquinanes, Mehta et al. reported the synthesis of a structurally interesting half-cage polyquinane $\mathbf{5 5 1}$ in $60 \%$ yield via diazomethane ring rearrangement of the appropriate cyclobutanone precursor. ${ }^{213}$ In research on linked donor-acceptor systems designed to test the effect of bridge configuration on the dynamics of long-range intramolecular electron transfer processes, polycycle $\mathbf{5 5 2}$ was synthesized as single regioisomer in nearly quantitative yield from its precursor, ${ }^{214}$ while adamantane derivative $\mathbf{5 5 3}$ was synthesized in $90 \%$ yield from the corresponding $\alpha, \alpha$ dichlorobutanone. ${ }^{215} 5 \alpha$-Cholestane-3-spirocyclopentanone $\mathbf{5 5 4}$ was synthesized in $97 \%$ yield from the precursor 5 $5 \alpha-2^{\prime}, 2^{\prime}$-dichlorospiro[cholestane-3,1'-cyclobutan]-3'-one via the described diazomethane ring enlargement. ${ }^{216}$ 

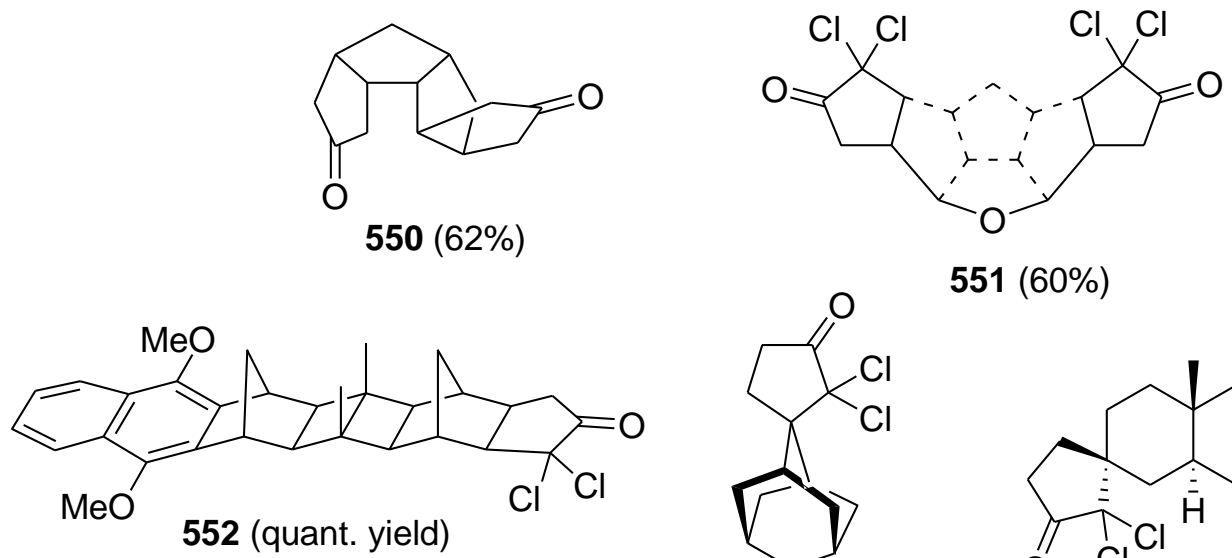

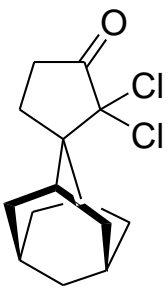

$553(90 \%)$

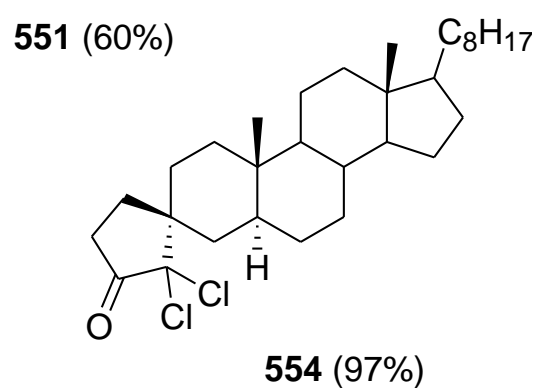

Figure 9

The preparation of conformationally restricted analogues of glutamic acid (both diastereomers), e.g. proline derivative 558, from endocyclic enecarbamates proceeded through oxidative cleavage of bicyclic compound 557, obtained via ring expansion of the corresponding 2-aza-7,7-dichlorobicyclo[3.2.0]heptan-6-one 556 (Scheme 151). ${ }^{217}$ The starting cyclobutanone 556 was synthesized by [2+2]-cycloaddition of dichloroketene to a five-membered endocyclic enecarbamate. Ring expansion utilizing 1.5 equiv of diazomethane in the presence of methanol (3\%) gave dichlorocyclopentanone 557 in $80 \%$ yield.<smiles>CCN(CC)CC(Cl)C(Cl)Cl</smiles>

555<smiles>O=C(c1ccccc1)N1CCC2C(=O)C(Cl)(Cl)C21</smiles>

$556(92 \%)$

\section{$\frac{1.5 \text { equiv } \mathrm{CH}_{2} \mathrm{~N}_{2}}{\mathrm{MeOH}, \mathrm{rt}}$}<smiles>O=C(O)N1CC[C@H]2CC(=O)C(Cl)(Cl)[C@@H]21</smiles>

$557(80 \%)$<smiles>CCC[C@@H]1C[C@@H](CC(=O)O)[C@H](C(=O)O)N1</smiles>

558

Scheme 151

In a final example, the cycloadduct 559, when reacted with four equiv of diazomethane in

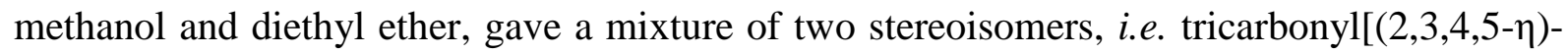


10-exo-chlorobicyclo[5.3.0]deca-2,4-dien-9-one]iron exo-560 and 10-endo-chloro derivative endo-560 in $30 \%$ and $19 \%$ yield, respectively (Scheme 152). ${ }^{209 \mathrm{~b}}$

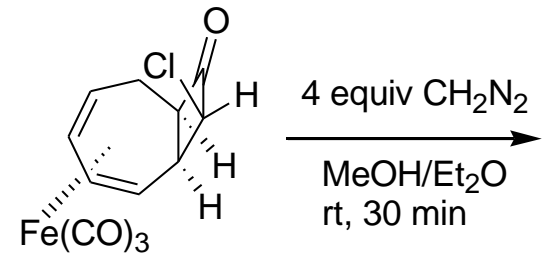

559

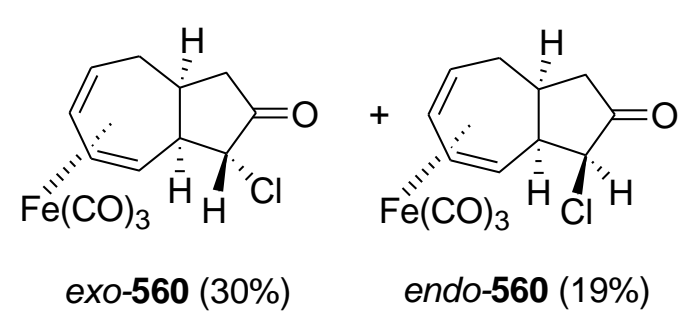

Scheme 152

\subsection{An activated nitro group as leaving group}

The nitro group, when connected to a carbon atom bearing carbenium ion stabilizing substituents, has been reported to act as a leaving group in the presence of Lewis acids. ${ }^{218}$ (Phenylthio)nitromethane was applied as a useful one carbon and $\alpha$-heteroatom source in the ring expansion of cyclic ketones (Scheme 153). ${ }^{219}$ Treatment of cyclobutanones 561 with the dianion of (phenylthio)nitromethane 562 at $-80{ }^{\circ} \mathrm{C}$ afforded cyclobutanols 563 in 78 to $85 \%$ yield. The rearrangement proceeded upon treatment with two equiv of aluminium(III) chloride in dichloromethane at $0{ }^{\circ} \mathrm{C}$ for 30 minutes to produce ring expanded $\alpha$-phenylthio ketones 564 in 66 to $74 \%$ yield.
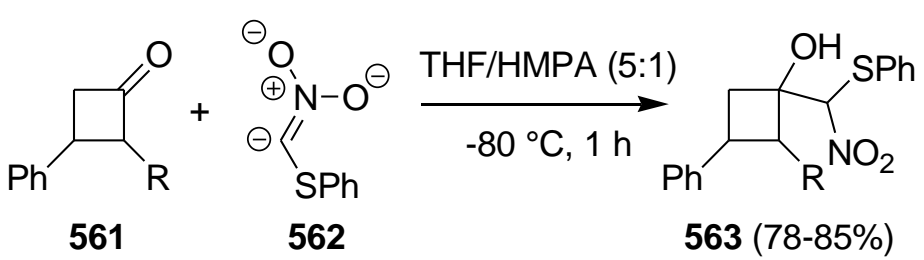

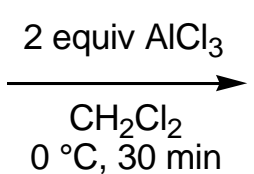

$563(78-85 \%)$<smiles>O=C1CC(c2ccccc2)C(P)C1Sc1ccccc1</smiles>

$564(66-74 \%)$

$\mathrm{R}=\mathrm{H}, \mathrm{Me}$ 


\subsection{An activated hydroxy group as leaving group}

In this section, cyclopenta(e)ne and cyclopenta(e)none synthesis is described, starting from 1(hydroxymethyl)cyclobutane or 1-(hydroxymethyl)cyclobutanol derivatives. Several methods are discussed in the next paragraphs.

\subsubsection{Cyclopentane/Cyclopentene synthesis}

The first reaction described here comprises the classical and basic example of this type of ring expansions. In an attempt to prepare cyclobutylmethyl bromide, and not the rearranged product, cyclobutylcarbinol 565 was treated with 0.4 equiv of phosphorus(III) bromide without solvent. ${ }^{220}$ The method of Bartleson, Burk and Lankelma ${ }^{221}$ was chosen by the authors because it would be less likely to lead to rearrangement than for example by the use of hydrogen bromide. ${ }^{222}$ However, a combined yield of $72 \%$ was obtained for a 56:44 mixture of cyclopentyl bromide 566 and cyclobutylmethyl bromide 567, respectively (Scheme 154).

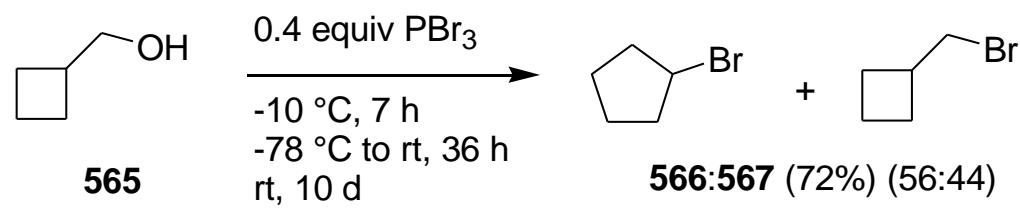

Scheme 154

Cationic rearrangement of homocubane carbinols $\mathbf{5 6 8}$ to bridgehead 1,3-bishomocubane alcohols $\mathbf{5 7 0}$ was executed via treatment with an excess of thionyl chloride or phosphorus(III) bromide. $^{223}$ Both reactions, performed at room temperature for 16 hours or two days, respectively, gave mixtures of the rearranged halocubane $\mathbf{5 6 9}$ and hydroxycubane $\mathbf{5 7 0}$ 
(Scheme 155). Again, the driving force in this ring expansion was the relief of strain leading to the 1,3-bishomocubane cage systems by selective bond migration in the homocubane skeleton. Isomeric 1,4-bishomocubane derivatives were not observed.

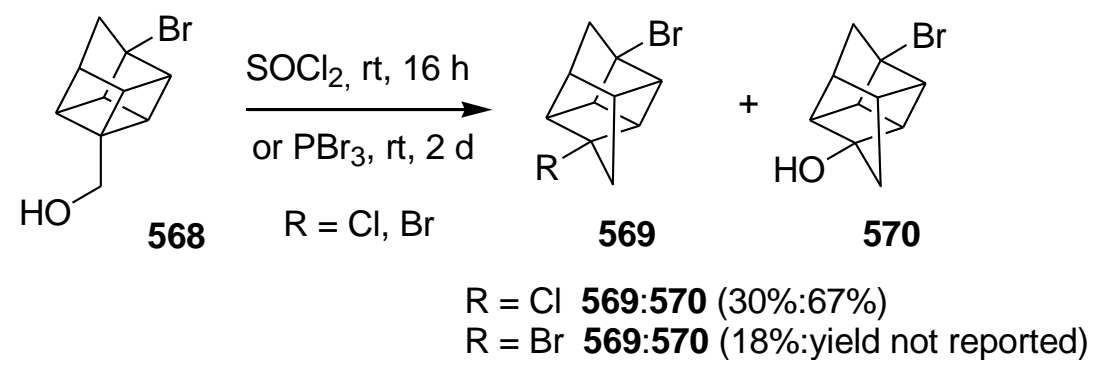

Scheme 155

In a synthesis toward racemic ( \pm )-quadrone $\mathbf{2 9 8}$, the first bicyclic five-membered ring in the precursor 6,6-dimethyl-1-(2-propynyl)bicyclo[3.2.1]octan-8-ol 572 was synthesized in 77\% yield using an acid-catalyzed ring expansion of 7,7-dimethyl-2-(2-propynyl)-cisbicyclo[4.2.0]octan-2-ol $\mathbf{5 7 1}$ with $90 \%$ formic acid at reflux temperature for 30 minutes (Scheme 156). ${ }^{224}$

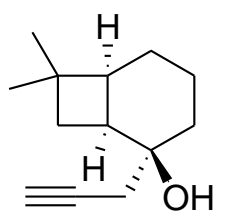

571
$\mathrm{HCO}_{2} \mathrm{H}, \Delta, 30 \mathrm{~min}$

$\mathrm{K}_{2} \mathrm{CO}_{3}, \mathrm{MeOH} / \mathrm{H}_{2} \mathrm{O}$

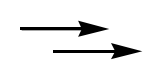

$\mathrm{HO}$<smiles>C#CCC12CCC(CC)(CC1)C(C)(C)C2</smiles>

$\mathrm{H}$

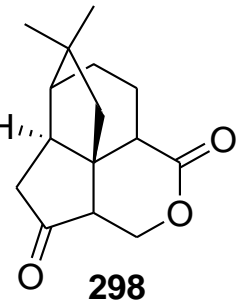

Scheme 156

Next to formic acid, acetic acid has also been used as a promoter for the rearrangement of cyclobutylmethyl carbenium ions. When 1-(1-hydroxyethyl)-1-alkylcyclobutanes 573 were treated with 0.02 equiv of iodine in acetic acid at reflux for three hours, the corresponding 1- 
alkyl-2-methylcyclopentenes $\mathbf{5 7 4}$ were obtained in 80 to $89 \%$ yield, as precursors for 1,5diketones 575 (Scheme 157). ${ }^{225}$

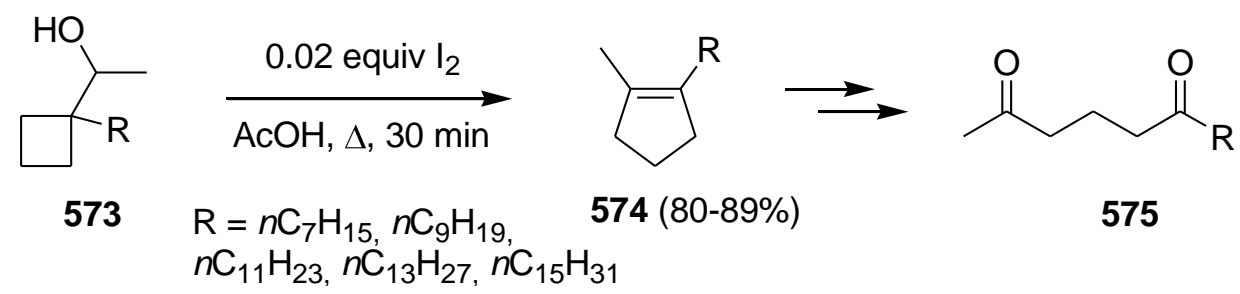

Scheme 157

In a study on base-induced proton tautomerism in the primary photocyclization product of stilbene, the starting compounds 1,2-diphenylcyclopentenes 577 were synthesized by means of ring enlargements of cyclobutyldiphenylcarbinols 576. ${ }^{226}$ Rearrangement was effective in 40-75\% yield upon reaction of cyclobutyl carbinols $\mathbf{5 7 6}$ in $98-100 \%$ formic acid at reflux for eight hours (Scheme 158). ${ }^{227}$
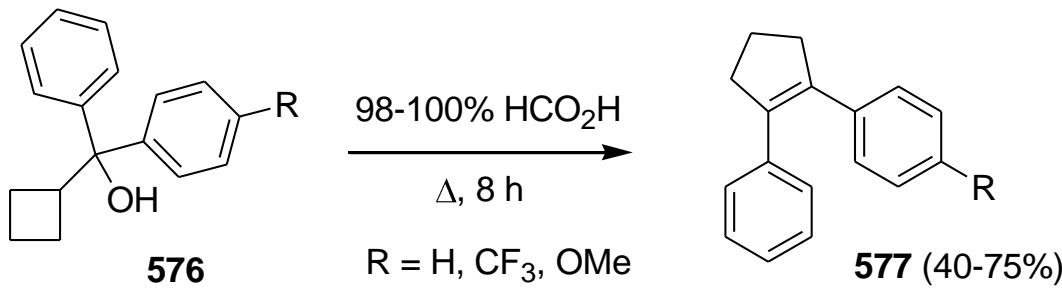

Scheme 158

In another approach, solvolytic trifluoroacetic acid-catalyzed rearrangement of bicyclo[3.2.0]heptan-2-ols $\mathbf{5 7 8}$ has been reported to afford 7-hydroxynorbonane derivatives 579. ${ }^{228}$ The exo-isomer $\mathbf{5 7 9}$ was mainly formed by heating the starting products $\mathbf{5 7 8}$ in $90 \%$ trifluoroacetic acid at reflux temperature for two to three hours in 64 to $85 \%$ yield (maximum 17\% of endo-isomer, ratio 83-98:2-17) (Scheme 159). 


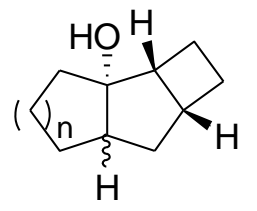

exo- or endo-578

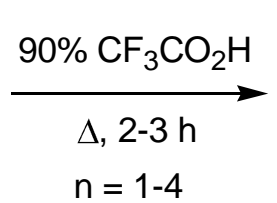

exo-579 (64-85\%) (83-98:2-17)

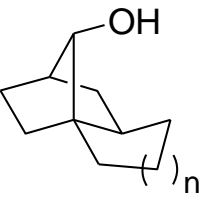

Scheme 159

Other 7-hydroxynorbonane derivatives $\mathbf{5 7 9}$ have been synthesized by the same authors as single epimeric alcohols in 43 to $47 \%$ yield by reaction of bicyclo[3.2.0]heptan-2-ols $\mathbf{5 7 8}$ in a mixture of tetrahydrofuran and $40 \%$ sulfuric acid at $0{ }^{\circ} \mathrm{C}$, followed by stirring for 16 hours at ambient temperature (Scheme 160). ${ }^{228}$

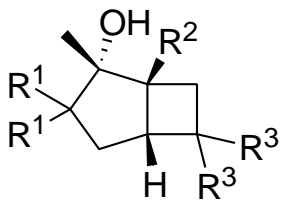

578

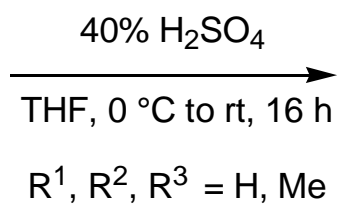

$R^{1}, R^{2}, R^{3}=H, M e$ 
expansion of the four-membered ring. The carbenium ion $\mathbf{5 8 1}$ thus formed, rearranged further to carbenium ions $\mathbf{5 8 3}, \mathbf{5 8 4}$ and $\mathbf{5 8 6}$ and thereby not only accounted for the formation of $\mathbf{5 8 2}$, but also for $\mathbf{5 8 5}$ and 587. An initial enlargement of the three-membered ring, which would have opened a way to synthesize 592, was excluded since neither compound 592, nor any product derived from carbenium ions $\mathbf{5 8 8 , 5 8 9 , 5 9 0}$ or $\mathbf{5 9 1}$ was detected. This was explained both by a more favorable alignment of the cyclobutane bond with respect to the neighbouring cationic centre ${ }^{230}$ and by the greater thermodynamic advantage associated with $\mathrm{C}_{4}-\mathrm{C}_{5}$ as to $\mathrm{C}_{3^{-}}$$\mathrm{C}_{4}$ ring enlargements. ${ }^{231}$

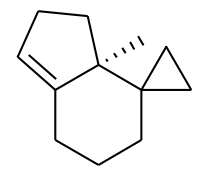

$582(100 \%)$<smiles>C1=C[Al]1</smiles>

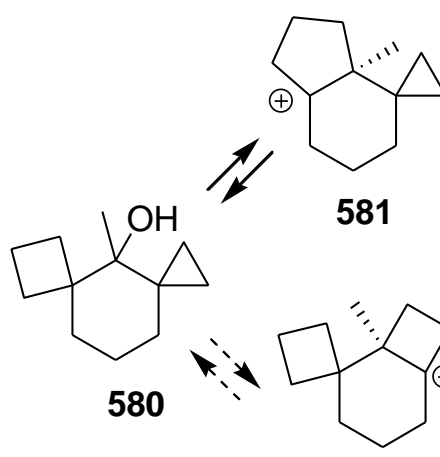

588<smiles>CC[C@]1(OC=O)CCC[C@@]2(C)CCC[C@@H]12</smiles>
$585(67 \%)$

b $\uparrow$<smiles>C=C[C@H]1CCC[C@H]2C3(CCCC21C)CC3</smiles>

583

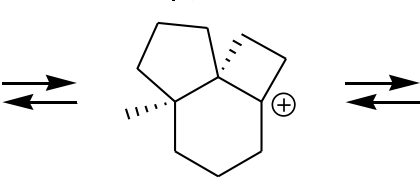

584<smiles>[R]C1=C2CCC[C@@H]2CCC1</smiles>
$587(100 \%)$<smiles></smiles><smiles>[CH2-]CC1=C2CCC[C@@H]2CCC1</smiles>

586

a) 0.01 equiv $\mathrm{AgBF}_{4}, \mathrm{CH}_{2} \mathrm{Cl}_{2}$, rt, $30 \mathrm{~min}$

b) 3.6 equiv $\mathrm{HCO}_{2} \mathrm{H}$, pentane, rt, $2 \mathrm{~h}$

c) 3.6 equiv $\mathrm{CF}_{3} \mathrm{CO}_{2} \mathrm{H}, \mathrm{CHCl}_{3}$, rt, $30 \mathrm{~min}$

$\mathrm{R}=\left(\mathrm{CH}_{2}\right)_{2} \mathrm{OCOCF}_{3}$

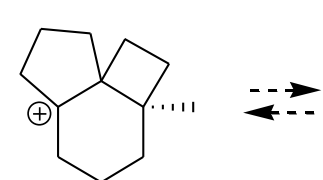

590

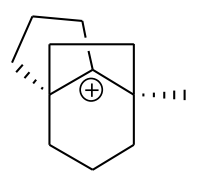

591

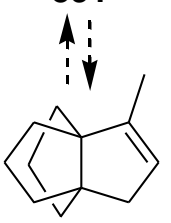

592

Scheme 161

Among other cascade cationic reactions, also reported by Fitjer's group, a synthesis of $( \pm)$ modhephene $\mathbf{4 1 0}$ and its enantiomer $( \pm)$-epimodhephene was executed from the epimeric 
dispiroundecanols 593 (Scheme 162). ${ }^{134 d, 232}$ The rearrangements were initiated by treatment with equimolar amounts of anhydrous $p$-toluenesulfonic acid in benzene at $70{ }^{\circ} \mathrm{C}$. After 20 minutes, alcohol 593 was completely consumed and rearranged into 65\% ( \pm )-modhephene 410 and $34 \%$ triquinane 598. The synthesis of $( \pm)$-epimodhephene was accomplished starting from the enantiomer of dispiroundecanol 593 to give $65 \%$ of ( \pm -epimodhephene and $35 \%$ of the corresponding triquinane.

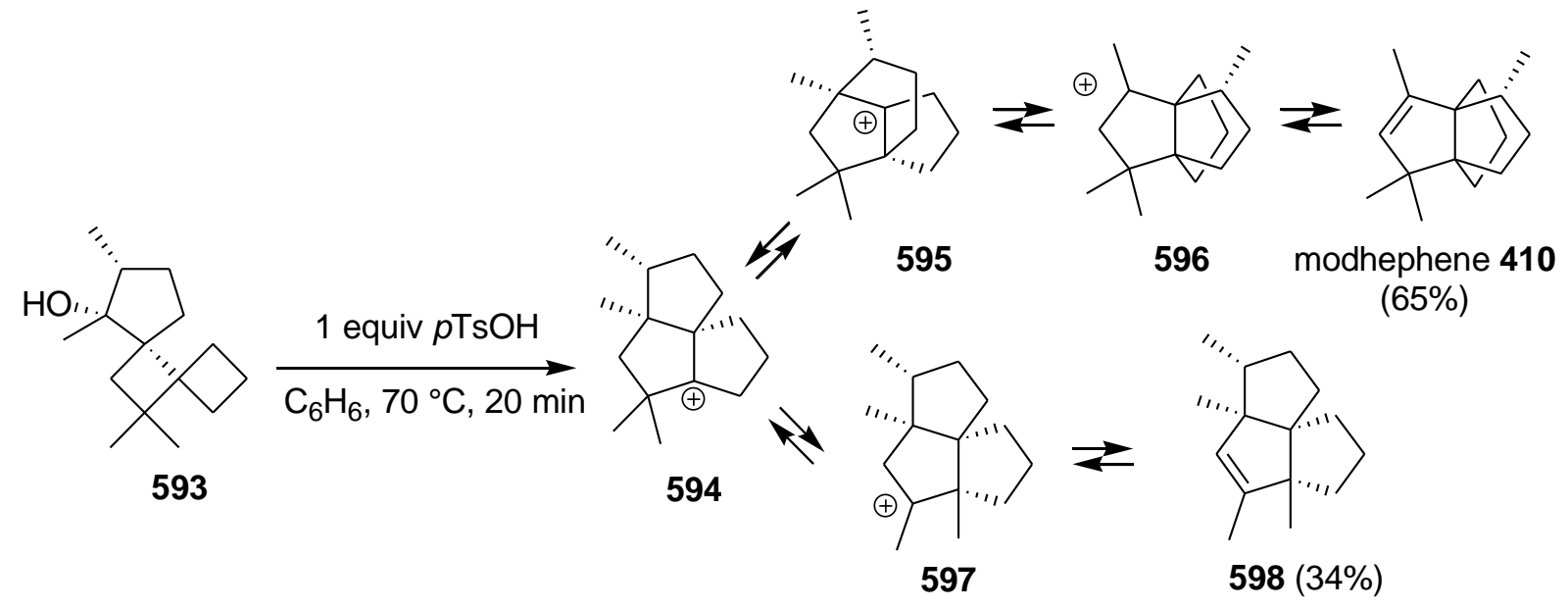

Scheme 162

Another $p$-toluenesulfonic acid-catalyzed rearrangement, starting from 1methylcyclobutylmethanols, has also been reported by Mandelt and Fitjer (Scheme 163). ${ }^{233}$ Quantitative rearrangements were observed when compounds 599 were reacted with equimolar amounts of $p$-toluenesulfonic acid in benzene at $70{ }^{\circ} \mathrm{C}$ for three hours. With the exception of alcohol $601(\mathrm{n}=1,10 \%$ yield) and bicycle $602(\mathrm{n}=2,7 \%$ yield), only hydrocarbons 600 and $\mathbf{6 0 3}$ were formed in a high yield of 90-100\%. In all cases, the product formation involved a cyclobutylmethyl to cyclopentyl rearrangement, eventually followed by a second cyclobutylmethyl to cyclopentyl rearrangement (600 and 601), a cyclopentylmethyl to cyclohexyl rearrangement $(\mathbf{6 0 2})$, or a 1,2-methyl shift (606). Of the products formed, $\mathbf{6 0 5}$ 
$\left(\mathrm{R}=p\right.$-tolyl) has been used in the synthesis of $( \pm)$-laurene $142,{ }^{234 a} \mathbf{6 0 6}(\mathrm{R}=p$-tolyl $)$ in the synthesis of $( \pm)$-cuparene $e^{234 \mathrm{~b}}$ and $\mathbf{6 0 5}(\mathrm{R}=m$-tolyl $)$ for $( \pm)$-herbertene. ${ }^{234 \mathrm{c}}$ These cyclopentenes $\mathbf{6 0 5}$ were produced in a much higher yield (96-97\%) when 1methylcyclobutylmethanols $\mathbf{6 0 4}$ were treated with hydrochloric acid in methanol at reflux temperature for two hours (method B).

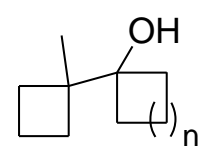

599

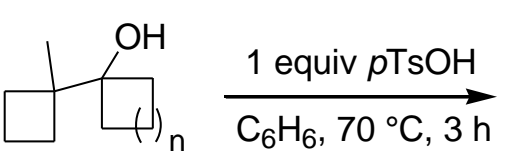

599

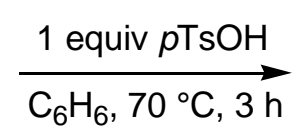

$\mathrm{n}=1,2$

$$
\mathrm{n}=3
$$<smiles>CC12[CH-][OH+]CC1=CCC2</smiles>

$600(90-93 \%)$

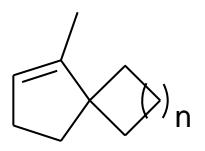

$603(100 \%)$<smiles>CC12CC[C@H](CC([C@H]3C=C4CCCC4(C)C3)C1)C2</smiles>

$601(10 \%)$

$\mathrm{n}=1$

$\mathrm{n}=2$
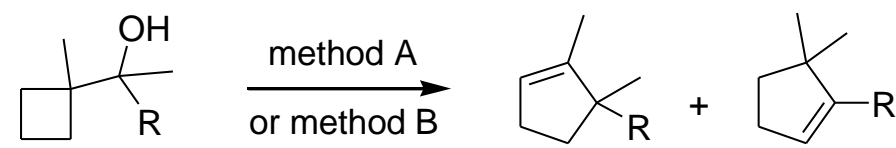

$604 \mathrm{R}=p$-tolyl, $m$-toly

605

606

A: $605(24-45 \%) 606(55-76 \%)$

B: $605(96-97 \%) 606$ (3-4\%)

method $\mathrm{A}$ : 1 equiv $p \mathrm{TsOH}, \mathrm{C}_{6} \mathrm{H}_{6}, 70{ }^{\circ} \mathrm{C}, 3 \mathrm{~h}$ method B: aq. $\mathrm{HCl} / \mathrm{MeOH}, \Delta, 2 \mathrm{~h}$

\section{Scheme 163}

A final example of a cationic cascade reaction of this type of rearrangements included the five-fold cyclobutylmethyl to cyclopentyl rearrangement of pentaspirohenicosanol $\mathbf{6 0 7}$ to the all-cis annelated precursor $\mathbf{6 0 8}$ of [6.5]coronane (Scheme 164). ${ }^{235}$ The reaction was speculated to proceed with conformational control, starting from an initially formed chlorosulfite. When pentaspirohenicosanol $\mathbf{6 0 7}$ was treated with five equiv of thionyl chloride in pyridine, the corresponding hexacyclohenicos-16-ene 608 was obtained in $83 \%$ yield. 


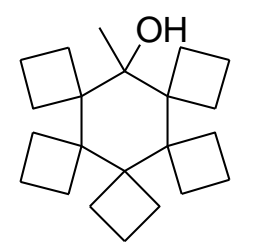

607

\section{$\underset{\text { py, } 0^{\circ} \mathrm{C}, 15 \mathrm{~min}}{\stackrel{5 \text { equiv } \mathrm{SOCl}_{2}}{\longrightarrow}}$}

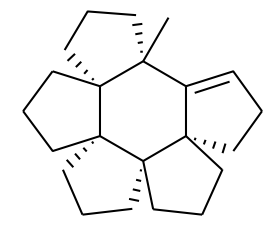

$608(83 \%)$

Scheme 164

When an incipient primary carbenium ion centre is generated adjacent to an alicyclic ring, the latter is prone to undergo ring expansion. This principle has been used by Olah and coworkers. ${ }^{136}$ A ring enlargement of cyclobutylmethyl alcohol $\mathbf{6 0 9}$ via treatment with a mixture of two equiv of sodium borohydride and 12 equiv of triflic acid in diethyl ether afforded cyclopentane 317 in $96 \%$ yield (Scheme 165). This approach comprised an alternative route for the synthesis of cyclopentane $\mathbf{3 1 7}$ starting from cyclobutanecarboxylic acid 316, which was ring expanded applying the same reaction conditions (Scheme 90), also in 96\% yield.

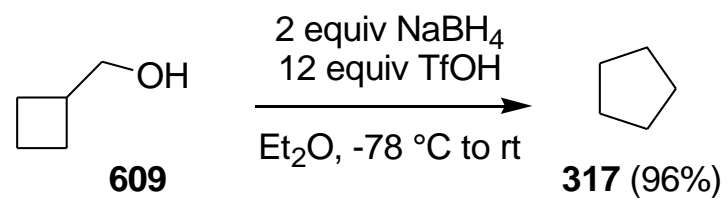

Scheme 165

Venkateswaran et al. have developed an acid- or Lewis acid-catalyzed rearrangement of a methylcyclobutane unit attached to chromanol to three different types of five-membered ring systems, i.e. cyclopentanones, cyclopentenes or cyclopentanes. According to the substitution pattern, as well as the solvent and acid, the authors described the outcome of the reaction as predictable. ${ }^{236}$ In the synthesis of the carbocyclic framework of the marine natural product aplysin, ${ }^{72 a}$ a rearrangement of tricyclic alcohol $\mathbf{6 1 0}$ via an incipient trichothecane-like cationic intermediate 611 has been reported. ${ }^{236 a}$ Treatment of cyclobutachromanol 610 with $p$ - 
toluenesulfonic acid in benzene at reflux temperature led to a mixture of $p$-toluenesulfonates $\mathbf{6 1 3}$ in $70 \%$ yield via migration of an external bond, followed by an aryl migration (Scheme 166). The oxidation of this mixture afforded the tricyclic compound $\mathbf{6 1 4}$ as the skeleton of aplysin $\mathbf{1 5 0 .}$

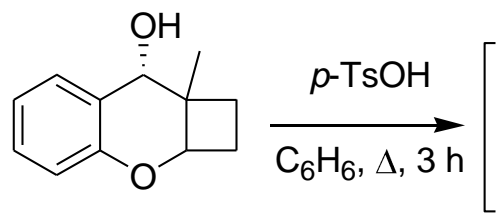

610<smiles>Cc1cc2c(cc1Br)[C@@]1(C)CC[C@@H](C)[C@]1(C)O2</smiles>

aplysin 150<smiles>c1ccc2c(c1)OC1C3CCC2C31</smiles>

611<smiles>CC1(C)CCC2Oc3ccccc3C21C</smiles>

612<smiles>CC1(C)c2ccccc2OC1CC[C@@H](O)CO</smiles>

$613(70 \%)$

Scheme 166

In analogous research by the same group, rearrangement of cyclobutachromanol $\mathbf{6 1 5}$ proved to be predictable by choice of the catalyst and solvent. ${ }^{236 \mathrm{~b}}$ Treatment of this carbinol $\mathbf{6 1 5}$ with boron(III) fluoride etherate in benzene, petroleum ether or nitromethane gave mixtures of two different ring expanded products 616 and $\mathbf{6 1 7}$. When a catalytic amount of boron(III) fluoride etherate in nitroethane at $-78{ }^{\circ} \mathrm{C}$ was used, the desired precursor 616 of debromoaplysin 151 was obtained in $82 \%$ yield (Scheme 167$)$. 
<smiles>Cc1ccc2c(c1)O[C@]1(C)CC[C@@]1(C)[C@@]2(C)O</smiles>

615

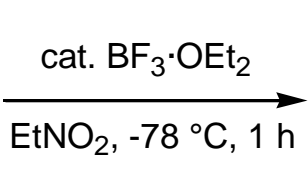

$\mathrm{EtNO}_{2},-78^{\circ} \mathrm{C}, 1 \mathrm{~h}$$$
\text { (1) }
$$

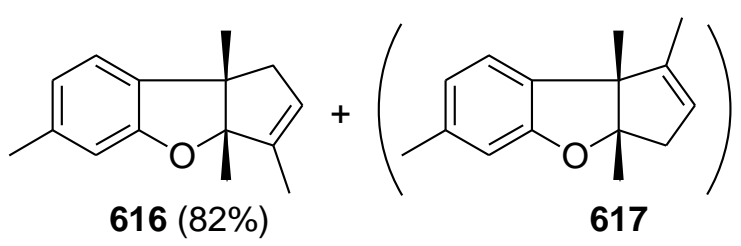<smiles>Cc1ccc2c(c1)OC1(C)[C@H](C)CC[C@]1(C)C2(C)C</smiles>

debromoaplysin 151

Scheme 167

A last example of the acid-catalyzed rearrangement of (hydroxymethyl)cyclobutane derivatives involved the ring expansion of alcohols $618 .{ }^{237}$ When these carbinols 618 were treated with 0.7 equiv of $\mathrm{ZnBr}_{2}$ in $48 \%$ aqueous hydrogen bromide at $0{ }^{\circ} \mathrm{C}$ for three hours, the corresponding norbornanes $\mathbf{6 1 9}$ were obtained in 57 to 58\% yield (Scheme 168). Due to the retention of the stereocentres at $\mathrm{C}-1$ and $\mathrm{C}-7$, the rearrangement of $\mathbf{6 1 8}$ led to the $\mathrm{C}_{S^{-}}$ symmetrical annelated norbornane derivatives 619.

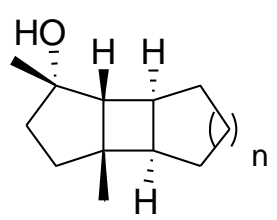

618

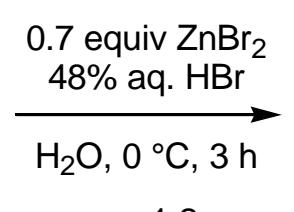

$\mathrm{n}=1,2$

Scheme 168

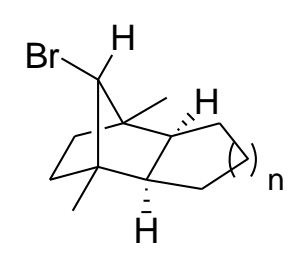

$619(57-58 \%)$

\subsubsection{Pinacol rearrangement (cyclopentanone synthesis)}


Since the pinacol rearrangement involves the formation of a carbenium ion, starting from a fully substituted 1,2-diol, followed by a 1,2-alkyl shift, this methodology has been applied for cyclobutylmethylcarbenium to cyclopentylcarbenium ion rearrangements as well.

For example, the rearrangement of monosilylated pinacols $\mathbf{6 2 0}$, controlled by the presence of an acyl group adjacent to the diol moiety, has been reported to give 1,3-cyclopentanediones 622 in 87 to $97 \%$ yield upon treatment with trifluoroacetic acid (Scheme 169). ${ }^{238}$ Exact reaction conditions were not given by the authors, except for a reaction temperature of $30{ }^{\circ} \mathrm{C}$.<smiles>[R]C([R])(O)C1(O[Na])CCC(=O)C1(O)O</smiles>

620

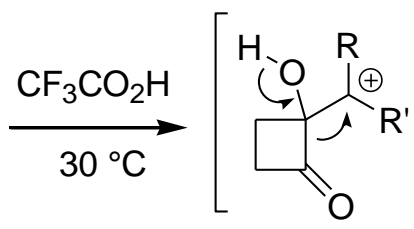

621<smiles>[R]C1(P)C(=O)CCC1=O</smiles>

$622(87-97 \%)$

$\mathrm{R}=\mathrm{Ph}, n \mathrm{C}_{9} \mathrm{H}_{19} ; \mathrm{R}^{\prime}=\mathrm{H}$

$\mathrm{R}, \mathrm{R}^{\prime}=\mathrm{Et}, \mathrm{Et}$

$\mathrm{R}^{-\mathrm{R}^{\prime}}=\left(\mathrm{CH}_{2}\right)_{5},\left(\mathrm{CH}_{2}\right)_{11}$,

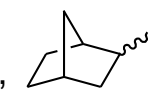

Scheme 169

In the study on the synthesis of ferrocenes, a pinacol rearrangement of (hydroxymesityl)cyclobutanone $\mathbf{6 2 3}$ was executed via treatment with 1.2 equiv of trifluoroacetic acid at room temperature for one hour, affording the corresponding ring expanded product $\mathbf{6 2 4}$ in $42 \%$ yield (Scheme 170). ${ }^{239}$ The latter compounds served as substrates for the preparation of iron complex $\mathbf{6 2 5}$. 


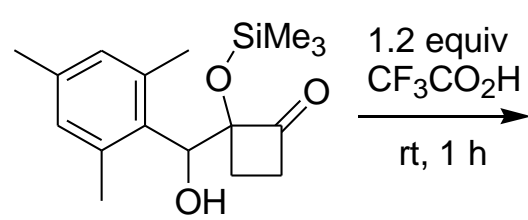

623

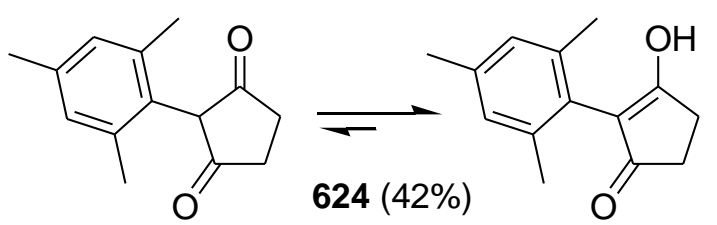

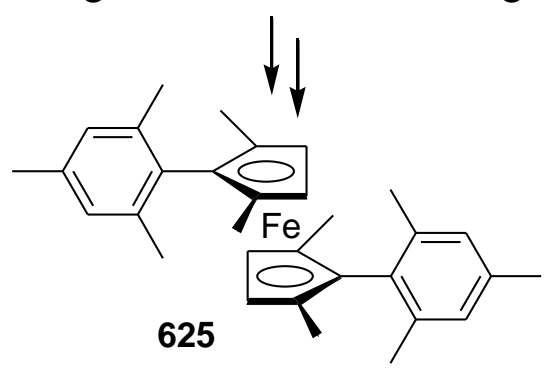

Scheme 170

In analogy with sesquiterpene syntheses described in the previous section, a synthesis toward filiformin 152 by means of a semipinacol rearrangement has been reported. ${ }^{240}$ The rearrangement of diols $\mathbf{6 2 6}$ resulted in the bridged ketones $\mathbf{6 2 7}$ in $81-90 \%$ yield by treatment with a catalytic amount of $\mathrm{BF}_{3} \cdot \mathrm{Et}_{2} \mathrm{O}$ in benzene at room temperature for one hour (Scheme 171). In all cases, only isomer $\mathbf{6 2 7}$ was formed, arising from the exclusive migration of the external bond. ${ }^{240 a}$ Also two other methods were described, i.e. addition of a catalytic amount of $\mathrm{BF}_{3} \cdot \mathrm{Et}_{2} \mathrm{O}$ or $\mathrm{H}_{2} \mathrm{SO}_{4}$ in petroleum ether at $-78{ }^{\circ} \mathrm{C}$ for one hour, or addition of a catalytic amount of $\mathrm{BF}_{3} \cdot \mathrm{Et}_{2} \mathrm{O}$ or $\mathrm{H}_{2} \mathrm{SO}_{4}$ in nitroethane at $-78{ }^{\circ} \mathrm{C}$ for 30 minutes, however without mentioning the yields of the obtained ketone. ${ }^{240 \mathrm{~b}}$ An analogous reaction has been reported in the synthesis of heliannuol D 628, a phenolic sesquiterpene isolated from the sun flower Helianthus annus (Figure 10). ${ }^{241}$<smiles>[R]C[C@]1(O)c2ccc([R1])cc2O[C@]2(C)CC[C@]21C</smiles>

626 cat. $\mathrm{BF}_{3} \cdot \mathrm{Et}_{2} \mathrm{O}$<smiles>c1ccccc1</smiles>
$R^{1}, R^{2}=H, M e$<smiles>[R]CC12CCC(C)(Oc3cc([R10])ccc31)C2(C)C</smiles>

$627(81-90 \%)$<smiles>Cc1cc2c(cc1Br)C1(C)CCC[C@]1(C)O2</smiles>

filiformin 152

Scheme 171 


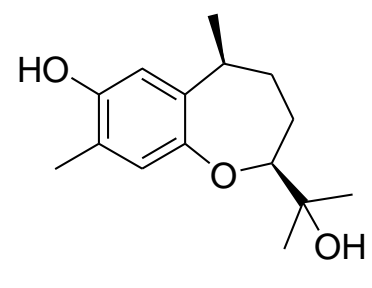

heliannuol D 628

Figure 10

In an alternative approach, spiroannelated cyclopentanones have been synthesized using cyclobutyl phenyl sulfides. ${ }^{242}$ Treatment of $\beta$-hydroxy sulfides $\mathbf{6 2 9}$ with tin(IV) chloride in dichloromethane for 15 minutes at $0{ }^{\circ} \mathrm{C}$ and five minutes at room temperature afforded the corresponding cyclopentanones $\mathbf{6 3 0}$ in 7 to $84 \%$ yield (Scheme 172). Cyclohexanones, cycloheptanones, cyclooctanones and acyclic ketones were shown to be well suited for the spiroannelation, but cyclobutanones $\left(\mathrm{R}^{1}-\mathrm{R}^{2}=\left(\mathrm{CH}_{2}\right)_{3}\right)$ and cyclopentanones $\left(\mathrm{R}^{1}-\mathrm{R}^{2}=\left(\mathrm{CH}_{2}\right)_{3}\right)$ were not.

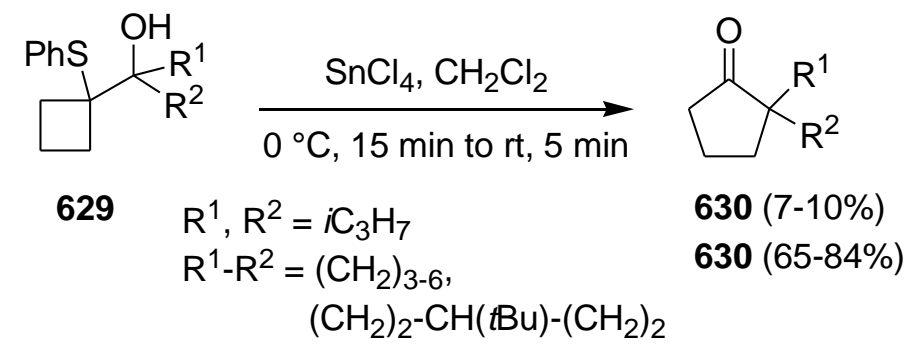

Scheme 172

Pinacol derivatives have also been prepared via Grignard addition across carbonyl compounds. For example, the synthesis of $\alpha, \alpha$-dialkylcyclopentanones was achieved via Brǿnsted and Lewis acid induced ring expansions of 1-hydroxycarbinols 632 and $636 .{ }^{243}$ The ring expansion step was executed via treatment of diols 632 and 636 with a catalytic amount 
of trifluoroacetic acid in dichloromethane at room temperature or reflux temperature to afford $\alpha, \alpha$-dialkylcyclopentanones 633 in 92 to $96.5 \%$ yield and $\alpha, \alpha$-dialkylcyclopentanones 637 in 89 to $98 \%$ yield, respectively (Scheme 173). The required 1,2-diols were prepared via Grignard addition across ester 631 or nitrile 634.
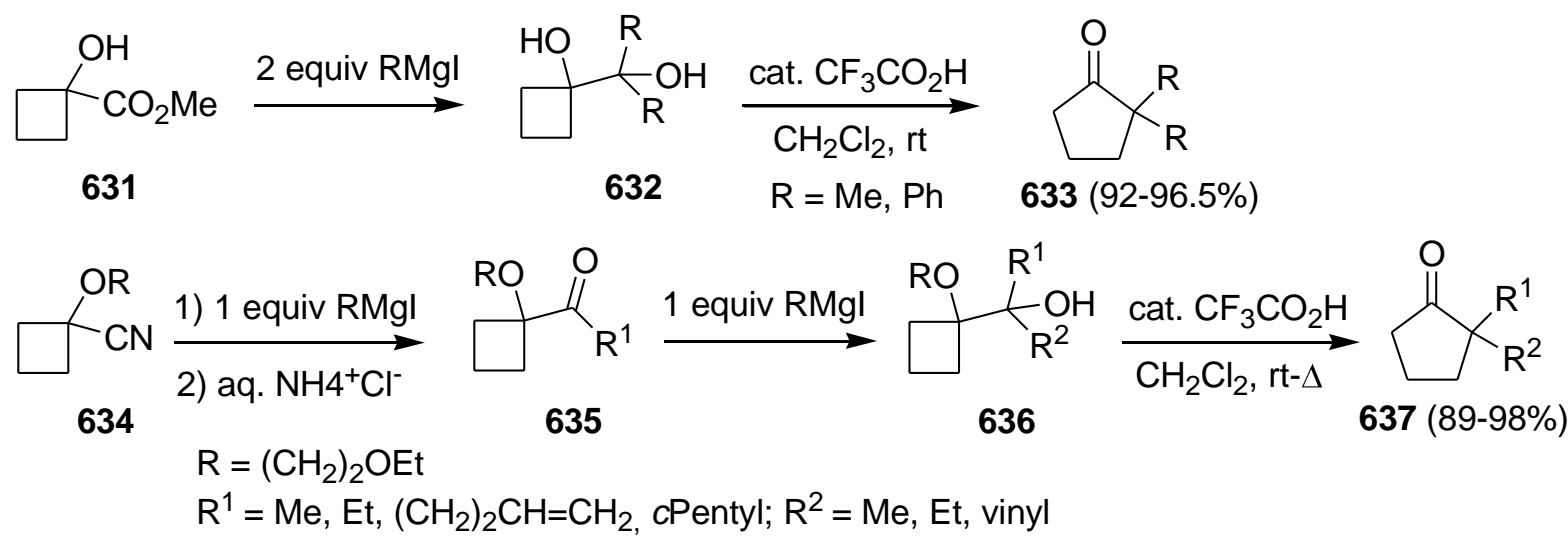

\section{Scheme 173}

Finally, a pinacol-type rearrangement has been used in the synthesis of cyclopentanediones. Thus, 4,4-dimethyl-1,3-cyclopentanediones 639 were prepared from 2-alkyl-2-hydroxy-4,4dimethylcyclobutanones 638, which were generated from open-chain or cyclic ketones by boron halide-mediated aldol reactions. ${ }^{244}$ The ring rearrangement was realized by means of trifluoroacetic acid at room temperature for 24 hours to afford 2-alkyl- or 2-aryl-2-methyl-1,3cyclopentanediones 639 in 47 to $83 \%$ yield (Scheme 174) and spiro-1,3-cyclopentanediones 639 in 46 to $98 \%$ yield. In comparison with the method depicted in Scheme $169,{ }^{238}$ no silylation of the hydroxy group was used, but lower yields were obtained. 


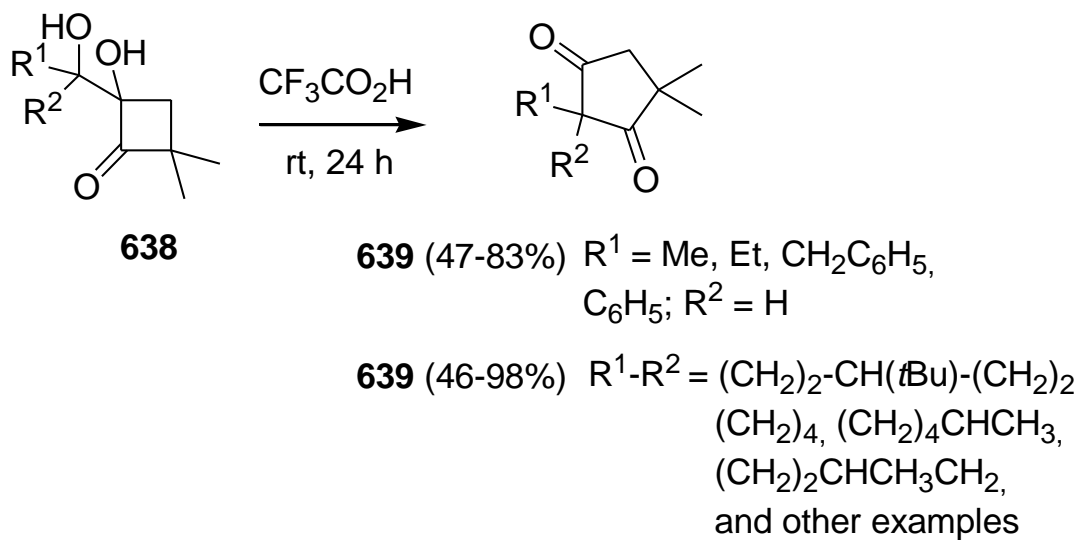

Scheme 174

\subsubsection{A mesyloxy group as leaving group}

A convenient way to enhance the leaving group ability of a hydroxy moiety comprises its transformation into a sulfonyloxy group. The most frequently applied methods in that respect involve the use of a mesyloxy or a tosyloxy group (vide infra).

Tricyclic cyclobutanols 640 with a four-membered ring located in the middle of the framework have been shown to be useful precursors toward bisannelated cyclopenta- or cyclopentenones. ${ }^{245}$ To this end, tricyclic compounds $\mathbf{6 4 0}$ were treated with 1.2 equiv of mesyl chloride in dichloromethane (Scheme 175). The monomesylated diol was then subjected to a ring enlargement reaction of the intermediate carbenium ion, generated by means of a base. Two different amines were evaluated as bases. The first method involved addition of 100 equiv of pyridine at $44{ }^{\circ} \mathrm{C}$ for five to 40 hours, while in a second method two equiv of triethylamine at $42{ }^{\circ} \mathrm{C}$ were applied for three to 72 hours. Both methods were used for the synthesis of the corresponding polycyclic cyclopentanones 641 in $0-100 \%$ yield and polycyclic cyclopentenones 642 in 0-70\% yield. 


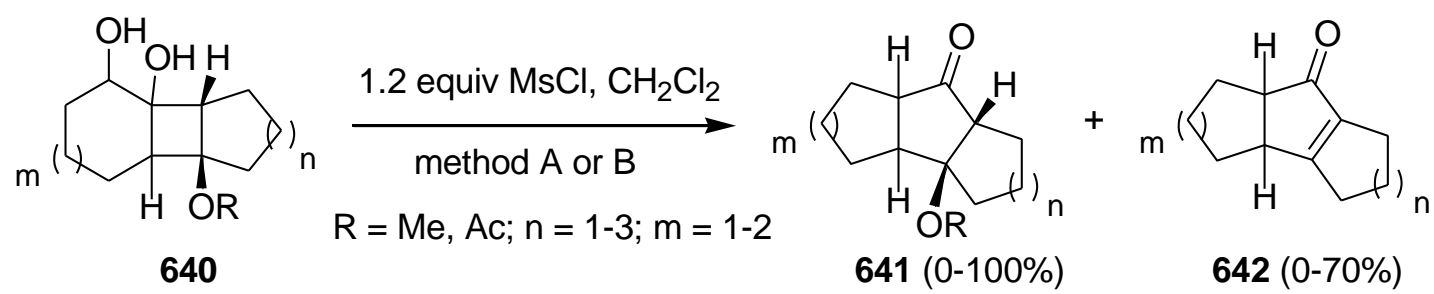

A) 100 equiv $\mathrm{C}_{5} \mathrm{H}_{5} \mathrm{~N}, 44^{\circ} \mathrm{C}, 5-40 \mathrm{~h}$

B) 2 equiv $\mathrm{Et}_{3} \mathrm{~N}, 42^{\circ} \mathrm{C}, 3-72 \mathrm{~h}$

Scheme 175

In an attempt to transform the secondary alcohol 643 into a methanesulfonate to produce the elimination product 644 as a precursor of the pheromone grandisol or its trans-isomer fraganol, the rearranged cyclopentene 646 was obtained as the sole product (Scheme 176). ${ }^{246}$ Treatment of cyclobutane $\mathbf{6 4 3}$ with two equiv of methanesulfonyl chloride in pyridine at 40 ${ }^{\circ} \mathrm{C}$ for three hours afforded cyclopentene $\mathbf{6 4 6}$ in $75 \%$ yield.

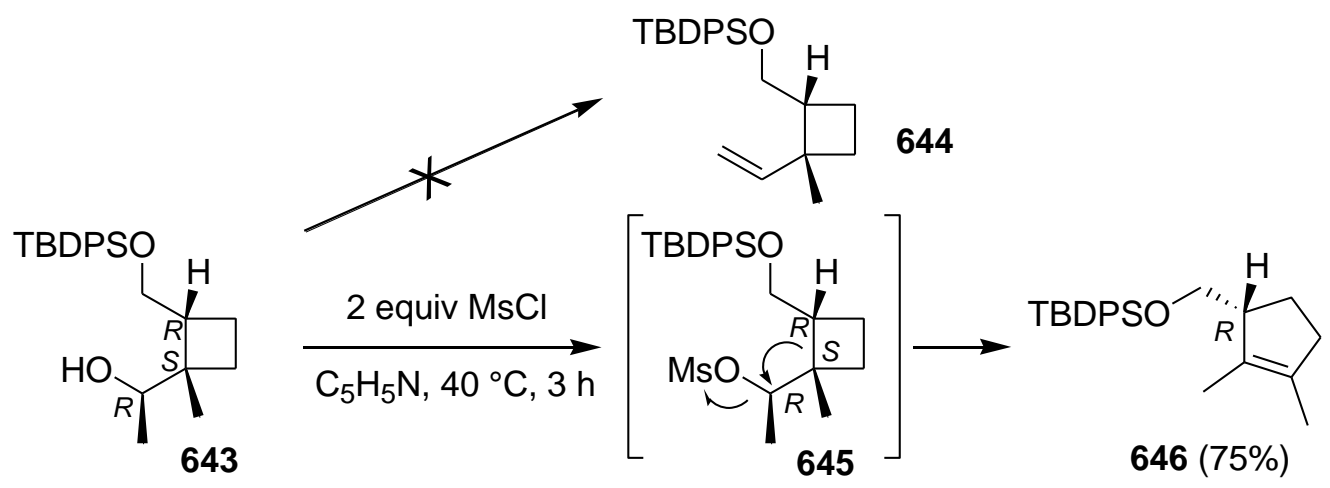

Scheme 176

In another example, efforts have been made toward the construction of the bicyclo[3.2.1]octane skeleton, found in kaurenoids and gibberellins. In this work, the methylenecyclobutane annelated mesyloxydecalin $\mathbf{6 4 7 a}$ was rearranged applying 1.2 equiv of methylaluminium dichloride in dichloromethane at $-78{ }^{\circ} \mathrm{C}$ (Scheme 177). ${ }^{247}$ The Lewis acidcatalyzed ring expansion reaction proceeded in $91 \%$ yield within five minutes, affording the 
annelated bicyclo[3.2.1] octane 648. However, when epimer $\mathbf{6 4 7 b}$ was treated with 1.1 equiv of diethylaluminium bromide in dichloromethane at $-78{ }^{\circ} \mathrm{C}$ for five minutes, allylbromide 649 was isolated in $91 \%$ yield instead of the corresponding annelated bicyclo[3.2.1] octane.

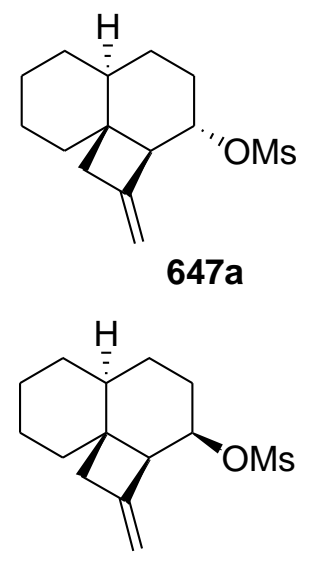

$647 b$

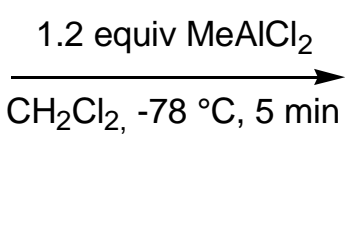

$\underset{\mathrm{CH}_{2} \mathrm{Cl}_{2},-78^{\circ} \mathrm{C}, 5 \mathrm{~min}}{\stackrel{1.1 \text { equiv } \mathrm{Et}_{2} \mathrm{AlBr}}{\longrightarrow}}$

Scheme 177

\subsubsection{A tosyloxy group as leaving group}

A first example involved the solvolysis of bicyclo[4.2.0]octane-1-methyl $p$-toluenesulfonate 650 (Scheme 178). ${ }^{248}$ The rearrangement proceeded exclusively to the bicyclo[4.2.1]nonyl system by treatment with acetic acid and sodium acetate at $61{ }^{\circ} \mathrm{C}$ for six hours, giving $90 \%$ of 1-bicyclo[4.2.1]nonyl acetate $\mathbf{6 5 1}$ and 10\% of 1-bicyclo[4.2.1]nonyl p-toluenesulfonate $\mathbf{6 5 2}$.

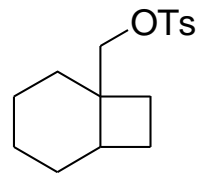

650
HOAc, NaOAc

$61^{\circ} \mathrm{C}, 6 \mathrm{~h}$

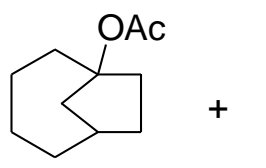

651 (90\%)<smiles>[O-]C12CCCCC1CC2</smiles>

652 (10\%)

Scheme 178 
A much less pronounced tendency toward ring expansion has been observed in the acetolysis of cyclobutylcarbinyl $p$-bromobenzenesulfonate $\mathbf{6 5 3}(\mathrm{R}=\mathrm{MeO})$, affording the corresponding 1-(4-methoxyphenyl)cyclopentene $\mathbf{6 5 5}$ in only $10 \%$ as the minor component, next to $90 \%$ of 1-(4-methoxybenzyl)cyclobutyl acetate $\mathbf{6 5 4}$ (Scheme 179), ${ }^{249}$ according to a WagnerMeerwein rearrangement of the initially formed primary carbenium ion to a tertiary carbenium ion. Acetolysis of other derivatives $\left(\mathrm{R}=\mathrm{H}, \mathrm{NO}_{2}\right)$ did not yield any corresponding cyclopentene, and instead benzalcyclobutanes $\mathbf{6 5 6}$ were obtained in 92-100\% yield.

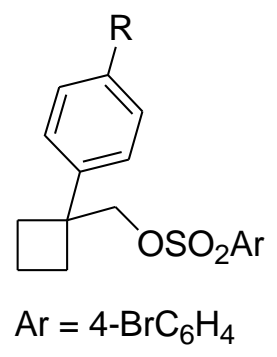

653

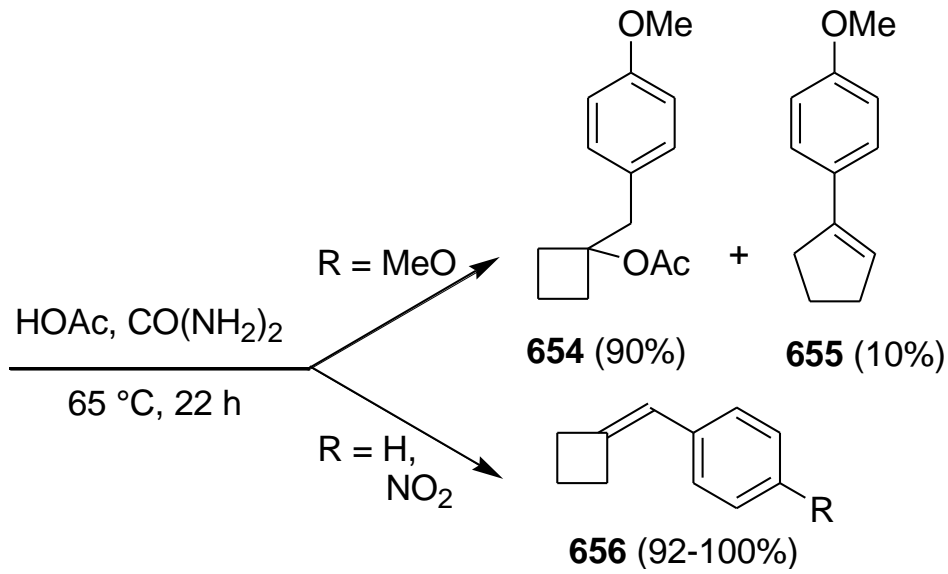

Scheme 179

On the other hand, acetolysis studies of bicyclo[3.2.0]hept-2-yls revealed stereospecific ring rearrangements. ${ }^{250}$ For example, treatment of anti-tricyclo[5.2.0.0 $\left.0^{2,5}\right]$ non-6-yl tosylate $\mathbf{6 5 7}$ with an acetate buffer of HOAc and NaOAc in a sealed tube at $25{ }^{\circ} \mathrm{C}$ for 42 hours afforded ring expansion to a mixture of compounds $\mathbf{6 5 8}$ and $\mathbf{6 5 9}$ in $66 \%$ and $20 \%$ yield, respectively (Scheme 180).

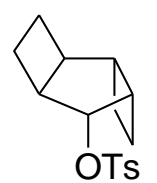

657
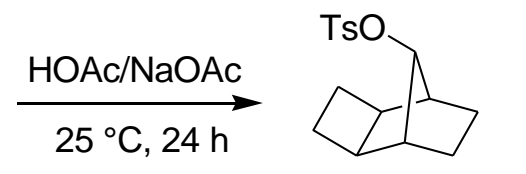

$658(66 \%)$

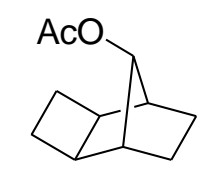

659 (20\%) 
Furthermore, ring rearrangements of [n.3.2]propellane tosylates have been achieved in the same manner. ${ }^{251}$ When endo-[n.3.2]propellane tosylates $\mathbf{6 6 0}$ were subjected to acetolysis, the corresponding rearranged olefins $\mathbf{6 6 2}$ were obtained in 39-68\% yield, next to the unrearranged alcohols 663 in $20-44 \%$ and a small amount of the rearranged alcohols 664 in $3-9 \%$ yield (Scheme 181). This transformation was believed to proceed through carbenium ion intermediate 661.

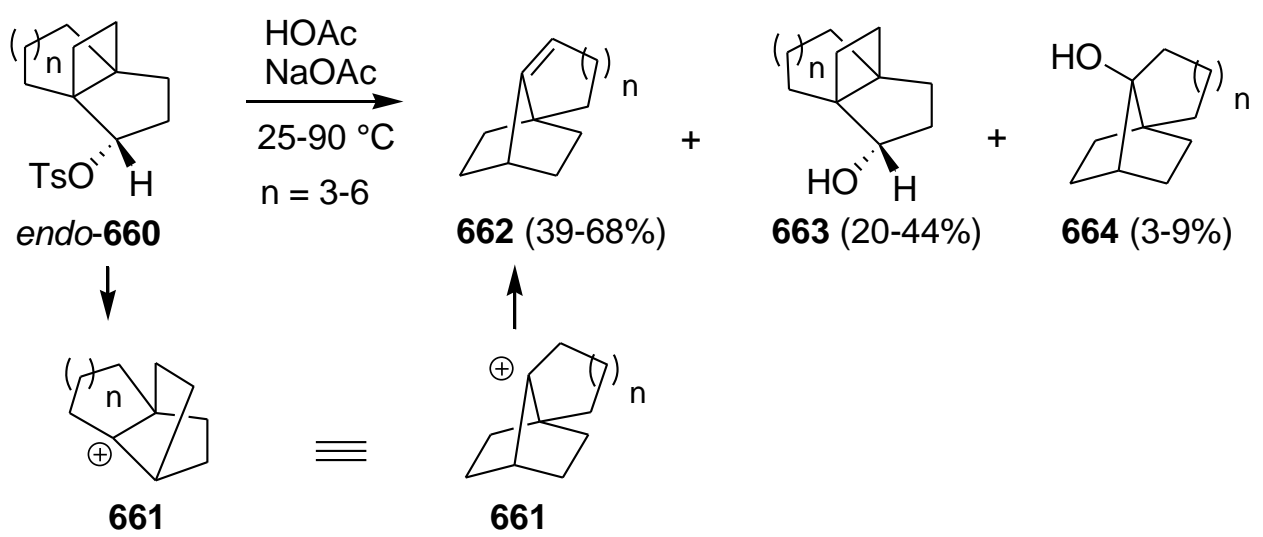

Scheme 181

As a key step in the synthesis of tricyclo[6.4.0.0 $\left.0^{2,6}\right]$ dodecane skeletons (6-5-5 ring systems), solvolysis of $\mathbf{6 6 5}$ sodium formate in formic acid afforded a mixture of enone $\mathbf{6 6 6}$ and the bridged formate $\mathbf{6 6 7}$ in a 64:36 ratio (Scheme 182). From this mixture, the desired tricyclic compound $\mathbf{6 6 6}$ was isolated in 59\% yield and the bridged formate $\mathbf{6 6 7}$ in $19 \%$ yield. ${ }^{252}$ 
<smiles>CCCCCCCC1(CO[Na-])C(=O)C2CCCC21</smiles>
$\frac{1 \text { equiv } \mathrm{HCO}_{2} \mathrm{Na}}{\mathrm{HCO}_{2} \mathrm{H}, \Delta, 50 \mathrm{~min}}$

665

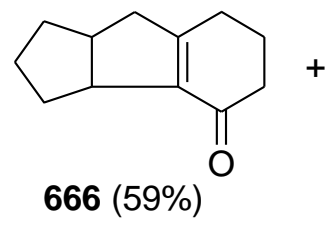

$666: 667(64: 36)$

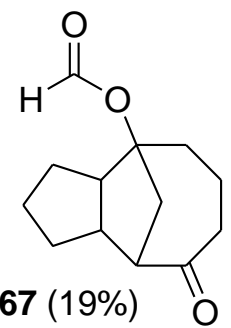

$667(19 \%)$

Scheme 182

The same authors prepared tricyclo[6.3.0.0 $\left.0^{2,6}\right]$ undecane skeletons as well, also called linear triquinane systems. ${ }^{252}$ Upon solvolysis with sodium formate in formic acid or trifluoroacetic acid and sodium acetate, sulfonates 668 were converted into enones 669 and sulfonates 670 in a 1:2 ratio, and in $25-28 \%$ and $57-59 \%$ yield, respectively (Scheme 183).

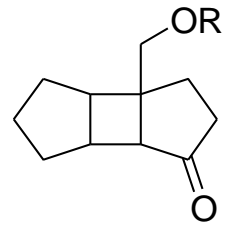

668
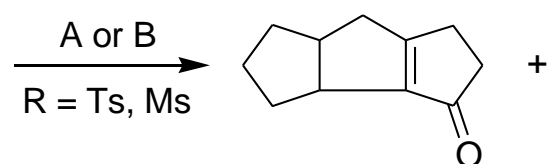

$669(25-28 \%)$

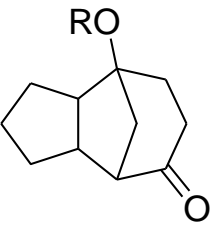

$670(57-59 \%)$

$\mathrm{R}=\mathrm{Ts}$ : method $\mathrm{A}: \mathrm{HCOONa}, \mathrm{HCO}_{2} \mathrm{H}, \Delta, 3 \mathrm{~h}$

$\mathrm{R}=\mathrm{Ms}$ : method $\mathrm{B}: \mathrm{NaOAc}, \mathrm{CF}_{3} \mathrm{CO}_{2} \mathrm{H}, \Delta, 2.5 \mathrm{~h}$

Scheme 183

Finally, when cis-cyclobutane derivative 671 was heated in ethanol at $80{ }^{\circ} \mathrm{C}$ for seven days, a mixture of cyclobutane 672 (substitution product) and ring expanded cyclopentane 673 was obtained in a low yield of $18 \%$ and in a ratio of 5:4 (Scheme 184). ${ }^{253}$

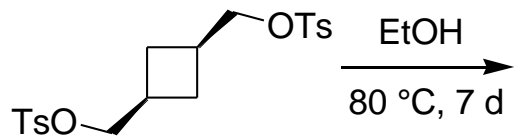

671<smiles>CCOCC1CC(COCC)C1</smiles>

672<smiles>CCOCC1CC[C@@H](OCC)C1</smiles>

673

$672: 673(18 \%)(5: 4)$

Scheme 184 


\subsection{An ether moiety as leaving group}

\subsubsection{An alkoxy or aryloxy group as leaving group}

In principle, also an alkoxy or aryloxy group can be modified into a good leaving group upon treatment with a Lewis acid or a strong acid, enabling analogous ring transformations as compared to these starting from cyclobutylmethyl alcohols.

Treatment of monosilylated cyclobutane-1,2-diol derivatives 674 with one equiv of tin(IV) chloride at $0{ }^{\circ} \mathrm{C}$ for 15 minutes led to the formation of the corresponding $\beta$ hydroxycyclopentanones $\mathbf{6 7 6}$ as the major isomers in 55-81\% yield and $\alpha$ hydroxycyclopentanones 678 as the minor isomers in 0-22\% yield (Scheme 185). ${ }^{254}$ Only one derivative $674\left(\mathrm{R}=\mathrm{H}, \mathrm{R}^{1}-\mathrm{R}^{2}=\left(\mathrm{CH}_{2}\right)_{5}\right)$ was ring expanded toward exclusively $\beta$ hydroxycyclopentanone $\mathbf{6 7 6}$ in $81 \%$ yield. The proposed mechanism involved initial formation of carbenium ion 675 under the influence of the Lewis acid. The ring opening reaction of the cyclobutane ring of $\mathbf{6 7 5}$ resulted in another oxygen-stabilized carbenium ion, i.e. oxonium ion $\mathbf{6 7 7}$, which was trapped by the internally formed silyl enol ether moiety to yield 676 as the major isomer. The minor isomer 678 was formed through a pinacol type rearrangement. 


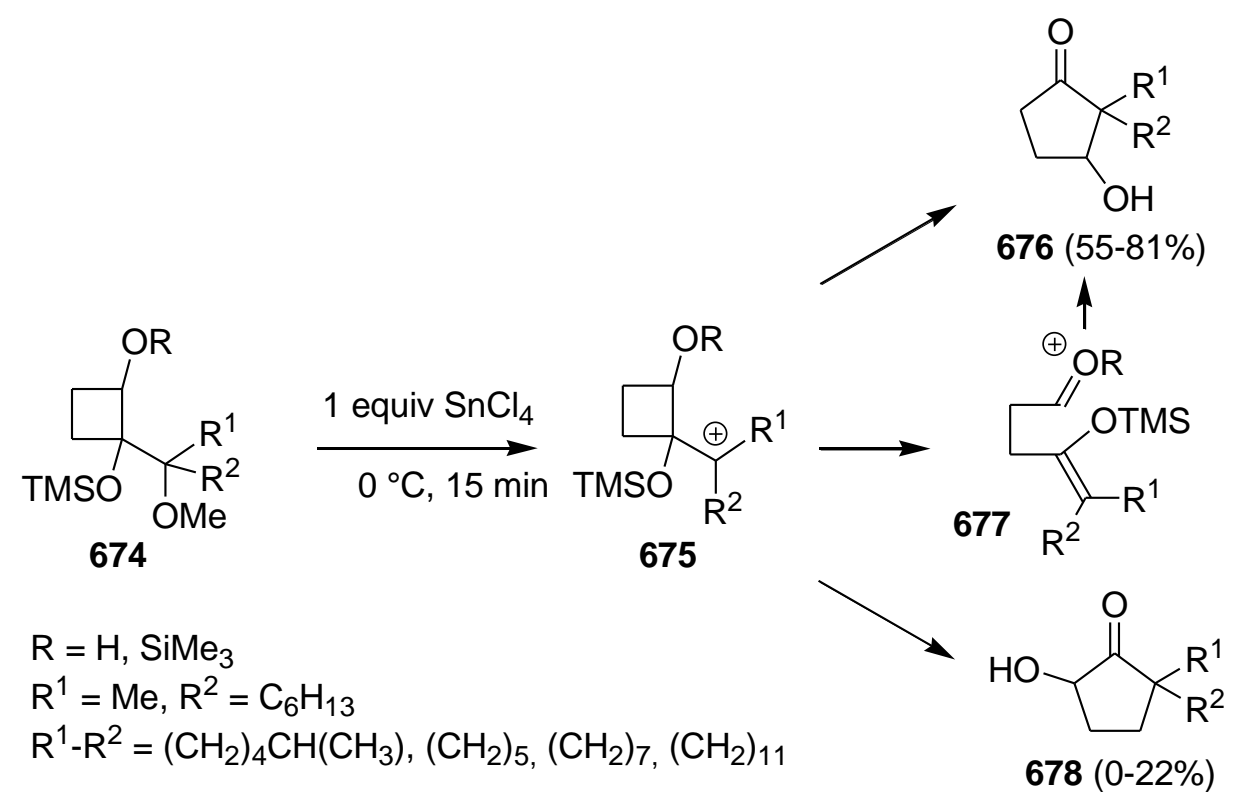

Scheme 185

In the total synthesis of the hydroazulenic sesquiterpene $\beta$-bulnesene $\mathbf{6 8 1}$, precursor 680 was prepared via a pinacol-type rearrangement approach. ${ }^{255}$ Addition of 2.5 equiv of $p$ toluenesulfonic acid monohydrate to cyclobutanone 679 in benzene at reflux for four hours afforded 2-(3-methyl-4-pentenyl)-1,3-cyclopentanedione $\mathbf{6 8 0}$ in 53\% yield (Scheme 186). Again, the presence of an acyl group, adjacent to the diol moiety, controlled the rearrangement.
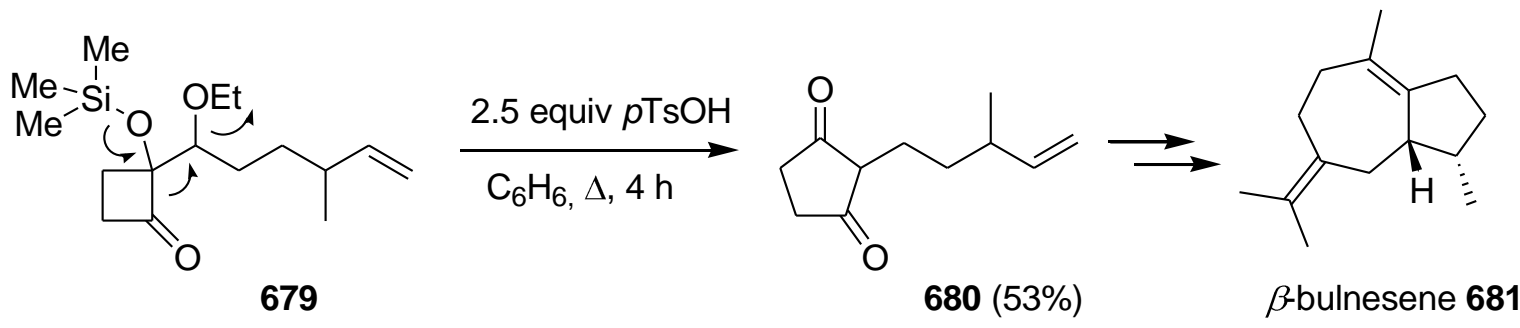

Scheme 186

Also other reagents have been used for the synthesis of 1,3 -cycloalkadiones. ${ }^{256}$ For example, treatment of 2-hydroxy-2-(methoxymethyl)cyclobutanone $\mathbf{6 8 2}$ with 0.2 equiv of potassium 
hydrogen sulfate at $170-180{ }^{\circ} \mathrm{C}$ under reduced pressure $(20-25 \mathrm{mmHg}$ ) formed the ring expanded 1,3-cyclopentanedione $\mathbf{6 8 3}$ in $75 \%$ yield (Scheme 187).

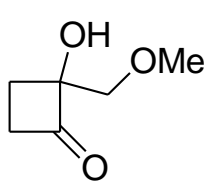

682

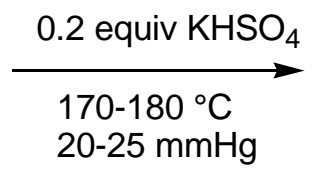

$683(75 \%)$

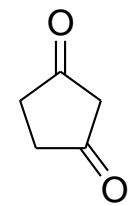

Scheme 187

As an extension of the synthesis of dicyclopentane-1,3-diones, different cyclobutanones have been treated with trifluoroacetic acid. ${ }^{238 a, 257}$ Attached directly to the diol moiety, the cyclobutanone ring was expected to exert directive effects in the cationic rearrangements. When cyclobutanones 684 were treated with an excess of trifluoroacetic acid at $25{ }^{\circ} \mathrm{C}$ to reflux temperature for one to 20 hours, depending on the substrate, the corresponding 2-alkyl3-hydroxy- or 2-aryl-3-hydroxy-2-cyclopentenones $\mathbf{6 8 5}$ were obtained in 78 to $97 \%$ yield (Scheme 188). $p$-Toluenesulfonic acid and boron(III) fluoride etherate were also found to be effective for this ring expansion.

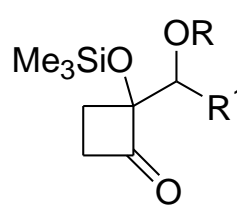

684

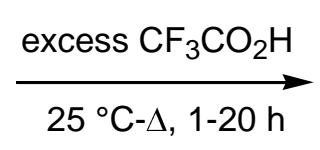

$\mathrm{R}=\mathrm{SiMe}_{3}, \mathrm{Me}, \mathrm{Et}$

$\mathrm{R}^{1}=\mathrm{Ph}, n_{5} \mathrm{H}_{11}, n \mathrm{C}_{9} \mathrm{H}_{19}$<smiles>O=C1CCC(O)=C1[Tl]</smiles>

$685(78-97 \%)$

Scheme 188 
However, when cyclobutanones 686, having an extra substituent at the $\alpha$-carbon of the ether, were treated with an excess of trifluoroacetic acid under the same conditions, 2,2-diethyl-1,3cyclopentadione or spiro-1,3-cyclopentadiones $\mathbf{6 2 2}$ were isolated in 87 to $94 \%$ yield (Scheme 189). Again, different acids or Lewis acids could be used, but an excess of trifluoroacetic acid was chosen for the sake of easy workup (vide supra).

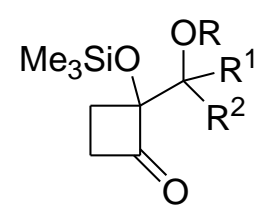

686

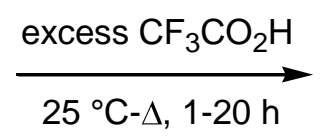

$\mathrm{R}=\mathrm{Me}, \mathrm{Et} ; \mathrm{R}^{1}, \mathrm{R}^{2}=\mathrm{Et}, \mathrm{Et}$

$\mathrm{R}^{1}-\mathrm{R}^{2}=\left(\mathrm{CH}_{2}\right)_{5},\left(\mathrm{CH}_{2}\right)_{11}$

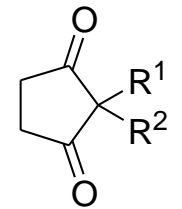

$622(87-94 \%)$

\section{Scheme 189}

In an effort to synthesize 2-methyl-, 2-ethyl- and 2-isopropyl-1,3-cyclopentadiones $\mathbf{6 8 8}$ the procedure of Nakamura and Kuwajima ${ }^{238 a}$ has been applied to silylated 2hydroxycyclobutanones $\mathbf{6 8 7} .^{258}$ Suprisingly, none of the expected products was obtained. Application of an additional acidic co-catalyst, i.e. Nafion- $\mathrm{H}$, a sulfonated tetrafluoroethylene based polymer, which was reported to give high yields in pinacol rearrangements proved to be successful. ${ }^{259}$ When Nafion-H was added to a solution of $\mathbf{6 8 7}$ in trifluoroacetic acid, followed by heating at $85{ }^{\circ} \mathrm{C}$ for ten hours, the corresponding 2-alkyl-1,3-cyclopentadiones $\mathbf{6 8 8}$ were obtained in 42-70\% yield (Scheme 190).<smiles>[R]C(OCC)C1(O[Si](C)(C)C)CCC1=O</smiles>

687

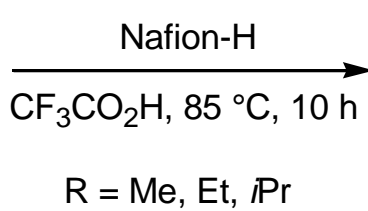

$\mathrm{R}=\mathrm{Me}, \mathrm{Et}, \mathrm{IPr}$<smiles>[R]C1C(=O)CCC1=O</smiles>

$688(42-70 \%)$ 
Lewis acid-mediated reactions of 1,2-bis(trimethylsilyloxy)cyclobutene with acetals, followed by treatment with Amberlyst 15 resin in trifluoroacetic acid, have been reported to yield 1,3cyclopentanediones. ${ }^{260}$ This type of rearrangement had already been investigated before by Kuwajima et al. and Rao et al. ${ }^{257,258}$ Now, the authors stated that addition of Amberlyst 15 resin to cyclobutanones 690 in trifluoroacetic acid afforded 1,3-cyclopentanediones, occurring mainly in the enolized form 691, in 49-87\% yield (Scheme 191).<smiles>CCOc1ccc(OCC)cc1</smiles>

689<smiles>[R]C(OCC)C1(O)CCC1=O</smiles>

690<smiles>[R]C1=C(O)CCC1=C[AsH3]</smiles>

$691(49-87 \%)$

$\mathrm{R}=\mathrm{CH}_{3}, \mathrm{CH}_{3}\left(\mathrm{CH}_{2}\right)_{8}$, cHex,

$\mathrm{C}_{6} \mathrm{H}_{5}, \mathrm{CH}_{2}(\mathrm{CH})_{2} \mathrm{C}_{6} \mathrm{H}_{5}$,

$\mathrm{CH}\left(\mathrm{CH}_{3}\right)\left(\mathrm{CH}_{2}\right)_{3} \mathrm{CH}\left(\mathrm{CH}_{3}\right) \mathrm{CH}_{2} \mathrm{CH}_{3}$

Scheme 191

In analogy, treatment of cyclobutene 692 with diethyl acetals afforded cyclobutanones 693 and a small fraction of $\mathbf{6 9 4}$ under the acidic conditions of the reaction. ${ }^{260}$ However, when gem-dimethyl cyclobutanones 693 and 694 were treated with Amberlyst 15 resin, no 1,3diketone was formed, but instead enols of 1,2-diketones 695 were obtained in 39-54\% yield (Scheme 192).

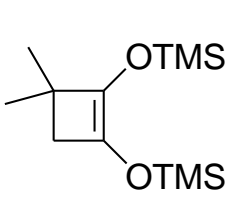

692

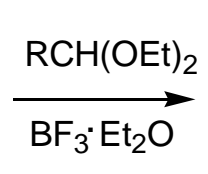

$\mathrm{R}=\mathrm{CH}_{3}, \mathrm{CH}_{3}\left(\mathrm{CH}_{2}\right)_{8}, \mathrm{C}_{6} \mathrm{H}_{5}, \mathrm{CHex}$ $\mathrm{CH}\left(\mathrm{CH}_{3}\right)\left(\mathrm{CH}_{2}\right)_{3} \mathrm{CH}\left(\mathrm{CH}_{3}\right) \mathrm{CH}_{2} \mathrm{CH}_{3}$<smiles>[2H]C1(O)CC(C)(C)C1=O</smiles>

694

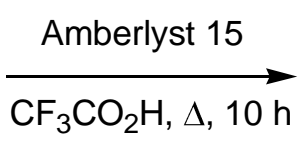<smiles>[R]C1=C(O)C(=O)CC1(C)C</smiles>

695 (39-54\%) 


\section{Scheme 192}

The preparation of $\alpha$-aryl- and $\alpha$-vinylcyclopentenones has been achieved via two approaches. In a first method, silylated $\alpha$-methylidenecyclobutanols 696 were treated with an excess of trifluoroacetic acid at room temperature for $30 \mathrm{~min}$ to 12 hours to afford the corresponding 3methyl-2-cyclopentenones $\mathbf{6 9 8}$ in 80-97\% yield (Scheme 193). ${ }^{261}$ The second route involved tin(IV) chloride treatment of silylated 1,2-cyclobutanediol 699 for the preparation of enones 700 (Scheme 193). Substrates 696 and 699 were prepared from 1,2bis(trimethylsilyloxy)cyclobutene $\mathbf{6 8 9}$.

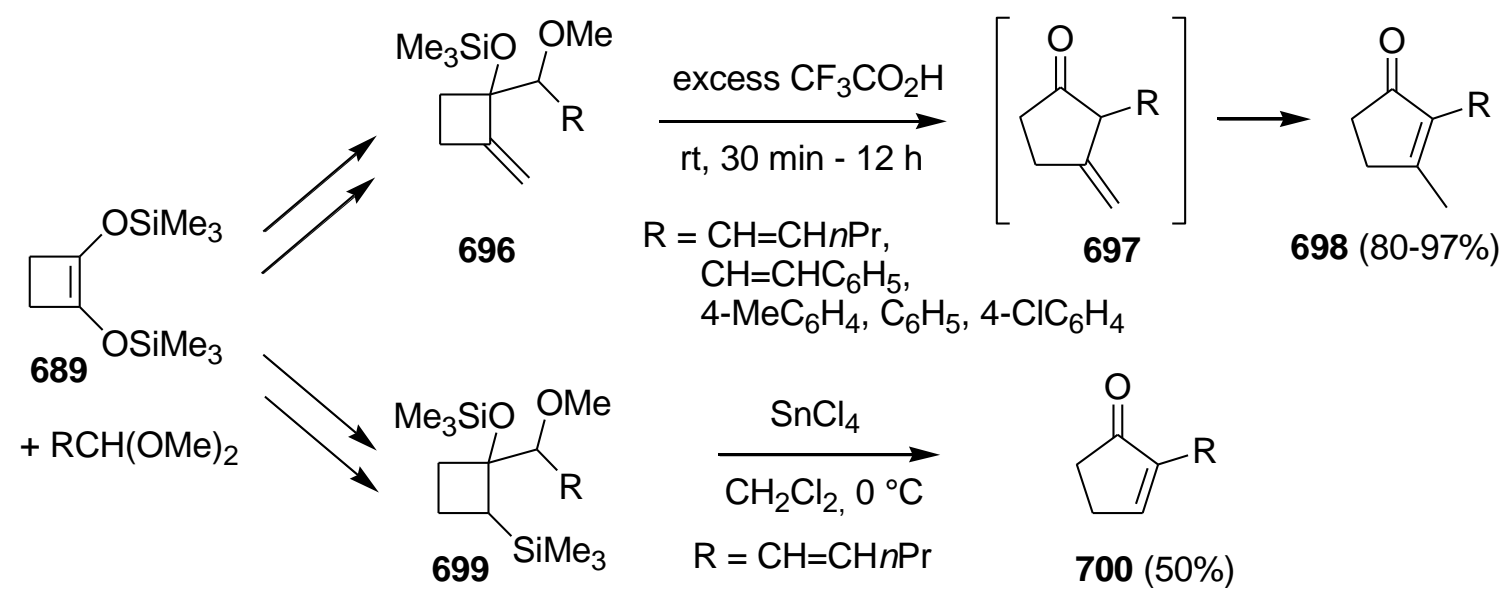

Scheme 193

In the course of the total synthesis of $( \pm)$-retigeranic acid 704, the last five-membered ring was constructed via ring enlargement of the corresponding cyclobutanone, using an activated methoxygroup as a promoter for this ring expansion. ${ }^{262}$ Treatment of ketone 701 with 1.5 equiv of the lithio derivative of acetaldehyde dimethylmonothioacetal in tetrahydrofuran at $78{ }^{\circ} \mathrm{C}$ formed the corresponding carbonyl adduct in $73 \%$ via rearrangement of intermediate $\mathbf{7 0 2}$ utilizing three equiv of cuprous triflate in the presence of 1.5 equiv of triethylamine in 
benzene at $23{ }^{\circ} \mathrm{C}$ for ten minutes (Scheme 194). No yield was mentioned for this step, and the crude compound $\mathbf{7 0 3}$ was used in the next reactions toward retigeranic acid $\mathbf{7 0 4}$.
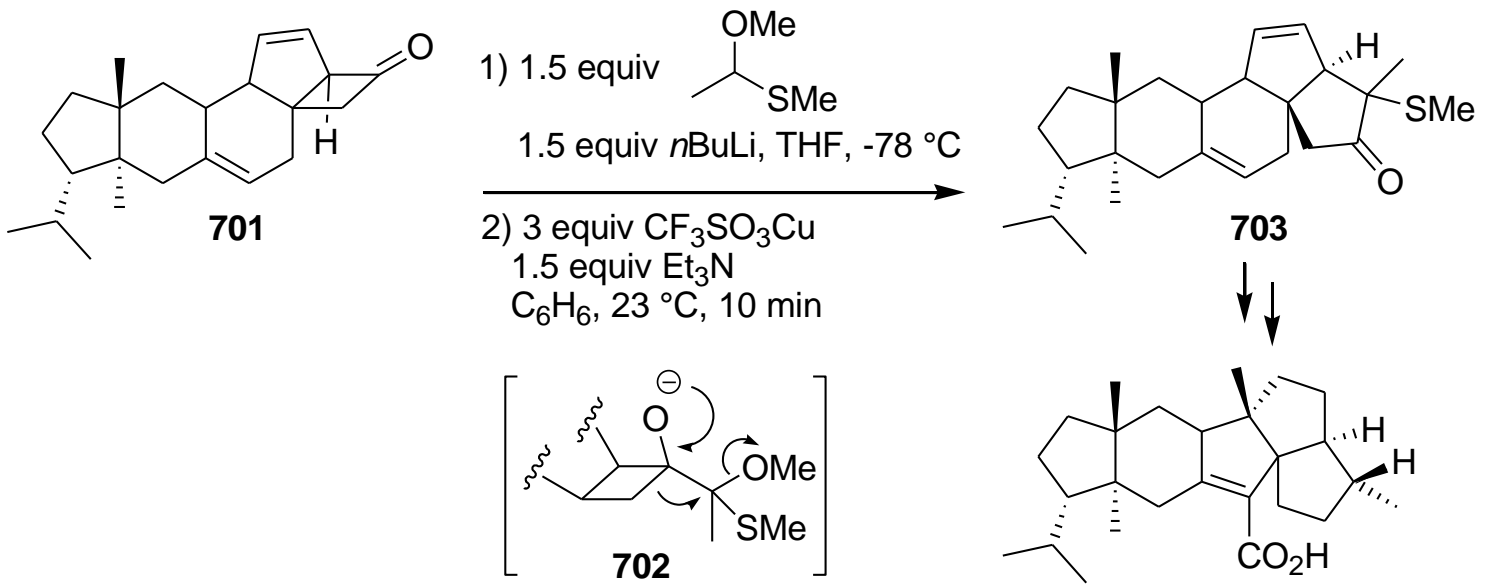

Scheme 194

Within the field of polycyclic aromatic hydrocarbon chemistry, attempts to isolate anthracene adduct 708, produced via an acid-catalyzed rearrangement, failed and instead, when heating cyclobutanone $\mathbf{7 0 5}$ in trifluoroacetic acid for 15 minutes, an equimolar mixture of anthracene 709 and 9,10-disubstituted anthracene 711 was isolated (Scheme 195). ${ }^{263}$ At room temperature, consumption of substrate $\mathbf{7 0 5}$ took about two hours, but again only anthracene $\mathbf{7 0 9}$ and $\mathbf{7 1 1}$ were obtained. As expected, the pinacol rearrangement of $\mathbf{7 0 5}$ to $\mathbf{7 0 8}$ occurred, but the spirodiketone $\mathbf{7 0 8}$ was not stable under these conditions. Acid-catalyzed retro-Diels Alder fragmentation produced anthracene $\mathbf{7 0 9}$ and 2-methylene-1,3-cyclopentanedione $\mathbf{7 1 0}$. Acceleration of the Diels Alder cycloaddition by acid-catalysis is well-known. ${ }^{264}$ The twofold electrophilic substitution of $\mathbf{7 1 0}$ on the cognate anthracene nucleus led to $\mathbf{7 1 1}$, and the overall stoichiometry of the process provided for a molar equivalent of anthracene. No yields were mentioned for this reaction. 
However, when the cyclobutanone ring of anthracene adduct $\mathbf{7 0 5}$ was converted into the corresponding methylenecyclobutane 706, pinacolic ring expansion of $\mathbf{7 0 6}$ proceeded with clean migration of the vinyl group, providing the spiroannelated cyclopentanone $\mathbf{7 0 7}$ in $\mathbf{7 5 \%}$ yield without tendency for retro-Diels Alder fragmentation. Conversion of alkene 707 to ketone $\mathbf{7 0 8}$ was accomplished by ozonolysis to synthesize the preferred adduct $\mathbf{7 0 8}$.

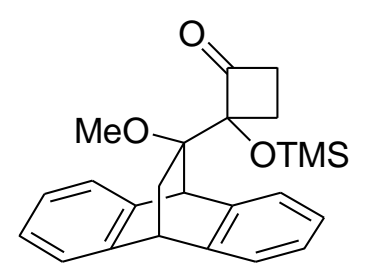

705

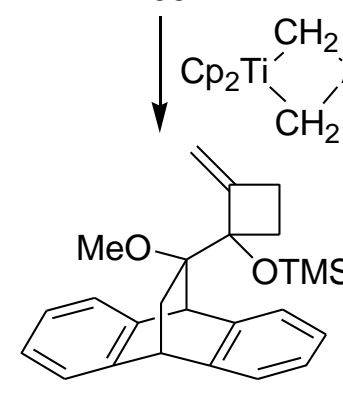

706

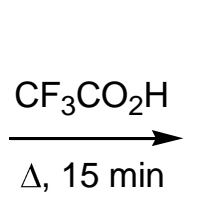

$\Delta, 15 \min$
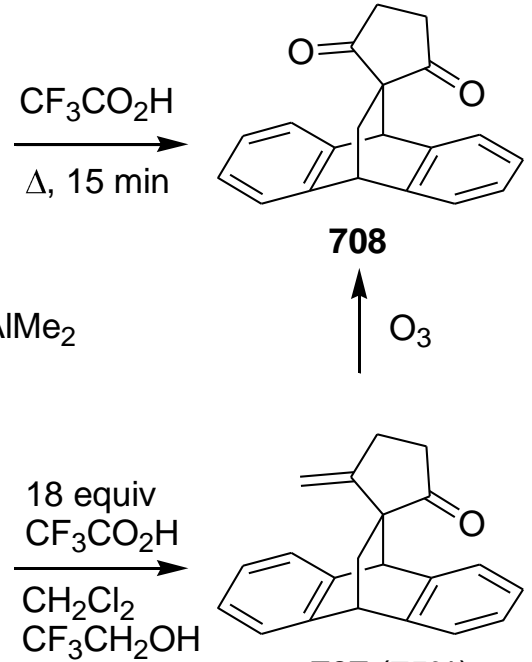

$\mathrm{rt}, 2 \mathrm{~h}$
708

$\uparrow \mathrm{O}_{3}$

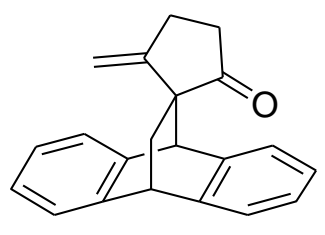

$707(75 \%)$<smiles>C=C1C(=O)CCC1=O</smiles>

709<smiles>O=C1CCC(O)=C1Cc1c2ccccc2c(CC2=C(O)CCC2=O)c2ccccc12</smiles>

Scheme 195

With the intention to synthesize the five-membered ring of the methyl ester of 15dehydroprostaglandin $\mathrm{B} 1714\left(\mathrm{R}=\mathrm{CO}_{2} \mathrm{CH}_{3}\right),{ }^{265}$ a ring rearrangement of silylated 2hydroxycyclobutanones has been performed according to Oppolzer's ${ }^{255}$ and Kuwajima and Nakamura's method. ${ }^{257}$ The silylated 2-hydroxycyclobutanones 712 were treated with 2.5 equiv of $p$-toluenesulfonic acid monohydrate in benzene at reflux for four hours to afford the corresponding 2-alkyl-1,3-cyclopentadiones $\mathbf{7 1 3}$, which were immediately used as such in the next step (Scheme 196). Also pyridinium 4-toluenesulfonate has been used for a ring rearrangement toward the synthesis of 2-substituted cyclopentanones. ${ }^{266}$ 

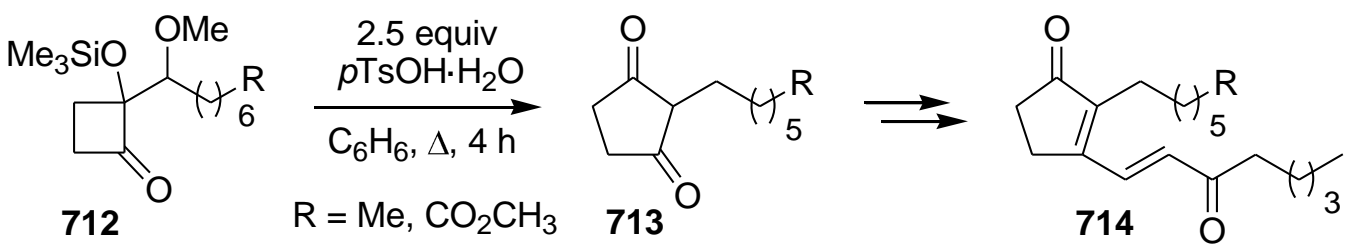

Scheme 196

Recently, in studies toward the synthesis of meloscine, a cyclobutane to cyclopentane rearrangement has been described using potassium carbonate. ${ }^{267}$ When cyclobutane 715 was stirred in methanolic potassium carbonate at room temperature for six hours, a cyclopentane1,2-diketone was formed in $98 \%$ yield, exclusively exisiting in the tautomeric enol form $\mathbf{7 1 7}$ (Scheme 197).

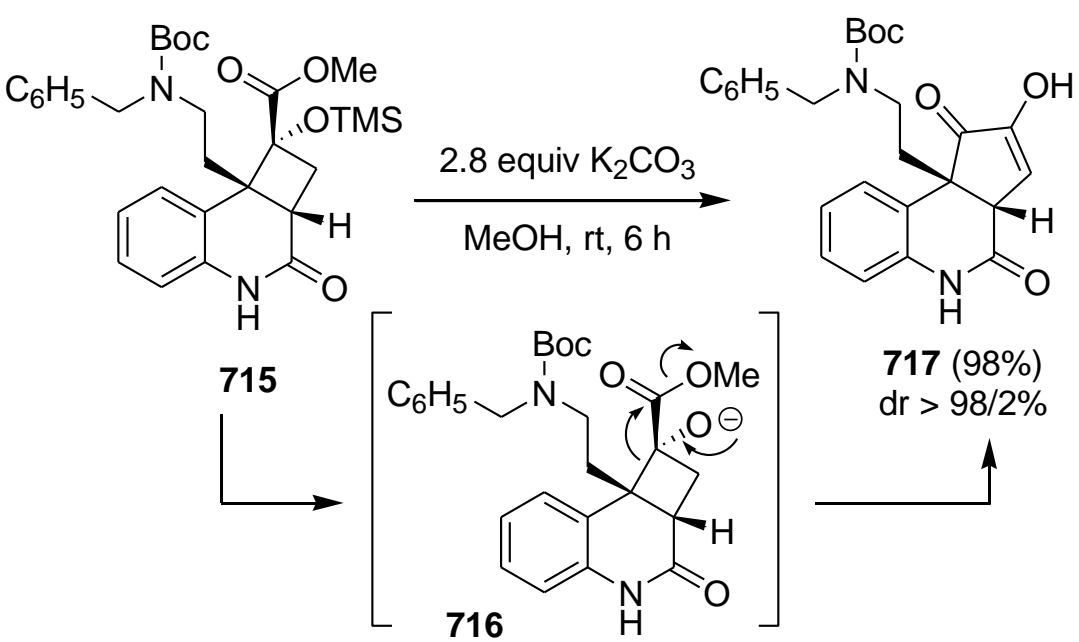

Scheme 197

A special case of cyclopentanone synthesis has been reported by Ito et al. ${ }^{268}$ When cyclobutanones 718 were treated with five mol\% of $[\mathrm{Rh}(\mathrm{nbd}) \mathrm{dppp}] \mathrm{PF}_{6}$ at $170{ }^{\circ} \mathrm{C}$ for 12 hours, cyclopentanones $\mathbf{7 2 2}$ were isolated in $81-88 \%$ yield (Scheme 198). First, a fivemembered cyclic acylrhodium intermediate $\mathbf{7 1 9}$ underwent $\beta$-oxygen elimination to form the olefin-coordinated acylrhodium intermediate $\mathbf{7 2 0}$, followed by recyclization to a six- 
membered acylrhodium $\mathbf{7 2 1}$ by addition of the $\mathrm{Rh}-\mathrm{O}$ linkage across the $\mathrm{C}-\mathrm{C}$ double bond in a 6-endo mode. Finally, reductive elimination forming a C-C bond afforded cyclopentanones 722. An important remark to this synthesis was the fact that the reaction lacked generality.

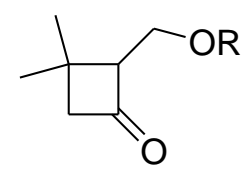

718

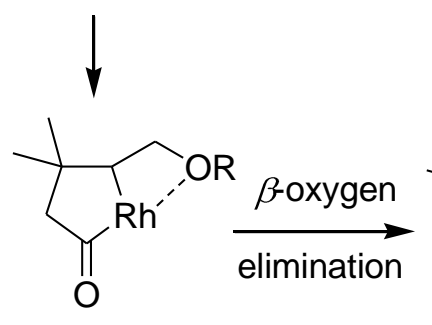

719

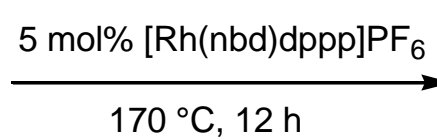

$\mathrm{R}=\mathrm{C}_{6} \mathrm{H}_{5}, \mathrm{CH}_{2} \mathrm{C}_{6} \mathrm{H}_{5}$

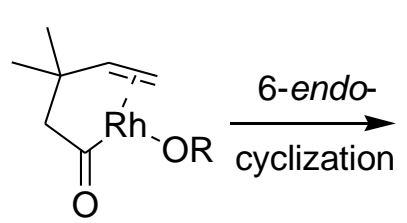

720<smiles>CC1(C)CC(=O)CC1O</smiles>

722 (81-88\%)

A reductive<smiles>[R]OC1CPC(=O)CC1(C)C</smiles>

721

Scheme 198

\subsubsection{Ring opening of an epoxide as driving force for the ring expansion reaction}

Due to the high ring strain energy associated with epoxides, 2-cyclobutyl oxirane systems can be regarded as suitable substrates for a cyclobutane to cyclopentane rearrangement. Nevertheless, only few examples are known in the literature based on this approach.

In a first example, the four racemic diastereoisomers of 7-oxiranylbicyclo[4.2.0]octan-7-ol 723 were treated with boron(III) fluoride etherate under mild conditions. ${ }^{269}$ Three of the isomers underwent regio- and stereoselective rearrangements to the ring expanded hydroxymethyl substituted ketones $\mathbf{7 2 4}$ and $\mathbf{7 2 5}$, the fourth diastereoisomer only gave unreacted starting material. 
In particular, treatment of bicyclo[4.2.0]octan-7-ols 723a-b with a catalytic amount of $\mathrm{BF}_{3} \cdot \mathrm{Et}_{2} \mathrm{O}$ in dichloromethane at $-78{ }^{\circ} \mathrm{C}$ afforded bicyclo[4.3.0]nonan-8-ones 724 with a shift of the bridgehead in a highly regioselective manner in $45 \%$ and $74 \%$ yield (Scheme 199). However, bicyclo[4.2.0] octan-7-ol 723c rearranged to bicyclo[4.3.0]nonan-7-one $\mathbf{7 2 5}$ at -17 ${ }^{\circ} \mathrm{C}$ in $88 \%$ yield by a shift of the methylene group (Scheme 199).

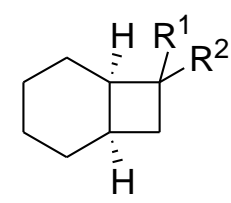

723a-b<smiles>[R]O[R]O[R]#[Y]C1CO1</smiles>

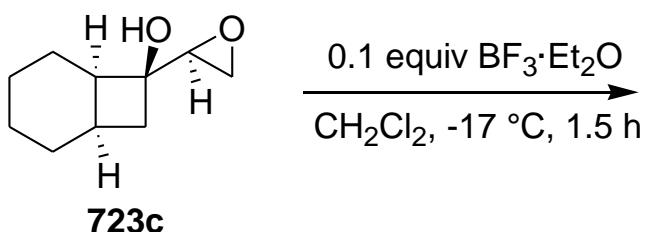

$$
\frac{0.1 \text { equiv } \mathrm{BF}_{3} \cdot \mathrm{Et}_{2} \mathrm{O}}{\mathrm{CH}_{2} \mathrm{Cl}_{2},-78^{\circ} \mathrm{C}, 1.5 \mathrm{~h}}
$$

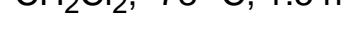

$$
\text { O }
$$$$
\text { 西 }
$$

Scheme 199<smiles>[R]C1C(=O)C[C@H]2CCCC[C@@H]12</smiles>

$724(45-74 \%)$

$\mathrm{R}=\cdots \cdot \mathrm{CH}_{2} \mathrm{OH}$

$\mathrm{R}=-\mathrm{CH}_{2} \mathrm{OH}$<smiles>O=C1[C@H](CO)C[C@H]2CCCC[C@H]12</smiles>

In an alternative enantioselective total synthesis of (+)-laurene 142, the five-membered ring was obtained via ring enlargement of the corresponding cyclobutane through activation of an adjacent epoxide (Scheme 200). ${ }^{82}$ A first approach was already described in this review in the part on palladium-mediated ring enlargements of vinylcyclobutanols (Scheme 42 ). $\mathrm{BF}_{3} \cdot \mathrm{Et}_{2} \mathrm{O}$ in tetrahydrofuran at $-78{ }^{\circ} \mathrm{C}$ for four hours effected the ring expansion of the cyclobutane ring of epoxides $\mathbf{7 2 6}$ to cyclopentanone 727, which underwent dehydration to furnish $\alpha$ methylenecyclopentanone $\mathbf{7 2 8}$ in $\mathbf{7 6 \%}$ overall yield from 726. This compound $\mathbf{7 2 8}$ was used as a precursor for (+)-laurene $\mathbf{1 4 2}$. 
$\overbrace{R^{2}}$

726

$\mathrm{R}^{1}=\cdots \cdot \mathrm{OH} \mathrm{R}^{2}=$

$\mathrm{O}$

$\mathrm{R}^{1}=-\mathrm{OH} \mathrm{R}^{2}=\stackrel{\cdots \prime \prime}{\mathrm{O}}$

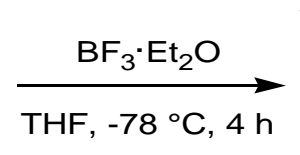

1....

727

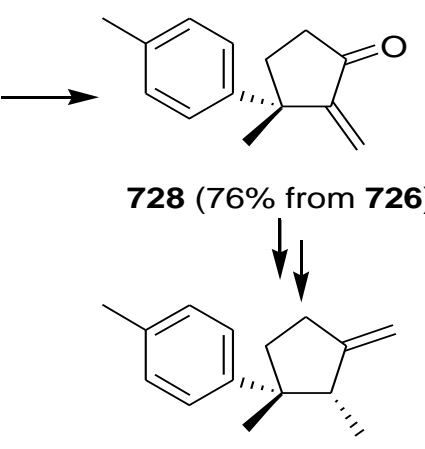

(+)-laurene 142

Scheme 200

Zinc(II) bromide has been used as a catalyst for the stereoselective construction of quaternary carbons in the synthesis of diastereomerically enriched spirocyclic diols. ${ }^{270}$ When hydroxy epoxide 729 was treated with five mol\% of zinc(II) bromide in dichloromethane at room temperature for 1.5 hours, the corresponding 1-hydroxyspiro[4.4]nonan-6-one $\mathbf{7 3 0}$ was isolated in $94 \%$ yield (Scheme 201). A bromo-substituted byproduct or a competitive rearrangement product (allylic alcohol) was not isolated. ${ }^{271}$ The synthesized compound 730 could be used as substrate for the preparation of the corresponding spirocyclic diol.

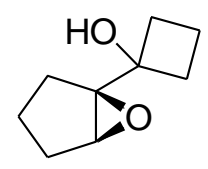

729

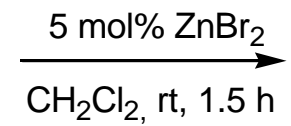

$\mathrm{CH}_{2} \mathrm{Cl}_{2}$, rt, $1.5 \mathrm{~h}$

$730(94 \%)(d r 57: 43)$

Scheme 201

In the next example, titanium(IV) chloride has been used for the formation of functionalized azaspirocyclic cyclopentanones 732 (Scheme 202). ${ }^{272}$ Epoxides 731 underwent facile ring expansion toward cyclopentanones 732a and 732b in $95-96 \%$ yield as 1.1-2.6:1 mixtures of diastereoisomers via addition of 1.1 equiv titanium(IV) chloride in dichloromethane at $-78{ }^{\circ} \mathrm{C}$ for 30 minutes, although with low stereoselectivity. Cyclopentanones 732a are the apparent 
products of an antiperiplanar 1,2-alkyl migration toward the epoxide, while cyclopentanones 732b seemingly result via a synperiplanar 1,2-alkyl migration process. Similar azaspirocyclic cyclopentanones have been made through an acid- and a halogen cation-promoted activation of a double bond (Scheme 27)..$^{61,67}$

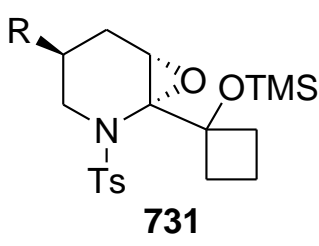

731

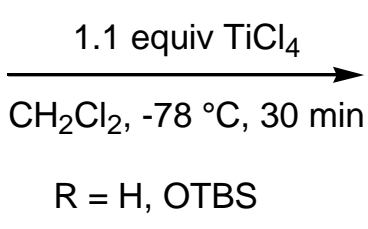

$\mathrm{R}=\mathrm{H}$, OTBS<smiles>[R]C1C[C@H](O)[C@@]2(CCCC2=O)[C@H]([18OH])C1</smiles>

732a $(50-69 \%)$<smiles>[R]C1C[C@H](O)[C@]2(CCCC2=O)N([AsH])C1</smiles>

$732 b(27-45 \%)$

732a:732b (1.1-2.6:1)

Recently, a rearrangement through ring opening of an epoxide has been reported in the synthesis of $( \pm)$-cerapicol 736, a protoilludane sesquiterpene. ${ }^{273}$ Upon treatment with 13 equiv of trifluoroacetic acid in pentane, bicycle $\mathbf{7 3 3}$ rearranged to yield a mixture of trifluoroacetates containing $48 \%$ of spiro compound $\mathbf{7 3 4}$ and $16 \%$ of tricyclic compound $\mathbf{7 3 5}$ (Scheme 203). The preferred formation of $\mathbf{7 3 4}$ indicated that the cyclopentyl cation formed by enlargement of the 3,3-dimethylcyclobutyl ring was effectively trapped.

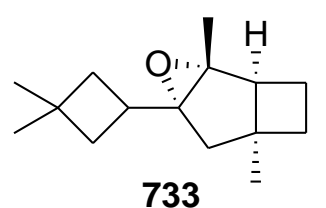

733

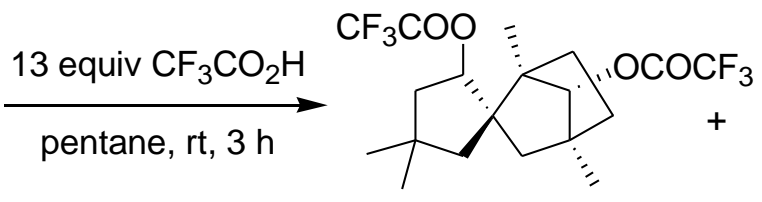

$734(48 \%)$<smiles>CC1(C)CC2=C(C1)[C@]1(C)C[C@](C)(C2)C[C@]1(C)OC(=O)F</smiles>

$735(16 \%)$

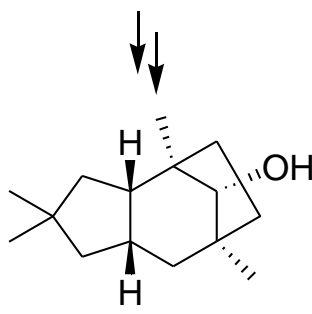

(士)-cerapicol 736

Scheme 203 


\subsubsection{Ring opening of an activated tetrahydrofuran ring as driving force for the ring expansion reaction}

In a few isolated cases, an activated oxolane ring has been employed as a way to trigger a cyclobutane to cyclopentane ring expansion.

For example, when bicyclo[3.2.0]heptanes 737 were treated with 0.5 equiv of $\mathrm{TfOH}$ in dichloromethane at $-78{ }^{\circ} \mathrm{C}$ to room temperature, a ring rearrangement was established toward 1,2-dialkylcyclopentanones 741 in $76-82 \%$ yield $\left(R^{3}=H\right)^{274}$ and in $52-76 \%$ yield $\left(R^{3} \neq H\right)^{275}$ in a stereospecific manner via migration of the $\mathrm{C}_{1}-\mathrm{C}_{5}$ bond (Scheme 204). These cyclopentanones $\mathbf{7 4 1}$ can be used in the synthesis of many natural products. ${ }^{276,277}$ For example, the same authors have reported the synthesis of spirocyclopentanone $741\left(\mathrm{R}^{1}-\mathrm{R}^{2}=\right.$ $\left.\left(\mathrm{CH}_{2}\right)_{2} \mathrm{CHCH}_{3}\left(\mathrm{CH}_{2}\right)_{2}\right)$ in $76 \%$ yield as a precursor in the total synthesis of the natural product $( \pm)$ - $\alpha$-cedrene $742 .{ }^{276}$ Also adduct $741\left(\mathrm{R}^{1}, \mathrm{R}^{2}=\mathrm{Me}\right)$ is an advanced intermediate in the synthesis of planococcyl acetate, the pheromone of the citrus mealy bug. ${ }^{278}$ The cyclopentanones $741\left(\mathrm{R}^{1}=\mathrm{Me}, \mathrm{R}^{2}=4\right.$-methylcyclohexyl) and $741\left(\mathrm{R}^{1}=\mathrm{Me}, \mathrm{R}^{2}=1,4-\right.$ dimethylcyclohexyl) comprise the carbon skeletons of cuprenolide and trichodiene, respectively.

The selectivity observed in the pinacol rearrangement of cyclobutane derivatives 737, involving exclusive migration of the $\mathrm{C}_{1}-\mathrm{C}_{5}$ bond in contrast to the stereoelectronically favoured $\mathrm{C}_{1}-\mathrm{C}_{7}$ bond, was explained based on the intermediates as depicted below. A concerted migration of the $\mathrm{C}_{1}-\mathrm{C}_{5}$ bond in the protonated species of 737 led to formation of carbenium ions $\mathbf{7 3 9}$, which were stabilized by the $\mathrm{OH}$ group through formation of the cyclic intermediate 740. Rapid collapse of $\mathbf{7 4 0}$ led to products 741. In case of $\mathrm{C}_{1}-\mathrm{C}_{7}$ bond migration, the stabilization of the intermediate carbenium ions by the $\mathrm{OH}$ group required unfavorable formation of the strained oxetanes $\mathbf{7 3 8}$ and was thus inhibited. 


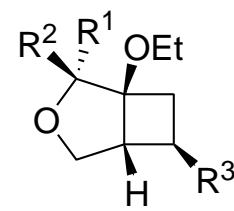

737

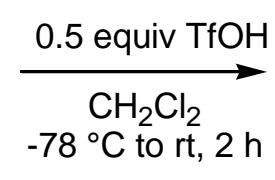

$\mathrm{R}^{3}=\mathrm{H}$ $\mathrm{R}^{3} \neq \mathrm{H}$<smiles>[R]C1CC(=O)[C@]([R7])(CO)[C@@H]1CO</smiles>

$741(76-82 \%)$ 741 (52-76\%)

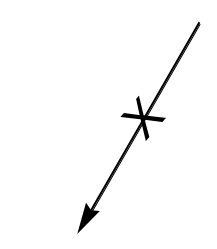

(OEt

738 $\mathrm{R}^{1}=\mathrm{Me}, \mathrm{Et}, \mathrm{CH}_{2} \mathrm{C}_{6} \mathrm{H}_{5} ; \mathrm{R}^{2}=\mathrm{Me}$, Et, $\mathrm{CH}_{2} \mathrm{C}_{6} \mathrm{H}_{5},\left(\mathrm{CH}_{2}\right)_{2} \mathrm{C}_{6} \mathrm{H}_{5}, \mathrm{CO}_{2} \mathrm{Me}$ 4-Me-cHex, 1,4-diMe-cHex $\mathrm{R}^{3}=\mathrm{H}, \mathrm{Me}, \mathrm{C}_{6} \mathrm{H}_{5}, \mathrm{CO}_{2} \mathrm{Me}$

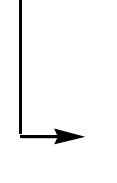

$\mathrm{HO}$<smiles>[R]C1([R7])[C@@H](O)CC[C@H]1CO</smiles>

739<smiles>[R]C([R])C1(OCC)C2CCC1OC2</smiles>

740

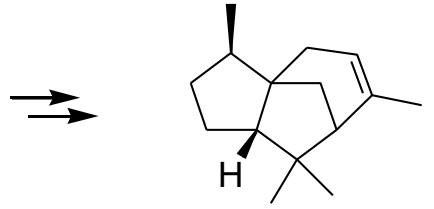

$\alpha$-cedrene $\mathbf{7 4 2}$

$\mathrm{R}^{1}-\mathrm{R}^{2}=\left(\mathrm{CH}_{2}\right)_{2} \mathrm{CHCH}_{3}\left(\mathrm{CH}_{2}\right)_{2}$ $\mathrm{R}^{3}=\mathrm{H}$

Scheme 204

In an effort to synthesize hydroxyalkyl-substituted cyclopentanones, a mixture of strong acids was used to effect bond migration of the appropriate cyclobutanes. ${ }^{279}$ Rearrangement of cyclobutanes $\mathbf{7 4 3}$ took place when treated with trifluoroacetic acid and a catalytic amount of trifluoromethane sulfonic acid at $50-55{ }^{\circ} \mathrm{C}$ for one hour to afford cyclopentanones $\mathbf{7 4 4}$ in 50$67 \%$ yield (Scheme 205). The cyclopentanones 744, obtained in each case, were mixtures of diastereoisomers epimeric at $\mathrm{C}_{5}$ in about 2.5:1 ratio. The stability of the carbenium ion formed after cyclobutane bond migration dictated the reaction course during rearrangement, providing a selectivity for 1,5-bond over 1,7-bond migration.

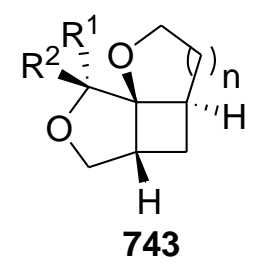

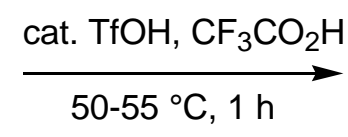

$$
\mathrm{n}=1,2
$$

$\mathrm{R}^{1}=\mathrm{Me}$

$\mathrm{R}^{2}=\mathrm{Me}, \mathrm{CH}_{2} \mathrm{C}_{6} \mathrm{H}_{5},\left(\mathrm{CH}_{2}\right)_{2} \mathrm{C}_{6} \mathrm{H}_{5}$

$\mathrm{R}^{1}-\mathrm{R}^{2}=\left(\mathrm{CH}_{2}\right)_{4},\left(\mathrm{CH}_{2}\right)_{5}$<smiles>[R7]C1([R7])C(=O)[C@@H](C[14CH2]O)C[C@H]1CO</smiles>

744 (50-67\%)

Scheme 205 


\subsubsection{A special case}

A last and rather special example involved gold-catalyzed isomerization of a propargylic ester. $^{280}$ Treatment of cyclobutane $\mathbf{7 4 5}$ with $10 \%$ of gold(I) triflate in dichloroethane at room temperature for 12 hours led to the isolation of cyclopentene $\mathbf{7 4 8}$ in 54\% yield (Scheme 206).

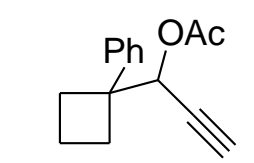

745<smiles>C#CC(OC(C)=O)C1(c2ccccc2)CCC1</smiles>

745
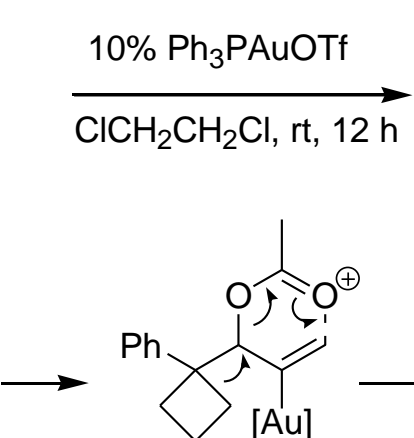

$<$<smiles>C1CC2CCCC2C1</smiles><smiles>C1CC2CCCC2C1</smiles>

746<smiles>CC(=O)OC=CC1=C(c2ccccc2)CCC1</smiles>

$748(54 \%)$

$\uparrow$

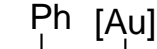

747

Scheme 206

\subsection{An alkyl- or arylthio group as leaving group}

Changing the leaving group from an alkoxide to an alkyl- or arylthio group implies a weaker $\sigma$-bond, quantitatively reflected in the dissociation energy of the single bond which is $355-380$ $\mathrm{kJ} / \mathrm{mol}$ for the carbon-oxygen bond and $255 \mathrm{~kJ} / \mathrm{mol}$ for the carbon-sulfur single bond. ${ }^{281}$ In pinacol-type ring expansions with removal of an alkyl- or arylthio group, thiophilic reagents such as copper(I) or mercury(II) salts are frequently used for generating cationic intermediates to direct the migrating group. Different examples of four-membered ring rearrangements using the acidity in $\alpha$-position of a sulfide, are described in this section.

Sulfur-stabilized carbenium ions, generated in organic solvents under mild conditions by removal of a thiophenoxide ion from a thioacetal using soluble cuprous trifluoromethanesulfonate, have for example been used in the synthesis of 2-sulfanylated 
cycloalkanones. $^{282,283}$ Addition of the lithio derivative of bis(phenylthio)methane to cyclobutanone 80 afforded $\alpha$-hydroxydiphenylthioacetal $\mathbf{7 4 9}$ in $86 \%$ yield (Scheme 207). Treatment of thioacetal $\mathbf{7 4 9}$ with two equiv of cuprous triflate and 1.3 equiv of diisopropylethylamine in benzene at $46{ }^{\circ} \mathrm{C}$ for 2.3 hours afforded $\alpha$-thiophenoxy cyclopentanone 464 in $72 \%$ yield, presumably via the intermediate carbenium ion 463 .

This ring expansion was also evaluated alternatively using the lithio derivative of tris(phenylthio)methane and failed. ${ }^{284}$ However, when the lithio derivative of tris(methylthio)methane was added to cyclobutanone 80, the $\alpha$-hydroxytrimethylthioacetal 750 was obtained in $72 \%$ yield (Scheme 207). One equiv of $n$-butyllithium converted the $\alpha$ hydroxytrimethylthioacetal $\mathbf{7 5 0}$ to its lithium salt. Two equiv of tetrakis(acetonitrile)copper(I) perchlorate were added and the mixture was heated to $75^{\circ} \mathrm{C}$ for one to four hours to afford $\alpha, \alpha$-dimethylthiocyclopentanone $\mathbf{7 5 1}$ in $\mathbf{7 5 \%}$ yield.

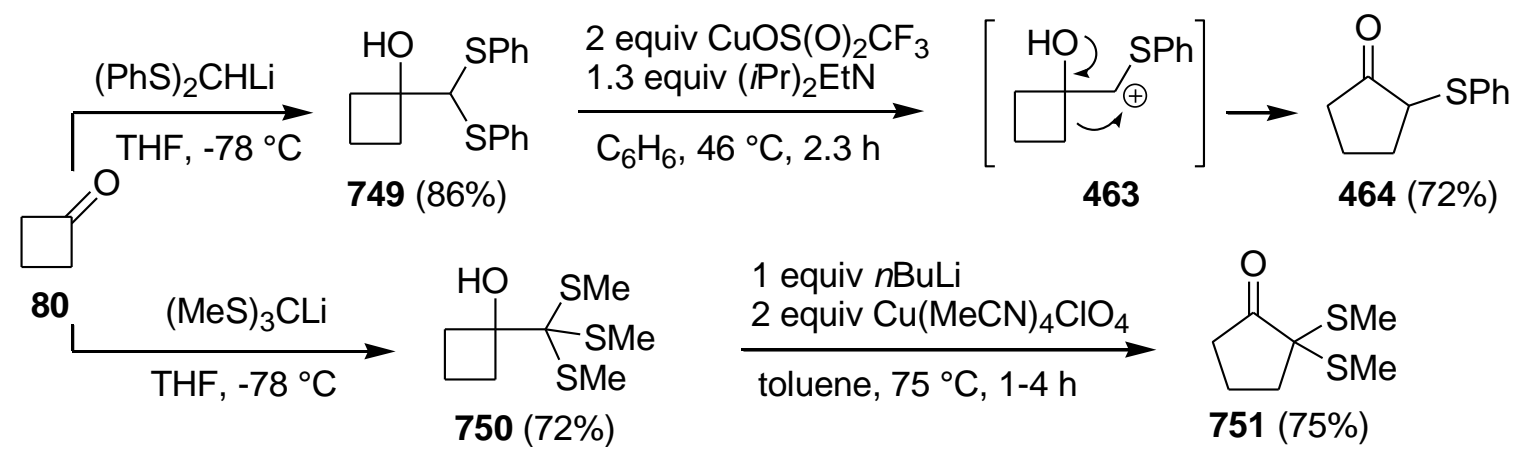

Scheme 207

The previous method has also been applied in an alternative synthesis of $\alpha$-cuparenone 89, reported by Ho and Chang. ${ }^{285}$ Treatment of $\mathbf{7 5 2}$ with 1.2 equiv of $n$-butyllithium and 2.2 equiv of tetrakis(acetonitrile)copper(I) perchlorate in toluene afforded 2,2-di(methylthio)-3methyl-3-(4-methylphenyl)cyclopentanone 753 in 64\% yield (Scheme 208). 
<smiles>Cc1ccc([C@]2(C)C[C@@](O)(C(C)(C)C)C2)cc1</smiles>

752

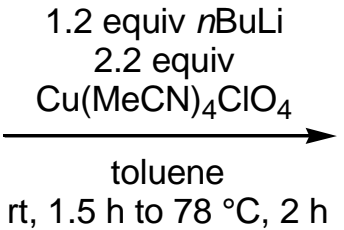

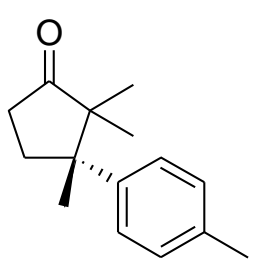

$\alpha$-cuparenone 89

Scheme 208

Furthermore, the above-described method using the lithio derivative of tris(phenylthio)methane has been used in the synthesis of coriolin $\mathbf{7 5 8}$, where the second fivemembered ring was obtained via ring rearrangement of the four-membered ring precursor. ${ }^{284}$ Treatment of bicyclo[3.2.0]heptanone $\mathbf{7 5 4}$ with the lithio derivative of tris(phenylthio)methane in tetrahydrofuran at $-78{ }^{\circ} \mathrm{C}$ gave adduct 755 in one isomer (Scheme 209). Addition of 1.1 equiv of mercury(II) chloride and diisopropylethylamine in dimethylformamide at $-40{ }^{\circ} \mathrm{C}$ resulted in the removal of one phenylthio group, and subsequent ring expansion resulted in cyclopentanone $\mathbf{7 5 6}$ in $74 \%$ yield with migration of the more substituted carbon atom. The authors stated that almost no regioisomer $\mathbf{7 5 7}$ was formed from ring expansion of the less substituted carbon atom, without mentioning the exact ratio.

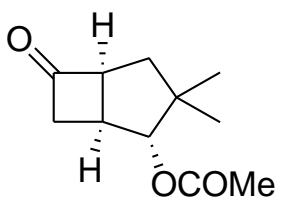

754

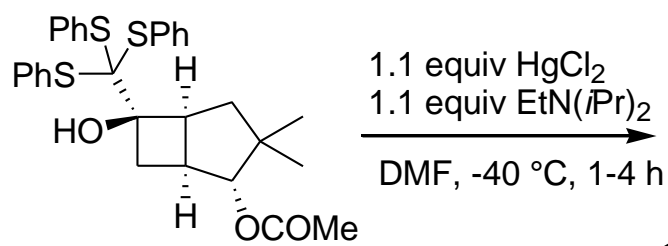

755

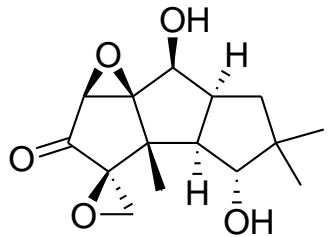

coriolin $\mathbf{7 5 8}$

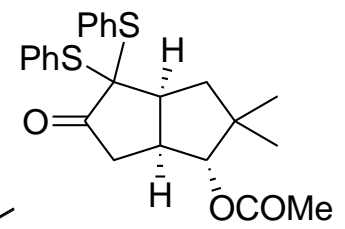

756 (74\%)

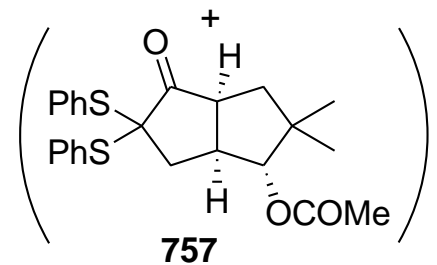

Scheme 209 
Also 3-benzoyloxy-4-(tert-butyldiphenylsilyloxymethyl)bicyclo[3.3.0]octan-7-one 760, as a precursor of carbacyclin $\mathbf{7 6 1}$, has been synthesized in $74 \%$ yield via the same method as described above (i.e. 1.3 equiv $\mathrm{HgCl}_{2}, 1.1$ equiv (iPr) ${ }_{2} \mathrm{EtN}, \mathrm{DMF},-40{ }^{\circ} \mathrm{C}, 1-4 \mathrm{~h}$, followed by reduction with Raney nickel) (Scheme 210). ${ }^{286}$ Carbacyclin is a chemically stabilized modification of natural prostaglandin $\mathrm{I}_{2}$ (prostacyclin), which has valuable biological activity.

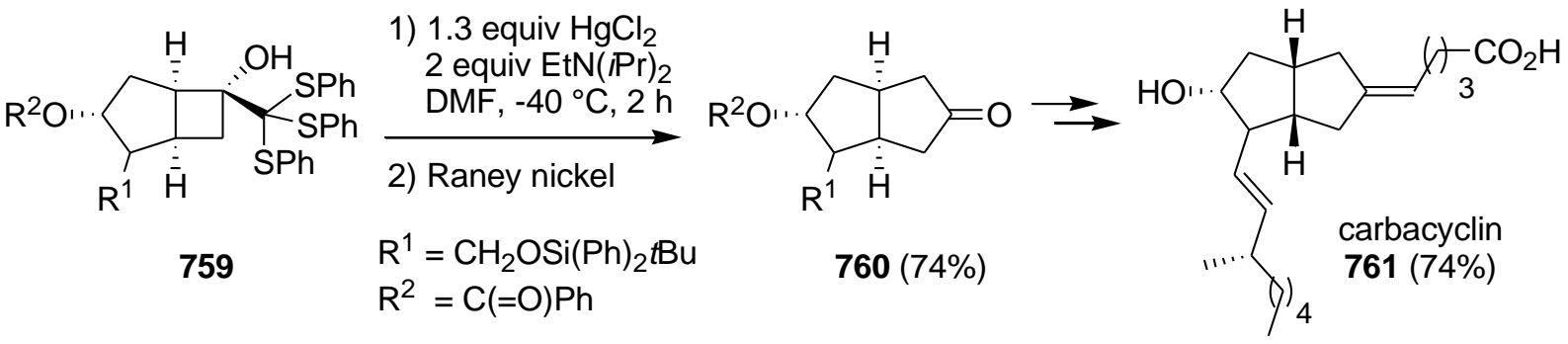

Scheme 210

In order to obtain the 1,4-diketospiro[4.4]nonane structure of fredericamycin A, which exhibits both antibiotic and antitumor activity, a mercury-mediated acyl migration in a modified version of the pinacol-type rearrangement has been reported. ${ }^{287}$ Compounds $\mathbf{7 6 3}$, generated from bissilylated cyclobutenediols $\mathbf{6 8 9}$ and dithioacetals $\mathbf{7 6 2}$, were desulfurated/desilylated in a single step and rearranged via acyl migration to the mixture of spiro compounds cis-765 in $81 \%$ yield $\left(\mathrm{R}^{1}-\mathrm{R}^{2}=\mathrm{CH}_{2} \mathrm{CH}=\mathrm{CHCH}_{2} ; \mathrm{R}^{3}-\mathrm{R}^{4}=\mathrm{CH}=\mathrm{CH}-\mathrm{CH}=\mathrm{CH}\right)$ by treatment with 1.1 equiv of mercury bistrifluoroacetate in benzene at $0{ }^{\circ} \mathrm{C}$ or in $55-91 \%$ yield using 1.1 equiv of mercury(II) chloride in benzene at reflux temperature (Scheme 211). Method A has also been used in another total synthesis of fredericamycin A. ${ }^{288}$ 
<smiles>[R]C1C(OC)=C(OC)C1[R]</smiles>
689

$\mathrm{R}^{1}=\mathrm{H} ; \mathrm{R}^{2}=\mathrm{H}$

$\mathrm{R}^{3}=\mathrm{H} ; \mathrm{R}^{4}=\mathrm{H}$

$\mathrm{R}^{1}-\mathrm{R}^{2}=\mathrm{CH}_{2}(\mathrm{CH})_{2} \mathrm{CH}_{2}$ $\mathrm{R}^{3}-\mathrm{R}^{4}=\mathrm{C}_{6} \mathrm{H}_{5}$<smiles>[R7]C1CCC([SiH2])([SiH2]C)C1[R]</smiles>

762

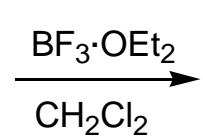

$\mathrm{CH}_{2} \mathrm{Cl}_{2}$

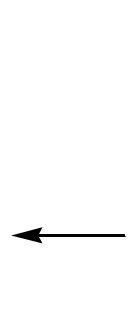

765 (method A: 81\%)

765 (method B: 55-91\%)

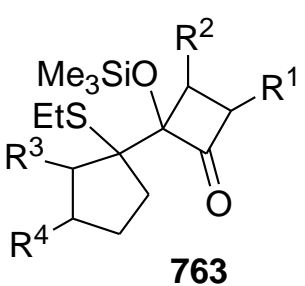

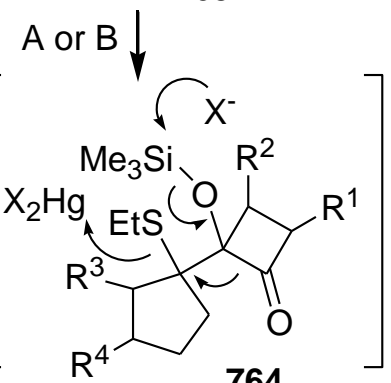

A) 1.1 equiv $\mathrm{Hg}\left(\mathrm{OCOCF}_{3}\right)_{2}, \mathrm{C}_{6} \mathrm{H}_{6}, 0^{\circ} \mathrm{C}, 1 \mathrm{~min}$

B) 1.1 equiv $\mathrm{HgCl}_{2}, \mathrm{C}_{6} \mathrm{H}_{6}, \Delta, 15 \mathrm{~min}$

\section{Scheme 211}

In the total synthesis of $( \pm)$-clovene $\mathbf{7 6 9}$, the crucial ring expansion step was effected by acid treatment of cyclobutanol $\mathbf{7 6 7}$, obtained by adding the anion of tris(methylthio)methane to cyclobutanone $\mathbf{7 6 6}^{289}$ Treatment with a thiophilic $\mathrm{Hg}(\mathrm{II})$ salt was not required for rearrangement, as instead addition of aqueous $\mathrm{HCl}$ in chloroform promoted facile rearrangement to cyclopentanone $\mathbf{7 6 8}$ in $66 \%$ overall yield (Scheme 212).

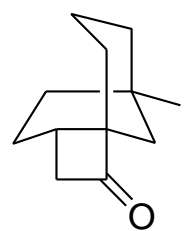

766

$\stackrel{(\mathrm{MeS})_{3} \mathrm{CLi}}{\longrightarrow}$

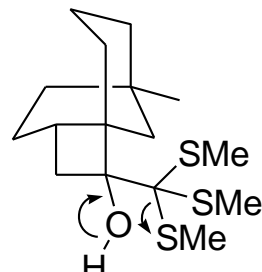

767

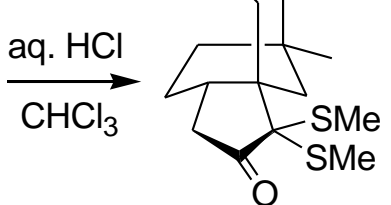

$768(66 \%)$

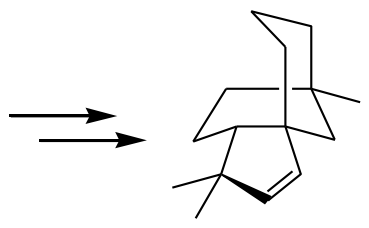

clovene 769

Scheme 212

As a special case, an electrooxidative ring expansion of 1-( $\alpha$-phenylthiobenzyl)cyclobutanol 770 was used to prepare 2-phenylcyclopentanone 771 (Scheme 213) ${ }^{290}$ A solution of $\beta$ hydroxy sulfide $\mathbf{7 7 0}$ in dichloromethane/methanol (9:1), containing two equiv of tetraethylammonium chloride, was electrolyzed at $6.0 \mathrm{~F} / \mathrm{mol}$ in an undivided cell equipped 
with carbon plate electrodes with a constant current of $100 \mathrm{~mA}$, furnishing 2phenylcyclopentanone $\mathbf{7 7 1}$ in $\mathbf{7 8 \%}$ yield.

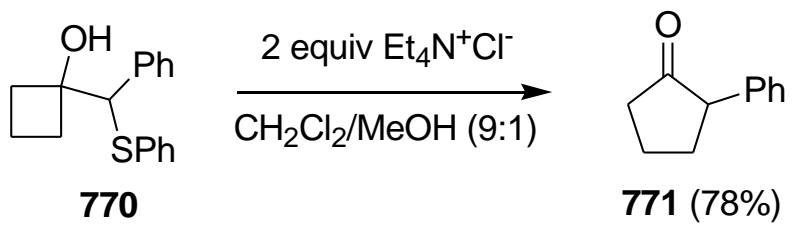

Scheme 213

\subsection{An alkyl- or arylselenyl group as leaving group}

Krief and co-workers have described that $\beta$-hydroxyalkylselenides, bearing two alkyl groups on the carbon atom where the seleno moiety is attached, are prone to rearrange to carbonyl compounds upon reaction with silver(I) tetrafluoroborate. ${ }^{148,291}$

In the synthesis of $\alpha$ - and $\beta$-cuparenone, this rearrangement was used via $\beta$-hydroxyselenide 773 as a precursor for the five-membered ring (Scheme 214). ${ }^{148}$ Addition of 2-lithio-2methylselenopropane to cyclobutanone $\mathbf{7 7 2}$ in diethyl ether at $-78{ }^{\circ} \mathrm{C}$ afforded $\beta$ hydroxyselenide $\mathbf{7 7 3}$ in $66 \%$ yield. Subsequently, three rearrangement conditions were investigated. The first method involved thallium ethoxide addition in chloroform to afford $\alpha$ cuparenone $\mathbf{8 9}$ in 57\% yield, though via generation of a carbene. A better yield of $69 \%$ was obtained when silver tetrafluoroborate on alumina in dichloromethane was added. Finally, $\alpha$ cuparenone $\mathbf{8 9}$ was obtained in $82 \%$ yield upon reaction of $\beta$-hydroxyselenide $\mathbf{7 7 3}$ with methyl fluorosulfonate in diethyl ether at $20^{\circ} \mathrm{C}$ for one hour. 


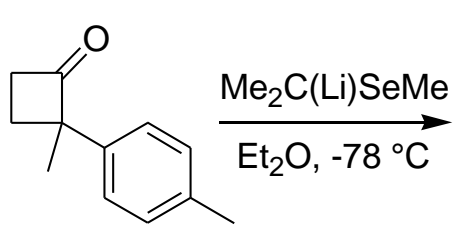

772

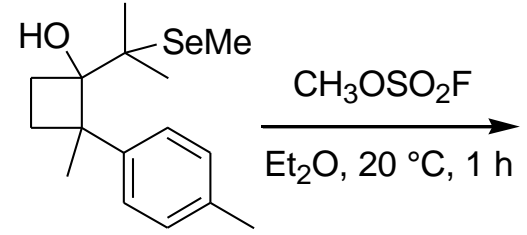

$773(66 \%)$<smiles>Cc1ccc(C2(C)CCC(=O)C2(C)C)cc1</smiles>

$\alpha$-cuparenone $89(82 \%)$

Scheme 214

The first step in the synthesis of permethylcyclohexane $\mathbf{7 7 6}$ was a ring expansion of hexamethylcyclobutanone $\mathbf{7 7 4}$ to octamethylcyclopentanone $\mathbf{7 7 5}$ according to a general procedure developed by Krief. ${ }^{292,293}$ Treatment of hexamethylcyclobutanone $\mathbf{7 7 4}$ with 1.5 equiv of 2-lithio-2-selenopropane in ether/pentane for 30 minutes at $-78{ }^{\circ} \mathrm{C}$ afforded the corresponding $\beta$-hydroxyselenide, which was subsequently treated with two equiv of silver tetrafluoroborate and eight equiv of alumina in tetrachloromethane for two hours at $0{ }^{\circ} \mathrm{C}$ and one hour at $25^{\circ} \mathrm{C}$ to obtain octamethylcyclopentanone $\mathbf{7 7 5}$ in $74 \%$ yield (Scheme 215).

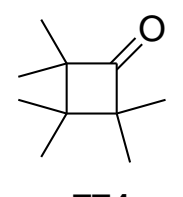

a) 1.5 equiv $\mathrm{Me}_{2} \mathrm{C}(\mathrm{Li}) \mathrm{SeMe}$ ether/pentane, $-78^{\circ} \mathrm{C}, 30 \mathrm{~min}$

b) 2 equiv $\mathrm{AgBF}_{4}$, 8 equiv $\mathrm{Al}_{2} \mathrm{O}_{3}, \mathrm{CCl}_{4}$ $774 \quad 0^{\circ} \mathrm{C}, 2 \mathrm{~h}$ to $25^{\circ} \mathrm{C}, 1 \mathrm{~h}$

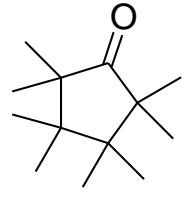

$775(74 \%)$

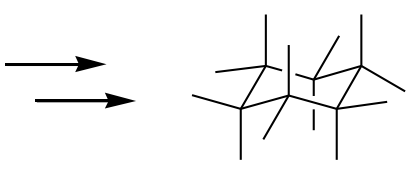

776

Scheme 215

Next to other approaches (Scheme 89), the synthesis of tetraspiroketone $\mathbf{3 1 1}$ has been accomplished via ring expansion of trispiroketone 777 via $\beta$-hydroxyselenide $\mathbf{7 7 8}$ (Scheme 216). ${ }^{134 \mathrm{~b}}$ The trispiroketone 777 was reacted with 1-lithio-1-(methylseleno)cyclobutane in ether/pentane at $-78{ }^{\circ} \mathrm{C}$ for two hours to afford the crude $\beta$-hydroxyselenide $\mathbf{7 7 8}$, which was treated with one equiv of silver tetrafluoroborate and eight equiv of silicium oxide in tetrachloromethane at $20{ }^{\circ} \mathrm{C}$ for 36 hours to furnish the tetraspiroketone $\mathbf{3 1 1}$ in $50 \%$ yield. 
This ketone $\mathbf{3 1 1}$ proved to be unstable towards acids. The same ring expansion was applied in the synthesis of a [5.4]rotane, using silver tetrafluoroborate on aluminium oxide instead of silicium oxide. $^{294}$

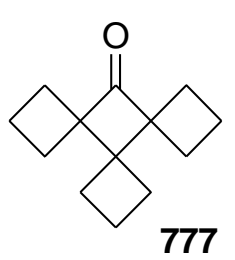

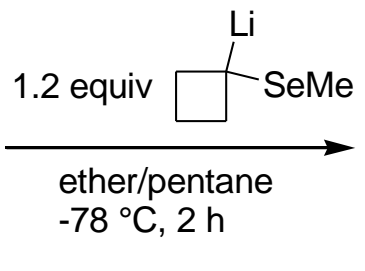

ether/pentan $-78^{\circ} \mathrm{C}, 2 \mathrm{~h}$
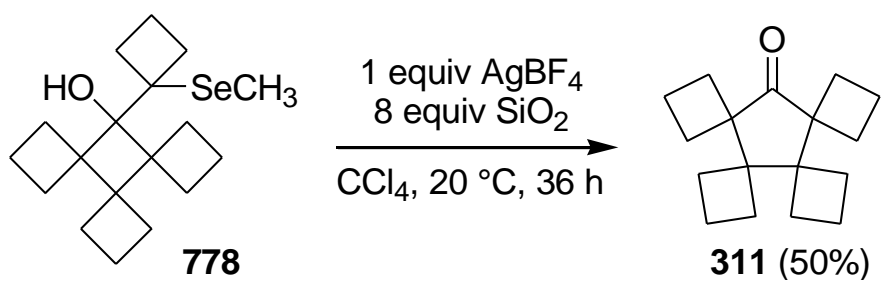

$311(50 \%)$

Scheme 216

Because reductive debromination of compound 112 (Scheme 33) with zinc in acetic acid failed, an alternative approach to the synthesis of pseudohelical compound $\mathbf{7 8 0}$ was proposed. ${ }^{69}$ This method used a rearrangement of $\beta$-hydroxyselenide $\mathbf{7 7 9}$, synthesized in $37 \%$ yield by treatment of tricyclic cyclobutanone 106 with 1-lithio-1-(methylseleno)cyclobutane in diethyl ether at $-78{ }^{\circ} \mathrm{C}$ for one hour. The ring expansion of $\beta$-hydroxyselenide $\mathbf{7 7 9}$ was executed via addition of 7.1 equiv of 3-chloroperoxybenzoic acid ( $m \mathrm{CPBA})$ in dichloromethane at room temperature for 45 minutes to afford trispiro[3.0.0.4.3.3] hexadecan16-one in $70 \%$ yield (Scheme 217).<smiles>CC1(C)C2CCCC23CCCC13</smiles>

106

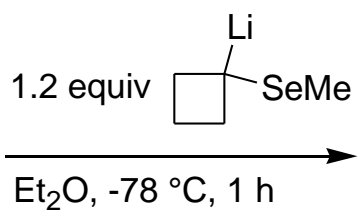

$\mathrm{Et}_{2} \mathrm{O},-78^{\circ} \mathrm{C}, 1 \mathrm{~h}$

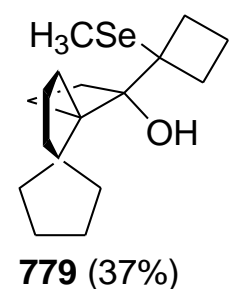

7.1 equiv $m \mathrm{CPBA}$

$\overrightarrow{\mathrm{CH}_{2} \mathrm{Cl}_{2}, \mathrm{rt}, 45 \mathrm{~min}}$

$779(37 \%)$

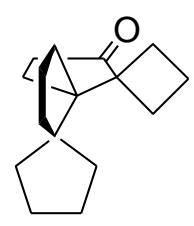

$780(70 \%)$

Scheme 217

\subsection{Sulfone, sulfoxide and selenoxide groups as leaving group}


Using the synthetic versatility of sulfons, sulfoxides and selenoxides as leaving groups, different methods are in hand for the ring rearrangement of four- to five-membered carbocycles and will be discussed in the next paragraphs.

\subsubsection{A sulfone group as leaving group}

A one-pot procedure for the ring expansion of bicyclic ketone $781\left(\mathrm{X}=\mathrm{CH}_{2}, \mathrm{n}=1\right)$ with concomitant introduction of an $\alpha$-methoxy group has been reported by Trost and Mikhail. ${ }^{295}$ In that approach, the sensitivity of sulfones as a leaving group in the presence of Lewis acids was used for the ring rearrangement. Addition of lithiated methoxymethylphenyl sulfone to bicyclo[3.2.0]ketone $781\left(\mathrm{X}=\mathrm{CH}_{2}, \mathrm{n}=1\right)$, followed by cationic rearrangement initiated by an excess of diisobutylaluminium chloride in chloroform at $-78{ }^{\circ} \mathrm{C}$ for seven hours, produced only bicyclo[3.3.0]ketone 782a $\left(\mathrm{R}=\mathrm{Me}, \mathrm{X}=\mathrm{CH}_{2}, \mathrm{n}=1\right)$ in an overall yield of $68 \%$ from the starting ketone (Scheme 218). The reaction proceeded in a regio- and stereoselective fashion toward the thermodynamically more stable diastereoisomer. The lithiation and addition reaction were carried out in dimethoxyethane using tert-butyllithium at $-78{ }^{\circ} \mathrm{C}$.

The potential of the previous approach has been employed in the synthesis of prostaglandin analogues, using different cyclobutanones as starting material. ${ }^{296}$ The same reaction conditions, i.e. addition of lithiated methoxymethylphenyl sulfone, followed by rearrangement via diisobutylaluminiun chloride, were used to afford a mixture of bicyclic ketones 782a and 782b in 14-94\% yield, in which for each example the one-pot reaction as well as the two-step reaction were investigated (Scheme 218). Only when cyclobutanone 781 was used $(n=1, X=$ $\mathrm{CH}_{2}$ ) in a one-pot reaction, one isomer 782a was isolated. These results showed that Troststyle ring expansions of cyclobutanone derivatives $\mathbf{7 8 1}$ rarely produced single stereoisomers. 
Neither isolation of the intermediate alcohol, the nature of the sulfone, nor the presence of an oxygen atom in the larger ring of the bicyclic ketone did appear to significantly alter the stereochemical outcome of the ring expansion product, in contrast with the size of the larger ring in the starting bicyclic ketone. In general, the two-step process was higher yielding than the one-pot reaction.

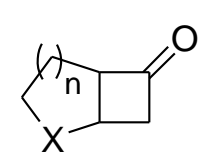

781
1)

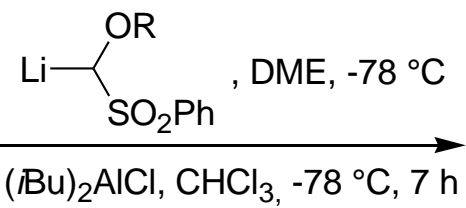

2) $(\mathrm{Bu})_{2} \mathrm{AICl}, \mathrm{CHCl}_{3},-78^{\circ} \mathrm{C}, 7 \mathrm{~h}$ $\mathrm{n}=1,2 ; \mathrm{X}=\mathrm{CH}_{2}, \mathrm{O}$ $\mathrm{R}=\mathrm{Me}, \mathrm{CH}_{2} \mathrm{Ph}$

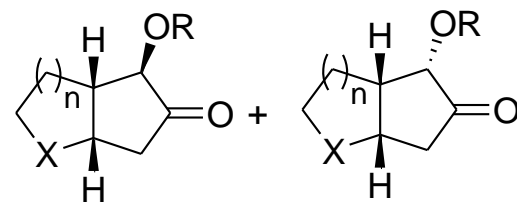

$782 a$

782a:782b (14-94\%) (0-100:0-100)

Scheme 218

\subsubsection{A sulfoxide as leaving group}

Ring expansion of 1-[1-methylsulfinyl-1-(methylthio)alkyl]cyclobutanol derivatives $\mathbf{7 8 3}$ has been achieved upon treatment with a catalytic amount of $25 \%$ sulfuric acid (Scheme 219). ${ }^{297}$ Starting from $783\left(\mathrm{R}=\mathrm{Me} ; \mathrm{R}^{3}=\mathrm{H}\right)$, two types of compounds were expected to be formed. If the ring expansion is fast, route A operated predominantly and a 2(methylthio)cyclopentanone $\mathbf{7 8 5}$ was produced as the major product. In contrast, a 2hydroxycyclopentanone $\mathbf{7 8 6}$ was preferably formed when the dithioacetal $S$-oxide group of $\mathbf{7 8 3}$ was first hydrolyzed to afford a 1-acylcyclobutanol 787 (route B). A solution of $\mathbf{7 8 3}$ in diethyl ether containing a few drops of $25 \%$ sulfuric acid was stirred at room temperature for 13-45 hours. The major product was alcohol $\mathbf{7 8 6}$ for $\mathrm{R}^{2}=$ butyl, synthesized in $53 \%$ yield next to $7-21 \%$ of sulfide $\mathbf{7 8 5}$, whereas $\mathbf{7 8 5}(42 \%)$ was predominantly formed when $\mathrm{R}^{2}$ was a hydrogen atom besides $25 \%$ of $\mathbf{7 8 6}$. This was explained by stabilization of the intermediate 
$\mathbf{7 8 4}$ by the butyl group to make $\mathbf{7 8 4}$ longer-living, increasing the probability of the intermolecular reaction of $\mathbf{7 8 4}$ with water.

Next, the effect of introducing a 2-methyl group on the cyclobutane ring $\left(\mathrm{R}=\mathrm{Me}, p \mathrm{Tol} ; \mathrm{R}^{3}=\right.$ Me) was investigated (Scheme 219). ${ }^{297}$ However, only one product was obtained in 66 to $82 \%$ yield when $\mathbf{7 8 3}$ was subjected to acidic conditions. No side products were observed, which could be attributed to the migration ability of the carbon atom enhanced by the presence of a methyl on the cyclobutanol ring of $\mathbf{7 8 3}$, leading to the chemo- and regioselective formation of sulfide $785\left(\mathrm{R}^{3}=\mathrm{Me}\right)$.

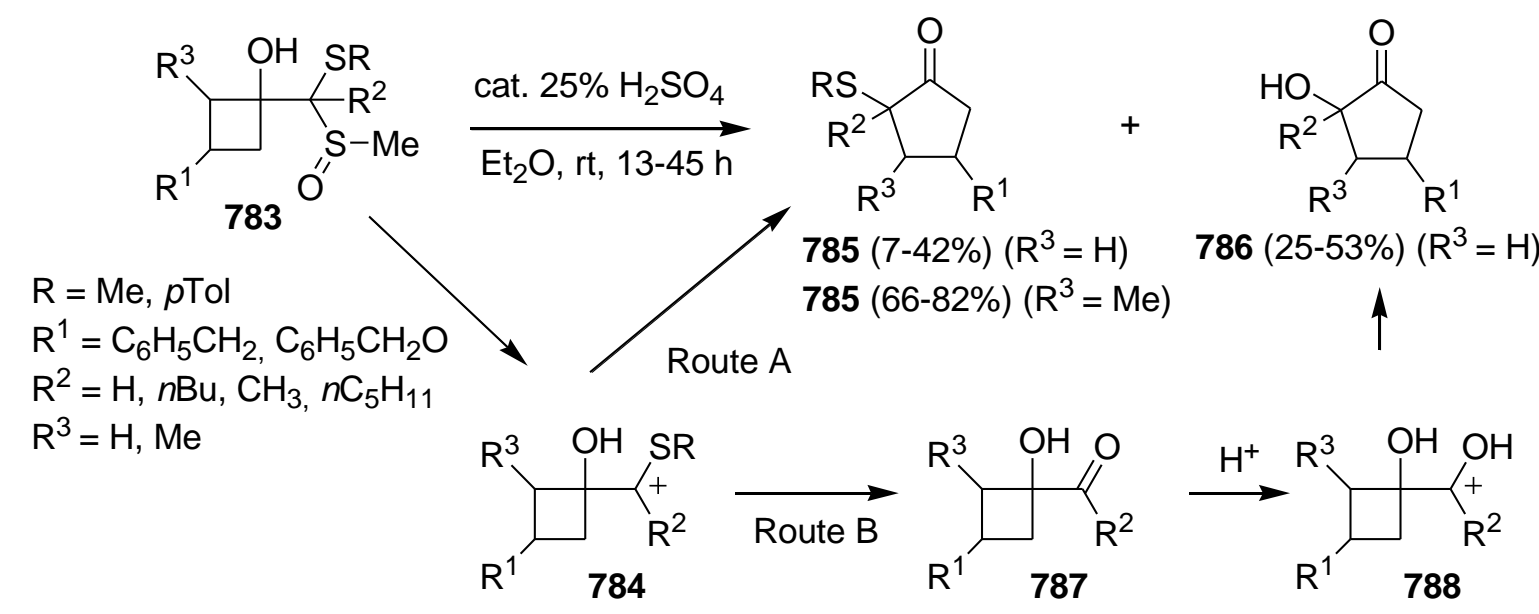

Scheme 219

Ring expansion of cyclobutanones 789, which have both a 2-alkyl and a 2-aryl or 2-alkenyl substituent, produced cyclopentanones 791 in 54 to $94 \%$ yield on reaction with $\alpha$-lithioalkyl 2-chlorophenyl sulfoxides, formed via deprotonation with LDA at $-78{ }^{\circ} \mathrm{C}$ (Scheme 220). ${ }^{298}$ The produced adducts underwent rapid ring expansion upon treatment with 1.5 equiv of potassium hydride at room temperature for 30 minutes. No evidence of the presence of $\alpha$ phenylsulfenylcyclopentanones was provided, as was observed with the selenium reagents 
(vide supra). Only one regioisomer was isolated in each case with migration of the more substituted cyclobutanone $\alpha$-carbon atom.

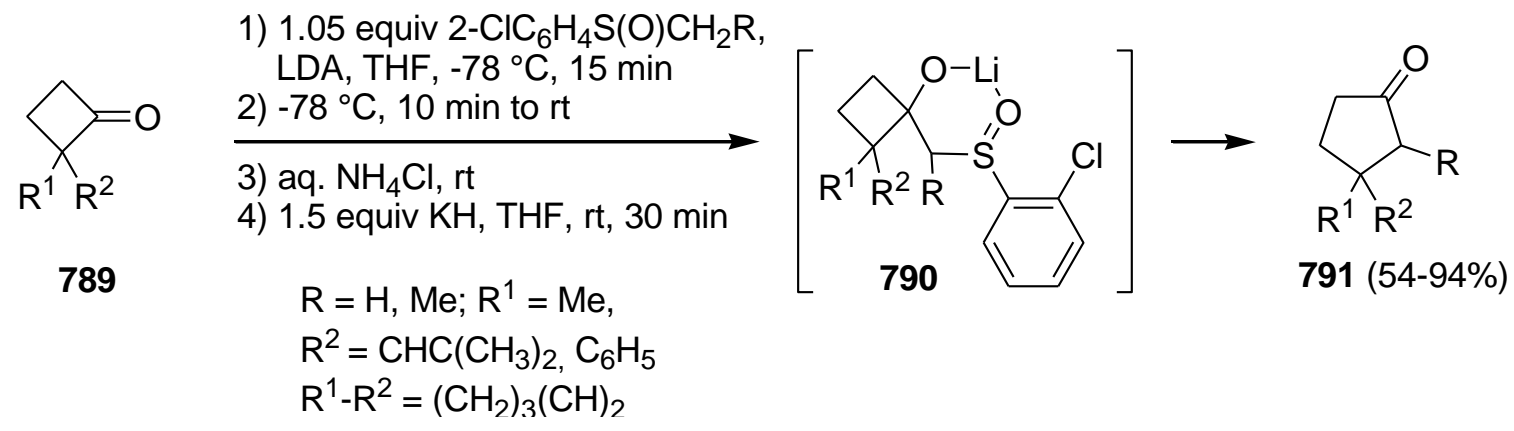

Scheme 220

Finally, also the ring expansion of cyclobutanones 792, bearing a single 2-alkenyl or 2-phenyl substituent, has been reported. ${ }^{298}$ The problem with this type of cyclobutanones upon treatment with any strongly basic carbanion was competitive proton transfer to afford the enolate. Still, reaction of cyclobutanones 792 with $\alpha$-lithioalkyl 2-chlorophenyl sulfoxides provided the corresponding cyclopentanones 793 in 34 to $63 \%$ yield (Scheme 221). Again, the ring rearrangement proceeded regiospecifically with migration of the more substituted $\alpha$ carbon atom.

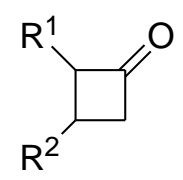

792

1) 1.05 equiv $2-\mathrm{ClC}_{6} \mathrm{H}_{4} \mathrm{~S}(\mathrm{O}) \mathrm{R}$, LDA, THF, $-78^{\circ} \mathrm{C}, 15 \mathrm{~min}$ 2) $-78^{\circ} \mathrm{C}, 10 \mathrm{~min}$ to rt

3) aq. $\mathrm{NH}_{4} \mathrm{Cl}, \mathrm{rt}$

4) 1.5 equiv $\mathrm{KH}$, THF, rt, $30 \mathrm{~min}$

$\mathrm{R}=\mathrm{Me}, \mathrm{Et}, \mathrm{Pr}$

$\mathrm{R}^{1}=(\mathrm{CH})_{2}\left(\mathrm{CH}_{2}\right)_{2} \mathrm{CH}_{3}, \mathrm{C}\left(\mathrm{CH}_{2}\right)\left(\mathrm{CH}_{2}\right)_{3} \mathrm{CH}_{3}, \mathrm{C}_{6} \mathrm{H}_{5}$

$\mathrm{R}^{1}-\mathrm{R}^{2}=(\mathrm{CH})_{2} \mathrm{CH}_{2}, \mathrm{C}\left(\mathrm{C}\left(\mathrm{CH}_{3}\right)_{2}\right)(\mathrm{CH})_{2}$

Scheme 221 


\subsubsection{A selenoxide as leaving group}

In a first example, ring expansion of 2,2-disubstituted cyclobutanones $\mathbf{7 8 9}$ using $\alpha$-lithioalkyl phenyl selenoxides, prepared in situ from ethyl phenyl selenide, afforded an adduct 794, which underwent ring expansion rather than the expected selenoxide elimination. ${ }^{299}$ Presumably, chelation in the adduct 794 caused elimination to occur more slowly than ring expansion. The corresponding cyclopentanones 791 were obtained after quenching with saturated aqueous $\mathrm{NH}_{4} \mathrm{Cl}$ and subsequent treatment with aluminium amalgam in 39 to $93 \%$ yield (Scheme 222). A lower yield was obtained somewhat in the reactions with the anion of isopropyl phenyl selenoxide (39-63\%), in part due to competitive enolization of the cyclobutanone. One of these examples comprised a short synthesis of racemic $( \pm)-\alpha-$ cuparenone $89\left(\mathrm{R}=i \operatorname{Pr}, \mathrm{R}^{1}=\mathrm{Me}, \mathrm{R}^{2}=4-\mathrm{MeC}_{6} \mathrm{H}_{4}\right)$ in the moderate yield of $39 \%$.

This selenoxide procedure was regiospecific, with exclusive migration of the more highly substituted carbon. A drawback of this method involved reaction of the cyclopentanone product with electrophilic selenium species produced in situ to afford a mixture of the product and several isomeric $\alpha$-phenylselenenylcyclopentanones. Reconversion of the $\alpha$ phenylselenenyl derivatives back to the cyclopentanone could be accomplished by means of aluminium amalgam, but this treatment could interfere with other easily reducible functionalities and thus limited the generality of this methodology.

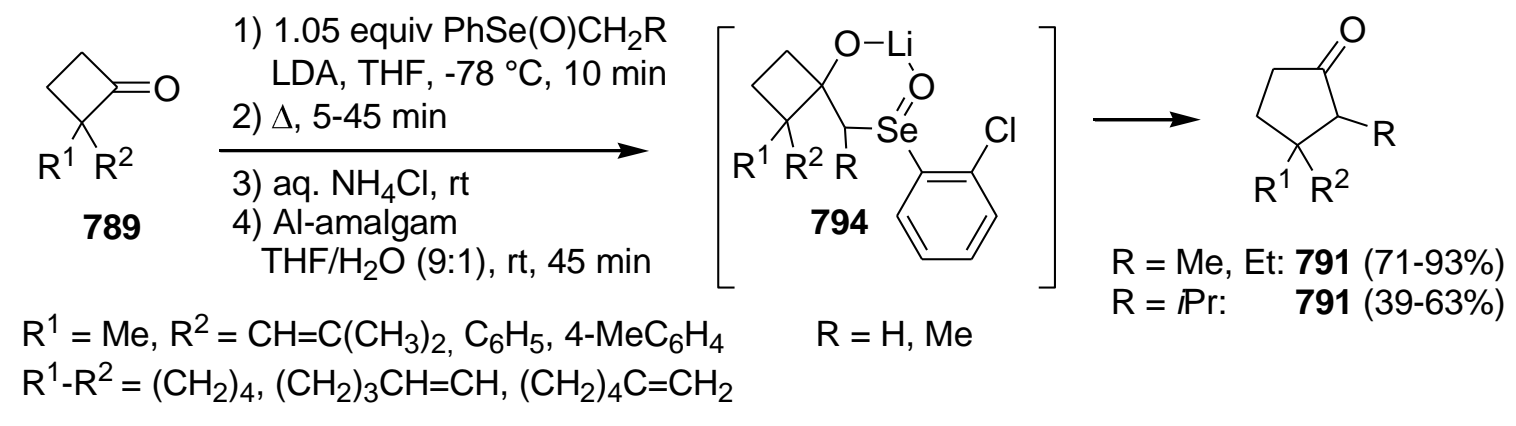


Gadwood et al. generalized this research by dividing the cyclobutanones in two classes, in an analogous manner as described in the previous paragraph. ${ }^{298}$ The first type included the cyclobutanones bearing two alkyl substituents at $\mathrm{C}_{2}$, and the second type were those with only one alkyl substituent (Scheme 223). The first type, when reacted under the same conditions as previously described, led to the corresponding cyclopentanones 796 in 9 to $78 \%$ yield. Rearrangement of the second type of cyclobutanones, the least reactive ones toward ring expansion, still afforded cyclopentanones 797 in 34 to $78 \%$ yield. Again, for both types, phenylselenenyl containing impurities were obtained, thus requiring treatment of the crude reaction mixture with aluminium amalgam before purification. Exclusive migration of the more substituted cyclobutane carbon was observed during the ring expansion.

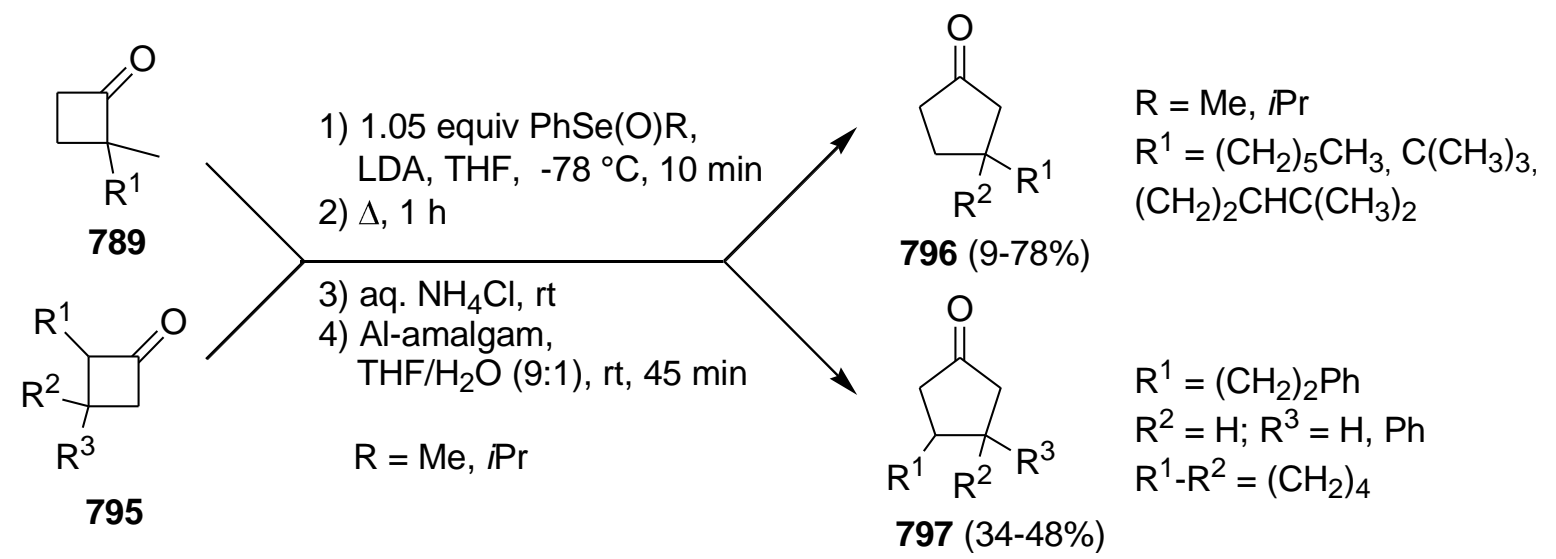

Scheme 223

\section{Miscellanous}

In this section, special or peculiar cases involving a cyclobutylmethyl to cyclopentyl rearrangement will be described which could not be divided into the previous subcategories. The first examples comprise ring expansions where a hydrogen or alkyl shift takes place 
before the actual rearrangement. Other examples involve rearrangement of iminium salts and palladium-catalyzed transformations of cyclobutanone $O$-benzoyloximes.

In a first example, addition of hydrogen bromide or hydrogen chloride to arylidenecyclobutane $\mathbf{7 9 8}$ produced 2,2-diphenylcyclopentyl halides $\mathbf{8 0 2}$ in $80-90 \%$ yield (Scheme 224). ${ }^{300}$ The formation of these cyclopentanes 802 was expected to involve a 2,2diphenylcyclopentyl carbenium ion 801. Further rearrangement of this electron-deficient species to the 1,2-diphenylcyclopentyl ion $\mathbf{8 0 3}$ would be energetically favored, but the absence of 1,2-diphenylcyclopentene $\mathbf{8 0 4}$ showed that capture of $\mathbf{8 0 1}$ by a nucleophile was extremely selective.

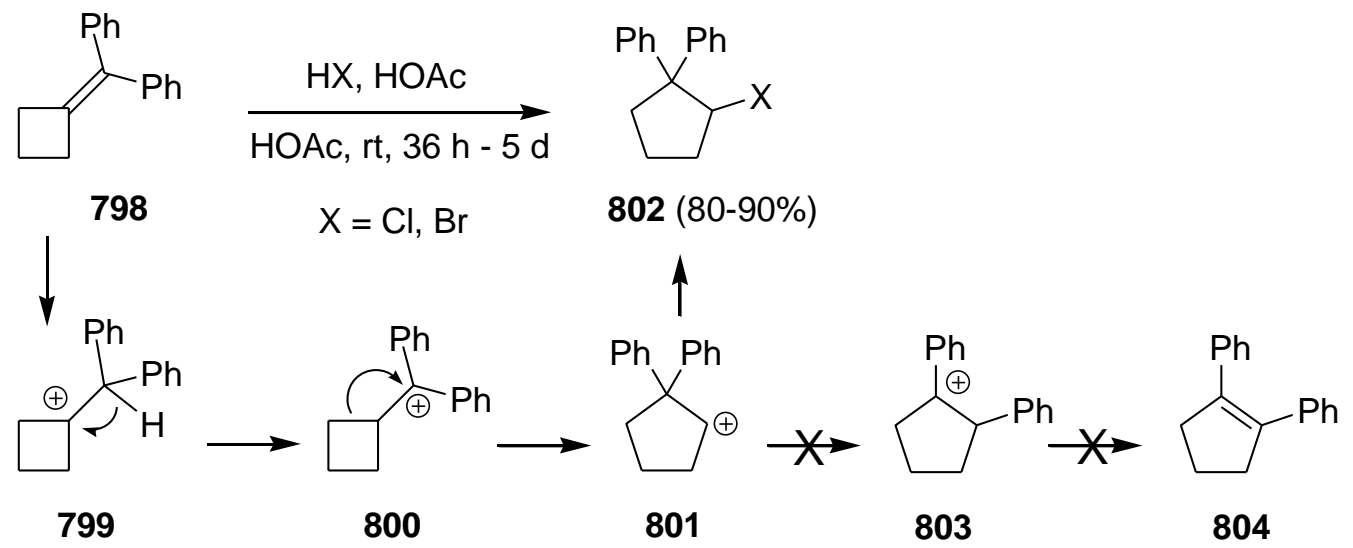

Scheme 224

A specific ring enlargement of tertiary cyclobutanols $\mathbf{8 0 5}$ into cyclopentene derivatives has been reported through an initial 1,2-alkyl or -aryl shift prior to ring enlargement (Scheme 225). ${ }^{301}$ Anhydrous iron(III) chloride, absorbed on silica gel, was reacted with tertiary cyclobutanol $805\left(R^{1}=H, R^{2}=M e\right)$ to give 1,5,5-trimethylcyclopentene 810, also know as isolaurolene, in $90 \%$ yield. The ring expansion involved Lewis acid induced formation of 1-tbutylcyclobutyl carbenium ion $\mathbf{8 0 6}$ and a Wagner-Meerwein-type methyl transfer giving the 
cyclobutylcarbinyl carbenium ion 807, followed by a $\mathrm{C}_{4} \rightarrow \mathrm{C}_{5}$ ring enlargement into cyclopentyl carbenium ion $\mathbf{8 0 8}$ and deprotonation to $\mathbf{8 1 0}$. The same ring enlargement was executed starting from 1-t-butyl-2-(2-hydroxyethyl)cyclobutanol $\mathbf{8 0 5}\left(\mathrm{R}^{1}=\left(\mathrm{CH}_{2}\right)_{2} \mathrm{OH}, \mathrm{R}^{2}=\right.$ $\mathrm{Me}$ ), but the rearranged cyclopentyl carbenium ion was trapped into the campholenic ether (2oxabicyclo[3.2.1] octane derivative) 809 in $70 \%$ yield. Ring enlargement of 1-(1-methyl-1aryl)ethylcyclobutanols $\mathbf{8 0 5}$ gave the corresponding 2-aryl-3,3-dimethylcyclopentenes $\mathbf{8 1 1}$ as the major products in 84 to $85 \%$ yield and 3-aryl-2,3-dimethylcyclopentenes $\mathbf{8 1 2}$ as the minor products in 14 to $15 \%$ yield. 3,3-Dimethyl-2-p-tolylcyclopentene $\mathbf{8 1 1}$ was used as a precursor of ( \pm )-cuparene, while the minor product, i.e. 3-p-tolyl-2,3-dimethylcyclopentene 812, was used as precursor for $( \pm)$-laurene synthesis.
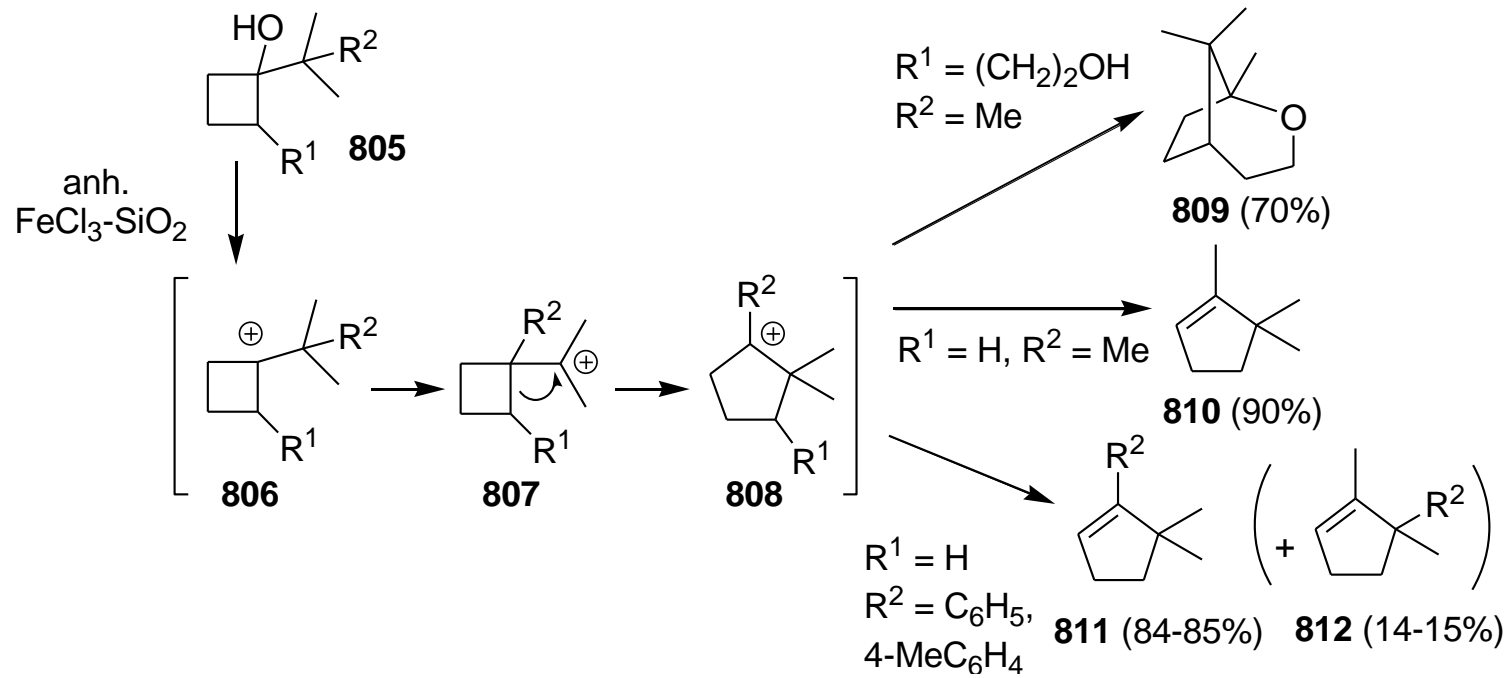

Scheme 225

Upon reaction with a catalytic amount of concentrated sulfuric acid and two equiv of trifluoromethanesulfonic acid in benzene at room temperature, cis,transtricyclo[6.3.0.0 $0^{1,4}$ undecan-5-ones $\mathbf{3 1 8}$ underwent an unusual and highly selective rearrangement to afford tricyclo[6.3.0.0 ${ }^{1,5}$ undecan-4-ones $\mathbf{3 2 5}$ in 56 to $83 \%$ yield (Scheme 
226). ${ }^{302}$ The use of Lewis acids was also investigated, e. $g . \mathrm{AlCl}_{3}, \mathrm{BF}_{3} \cdot \mathrm{OEt}_{2}, \mathrm{SnCl}_{4}, \mathrm{FeCl}_{3}$ and $\mathrm{TiCl}_{4}$, all giving rise to tricyclo[6.3.0.0 $\left.0^{1,5}\right]$ undecan-4-ones 325 in 63 to $99 \%$ yield.

If the Cargill rearrangement of $\mathbf{3 1 8}$ would take place, tricyclo[6.3.0.0 $\left.0^{1,5}\right]$ undecan-4-ones $\mathbf{3 2 1}$ would be the rearranged products. In order to explain these observations, the authors proposed a 1,2-alkyl shift of the unexpected cyclobutylmethyl carbenium ions $\mathbf{8 1 4}$, formed by hydrogen abstraction by the acid, followed by further rearrangement through carbenium ions $\mathbf{8 1 5}$ and/or $\mathbf{8 1 6}$ toward bicycles $\mathbf{3 2 5}$. Nonetheless, the formation of carbenium ions $\mathbf{8 1 4}$ from $\mathbf{3 1 8}$ under the given reaction conditions should be regarded as highly unlikely, and alternative pathways, e.g. involving a hydride shift in intermediates $\mathbf{3 1 9}$ and further transformation, might provide a more plausible explanation for the observed reactivity.

Kakiuchi and co-workers also performed the rearrangement of an analogous product, as described previously in Scheme $91 .^{137}$

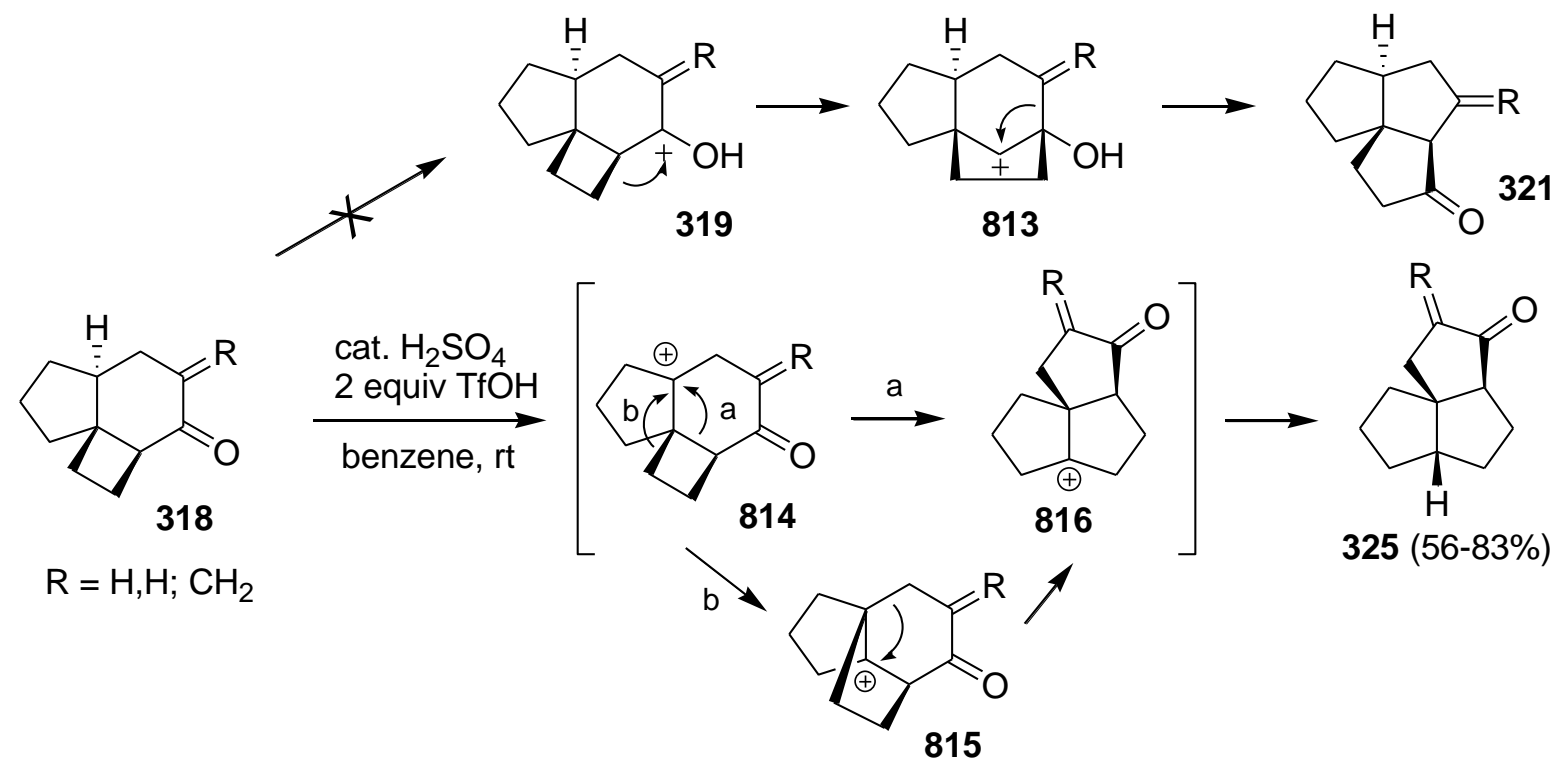

Scheme 226

Banik and Ghatak have published the synthesis of a cyclopentanone-bridged tricyclic system via a general route to functionalized abietane diterpenoids, involving a Meerwein salt-initiated 
cationic rearrangement of the ring-annelated cyclobutanone $\mathbf{8 1 7} .{ }^{303}$ The addition of an excess of triethyloxonium tetrafluoroborate in dichloromethane to cyclobutanone $\mathbf{8 1 7}$ for 24 hours at room temperature afforded the 19,20-cycloabieta-19-oxo-8,11,13-triene $\mathbf{8 1 8}$ in $75 \%$ yield (Scheme 227).

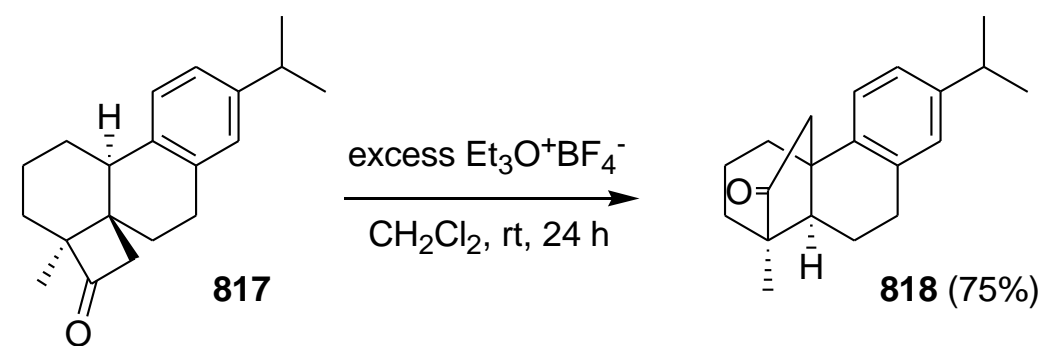

Scheme 227

In an approach to synthesize the precursor of dendrobine, a sesquiterpenoid alkaloid, a rearrangement of 5-azatricyclo[6.1.1.0 $\left.0^{5,9}\right]$ decane acyliminium ion $\mathbf{8 2 0}$ has been investigated. $^{304}$ Heating a mixture of 7-hydroxy-8-isobutyl-9-methyl-6azatricyclo[6.1.1.0 $\left.0^{4,9}\right]$ decane-6-carbaldehyde $\mathbf{8 1 9}$ in $95 \%$ formic acid under reflux for 12 hours gave a 1:1 mixture of (E)- and (Z)-9-isobutylidene-8-methyl-2azatricyclo[5.2.1.0 $\left.0^{4,10}\right]$ decane-2-carbaldehyde $\mathbf{8 2 2}$ and the secondary formate 10-isobutyl-8formyloxy-7-methyl-2-azatricyclo[5.2.1.0 $0^{4,10}$ ]decane-2-carbaldehyde $\mathbf{8 2 5}$ in $24 \%$ and 55\% yield, respectively (Scheme 228). Initial ionization of the starting product $\mathbf{8 1 9}$ formed the acyliminium species $\mathbf{8 2 0}$, which was followed by exclusive migration of the exo cyclobutane bond to give the tertiary carbenium ion $\mathbf{8 2 1}$. Once formed, 821 can lose a proton to form the isomeric mixture of olefins $\mathbf{8 2 2}$. Alternatively, 821 can undergo a skeletally degenerate 1,2alkyl shift to provide a secondary tricyclic tertiary carbenium ion 823. A final 1,2 -alkyl shift converted $\mathbf{8 2 3}$ into secondary carbenium ion $\mathbf{8 2 4}$, which was quenched by the solvent to give formate 825. Compound $\mathbf{8 2 5}$ is an analogue of the precursor of dendrobine $\mathbf{8 2 6}$. 


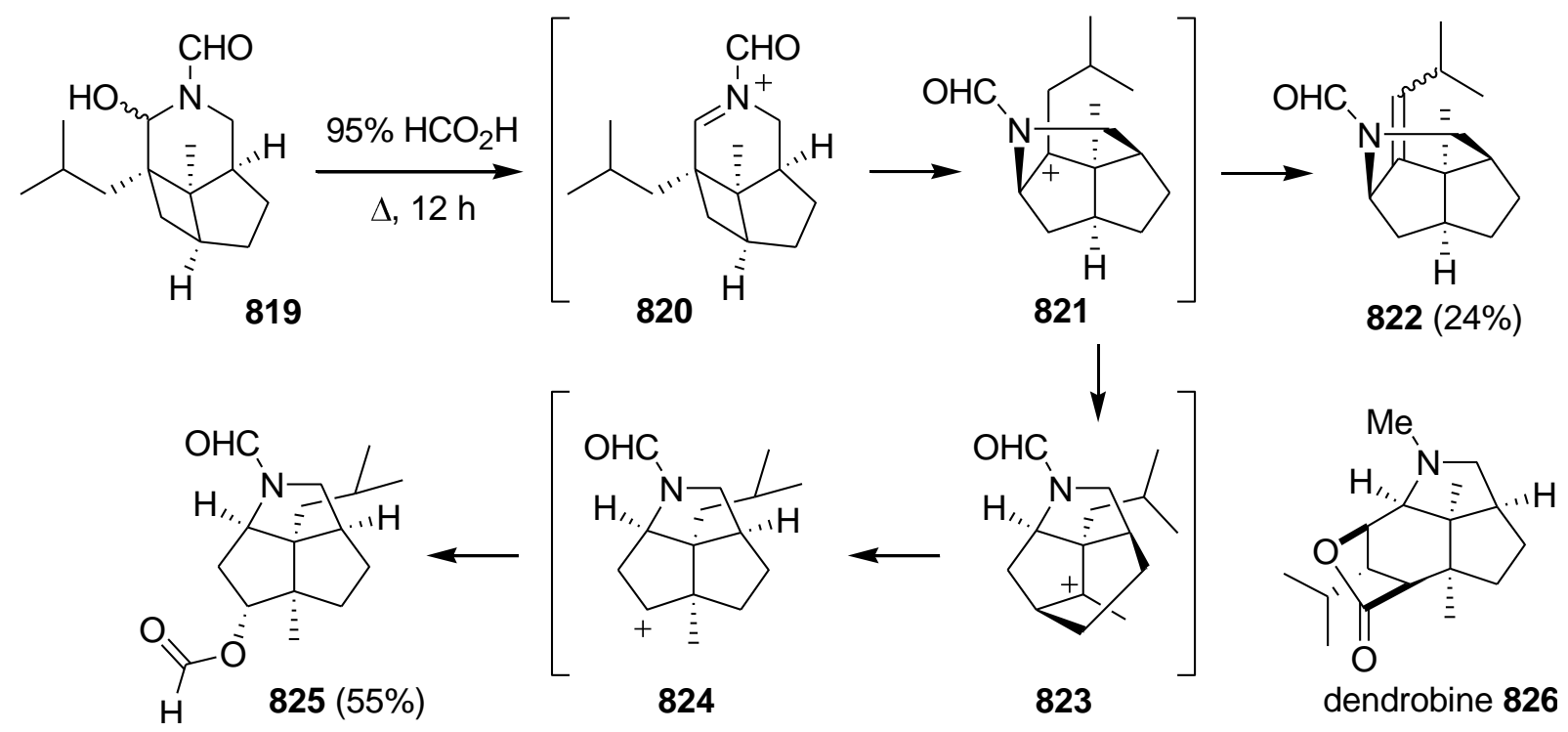

Scheme 228

In a totally different approach, cis-4-oxo-octahydrocyclopent[b]pyrroles $\mathbf{8 3 0}$ have been formed by a tandem cationic aza-Cope rearrangement - Mannich cyclization of 2-amino-1vinylcyclobutanols 827 (Scheme 229). ${ }^{305}$ Treatment of vinylcyclobutanols 827 with 1.1 equiv of $\mathrm{AgNO}_{3}$ in ethanol at $25-60{ }^{\circ} \mathrm{C}$ for 15 minutes to 25 hours afforded the corresponding bicyclic compounds 830 in $66-93 \%$ yield ( $31 \%$ for derivative $\mathrm{R}^{1}=\mathrm{CH}_{2} \mathrm{Ph}, \mathrm{R}^{2}, \mathrm{R}^{3}=\mathrm{H}$ ). The stereoselectivity was explained via the intermediates formed. The iminium ions 828 underwent a [3,3]-sigmatropic rearrangement in a chair geometry to give the azacycloocta1,5-diene intermediates 829, and rapid intramolecular Mannich cyclization of the latter intermediates 829 led to bicycles $\mathbf{8 3 0}$. 


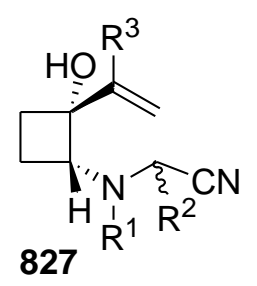

828

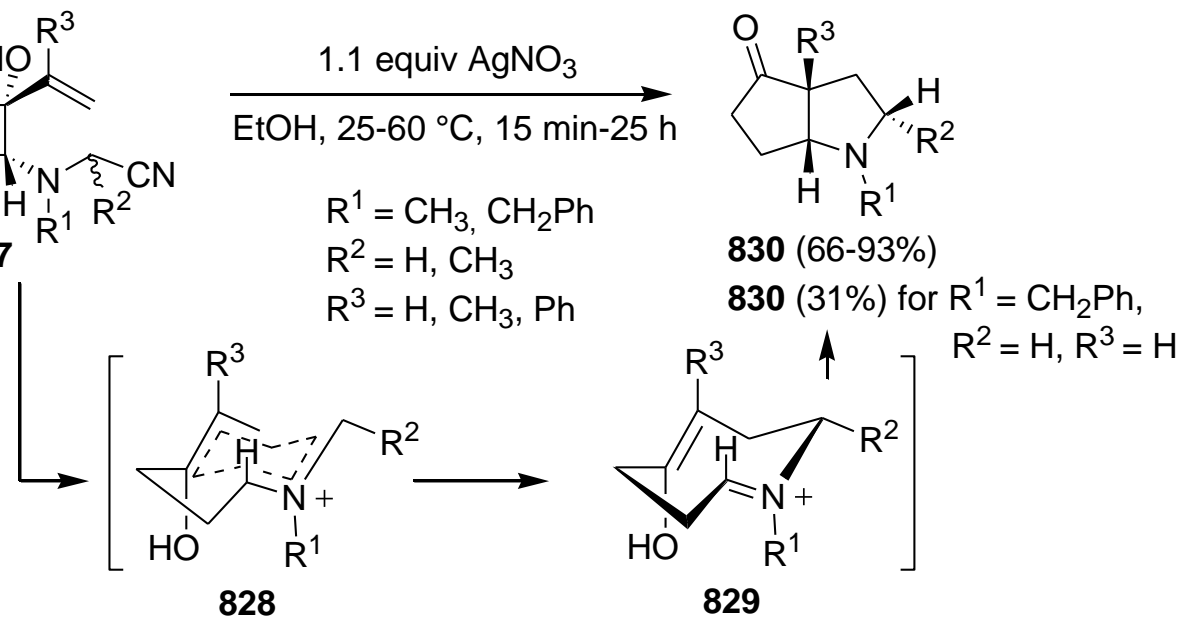

Scheme 229

Recently, a tandem aziridination/rearrangement protocol of alkenylcyclobutanols has been developed based on the combination of $\mathrm{N}$-aminophthalimide and phenyliodine diacetate in the presence of silica gel. ${ }^{306}$ When 2.5 equiv of $\mathrm{PhI}(\mathrm{OAc})_{2}, 2.5$ equiv of $\mathrm{PhthNH}_{2}$ and 20 equiv of $\mathrm{SiO}_{2}$ were added to alkenylcyclobutanols $\mathbf{8 3 1}$ in dichloromethane, the corresponding cyclopentanones $\mathbf{8 3 3}$ were obtained in $66-99 \%$ yield and in more than $99 \%$ diastereomeric excess (Scheme 230). An analogous pinacol-type rearrangement has been reported by the same group using zinc(II) bromide, but the protocol suffered from low yields (20-30\%) obtained for the aziridino alcohols. ${ }^{307}$

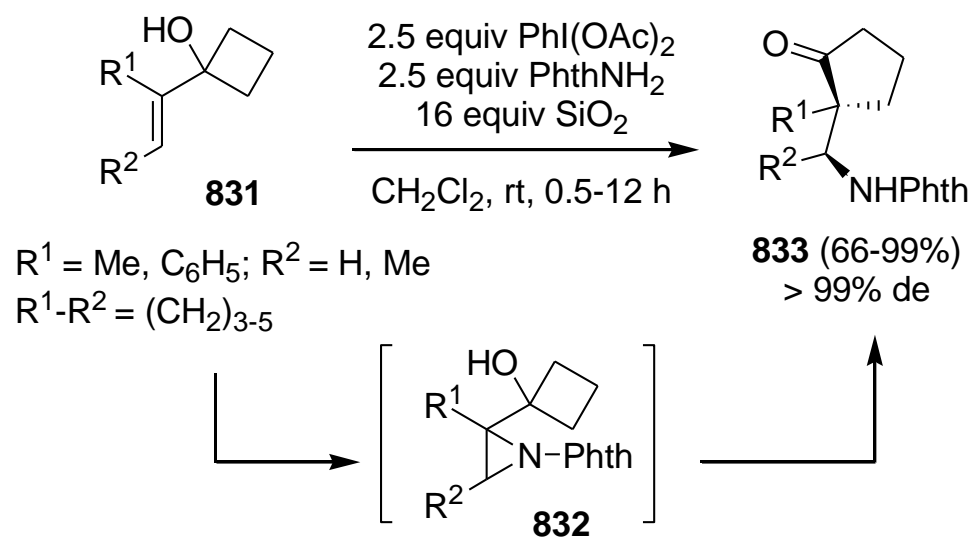

Scheme 230 
In a final example, a palladium-catalyzed transformation of cyclobutanone $O$-benzoyloximes $\mathbf{8 3 4}$ to nitriles $\mathbf{8 3 7}$ and $\mathbf{8 3 8}$ was reported (Scheme 231). ${ }^{308}$ When cyclobutanone $O$ benzoyloximes $(Z)-\mathbf{8 3 4}$ were treated with five mol\% of $\operatorname{Pd}(\mathrm{dba})_{2}$ and ten mol\% of ligand $(R)$ (S)-PPFCyA 843 (Figure 11) in the presence of one equiv of $\mathrm{K}_{2} \mathrm{CO}_{3}$ in tetrahydrofuran at reflux temperature for 24 hours, oxidative addition of the $\mathrm{N}-\mathrm{O}$ bond of the oxime to $\operatorname{Pd}(0)$ gave a (Z)-cyclobutylideneaminopalladium(II) species 835. Then, the $\mathrm{C}-\mathrm{C}$ bond (path a) was cleaved to afford a secondary alkylpalladium species $\mathbf{8 3 6}$, from which the nitrile $\mathbf{8 3 7}$ was produced by successive $\beta$-hydrogen elimination. On the other hand, when the $(Z)$ cyclobutylideneaminopalladium(II) species $\mathbf{8 3 4}$ isomerized to $\mathbf{8 3 9}$ and was subsequently cleaved (path b), a sterically less hindered primary alkylpalladium species 840 was formed. The latter underwent intramolecular cyclization with the alkenic moiety, followed by $\beta$ hydrogen elimination to afford nitrile $\mathbf{8 3 8}$. The ratio of the nitriles 837 and $\mathbf{8 3 8}$ was 16-27:7384 in 70 to $83 \%$ yield.

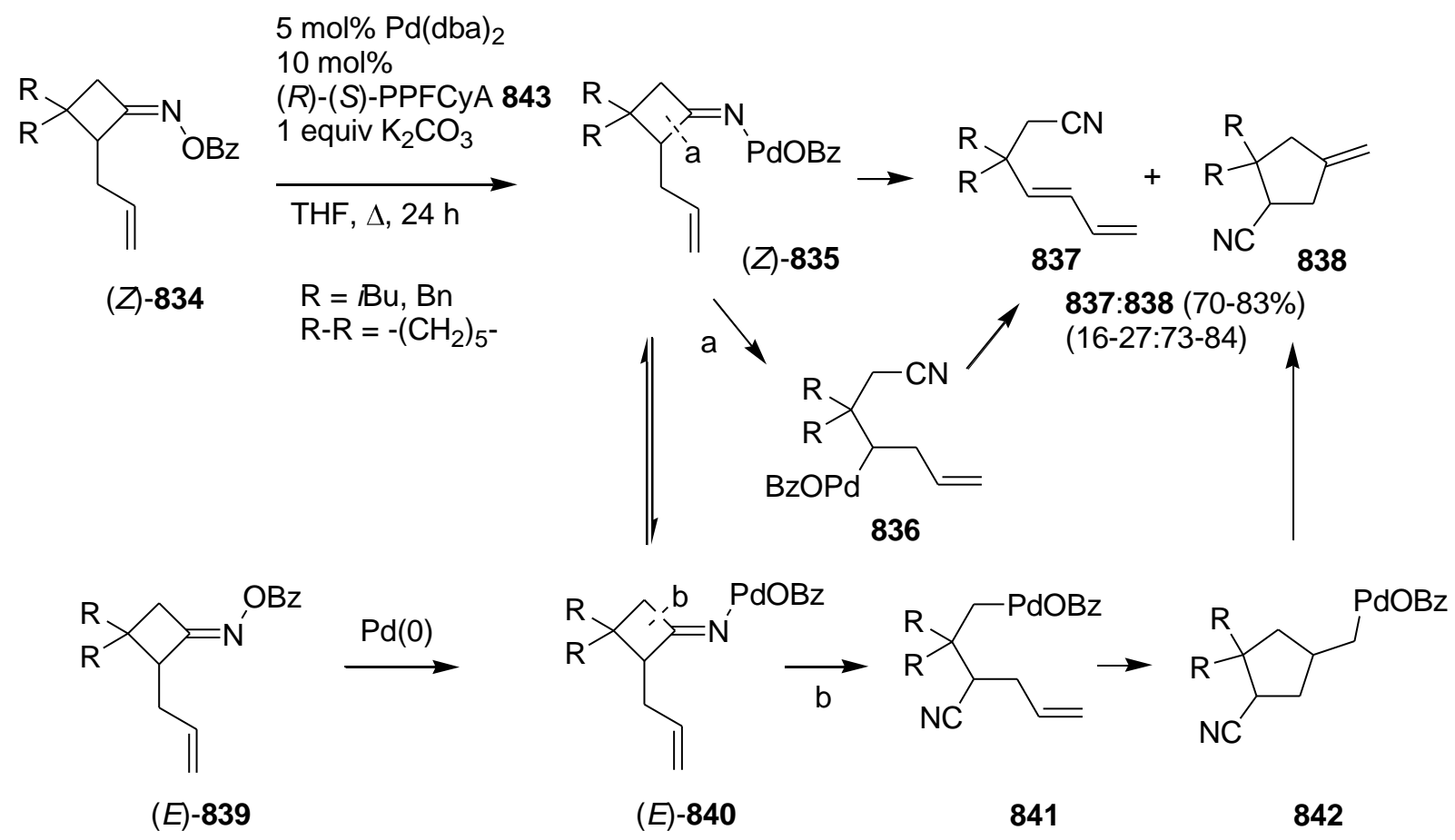

Scheme 231 


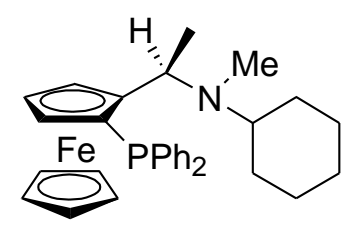

$(R)-(S)$-PPFCyA 843

Figure 11

\section{Concluding Remarks}

Different methods have been described for the synthesis of cyclopentane and cyclopentene derivatives starting from cyclobuta(no)nes through ring expansion of intermediate cyclobutylmethylcarbenium ions. Acid activation of the double bond of vinylcyclobutanes or vinylcyclobutanols proved to be a suitable methodology for the preparation of cyclopenta(e)(no)nes in good to excellent yields, and in most of the cases only one regioisomer was formed. Also metal activation has been applied successfully, as exemplified in a variety of natural product syntheses. Furthermore, allene activation for the formation of cyclobuylmethylcarbenium ions has attracted considerable interest, based on several examples found in the more recent literature. Interesting approaches have also been reported concerning the ring expansion of cyclobutylmethylcarbenium ions obtained through activation of an alkynyl substituent, although moderate yields were obtained in most of the cases.

Alternatively, the activation of a carbonyl compound via several methods has been described, with yields varying from moderate to good. Nonetheless, the vast majority of ring expansions of cyclobutylmethylcarbenium ions are induced by the initial expulsion of a leaving group, present at the $\alpha$-position with regard to the cyclobutane ring.

Although it is sometimes difficult to predict the outcome of the ring expansion reaction, in general, the more highly substituted carbon atom migrated preferentially. However, 
diazomethane induced ring expansions tend to favor migration of the less substituted $\alpha$ carbon. In this case, $\alpha$-chloro and $\alpha, \alpha$-dichlorocyclobutanones react faster and provide higher regioselectivities.

It is worth mentioning that recently the aza-analogue of the cyclobutylmethylcarbenium to cyclopentylcarbenium ion rearrangement has been described as well. In particular, a $\beta$-lactam to $\gamma$-lactam ring expansion has been developed starting from 4-(1-halo-1methylethyl)azetidin-2-ones via $\mathrm{N}$-acyliminium intermediates, providing access to a variety of functionalized mono- and bicyclic pyrrolidines-2-ones in good yields. ${ }^{309}$ A similar approach has been described starting from 4-oxoazetidine-2-carbaldehydes to afford 5-cyano-3,4dihydroxypyrrolidin-2-ones. ${ }^{310}$ It seems that the onset is given to the development of many such ring expansions in the heterocyclic series.

Due to the high synthetic and biological relevance of cyclopentane derivatives, the search for novel methodologies for the construction of substituted five-membered carbocycles remains of primordial importance. Consequently, the development of new approaches based on the ring expansion of cyclobutylmethylcarbenium ions, especially those with a focus on regioand stereoselectivity, will most certainly keep on attracting chemists in the future.

\section{References}

${ }^{1}$ (a) Paquette, L. A. Top. Curr. Chem. 1979, 79, 41. (b) Paquette, L. A. Top. Curr. Chem. 1984, $119,1$.

2 Leading references: (a) Gutsche, C. D.; Redmore, D. Carbocyclic Ring Expansion Reactions; Gutsche, G. D.; Redmore, D., Academic Press, New York, 1968, Chapter IV. (b) Salaün, J.; Karkour, B.; Ollivier, J. Tetrahedron 1989, 45, 3151. (c) Salaün, J. R. Y. Top. 
Curr. Chem. 1988, 144, 1. (d) Krief, A. Top. Curr. Chem. 1987, 135, 1. (e) Trost, B. M. Top. Curr. Chem. 1986, 133, 1. (f) Trost, B. M. Top. Curr. Chem. 1986, 133, 3. (g) Wong, H. N. C.; Lau, K.-L.; Tam, K.-F. Top. Curr. Chem. 1986, 133, 83.

${ }^{3}$ Breslow, R. in Molecular Rearrangements; de Mayo, P., Ed.; Wiley Interscience: New York, 1963, pp 276-280.

${ }^{4}$ The strain energies $(\mathrm{kcal} / \mathrm{mol})$ of cyclopropane (28.13), cyclobutane (26.90), cyclopentane (7.19) and cyclohexane (1.35), estimated based on single conformation increments; Schleyer, P. v. R.; Williams, J. E.; Blanchard, K. R. J. Am. Chem. Soc. 1970, 92, 2377.

${ }^{5}$ Saunders, M.; Chandrasekhar, J.; Schleyer, P. v. R. Rearrangements of Carbocations. In Rearrangements in Ground and Excited States; de Mayo, P. Ed.; Academic Press: New York 1980, pp.41-43.

${ }^{6}$ (a) Richey, H. G. Jr. Carbonium Ions 1972, 3, 1201. (b) Gassman, P. G.; Armour, E. A. J. Am. Chem. Soc. 1973, 95, 6129. (c) Schindler, M. J. Am. Chem. Soc. 1987, 109, 1020. (d) Schleyer, P. V. R.; Carneiro, J. W. D. M.; Koch, W.; Raghavachari, K. J. Am. Chem. Soc. 1989, 111, 5475. (e) Prakash, G. K. S.; Reddy, V. P.; Rasul, G.; Casanova, J.; Olah, G. A. J. Am. Chem. Soc. 1998, 120, 13362. (f) Reddy, V. P.; Rasul, G.; Prakash, G. K. S.; Olah, G. A. J. Org. Chem. 2007, 72, 3076.

${ }^{7}$ Smith, P. A.; Baer, D. R. Org. React., vol.11, Wiley, New York, N.Y., 1960, p157.

${ }^{8}$ For an overview of Wagner-Meerwein rearrangements and related reactions, see: Hanson, J.

R. In Comprehensive Organic Synthesis; Trost, B. M.; Fleming, I.; Pattenden, G.; Eds.; 'Pergamon Press: Oxford, 1991; Vol. 3, Chapter 3.1, pp 705-720; Rickborn, B., idem; Chapter 3.2, pp 721-732, and Chapter 3.3, pp 733-776; Coveney, D. J.; Chapter 3.4, pp 777802.

${ }^{9}$ Pocker, Y. Molecular Rearrangements, Part 1, P. de Mayo, Ed., Wiley, New York, N.Y., 1964, p1. 
${ }^{10}$ (a) Renz, M.; Meunier, B. Eur. J. Org. Chem. 1999, 737. (b) Mihovilovic, M. D.; Rudroff, F.; Grotzl, B. Curr. Org. Chem. 2004, 8, 1057. (c) ten Brink, G. J.; Arends, I. W. C. E.; Sheldon, R. A. Chem. Rev. 2004, 104, 4105.

${ }^{11}$ (a) Donaruma, L. G.; Heldt, W. Z. Org. React. 1960, 11, 1. (b) Gawley, R. E. Org. React. 1988, $35,14$.

12 Lee-Ruff, E. New Synthetic Pathways from Cyclobutanones. In Advanced Strain in Organic Chemistry, Vol.1; Halton, B. Ed., JAI Press: Greenwich, CN., 1991.

${ }^{13}$ Bellus, D.; Ernst, B. Angew. Chem. Int. Ed. 1988, 27, 797.

14 (a) Krepsi, L. R.; Hassner, A. J. Org. Chem. 1978, 43, 2879. (b) Bak. D. A. J. Org. Chem. 1979, 44, 107. (c) Greene, A. E.; Deprés, J.-P. J. Am. Chem. Soc. 1979, 101, 4003. (d) Ghosez, L.; Montaigne, R.; Roussel, A.; Vanlierde, H.; Mollet, P. Tetrahedron 1971, 27, 615. (e) Brady, W. T. Tetrahedron 1981, 37, 2949.

${ }^{15}$ Clark, G. R.; Lin, J.; Nikaido, M. Tetrahedron Lett. 1984, 25, 2645.

${ }^{16}$ Lee-Ruff, E.; Mladenova, G. Chem. Rev. 2003, 103, 1449.

${ }^{17}$ For a review on jasmonoid synthesis, see: Ho, T.-L. Synth. Commun. 1974, 4, 265.

${ }^{18}$ Das, S.; Chandrasekhar, S.; Yadav, J. S.; Grée, R. Chem. Rev. 2007, 107, 3286.

${ }^{19}$ (a) Umino, K.; Takeda, N.; Ito, Y.; Okuda, R. Chem. Pharm. Bull. 1974, 22, 1233. (b) Jernow, J.; Tautz, W.; Rosen, P.; Blount, J. F. J. Org. Chem. 1979, 44, 4210. (c) Nakayama, M.; Fukuoka, Y.; Nozaki, H.; Matsuo, A.; Hayashi, S. Chem. Lett. 1980, 1243. (d) Marx, J. N.; Minaskanian, G. J. Org. Chem. 1982, 47, 3306. (e) Smith III, A. B.; Boschelli, D. J. Org. Chem. 1983, 48, 1217; and references therein.

${ }^{20}$ Wong, H. C. N. Houben-Weyl Methods of Organic Chemistry; de Meijere, A., Ed.; Georg Thieme Verlag: Stuttgart, Germany, 1997; Vol. E17e, pp 495-515.

${ }^{21}$ Namyslo, J. C.; Kaufmann, D. E. Chem. Rev. 2003, 103, 1485. 
22 (a) Couty, F.; Evano, G. Synlett 2009, 3053. (b) Couty, F.; Durrat, F.; Prim, D. Tetrahedron Lett. 2003, 44, 5209.

23 (a) Brandi, A.; Cicchi, S.; Cordero, F. M. Chem. Rev. 2008, 108, 3988. (b) Alcaide, B.; Almendros, P.; Aragoncillo, C.; Salgado, N. R. J. Org. Chem. 1999, 64, 9596.

${ }^{24}$ Tran, J. A.; Chen, C. W.; Tucci, F. C.; Jiang, W.; Fleck, B. A.; Chen, C. Bioorg. Med. Chem. Lett. 2008, 18, 1124.

${ }^{25}$ Dowd, P.; Zhang, W. Chem. Rev. 1993, 93, 2091.

${ }^{26}$ Kočovský, P.; Tureček, F. Tetrahedron Lett. 1981, 22, 2699.

27 (a) Hoffmann, R.; Davidson, R. B. J. Am. Chem. Soc. 1971, 93, 5699. (b) Gleiter, R.; Kobayashi, R. Helv. Chim. Acta 1971, 54, 1081. (c) Jorgensen, W. L. J. Am. Chem. Soc. 1975, 97, 6649. (d) Gleiter, R.; Bischof, P.; Volz, W. E.; Paquette, L. A. J. Am. Chem. Soc. 1977, 99, 8. (e) Bischof, P.; Gleiter, R.; Haider, R. J. Am. Chem. Soc. 1978, 100, 1036. (f) Borden, W. T.; Gold, A.; Jorgensen, W. L. J. Org. Chem. 1978, 43, 491.

${ }^{28}$ Hehre, W. J. J. Am. Chem. Soc. 1972, 94, 6592.

${ }^{29}$ Simonsen, J. L. The Terpenes, 2nd ed.; Cambridge University Press: London, 1949; II, pp $156,171$.

${ }^{30}$ Ritter, J. J.; Ginsburg, D. J. Am. Chem. Soc. 1950, 72, 2381.

${ }^{31}$ Aschan, O. Ber. Dtsch. Chem. Ges. [Abteilung] B: Abhandlungen 1928, 61B, 38.

32 (a) Erickson, G. W.; Fry, J L. J. Org. Chem. 1987, 52, 462. (b) Williams, C. M.; Whittaker, D. J. Chem. Soc. [Section] D: Chem. Commun. 1970, 15, 960. (c) Berthelot, M. Annales de Chimie et de Physique 1854, 40, 5. (d) Wagner, G.; Slawinski, K. Ber. Dtsch. Chem. Ges. 1899, 32, 2064.

${ }^{33}$ Krishnamurti, R.; Kuivila, H. G. J. Org. Chem. 1986, 51, 4947.

${ }^{34}$ Yadav, V. K.; Babu, K. G. Eur. J. Org. Chem. 2005, 452.

${ }^{35}$ Wallace, R. H.; Lu, Y.; Liu, J.; Atwood, J. L. Synlett 1992, 992. 
${ }^{36}$ Kropp, P. J.; Daus, K. A.; Tubergen, M. W.; Kepler, K. D.; Wilson, V. P.; Craig, S. L.; Baillargeon, M. M.; Breton, G. W. J. Am. Chem. Soc. 1993, 115, 3071.

37 (a) Yu, S.; Xiao, J.; Ping, Z. Faming Zhuanli Shenqing Gongkai Shuomingshu 1993, 5 pp. Patent written in Chinese. (b) Li, N.; Wang, Y. Guilin Gongxueyuan Xuebao 2001, 21, 280; Chem. Abstr. 2001, 136, 386264.

${ }^{38}$ Rodriguez, J. B.; Gros, E. G.; Caram, J. A.; Marschoff, C. M. Tetrahedron Lett. 1995, 36, 7825.

${ }^{39}$ Beereboom, J. J. J. Org. Chem. 1965, 30, 4230.

${ }^{40}$ Do Khac Manh, D.; Fetizon, M.; Flament, J. P. Tetrahedron 1975, 31, 1897.

41 (a) Ohfune, Y.; Shirahama, H.; Matsumoto, T. Tetrahedron Lett. 1976, 2869. (b) Hayano, K.; Ohfune, Y.; Shirahama, H.; Matsumoto, T. Chem. Lett. 1978, 1301.

42 (a) Pirrung, M. C. J. Am. Chem. Soc. 1979, 101, 7130. (b) Pirrung, M. C. J. Am. Chem. Soc. 1981, 103, 82 .

43 (a) Matz, J. R.; Cohen, T. Tetrahedron Lett. 1981, 22, 2459. (b) Cohen, T.; Brockunier, L. Tetrahedron 1989, 45, 2917.

${ }^{44}$ Huston, R.; Rey, M.; Dreiding, A. S. Helv. Chim. Acta 1982, 65, 1563.

${ }^{45}$ Jackson, D. A.; Rey, M., Dreiding, A. S. Tetrahedron Lett. 1983, 24, 4817.

${ }^{46}$ Jackson, D. A.; Rey, M.; Dreiding, A. S. Helv. Chim. Acta 1985, 68, 439.

${ }^{47}$ Kirmse, W.; Streu, J. Synthesis 1983, 994.

${ }^{48}$ Barnier, J. P.; Karkour, B.; Salaün, J. J. Chem. Soc., Chem. Commun. 1985, 1270.

49 Jernow, J.; Tantz, W.; Rosen, P.; Williams, T. H. J. Org. Chem. 1979, 44, 4212. Mikolajczyk, M. Current Trends in Organic Synthesis, ed. Nozaki, N., Pergamon Press, Oxford and New York, 1983, p347.

${ }^{50}$ Johnson, C. R.; Herr, W. J. Org. Chem. 1973, 38, 3153.

${ }^{51}$ Cohen, T.; Yu, L. C.; Daniewski, W. M. J. Org. Chem. 1985, 50, 4596. 
${ }^{52}$ Kim, S.; Park, J. H. Tetrahedron Lett. 1989, 30, 6181.

${ }^{53}$ Wenkert, E.; Bookser, B. C.; Arrhenius, T. S. J. Am. Chem. Soc. 1992, 114, 644.

54 (a) Paquette, L. A.; Dullweber, U.; Branan, B. M. Heterocycles 1994, 37, 187. (b) Paquette,

L. A.; Fabris, F.; Gallou, F.; Dong, S. J. Org. Chem. 2003, 68, 8625.

55 Trost, B. M.; Chen, D. W. C. J. Am. Chem. Soc. 1996, 118, 12541.

${ }^{56}$ Satoh, T.; Yoshida, M.; Takahashi, Y.; Ota, H. Tetrahedron: Asymmetry 2003, 14, 281.

${ }^{57}$ Leriverend, M.-L.; Vazeux, M. J. Chem. Soc. Chem. Commun. 1982, 866.

${ }^{58}$ Srikrishna, A.; Rao, M. S. Tetrahedron Lett. 2001, 42, 5781 and references cited therein.

59 (a) Bernard, A. M.; Cadoni, E.; Frongia, A.; Piras, P. P.; Secci, F. Tetrahedron 2004, 60, 449. (b) Bernard, A. M.; Frongia, A.; Secci, F.; Piras, P. P. Chem. Commun. 2005, 3853.

${ }^{60}$ Bowden, R. D.; Cooper, R. D. G.; Harris, C. J.; Moss, G. P.; Weedon, B. C. L.; Jackman, L. M. J. Chem. Soc., Perkin Trans. 1 1983, 1465.

${ }^{61}$ (a) Fenster, M. D. B.; Patrick, B. O.; Dake, G. R. Org. Lett. 2001, 3, 2109. (b) Dake, G. R.; Fenster, M. D. B.; Hurley, P. B.; Patrick, B. O. J. Org. Chem. 2004, 69, 5668.

${ }^{62}$ Zhang, E.; Fan, C.-A.; Tu, Y.-Q.; Zhang F.-M.; Song, Y.-L. J. Am. Chem. Soc. 2009, 131, 14626.

${ }^{63}$ Zhang, Q.-W.; Fan, C.-A.; Zhang, H.-J.; Tu, Y.-Q.; Zhao, Y.-M.; Gu, P.; Chen, Z.-M. Angew. Chem. Int. Ed. 2009, 48, 8572.

${ }^{64}$ Ruggles, E. L.; Maleczka, R. E. Jr. Org. Lett. 2002, 4, 3899.

65 (a) Nemoto, H.; Shiraki, M.; Fukumoto, K. Tetrahedron Lett. 1995, 36, 8799. (b) Nemoto, H.; Shiraki, M.; Fukumoto, K. J. Org. Chem. 1996, 61, 1347.

${ }^{66}$ Paquette, L. A.; Owen, D. R.; Bibart, R. T.; Seekamp, C. K.; Kahane, A. L.; Lanter, J. C.; Corral, M. A. J. Org. Chem. 2001, 66, 2828.

${ }^{67}$ (a) Hurley, P. B.; Dake, G. R. Synlett 2003, 2131. (b) Hurley, P. B.; Dake, G. R. J. Org. Chem. 2008, 73, 4131. 
${ }^{68}$ Wang, B. M.; Song, Z. L.; Fan, C. A.; Tu, Y. Q.; Chen, W. M. Synlett 2003, 1497.

${ }^{69}$ (a) Widjaja, T.; Fitjer, L.; Pal, A.; Schmidt, H.-G.; Noltemeyer, M.; Diedrich, C.; Grimme, S. J. Org. Chem. 2007, 72, 9264. (b) Widjaja, T.; Fitjer, L.; Meindl, K.; Herbst-Irmer, R. Tetrahedron 2008, 64, 4304.

${ }^{70}$ Chianese, A. R.; Lee, S. J.; Gagné, M. R. Angew. Chem. Int. Ed. 2007, 46, 4042.

71 (a) Boontanonda, P.; Grigg, R. J. Chem. Soc. Chem. Commun. 1977, 583. (b) Clark, G. R.; Thiensathit, S. Tetrahedron Lett. 1985, 26, 2503. (c) de Almeida Barbosa, L.-C.; Mann, J. J. Chem. Soc., Perkin Trans. 1 1990, 177. (d) Kim, S.; Uh, K. H.; Lee, S.; Park, J. H. Tetrahedron Lett. 1991, 32, 3395. (e) Nemoto, H.; Shiraki, M.; Fukumoto, K. Synlett 1994, 599. (f) Nemoto, H.; Miyata, J.; Fukumoto, K. Tetrahedron 1996, 52, 10363. (g) Nemoto, H.; Miyata, J.; Yoshida, M.; Raku, N.; Fukumoto, K. J. Org. Chem. 1997, 62, 7850.

72 (a) Nemoto, H.; Nagamochi, M.; Ishibashi, H.; Fukumoto, K. J. Org. Chem. 1994, 59, 74. (b) Nemoto, H.; Miyata, J.; Hakamata, H.; Nagamochi, M.; Fukumoto, K. Tetrahedron 1995, 51, 5511. (c) Nemoto, H.; Yoshida, M.; Fukumoto, K.; Ihara, M. Tetrahedron Lett. 1999, 40, 907. (d) Nemoto, H.; Miyata, J.; Ihara, M. Tetrahedron Lett. 1999, 40, 1933.

${ }^{73}$ Kim, S.; Uh, K. H. Tetrahedron Lett. 1992, 33, 4325.

${ }^{74}$ (a) Giese, B. Radicals in Organic Synthesis: Formation of Carbon-Carbon Bonds, Pergamon, New York, 1986 and references cited herein. (b) Giese, B.; Horler, H.; Zwick, W. Tetrahedron Lett. 1982, 23, 931.

${ }^{75}$ Ryu, I.; Matsumoto, K.; Ando, M.; Murai, S.; Sononda, N. Tetrahedron Lett. 1980, 21, 4283.

${ }^{76}$ Smidt, J.; Hafner, W. R.; Jira, R.; Sieber, J.; Sedlemeier, J.; Sabel, A. Angew. Chem. Int. Ed. 1962, 1, 80 .

${ }^{77}$ Boontanonda, P.; Grigg, R. J. Chem. Soc. Chem. Commun. 1977, 583.

${ }^{78}$ Clark, G. R.; Thiensathit, S. Tetrahedron Lett. 1985, 26, 2503. 
${ }^{79}$ Demuth, M.; Pandey, B.; Wietfeld, B.; Said, H.; Viader, J. Helv. Chim. Acta 1988, 71, 1392.

${ }^{80}$ de Almeida Barbosa, L.-C.; Mann, J. J. Chem. Soc., Perkin Trans. 1 1990, 177.

${ }^{81}$ Kim, S.; Uh, K. H.; Lee, S.; Park, J. H. Tetrahedron Lett. 1991, 32, 3395.

${ }^{82}$ Nemoto, H.; Nagamochi, M.; Fukumoto, K. J. Chem. Soc., Perkin Trans. 1 1993, 2329.

83 (a) Devon, T. K.; Scott, A. I. Handbook of Naturally Occurring Compounds, vol. II, Terpenes, Academic Press, New York, 1972. (b) Heathcock, C. H. Total Synthesis of Natural Products, ed. ApSimon, J. Wiley, New York, 1973, vol. 2, p.197.

${ }^{84}$ Hall, S. S.; Faulkner, D. J.; Fayos, J.; Clardy, J. J. Am. Chem. Soc. 1973, 95, 7187.

${ }^{85}$ Fenical, W.; Howard, B.; Gifkins, K. B.; Clardy, J. Tetrahedron Lett. 1975, 3983.

${ }^{86}$ Nemoto, H.; Shiraki, M.; Fukumoto, K. Tetrahedron 1994, 50, 10391.

87 (a) Nemoto, H.; Miyata, J.; Hakamata, H.; Nagamochi, M.; Fukumoto, K. Tetrahedron 1995, 51, 5511. (b) Nemoto, H.; Hakamata, H.; Nagamochi, M.; Fukumoto, K. Heterocycles 1994, 39, 467.

${ }^{88}$ (a) Kazlauskas, R.; Murphy, P. T.; Quinn, R. J.; Wells, R. J. Aust. J. Chem. 1976, 29, 2533. (b) Wratten, S. J.; Faulkner, D. J. J. Org. Chem. 1977, 42, 3343.

${ }^{89}$ Nemoto, H.; Miyata, J.; Fukumoto, K. Tetrahedron 1996, 52, 10363.

${ }^{90}$ Anderson, W. K.; Lee, G. E. J. Med. Chem. 1980, 23, 96.

${ }^{91}$ Miyata, J.; Nemoto, H.; Ihara, M. J. Org. Chem. 2000, 65, 504.

${ }^{92}$ Nemoto, H.; Takahashi, E.; Ihara, M. Org. Lett. 1999, 1, 517.

${ }^{93}$ Yoshida, M.; Ismail, A.-H.; Nemoto, H.; Ihara, M. J. Chem. Soc., Perkin Trans. 12000 , 2629.

${ }^{94}$ Kočovský, P.; Dunn, V.; Gogoll, A.; Langer, V. J. Org. Chem. 1999, 64, 101.

${ }^{95}$ Hegedus, L. S.; Ranslow, P. B. Synthesis 2000, 953. 
96 (a) Nishimura, T.; Ohe, K.; Uemura, S. J. Am. Chem. Soc. 1999, 121, 2645. (b) Nishimura, T.; Ohe, K.; Uemura, S. J. Org. Chem. 2001, 66, 1455.

${ }^{97}$ Trost, B. M.; Yasukata, T. J. Am. Chem. Soc. 2001, 123, 7162.

${ }^{98}$ McKillop, A.; Taylor, E. C. In Comprehensive Organometallic Chemistry; Wilkinson, G.; Stone, F. G. A.; Abel, E. W.; Eds.; Pergamon Press: New York, 1982, Vol. 7, p465-513.

${ }^{99}$ Fărcașiu, D.; Schleyer, P. v. R.; Ledlie, D. B. J. Org. Chem. 1973, 38, 3455.

100 (a) Byrd, J. E.; Halpern, J. J. Am. Chem. Soc. 1973, 95, 2586. (b) Abley, P.; Byrd, J. E.; Halpern, J. J. Am. Chem. Soc. 1973, 95, 2591.

${ }^{101}$ Kim, S.; Uh, K. H. Tetrahedron Lett. 1996, 37, 3865.

${ }^{102}$ Feiner, N. F.; Abrams, G. D.; Yates, P. Can. J. Chem. 1976, 54, 3955.

${ }^{103}$ Yoshida, M.; Sugimoto, K.; Ihara, M. Org. Lett. 2004, 6, 1979.

104 (a) Stone, G. B.; Liebeskind, L. S. J. Org. Chem. 1990, 55, 4614. (b) Paquette, L. A.; Hofferberth, J. E. Org. React. 2003, 62, 477.

${ }^{105}$ For studies on the intermolecular carbopalladation of allenes, see: (a) Yamamoto, Y.; AlMasum, M.; Asao, N. J. Am. Chem. Soc. 1994, 116, 6019. (b) Larock, R. C.; Zenner, J. M. J. Org. Chem. 1995, 60, 482. (c) Trost, B. M.; Gerusz, V. J. J. Am. Chem. Soc. 1995, 117, 5156. (d) Desarbre, E.; Mérour, J.-Y. Tetrahedron Lett. 1996, 37, 43. (e) Yamamoto, Y.; Al-Masum, M.; Fujiwara, N. J. Chem. Soc., Chem. Commun. 1996, 381.

${ }^{106}$ For studies on the intramolecular carbopalladation of allenes, see: (a) Ma, S.; Negishi, E. J. Org. Chem. 1994, 59, 4730. (b) Ma, S.; Negishi, E. J. Am. Chem. Soc. 1995, 117, 6345. (c) Doi, T.; Yanagisawa, A.; Nakanishi, S.; Yamamoto, K.; Takahashi, T. J. Org. Chem. 1996, $61,2602$.

107 (a) Nemoto, H.; Yoshida, M.; Fukumoto, K. J. Org. Chem. 1997, 62, 6450. (b) Yoshida, M.; Sugimoto, K.; Ihara, M. Tetrahedron Lett. 2000, 41, 5089. (c) Yoshida, M.; Sugimoto, K.; Ihara, M. Tetrahedron 2002, 58, 7839. 
${ }^{108}$ Trost, B. M.; Xie, J. J. Am. Chem. Soc. 2006, 128, 6044.

109 (a) Brown, M. J.; Harrison, T.; Herrinton, P. M.; Hopkins, M. H.; Hutchinson, K. D.; Overman, L. E., Mishra, P. J. Am. Chem. Soc. 1991, 113, 5365. (b) Brown, M. J.; Harrison, T.; Overman, L. E. J. Am. Chem. Soc. 1999, 113, 5378.

${ }^{110}$ Trost, B. M.; Xie, J. J. Am. Chem. Soc. 2008, 130, 6231.

111 (a) Yoshida, M.; Sugimoto, K.; Ihara, M. Tetrahedron Lett. 2001, 42, 3877. (b) Trost, B. M.; Pinkerton, A. B. J. Am. Chem. Soc. 1999, 121, 10842.

112 Gill, T. B.; Mann, K. R. Organometallics 1982, 1, 485.

${ }^{113}$ Seiser, T.; Cramer, N. Angew. Chem. Int. Ed. 2008, 47, 9294.

${ }^{114}$ Yao, L.-F.; Wei, Y.; Shi, M. J. Org. Chem. 2009, 74, 9466.

115 (a) Liebeskind, L. S.; Mitchell, D.; Foster, B. S. J. Am. Chem. Soc. 1987, 109, 7908. (b) Mitchell, D.; Liebeskind, L. S. J. Am. Chem. Soc. 1990, 112, 291.

116 Tsuji, J. Palladium Reagents and Catalysts, John Wiley \& Sons Ltd., England, 2004, p.543.

${ }^{117}$ For reviews on palladium-catalysed reactions of propargylic compounds, see: (a) Tsuji, J.; Minami, I. Acc. Chem. Res. 1987, 20, 140. (b) Minami, I.; Yuhara, M.; Watanabe, H.; Tsuji, J. J. Organomet. Chem. 1987, 334, 225. (c) Tsuji, J.; Mandai, T. Angew. Chem. Int. Ed. Engl. 1996, 34, 2589.

118 (a) Yoshida, M.; Nemoto, H.; Ihara, M. Tetrahedron Lett. 1999, 40, 8583. (b) Yoshida, M.; Fujita, M.; Ishii, T.; Ihara, M. J. Am. Chem. Soc. 2003, 125, 4874. (c) Yoshida, M.; Komatsuzaki, Y.; Nemoto, H.; Ihara, M. Org. Biomol. Chem. 2004, 2, 3099.

119 (a) Larock, R. C.; Reddy, C. K. Org. Lett. 2000, 2, 3325. (b) Larock, R. C.; Reddy, C. K. J. Org. Chem. 2002, 67, 2027.

${ }^{120}$ (a) Wu, M.-J.; Wei, L.-M.; Lin, C.-F.; Leou, S.-P.; Wei, L.-L. Tetrahedron 2001, 57, 7839.

(b) Wei, L.-M.; Wei, L.-L.; Pan, W.-B.; Wu, M.-J. Tetrahedron Lett. 2003, 44, 595. 
${ }^{121}$ Yoshida, M.; Sugimoto, K.; Ihara, M. ARKIVOC 2003, VIII, 35.

${ }^{122}$ Sugimoto, K.; Yoshida, M.; Ihara, M. Synlett 2006, 1923.

${ }^{123}$ Markham, J. P.; Staben, S. T.; Toste, F. D. J. Am. Chem. Soc. 2005, 127, 9708.

${ }^{124}$ Yeom, H.-S.; Yoon, S.-J.; Shin, S. Tetrahedron Lett. 2007, 48, 4817.

125 (a) Cargill, R. L.; Beckham, M. E.; Siebert, A. E.; Dorn, J. J. Org. Chem. 1965, 30, 3647.

(b) Cargill, R. L.; Damewood, J. R.; Cooper, M. M. J. Am. Chem. Soc. 1966, 88, 1330. (c) Cargill, R. L.; Crawford, J. W. Tetrahedron Lett. 1967, 169. (d) Peet, N. P.; Cargill, R. L.; Bushey, D. F. J. Org. Chem. 1973, 38, 1218. (e) Cargill, R. L.; Jackson, T. E.; Peet, N. P.; Pond. D. M. Acc. Chem. Res. 1974, 7, 106.

126 (a) Tobe, Y.; Kimura, K.; Odaira, Y. J. Org. Chem. 1979, 44, 639. (b) Tobe, Y.; Hayauchi, Y. Sakai, Y.; Odaira, Y. J. Org. Chem. 1980, 45, 637. (c) Eaton, P. E.; Jobe, P. G.; Nyi, K. J. Am. Chem. Soc. 1980, 102, 6636.

127 (a) Do Khac Manh, D.; Fetizon, M.; Lazare, S. J. Chem. Soc. Chem. Commun. 1975, 282. (b) Do Khac Manh, D.; Fetizon, M.; Lazare, S. J. Chem. Soc. Chem. Commun. 1980, 1209.

${ }^{128}$ Do Khac Manh, D.; Fetizon, M.; Flament, J. P. Tetrahedron 1978, 34, 3513.

${ }^{129}$ Yamashita, M.; Onozuka, J.; Tushihashi, G.-I.; Ogura, K. Tetrahedron Lett. 1983, 24, 79.

${ }^{130}$ Birch, A. J.; Dahler, P.; Narula, A. S.; Stephenson, C. R. Tetrahedron Lett. 1980, 21, 3817. ${ }^{131}$ Erden, I. Tetrahedron Lett. 1985, 26, 5635.

132 (a) Kakiuchi, K.; Nakao, T.; Takeda, M.; Tobe, Y.; Odaira, Y. Tetrahedron Lett. 1984, 25, 557. (b) Kakiuchi, K.; Itoga, K.; Tsugaru, T.; Hato, Y.; Tobe, Y.; Odaira, Y. J. Org. Chem. 1984, 49, 659. (c) Kakiuchi, K.; Tsugaru, T.; Takeda, M.; Wakaki, I.; Tobe, Y.; Odaira, Y. J. Org. Chem. 1985, 50, 488. (d) Kakiuchi, K.; Ue, M.; Takaki, T.; Tobe, Y.; Odaira, Y. Chem. Lett. 1986, 507.

133 (a) Sasaki, K.; Kushida, T.; Iyoda, M.; Oda, M. Tetrahedron Lett. 1982, 23, 2117. (b) Iyoda, M.; Kushida, T.; Kitami, S.; Oda, M. J. Chem. Soc. Chem. Commun. 1986, 1049. 
134 (a) Fitjer, L.; Kanschik, A.; Majewski, M. Tetrahedron Lett. 1985, 26, 5277. (b) Fitjer, L.; Quabeck, U. Angew. Chem. Int. Ed. 1987, 26, 1023. (c) Fitjer, L.; Quabeck, U. Angew. Chem. 1987, 26, 1054. (d) Fitjer, L.; Majewski, M.; Kanschik, A. Tetrahedron Lett. 1988, 29, 1263. (e) Fitjer, L.; Quabeck, U. Angew. Chem., Int. Ed. Engl. 1989, 28, 94. (f) Fitjer, L.; Kanschik, A.; Majewski, M. Tetrahedron 1994, 50, 10867.

${ }^{135}$ Compare the heats of formation $(\mathrm{kcal} / \mathrm{mol})$ of the primary (201), secondary (183) and tertiary butylcarbenium ion (166): Lossing, F. P.; Holmes, J. L. J. Am. Chem. Soc. 1984, 106, 6917, and references therein.

${ }^{136}$ Olah, G. A.; Wu, A. H.; Farooq, O. J. Org. Chem. 1989, 54, 1452.

${ }^{137}$ (a) Kakiuchi, K.; Ue, M.; Tsukahara, H.; Shimizu, T.; Miyao, T.; Tobe, Y.; Odaira, Y.; Yasuda, M.; Shima, K. J. Am. Chem. Soc. 1989, 111, 3707. (b) Kakiuchi, K.; Ohnishi, Y.; Kobiro, K.; Tobe, Y.; Odaira, Y. J. Org. Chem. 1991, 56, 463. (c) Ue, M.; Ohnishi, Y.; Kobiro, K.; Kakiuchi, K.; Tobe, Y.; Odaira, Y. Chem. Lett. 1990, 149.

138 (a) Creary, X.; Inocencio, P. A.; Underiner, T. L.; Kostromin, R. J. Org. Chem. 1985, 50, 1932. (b) Brunner, H.; Kagan, H. B.; Kreutzer, G. Tetrahedron: Asymmetry 2001, 12, 497.

139 (a) Fujiwara, T.; Tomaru, J.; Suda, A.; Takeda, T. Tetrahedron Lett. 1992, 33, 2583. (b) Takeda, T.; Fujiwara, T. Synlett 1996, 481.

${ }^{140}$ (a) Paquette, L. A.; Lawhorn, D. E.; Teleha, C. A. Heterocycles 1990, 30, 765. (b) Negri, J. T.; Rogers, R. D.; Paquette, L. A. J. Am. Chem. Soc. 1991, 113, 5073. (c) Paquette, L. A.; Negri, J. T.; Rogers, R. D. J. Org. Chem. 1992, 57, 3947.

${ }^{141}$ Paquette, L. A.; Lanter, J. C.; Johnston, J. N. J. Org. Chem. 1997, 62, 1702.

${ }^{142}$ (a) Paquette, L. A.; Dullweber, U.; Cowgill, L. D. Tetrahedron Lett. 1993, 34, 8019. (b) Paquette, L. A.; Kinney, M. J.; Dullweber, U. J. J. Org. Chem. 1997, 62, 1713.

${ }^{143}$ Shinohara, I.; Nagaoka, H. Tetrahedron Lett. 2004, 45, 1495. 
144 (a) Ishihara, K.; Nakano, K. J. Am. Chem. Soc. 2007, 129, 8930. (b) Davies, H. M. L.; Dai, X. J. Am. Chem. Soc. 2004, 126, 2692. (c) Dai, X.; Davies, H. M. L. Adv. Synth. Catal. 2006, 348, 2449.

${ }^{145}$ Chatani, N.; Furukawa, H.; Kato, T.; Murai, S.; Sonoda, N. J. Am. Chem. Soc. 1984, 106, 430.

${ }^{146}$ Kashima, H.; Kawashima, T.; Wakasugi, D.; Satoh, T. Tetrahedron 2007, 63, 3953.

${ }^{147}$ Karrenbrock, F.; Schäfer, H. J. Tetrahedron Lett. 1978, 1521.

${ }^{148}$ Halazy, S.; Zutterman, F.; Krief, A. Tetrahedron Lett. 1982, 23, 4385.

149 (a) Satoh, T.; Hayashi, Y.; Mizu, Y.; Yamakawa, K. Tetrahedron Lett. 1992, 33, 7181. (b)

Satoh, T.; Hayashi, Y.; Mizu, Y.; Yamakawa, K. Bull. Chem. Soc. Jpn. 1994, 67, 1412.

150 (a) Satoh, T.; Itoh, N.; Gengyo, K.; Yamakawa, K. Tetrahedron Lett. 1992, 33, 7543. (b)

Satoh, T.; Itoh, N.; Gengyo, K.; Takada, S.; Asakawa, N.; Yamani, Y.; Yamakawa, K. Tetrahedron 1994, 50, 11839.

151 (a) Satoh, T.; Mizu, Y.; Kawashima, T.; Yamakawa, K. Tetrahedron 1995, 51, 703. (b)

Satoh, T.; Awata, Y.; Ogata, S.; Sugiyama, S.; Tanaka, M.; Tori, M. Tetrahedron Lett. 2009, $50,1961$.

${ }^{152}$ Falck, J. R.; He, A.; Reddy, L. M.; Kundu, A.; Barma, D. K.; Bandyopadhyay, A.; Kamila, S.; Akella, R.; Bejot, R.; Mioskowski, C. Org. Lett. 2006, 8, 4645.

153 Ochiai, M.; Hirobe, M.; Yoshimura, A.; Nishi, Y.; Miyamoto, K.; Shiro, M. Org. Lett. 2007, 9, 3335

${ }^{154}$ Trost, B. M.; Latimer, L. H. J. Org. Chem. 1978, 43, 1031.

155 Tobe, Y.; Yamashita, S.; Yamashita, T.; Kakiuchi, K.; Odaira. Y. J. Chem. Soc., Chem. Commun. 1984, 1259.

156 Tobe, Y.; Yamashita, T.; Kakiuchi, K.; Odaira, Y. J. Chem. Soc., Chem. Commun. 1985, 898. 
${ }^{157}$ Wenkert, E.; Arrhenius, T. S. J. Am. Chem. Soc. 1983, 105, 2030.

${ }^{158}$ Pirrung, M. C.; Thomson, S. A. J. Org. Chem. 1988, 53, 227.

159 (a) Tobe, Y.; Yamashita, T.; Kakiuchi, K.; Odaira, Y. Chem. Lett. 1985, 898. (b) Tobe, Y.; Kishida, T.; Yamashita, T.; Kakiuchi, K.; Odaira, Y. Chem. Lett. 1985, 1437.

160 (a) Taguchi, H.; Yamamoto, H.; Nozaki, H. Bull. Chem. Soc. Jpn. 1977, 50, 1592. (b) Vedejs, E.; Larsen, S. D. J. Am. Chem. Soc. 1984, 106, 3030.

${ }^{161}$ Hamer, N. K. Tetrahedron Lett. 1986, 27, 2167.

162 Jahangir; Fisher, L. E.; Clark, R. D.; Muchowski, J. M. J. Org. Chem. 1989, 54, 2992.

163 (a) Leriverend, M. L.; Leriverend, P. C. R. Acad. Sci. Ser. C. 1975, 280, 791. (b) Leriverend, M.-L.; Leriverend, P. Chem. Ber. 1976, 109, 3492.

${ }^{164}$ Morton, D. R., Jr.; Brokaw, F. C. J. Org. Chem. 1979, 44, 2880.

${ }^{165}$ Halazy, S.; Krief, A. J. Chem. Soc., Chem. Commun. 1982, 1200.

${ }^{166}$ Hart, T. W.; Comte, M.-T. Tetrahedron Lett. 1985, 26, 2713.

${ }^{167}$ Lombardo, L. Tetrahedron Lett. 1982, 23, 4293.

${ }^{168}$ Riefling, B. F. Tetrahedron Lett. 1985, 26, 2063.

169 (a) Mahuteau-Betzer, F.; Ghosez, L. Tetrahedron Lett. 1999, 40, 5183. (b) MahuteauBetzer, F.; Ghosez, L. Tetrahedron 2002, 58, 6991.

${ }^{170}$ Brown, B.; Hegedus, L. S. J. Org. Chem. 2000, 65, 1865.

${ }^{171}$ Bernard, A. M.; Frongia, A.; Guillot, R.; Piras, P. P.; Secci, F.; Spiga, M. Org. Lett. 2007, $9,541$.

172 (a) Shen, Y.-M.; Wang, B.; Shi, Y. Angew. Chem. Int. Ed. 2006, 45, 1429. (b) Shen, Y.M.; Wang, B.; Shi, Y. Tetrahedron Lett. 2006, 47, 5455.

${ }^{173}$ Reutrakul, V.; Panyachotipun, C.; Hahnvajanawong, V.; Sotheeswaran, S. Tetrahedron Lett. 1984, 25, 1825.

${ }^{174}$ Fukuzawa, S.; Tsuchimoto, T. Tetrahedron Lett. 1995, 36, 5937. 
(a) Wohl, R. A. J. Org. Chem. 1973, 38, 3862. (b) McManus, S. P.; Ortiz, M.; Abramovitch, R. A. J. Org. Chem. 1981, 46, 336.

${ }^{176}$ Fitjer, L. Chem. Ber. 1982, 115, 1047.

177 (a) Demjanov, N. J.; Lushnikov, M. Russ. Phys. Chem. Soc. 1903, 35, 26. (b) Demjanov, N. J.; Lushnikov, M. Chem. Zentralbl. 1903, 1, 828. (c) Smith, P. A. S.; Baer, D. R. Org. React. 1960, 11, 157. (d) Sietter, H.; Goebel, P. Chem. Ber. Recl. 1963, 96, 550. (d) Kotani, R. J. Org. Chem. 1965, 30, 350. (e) Dave, V.; Stothers, J. B.; Warnhoff, E. W. Can. J. Chem. 1979, 52, 1557. (f) Murray, R. K.; Ford, T. M. J. Org. Chem. 1979, 44, 3504. (g) Fattori, D.; Henry, S.; Vogel, P. Tetrahedron 1993, 49, 1649.

178 (a) Smith, P. A. S.; Baer, D. R. Org. React. 1960, 11, 157. (b) Hesse, M. Ring Enlargement in Organic Chemistry; VCH: New York, 1991; pp9-16.

179 (a) Roberts, J. D.; Gorham, W. F. J. Am. Chem. Soc. 1952, 74, 2278. (b) Nee, M.; Roberts, J. D. J. Org. Chem. 1981, 46, 67.

${ }^{180}$ For reviews on the diazomethane ring expansion reaction, see: (a) Gutsche, C. D. Org. React. 1954, 8, 364. (b) Carbocyclic Ring Expansion Reactions; Gutsche, G. D.; Redmore, D., Academic Press, New York, 1968, Chapter IV. (c) Cowell, G. W.; Ledwith, A. Q. Rev. Chem. Soc. 1970, 24, 119. (d) Synthetic Reagents 2; Pizey, J. S.; Wiley: New York 1974.

181 (a) Liu, H. J.; Ogino, T. Tetrahedron Lett. 1973, 4937. (b) Liu, H. J.; Majumdar, S. P. Synth. Commun. 1975, 5, 125.

${ }^{182}$ Whitesell, J. K.; Minton, M. A.; Flanagan, W. G. Tetrahedron 1981, 37, 4451.

183 (a) Greene, A. E.; Deprés, J. P.; Nagano, H.; Crabbé, P. Tetrahedron Lett. 1977, 2365. (b) Deprés, J. P.; Greene, A. E.; Crabbé, P. Tetrahedron 1981, 37, 621.

${ }^{184}$ Greene, A. E.; Deprés, J. P.; Meana, M. C.; Crabbé, P. Tetrahedron Lett. 1976, 3755.

${ }^{185}$ Collington, E. W.; Finch, H.; Montana, J. G.; Taylor, R. J. K. J. Chem. Soc., Perkin Trans. $11990,1839$. 
${ }^{186}$ Greene, A. E.; Luche, M. J.; Serra, A. A. J. Org. Chem. 1985, 50, 3957.

187 (a) Takeuchi, T.; Iinuma, H.; Iwanaga, J.; Takahashi, S.; Takita, T.; Umezawa, H. J. Antibiot. 1969, 22, 215. (b) Takeuchi, T.; Takahashi, S.; Iinuma, H.; Takita, T.; Maeda, K.; Umezawa, H. J. Antibiot. 1971, 24, 631.

${ }^{188}$ Liu, H. J.; Kulkarni, M. G. Tetrahedron Lett. 1985, 26, 4847.

${ }^{189}$ Stille, J. R.; Grubbs, R. H. J. Am. Chem. Soc. 1986, 108, 855.

190 Sonawane, H. R.; Nanjundiah, B. S.; Shah, V. G.; Kulkarni, D. G.; Ahuja, J. R. Tetrahedron Lett. 1991, 32, 1107.

191 (a) Ghosh, A.; Biswas, S.; Venkateswaran, R. V. J. Chem. Soc, Chem. Commun. 1988, 1421. (b) Biswas, S.; Ghosh, A.; Venkateswaran, R. V. J. Org. Chem. 1990, 55, 3498.

${ }^{192}$ Hébrault, D.; Uguen, D.; De Cian, A.; Fischer, J. Tetrahedron Lett. 1998, 39, 6703.

${ }^{193}$ Reeder, L. M.; Hegedus, L. S. J. Org. Chem. 1999, 64, 3306.

194 (a) Wen, X.; Norling, H.; Hegedus, L. S. J. Org. Chem. 2000, 65, 2096. (b) For a review, see: Bereubar, A.; Grandjean, C.; Siriwardena, A. Chem. Rev. 1999, 99, 779. (c) Sebahar, H. L.; Yoshida, K.; Hegedus, L. S. J. Org. Chem. 2002, 67, 3788.

${ }^{195}$ Greene, A. E.; Deprés, J.-P. J. Am. Chem. Soc. 1979, 101, 4003.

196 (a) Jaz, J.; Davreux, J. P. Bull. Soc. Chim. Belg. 1965, 74, 370. (b) Fachinetti, G.; Pietra, F.; Marsili, A. Tetrahedron Lett. 1971, 393.

${ }^{197}$ Au-Yeung, B.-W.; Fleming, I. J. Chem. Soc. Chem. Commun. 1977, 81.

${ }^{198}$ Deprés, J.-P.; Greene, A. E. J. Org. Chem. 1980, 45, 2036.

199 (a) Seto, H.; Yonehara, H. J. Antibiot. 1980, 33, 92. (b) Annis, G. D.; Paquette, L. A. J. Am. Chem. Soc. 1982, 104, 4504. (c) Paquette, L. A.; Annis, G. D. J. Am. Chem. Soc. 1983, $105,7358$.

${ }^{200}$ Greene, A. E. Tetrahedron Lett. 1980, 21, 3059.

${ }^{201}$ Greene, A. E.; Luche, M.-J.; Deprés, J.-P. J. Am. Chem. Soc. 1983, 105, 2435. 
${ }^{202}$ Greene, A. E.; Lansard, J.-P.; Luche, J.-L.; Petrier, C. J. Org. Chem. 1983, 48, 4763.

${ }^{203}$ Greene, A. E.; Lansard, J.-P.; Luche, J.-L.; Petrier, C. J. Org. Chem. 1984, 49, 931.

${ }^{204}$ Paquette, L. A.; Valpey, R. S.; Annis, G. D. J. Org. Chem. 1984, 49, 1317.

${ }^{205}$ Greene, A. E.; Charbonnier, F. Tetrahedron Lett. 1985, 26, 5525.

206 (a) Mehta, G.; Padma, S.; Rao, K. S. Synth. Commun. 1985, 15, 1137. (b) Mehta, G.; Rao, K. S. Tetrahedron Lett. 1984, 25, 1839. (c) Mehta, G.; Rao, K. S. Tetrahedron Lett. 1984, 25 , 3481.

${ }^{207}$ Lee, T. V.; Toczek, J.; Roberts, S. M. J. Chem. Soc., Chem. Commun. 1985, 371.

${ }^{208}$ Sugihara, Y.; Fujita, H.; Murata, I. J. Chem. Soc., Chem. Commun. 1986, 1130.

209 (a) Yokoyama, R.; Ito, S.; Watanabe, M.; Harada, N.; Kabuto, C.; Morita, N. J. Chem. Soc., Perkin Trans. 1 2001, 18, 2257. (b) Ito, S.; Yokoyama, R.; Asao, T.; Watanabe, M.; Harada, N.; Morita, N. J. Organomet. Chem. 2002, 648, 164.

${ }^{210}$ MaGee, D. I.; Mallais, T.; Strunz, G. M. Can. J. Chem. 2004, 82, 1686.

${ }^{211}$ Cousin, D.; Mann, J. Tetrahedron 2008, 64, 3534.

${ }^{212}$ Mehta, G.; Rao, K. S. J. Org. Chem. 1985, 50, 5537.

${ }^{213}$ Mehta, G.; Nair, M. S. J. Am. Chem. Soc. 1985, 107, 7519.

${ }^{214}$ Craig, D. C.; Lawson, J. M.; Oliver, A. M.; Paddon-Row, M. N. J. Chem. Soc., Perkin Trans. 1 1990, 3305.

215 (a) Farcasiu, D.; Seppo, E.; Kizirian, M.; Ledlie, D. B.; Sevin, A. J. Am. Chem. Soc. 1989, 111, 8466. (b) Li, H.; Silver, J. E.; Watson, W. H.; Kashyap, R. P.; Le Noble, W. J. J. Org. Chem. 1991, 56, 5932.

${ }^{216}$ Paryzek, Z.; Blaszczyk, K. Liebigs Ann. Chem. 1993, 615.

${ }^{217}$ Carpes, M. J. S.; Miranda, P. C. M. L.; Correia, C. R. D. Tetrahedron Lett. 1997, 38, 1869.

218 (a) Ono, N.; Yanai, T.; Kaji, A. J. Chem. Soc. Chem. Commun. 1986, 1040. (b) Ono, N.; Yanai, Y.; Kamimura, A.; Kaji, A. J. Chem. Soc. Chem. Commun. 1986, 1285. (c) Miyake, 
H.; Yamamura, K. Tetrahedron Lett. 1986, 27, 3025. (d) Ono, N.; Hashimoto, T.; Jun, T. X.; Kaji, A. Tetrahedron Lett. 1987, 28, 2277.

${ }^{219}$ Kim, S.; Park, J. H. Chem. Lett. 1988, 8, 1323.

${ }^{220}$ Kuivila, H. G.; Masterton, W. L. J. Am. Chem. Soc. 1952, 74, 4953.

${ }^{221}$ Bartleson, J. D.; Burk, R. E.; Lankelma, H. P. J. Am. Chem. Soc. 1946, 68, 2513.

${ }^{222}$ Noller, C. R.; Adams, R. J. Am. Chem. Soc. 1926, 48, 1080.

${ }^{223}$ Klunder, A. J. H.; Zwanenburg, B. Tetrahedron 1973, 29, 161.

${ }^{224}$ Takeda, K.; Shimono, Y.; Yoshii, E. J. Am. Chem. Soc. 1983, 105, 563.

${ }^{225}$ Abe, K.; Okumura, H.; Tsugoshi, T.; Nakamura, N. Synthesis 1984, 603.

${ }^{226}$ Somers, J. B. M.; Couture, A.; Lablache-combier, A.; Laarhoven, W. H. J. Am. Chem. Soc 1985, 107, 1387.

${ }^{227}$ Rio, G.; Bricout, D. Bull. Soc. Chim. Fr. 1971, 3557.

${ }^{228}$ Avasthi, K.; Salomon, R. G. J. Org. Chem. 1986, 51, 2556.

${ }^{229}$ Fitjer, L.; Majewski, M.; Kanschik, A.; Egert, E.; Sheldrick, G. M. Tetrahedron Lett. 1986, $27,3603$.

${ }^{230}$ If alternative 1,2-shifts can occur, the bond which forms the smaller dihedral angle with the vacant p-orbital, will be broken: Saunders, M.; Chandrasekhar, J.; Schleyer P. v. R. in Rearrangements in Ground and Excited States (P. de Mayo Ed.), Vol. 1, Academic Press, New York 1980.

231 (a) Compare the heats of formation of ethylcyclopropane ${ }^{b}\left(\Delta H_{f}^{\circ}=1.1 \mathrm{kcal} / \mathrm{mol}\right)$, methylcyclobutane $^{\mathrm{c}}\left(\Delta \mathrm{H}_{\mathrm{f}}{ }^{\circ}=-0,6 \mathrm{kcal} / \mathrm{mol}\right)$ and cyclopentane ${ }^{\mathrm{c}}\left(\Delta \mathrm{H}_{\mathrm{f}}{ }^{\circ}=-18.5 \mathrm{kcal} / \mathrm{mol}\right)$. (b) Turner, R. B.; Goebel, P.; Mallon, B. J.; von E. Doering, W.; Coburn, J. F. Jr.; Pomerantz, M. J. Am. Chem. Soc. 1968, 90, 4315. (c) Benson, S. W.; Cruickshank, F. R.; Golden, D. M.; Haugen, G. R.; O’Neal, H. E.; Rodgers, A. S.; Shaw, R.; Walsh, R. Chem. Rev. 1969, 69, 279. 
232 (a) Fitjer, L.; Kanschik, A.; Majewski, M. Tetrahedron Lett. 1988, 29, 5525. (b) Fitjer, L.; Majewski, M.; Monzó-Oltra, H. Tetrahedron 1995, 51, 8835.

233 (a) Mandelt, K.; Fitjer, L. Synthesis 1998, 1523. (b) Mandelt, K.; Meyer-Wilmes, I.; Fitjer, L. Tetrahedron 2004, 60, 11587.

234 (a) McMurry, J. E.; von Beroldingen, L. A. Tetrahedron 1974, 30, 2027. (b) de Mayo, P.; Suau, R. J. Chem. Soc., Perkin Trans 1 1974, 2559. (c) Chandrasekaran, S.; Turner, J. V. Tetrahedron Lett. 1982, 23, 3799.

${ }^{235}$ Giersig, M.; Wehle, D.; Fitjer, L.; Schormann, N.; Clegg, W. Chem. Ber. 1988, 121, 525.

236 (a) Sengupta, D.; Venkateswaran, R. V. J. Chem. Soc, Chem. Commun. 1986, 1638. (b) Nath, A.; Ghosh, A.; Venkateswaran, R. V. J. Org. Chem. 1992, 57, 1467. (c) Mal, J.; Nath, A.; Venkateswaran, R. V. J. Org. Chem. 1996, 61, 9164.

${ }^{237}$ Grota, J.; Domke, I.; Stoll, I.; Schroeder, T.; Mattay, J.; Schmidtmann, M.; Boegge, H.; Mueller, A. Synthesis 2005, 2321.

238 (a) Nakamura, E.; Kuwajima, I. J. Am. Chem. Soc. 1977, 99, 961. (b) Nakamura, E.; Hashimoto, K.; Kuwajima, I. J. Org. Chem. 1977, 42, 4166.

${ }^{239}$ Eberhardt, U.; Deppisch, B.; Musso, H. Chem. Ber. 1983, 116, 119.

${ }^{240}$ (a) Nath, A.; Venkateswaran, R. V. J. Chem. Soc, Chem. Commun. 1993, 281. (b) Nath, A.; Mal, J.; Venkateswaran, R. V. J. Org. Chem. 1996, 61, 4391. (c) Mal, J.; Nath, A.; Venkateswaran, R. V. J. Org. Chem. 1998, 63, 3855.

${ }^{241}$ Sabui, S. K.; Venkateswaran, R. V. Tetrahedron Lett. 2004, 45, 983.

${ }^{242}$ Fitjer, L.; Schlotmann, W.; Noltemeyer, M. Tetrahedron Lett. 1995, 36, 4985.

${ }^{243}$ Estieu, K.; Ollivier, J.; Salaün, J. Tetrahedron 1998, 54, 8075.

${ }^{244}$ Crane, S. N.; Burnell, D. J. J. Org. Chem. 1998, 63, 5708.

${ }^{245}$ Jamart-Gregoire, B.; Brosse, N.; Ianelli, S.; Nardelli, M.; Caubere, P. J. Org. Chem. 1993, $58,4572$. 
${ }^{246}$ Martín, T.; Rodríguez, C. M.; Martín, V. S. Tetrahedron: Asymmetry 1995, 6, 1151.

${ }^{247}$ Corey, E. J.; Liu, K. Tetrahedron Lett. 1997, 38, 7491.

${ }^{248}$ Dauben, W. G.; Chitwood, J. L. J. Am. Chem. Soc. 1970, 92, 1624.

${ }^{249}$ Roberts, D. D. J. Org. Chem. 1976, 41, 486.

${ }^{250}$ Yano, K.; Isobe, M.; Yoshida, K. J. J. Am. Chem. Soc. 1978, 100, 6166.

${ }^{251}$ Tobe, Y.; Hayauchi, Y. Sakai, Y.; Odaira, Y. J. Org. Chem. 1980, 45, 637.

${ }^{252}$ Lange, G. L.; Decicco, C. P.; Wilson, J.; Strickland, L. A. J. Org. Chem. 1989, 54, 1805.

${ }^{253}$ Bentley, T. W.; Llewellyn, G.; Kottke, T.; Stalke, D.; Cohrs, C.; Herberth, E.; Kunz, U.

Christl, M. Eur. J. Org. Chem. 2001, 7, 1279.

${ }^{254}$ Kuwajima, I.; Azegami, I. Tetrahedron Lett. 1979, 25, 2369.

${ }^{255}$ Oppolzer, W.; Wylie, R. D. Helv. Chim. Acta 1980, 63, 1198.

${ }^{256}$ Nishiguchi, I.; Hirashima, T.; Shono, T.; Sasaki, M. Chem. Lett. 1981, 4, 551.

${ }^{257}$ Shimada, J.; Hashimoto, K.; Kim, B. H.; Nakamura, E.; Kuwajima, I. J. Am. Chem. Soc. 1984, 106, 1759.

${ }^{258}$ Martinez, R.; Rao, P.; Kim, H. Synth. Commun. 1989, 19, 373.

${ }^{259}$ Olah, G. A.; Meidar, D. Synthesis 1978, 5, 358.

${ }^{260}$ Gao, F. Y.; Burnell, D. J. J. Org. Chem. 2006, 71, 356.

${ }^{261}$ Nakamura, E.; Shimada, J.; Kuwajima, I. J. Chem. Soc., Chem. Commun. 1983, 498.

${ }^{262}$ Corey, E. J.; Desai, M. C.; Engler, T. A. J. Am. Chem. Soc. 1985, 107, 4339.

${ }^{263}$ Bunnelle, W. H.; Shangraw, W. R. Tetrahedron 1987, 43, 2005.

264 (a) Yates, P.; Eaton, P. J. Am. Chem. Soc. 1960, 82, 4436. (b) Fray, G. I.; Robinson, R. J. Am. Chem. Soc. 1961, 83, 249.

${ }^{265}$ Hyuga, S.; Hara, S.; Suzuki, A. Bull. Chem. Soc. Jpn. 1992, 65, 2303.

${ }^{266}$ Lange, A.; Heydenreuter, W.; Menz, H.; Kirsch, S. F. Synlett 2009, 2987.

${ }^{267}$ Selig, P.; Herdtweck, E.; Bach, T. Chem. Eur. J. 2009, 15, 3509. 
${ }^{268}$ Murakami, M.; Itahashi, T.; Amii, H.; Takahashi, K.; Ito, Y. J. Am. Chem. Soc. 1998, 120, 9949.

269 (a) Hwang, C.-S.; Reusch, W. Heterocycles 1987, 25, 589. (b) Hwang, C.-S.; Ward, D. L.; Reusch, W. J. Org. Chem. 1989, 55, 4318.

${ }^{270}$ Tu, Y. Q.; Fan, C. A.; Ren, S. K.; Chan, A. S. C. J. Chem. Soc., Perkin Trans. 1 2000, 3791.

271 (a) Eschinasi, E. J. Org. Chem. 1970, 35, 1598. (b) Tu, Y. Q.; Sun, L. D.; Wang, P. Z. J. Org. Chem. 1999, 64, 629.

${ }^{272}$ Dake, G. R.; Fenster, M. D. B.; Fleury, M.; Patrick, B. O. J. Org. Chem. 2004, 69, 5676.

${ }^{273}$ El-Hachach, N.; Gerke, R.; Noltemeyer, M.; Fitjer, L. Tetrahedron 2009, 65, 1040.

${ }^{274}$ Ghosh, S.; Patra, D. Pure Appl. Chem. 1996, 68, 597.

${ }^{275}$ Samajdar, S.; Patra, D.; Ghosh, S. Tetrahedron 1998, 43, 1789.

${ }^{276}$ Patra, D.; Ghosh, S. J. Chem. Soc., Perkin Trans. 1 1995, 2635.

277 (a) Patra, D.; Ghosh, S. J. Org. Chem. 1995, 60, 2526. (b) Nayek, A.; Ghosh, S. Tetrahedron Lett. 2002, 43, 1313.

${ }^{278}$ Ghosh, A.; Banerjee, U. K.; Venkateswaran, R. V. Tetrahedron 1990, 46, 3077.

${ }^{279}$ Haque, A.; Ghatak, A.; Ghosh, S.; Ghoshal, N. J. Org. Chem. 1997, 62, 5211.

${ }^{280}$ Dudnik, A. S.; Schwier, T.; Gevorgyan, V. Org. Lett. 2008, 10, 1465.

${ }^{281}$ Schaumann, E. Top. Curr. Chem. 2007, 274, 1.

${ }^{282}$ Cohen, T.; Kuhn, D.; Falck, J. R. J. Am. Chem. Soc. 1975, 97, 4749.

${ }^{283}$ Abraham, W. D.; Bhupathy, M.; Cohen, T. Tetrahedron Lett. 1987, 28, 2203.

${ }^{284}$ Knapp, S.; Trope, A. F.; Ornaf, R. M. Tetrahedron Lett. 1980, 21, 4301.

${ }^{285}$ Ho, T.-L.; Chang, M.-H. Can. J. Chem. 1997, 75, 621.

${ }^{286}$ Ferrier, R. J.; Tyler, P. C.; Gainsford, G. J. J. Chem. Soc., Perkin Trans. 1 1985, 2, 295. 
${ }^{287}$ (a) Bach, R. D.; Klix, R. C. J. Org. Chem. 1986, 51, 749. (b) Bach, R. D.; Klix, R. C. Tetrahedron Lett. 1986, 27, 1983. (c) Evans, J. C.; Klix, R. C.; Bach, R.D. J. Org. Chem. 1988, 53, 5519 .

${ }^{288}$ Wendt, J. A.; Gauvreau, P. J.; Bach, R. D. J. Am. Chem. Soc. 1994, 116, 9921.

${ }^{289}$ Funk, R. L.; Novak, P. M.; Abelman, M. M. Tetrahedron Lett. 1988, 29, 1493.

${ }^{290}$ Kimura, M.; Kobayashi, K.; Yamamoto, Y.; Sawaki, Y. Tetrahedron 1996, 52, 4303.

${ }^{291}$ (a) Laboureur, J. L.; Krief, A. Tetrahedron Lett. 1984, 25, 2713. (b) Krief, A.; Laboureur, J. L. Tetrahedron Lett. 1987, 28, 1545. (c) Krief, A.; Laboureur, J. L. J. Chem. Soc. Chem. Commun. 1986, 702. (d) Krief, A.; Laboureur, J. L.; Dumont, W. Tetrahedron Lett. 1987, 28, 1549.

292 (a) Labar, D.; Krief, A. J. Chem. Soc. Chem. Commun. 1982, 564. (b) Labar, D.; Laboureur, J. L.; Krief, A. Tetrahedron Lett. 1982, 23, 983. (c) Fitjer, L.; Scheuermann, H.-J.; Wehle, D. Tetrahedron Lett. 1984, 25, 2329.

${ }^{293}$ Fitjer, L.; Wehle, D.; Scheuermann, H.-J. Chem. Ber. 1986, 119, 1162.

${ }^{294}$ Fitjer, L.; Steeneck, C.; Gaini-Rahimi, S.; Schroeder, U.; Justus, K.; Puder, P.; Dittmer, M.; Hassler, C.; Weiser, J.; Noltemeyer, M.; Teichert, M. J. Am. Chem. Soc. 1998, 120, 317. ${ }^{295}$ Trost, B. M.; Mikhail, G. K. J. Am. Chem. Soc. 1987, 109, 4124. ${ }^{296}$ Finch, H.; Mjalli, A. M. M.; Montana, J. G.; Roberts, S. M.; Taylor, R. J. K. Tetrahedron 1990, 46, 4925 .

${ }^{297}$ Ogura, K.; Yamashita, M.; Suzuki, M.; Tsuchihashi, G.-I. Chem. Lett. 1982, 93.

${ }^{298}$ Gadwood, R. C.; Mallick, I. M.; DeWinter, A. J. J. Org. Chem. 1987, 52, 774.

${ }^{299}$ Gadwood, R. C. J. Org. Chem. 1983, 48, 2098.

${ }^{300}$ Graham, S. H.; Williams, A. J. S. J. Chem. Soc. C 1969, 390.

${ }^{301}$ Fadel, A.; Salaün, J. Tetrahedron 1985, 41, 413. 
${ }^{302}$ Ue, M.; Tsukahara, H.; Kobiro, K.; Kakiuchi, K.; Tobe, Y.; Odaira, Y. Tetrahedron Lett. 1987, 28, 3979.

${ }^{303}$ Banik, B. K.; Ghatak, U. R. Tetrahedron 1989, 45, 3547.

${ }^{304}$ Connolly, P. J.; Heathcock, C. H. J. Org. Chem. 1985, 50, 4135.

${ }^{305}$ Overman, L. E.; Okazaki, M. E.; Jon Jacobsen, E. J. Org. Chem. 1985, 50, 2403.

${ }^{306}$ Zhang, E.; Tu, Y.-Q.; Fan, C.-A.; Zhao, X.; Jiang, Y.-J.; Zhang, Z.-Y. Org. Lett. 2008, 10, 4943.

${ }^{307}$ Wang, B. M.; Song, Z. L.; Fan, C. A.; Tu, Y. Q.; Shi, Y. Org. Lett. 2002, 4, 363.

${ }^{308}$ Nishimura, T.; Nishiguchi, Y.; Maeda, Y.; Uemura, S. J. Org. Chem. 2004, 69, 5342.

309 (a) Van Brabandt, W.; De Kimpe, N. J. Org. Chem. 2005, 70, 3369. (b) Van Brabandt, W.; De Kimpe, N. J. Org. Chem. 2005, 70, 8717.

${ }^{310}$ (a) Alcaide, B.; Almendros, P.; Cabrero, G.; Ruiz, M. P. Synthesis 2008, 2835. (b) Alcaide, B.; Almendros, P.; Cabrero, G.; Callejo, R.; Pilar Ruiz, M.; Arnó, M.; Domingo, L. R. Adv. Synth. Catal. 2010, 352, 1688. 